\title{
Charakterisierung von SNARE-Proteinen in der Hefe Saccharomyces cerevisiae
}

\author{
Dissertation \\ zur Erlangung des Doktorgrades \\ der Mathematisch-Naturwissenschaftlichen Fakultäten \\ der Georg-August-Universität zu Göttingen
}

\author{
vorgelegt von \\ Meik Dilcher \\ aus Bad Hersfeld
}

Göttingen 2002 
D7

Referent:

Prof. Dr. Kurt von Figura

Korreferent:

Prof. Dr. Gerhard Gottschalk

Tag der mündlichen Prüfung:

30.01 .2003 



\section{Inhaltsverzeichnis}

\section{Abkürzungsverzeichnis}

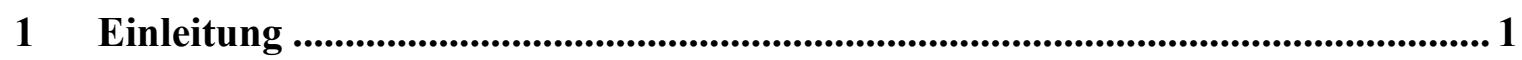

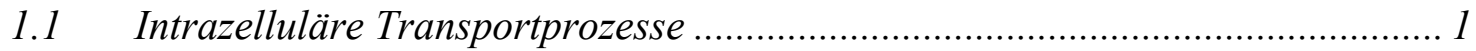

1.2 Prinzip des Vesikeltransportes ...................................................................... 4

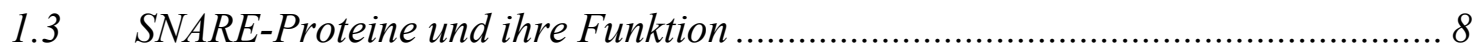

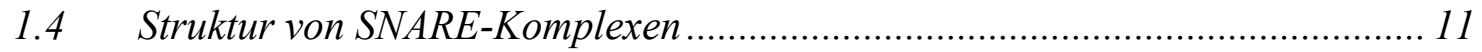

1.5 Molekulare Mechanismen der Membranfusion ............................................... 16

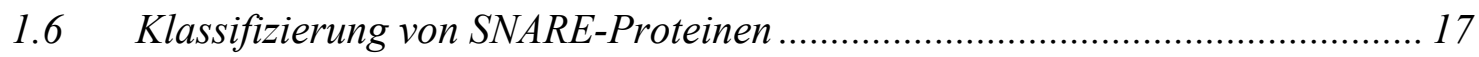

1.7 SNARE-Proteine in der Hefe Saccharomyces cerevisiae ............................... 18

1.7.1 Biosynthetische Transportwege zur Hefe-Vakuole .................................. 19

1.7.2 Funktion von Vtilp und seinen Homologen in höheren Eukaryonten ...... 21

1.7.3 Temperatursensitive Mutanten von Vti1p .............................................. 23

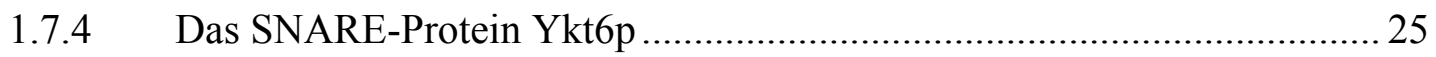

1.7.5 SNARE-Proteine des anterograden und retrograden ER-Golgi-

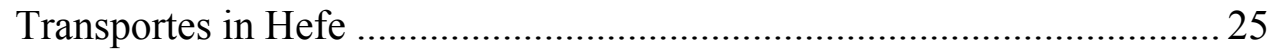

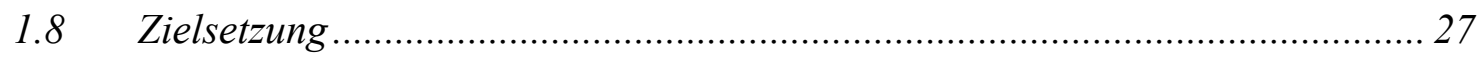

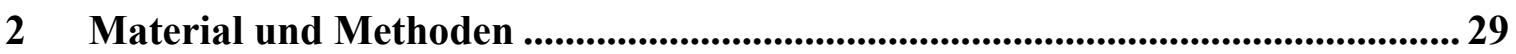

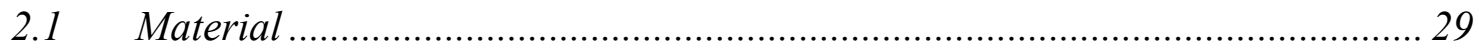

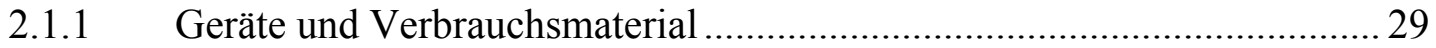

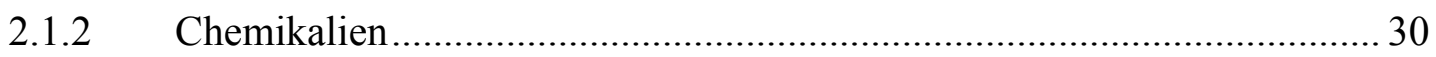

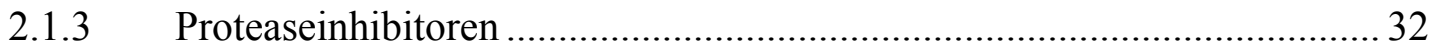

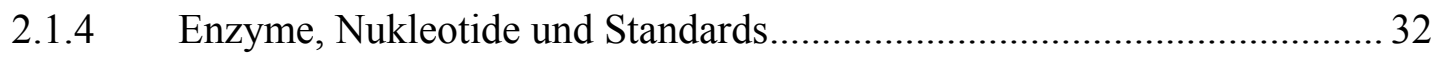

2.1.5 Antibiotika ..................................................................................... 32

2.1.6 Kits zur Bearbeitung von DNA und Proteinen ........................................ 33

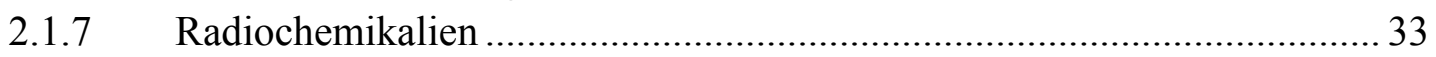

2.1.8 Häufig verwendete Puffer und Stammlösungen ........................................ 33

2.1.9 Hefe- und Bakterienstämme …............................................................. 34

2.1.10 Verwendete Plasmide ............................................................................. 35

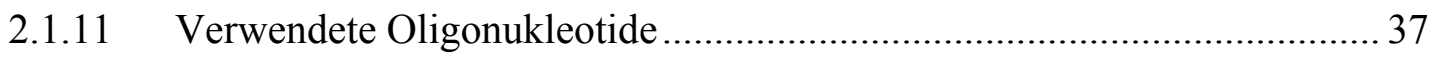

2.1.12 Nährmedien zur Kultivierung von Bakterien ........................................... 38

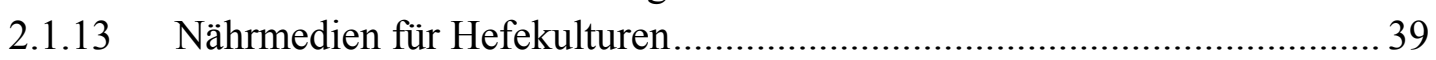

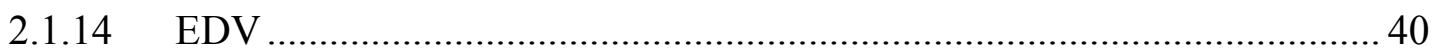

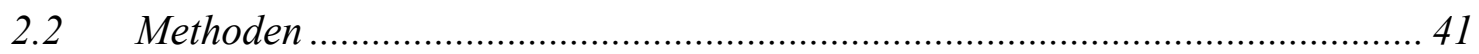

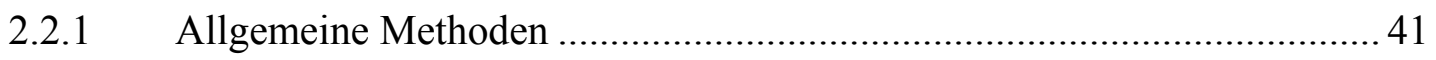


2.2.1.1 Kultivierung von E. coli

2.2.1.1.1 Nährmedien für $E$. coli ................................................................. 41

2.2.1.1.2 Anzucht von E. coli-Kulturen................................................. 41

2.2.1.1.3 Anlegen von Bakteriendauerkulturen .......................................... 41

2.2.1.1.4 Herstellung elektrokompetenter Bakterien .................................... 42

2.2.1.1.5 Transformation von E. coli-Zellen durch Elektroporation .............. 42

2.2.1.2 Kulturbedingungen für Saccharomyces cerevisiae ............................. 43

2.2.1.2.1 Nährmedien für $S$. cerevisiae ...................................................... 43

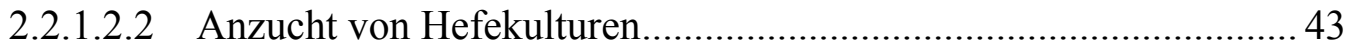

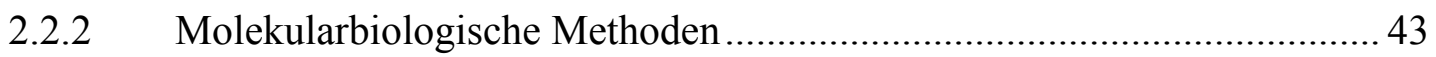

2.2.2.1 Minipräparation von Plasmid-DNA (Alkalische Lyse) ........................ 43

2.2.2.2 Photometrische Konzentrations- und Reinheitsbestimmung von

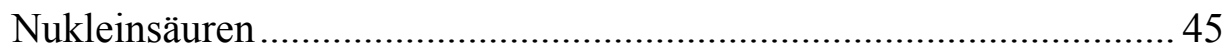

2.2.2.3 Enzymkatalysierte Reaktionen an DNA............................................ 46

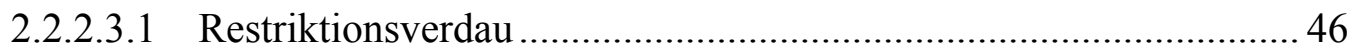

2.2.2.3.2 Behandlung von linearisierter DNA mit alkalischer Phosphatase... 49

2.2.2.3.3 Ligation von DNA-Doppelstrang-Fragmenten.............................. 50

2.2.2.3.4 Polymerase-Ketten-Reaktion (PCR) ........................................... 51

2.2.2.3.5 Phenolextraktion und Ethanolpräzipitation von DNA..................... 53

2.2.2.3.6 Gerichtete in vitro-Mutagenese über PCR..................................... 54

2.2.2.3.7 Ungerichtete in vitro-Mutagenese über PCR zur Herstellung von tsMutanten .............................................................................. 56

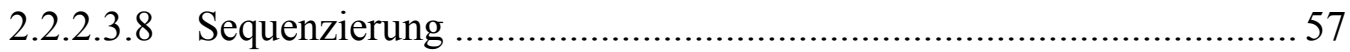

2.2.2.4 Gelelektrophoretische Auftrennung von DNA...................................... 59

2.2.2.4.1 Analytische und präparative Agarose-Gelelektrophorese .............. 59

2.2.2.5 QIAEX ${ }^{\circledR}$ II-DNA-Extraktion aus präparativen Agarosegelen................6 60

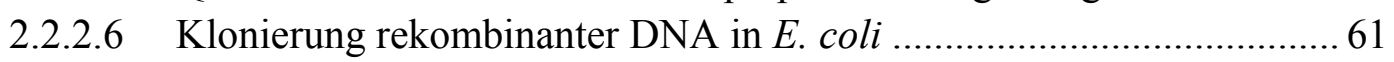

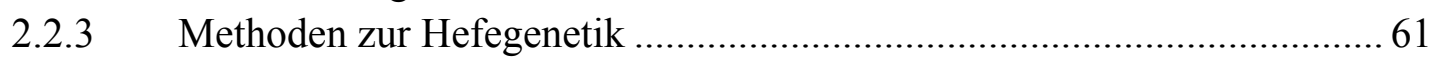

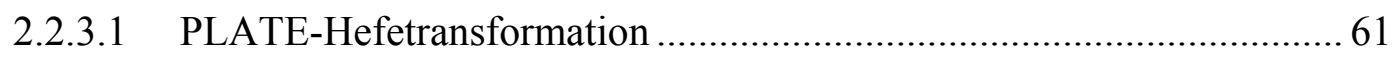

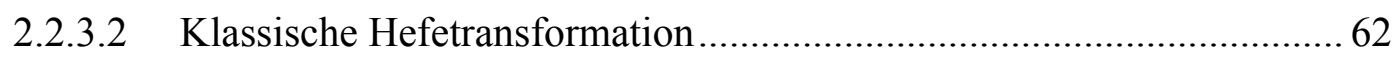

2.2.3.2.1 Herstellung transformationskompetenter Hefezellen ...................... 62

2.2.3.2.2 Klassische Transformation von Hefezellen ...................................... 63

2.2.3.3 Lithiumacetat-Transformation von Hefezellen.........................................64 64

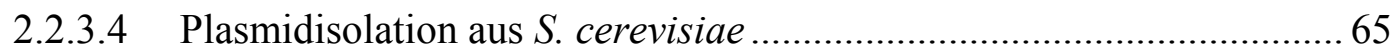

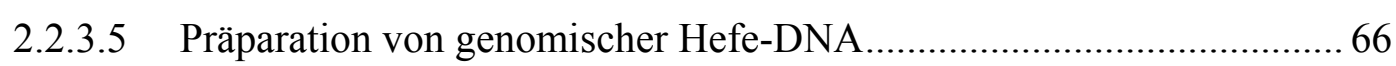

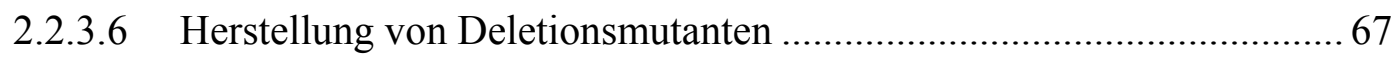

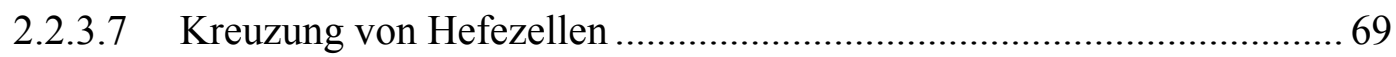

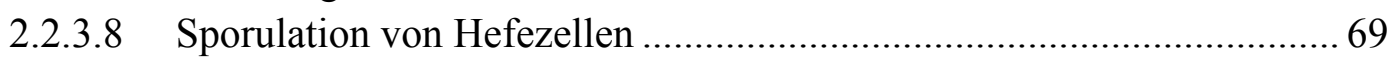

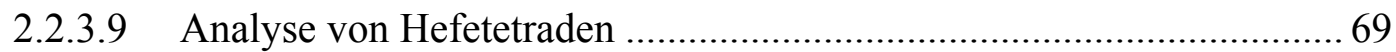

2.2.3.10 Bestimmung des Paarungstyps durch den „Halo“-Test..................... 70

2.2.3.11 Identifizierung PEP4-defizienter Stämme durch den APNE-Test .... 71

2.2.3.12 Bestimmung des Wachstums von Hefezellen auf Agarplatten.......... 72

2.2.4 Biochemische Methoden .................................................................. 72 
2.2.4.1 Herstellung von Proteinextrakten aus Hefezellen................................. 72

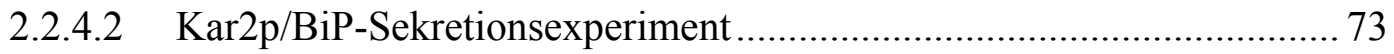

2.2.4.3 Bestimmung der Proteinkonzentration ................................................... 74

2.2.4.4 Trennung von Proteinen durch SDS-Polyacrylamid-

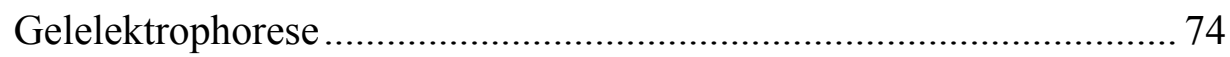

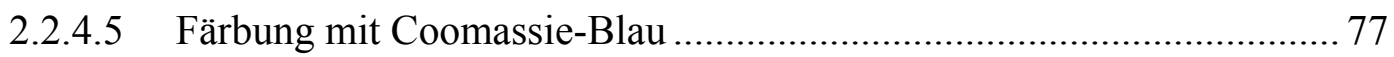

2.2.4.6 Nachweis radioaktiv markierter Proteine .............................................. 77

2.2.4.7 Transfer von Proteinen auf Nitrozellulose-Membranen $($,Western-Blot“) ........................................................................ 78

2.2.4.8 Immunologischer Nachweis von Proteinen auf NitrozelluloseMembranen (Immunoblot-Analyse) .................................................. 79

2.2.4.9 Proteolytische Prozessierung von $\alpha$-Faktor-erweitertem Sec22p

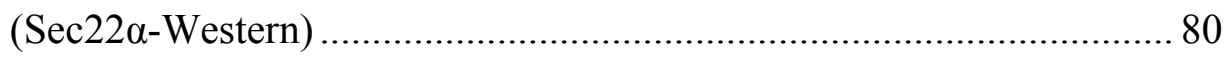

2.2.4.10 Immunpräzipitation radioaktiv markierter Proteinen aus Zellextrakten („Pulse-Chase“-Immunpräzipitation) ................................................ 81

2.2.4.11 Reinigung eines 6xHis-Use1-Fusionsproteins zur Immunisierung und

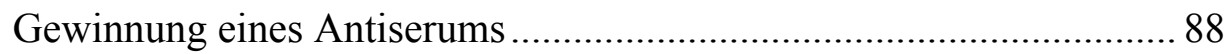

2.2.4.11.1 Expression eines 6xHis-Use1-Fusionsproteins .......................... 88

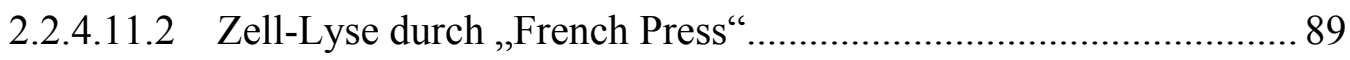

2.2.4.11.3 Reinigung des 6xHis-Use1-Fusionsproteins ............................... 89

2.2.4.11.4 Immunisierung eines Kaninchens................................................ 90

2.2.4.11.5 Gewinnung, Aufarbeitung und Lagerung des Antiserums ............ 90

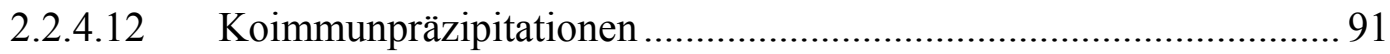

2.2.4.12.1 Kopplung von Antikörpern und Präimmunserum an Protein-A-bzw. Protein-G-Sepharose ............................................ 91

2.2.4.12.2 Versuch zur Koimmunpräzipitation von HA-Vts1p und Vti1p..... 92

2.2.4.12.3 Kreuzvernetzung („Crosslinking“) von Proteinen mit DSP und anschließende Immunpräzipitation ............................................ 93

2.2.4.12.4 Native Immunpräzipitation von Use1-SNARE-Komplexen ......... 93

2.2.4.13 Analyse der SNARE-Komplex-Assemblierung mittels Gelfiltration und Ionenaustausch-Chromatographie ............................................95

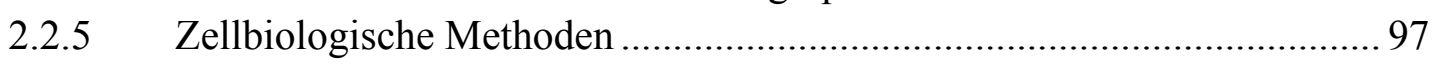

2.2.5.1 Indirekte Immunfluoreszenz mit Hefezellen ..................................... 97

2.2.5.2 Indirekte Immunfluoreszenz für Emp47p in Hefezellen ..................... 100

2.2.5.3 Subzelluläre Fraktionierung von Hefekompartimenten ...................... 101

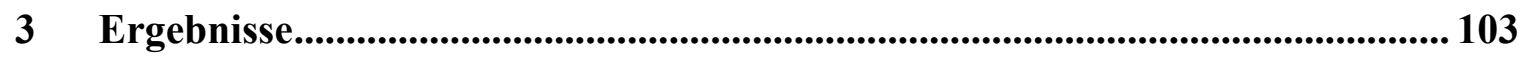

3.1 Identifizierung von Suppressoren der vtil-2-Mutante .................................. 103

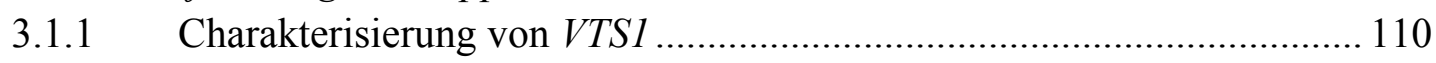

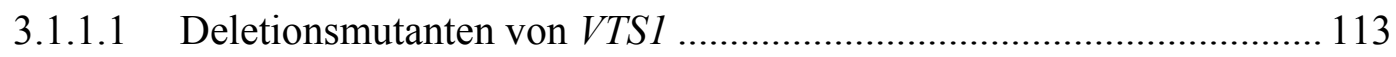

3.1.1.2 Analyse der subzellulären Lokalisation von Vts1p ........................... 117

3.1.1.3 Untersuchung der Interaktion zwischen Vti1p und Vts1p.................. 119

3.1.2 Charakterisierung des vti1-2-Suppressors Ykt6p ................................ 121 
3.2 Identifizierung einer SNARE-verwandten Sequenz

3.3 Charakterisierung des von YGL098w codierten Proteins .............................. 129

3.3.1 Herstellung von YGL098w-Deletionsmutanten ...................................... 129

3.3.2 Subzelluläre Lokalisation des von YGL098w codierten Proteins............ 129

3.3.3 Temperatursensitive Mutanten von USE1 ............................................... 132

3.3.4 Untersuchung der Funktion von Use1p im ER-Golgi-Transport ............ 133

3.3.5 Untersuchung der use1-Mutanten auf Defekte im anterograden bzw.

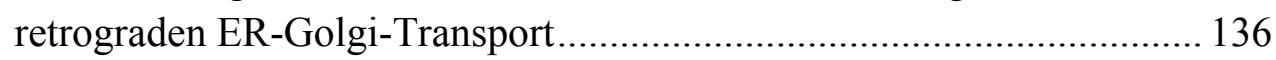

3.3.6 Genetische Interaktionen zwischen USE1 und ER-Golgi-SNAREs ....... 142

3.3.7 Biochemische Charakterisierung des Use1p-SNARE-Komplexes ......... 144

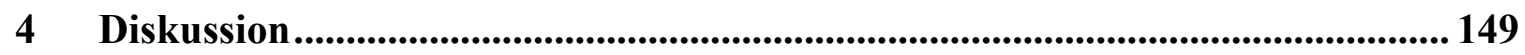

4.1 Analyse von Suppressoren der vtil-2-Mutante .............................................. 149

4.1.1 Identifizierung des vtil-2-Suppressors VTS1 (YOR359w)...................... 149

4.1.1.1 Charakterisierung des vtil-2-Suppressors VTS1 (YOR359w)............. 150

4.1.1.2 VTS1 ist im letzten Transportschritt zur Vakuole involviert ............... 152

4.1.2 Identifizierung und Charakterisierung des vtil-2-Suppressors YKT6 ..... 153

4.1.2.1 Ykt6p ist eine Komponente der SNARE-Komplexe des biosynthetischen Transportes zur Vakuole ............................................. 153

4.1.2.2 Ykt6p ist auch am Aufbau des prävakuolären SNARE-Komplexes

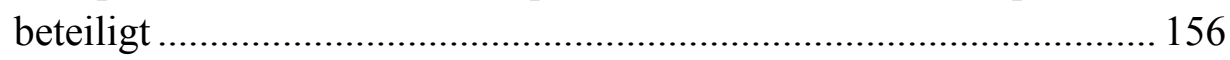

4.2 Identifizierung eines neuen SNARE-Proteins in Hefe ................................ 158

4.3 Uselp ist ER-lokalisiert und im Transport zwischen ER und Golgi involviert 159

4.4 Uselp wird für den retrograden Transport zum ER benötigt ........................ 160

4.5 USE1 zeigt eine starke genetische Interaktion mit SNAREs des retrograden Golgi-ER-Transportes ................................................................................. 161

4.6 Uselp ist Bestandteil des retrograden Golgi-ER-SNARE-Komplexes ............ 162

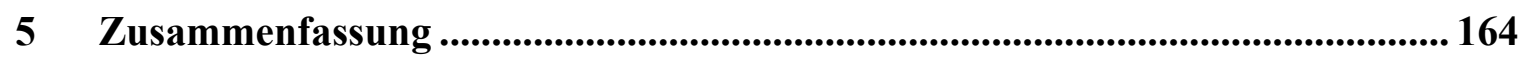

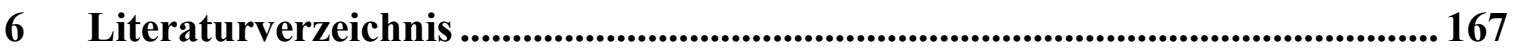




\section{Abkürzungsverzeichnis}

AA

Abb.

ad

ALP

Amp

API

APNE

APS

ATP

$\mathrm{bp}$

BSA

cDNA

CEN

Chrom.

CPY

DAPI

$\mathrm{ddH}_{2} \mathrm{O}$

DMP

DMSO

DNA

dNTPs

ds

DTT

E. coli

EDTA

EGTA

Endkonz.

ER
Aminosäuren

Abbildung

auffüllen auf

Alkalische Phosphatase

Ampicillin

Aminopeptidase I

N-Acetyl-phenylalanin- $\beta$-naphtylester

Ammoniumperoxodisulfat

Adenosin-Triphosphat

Basenpaar(e)

Bovine Serum Albumin (Rinderserumalbumin)

komplementäre DNA

centromer

Chromosom

Carboxypeptidase $\mathrm{Y}$

4'-6-Diamino-2-phenylindol-dihydrochlorid

doppelt-destilliertes Wasser

Dimethyl-pimelinediimidat-dihydrochlorid

Dimethylsulfoxid

Desoxyribonukleinsäure

Desoxynucleosidtriphosphate (dATP, dGTP, dCTP, dTTP)

Doppelstrang-

Dithiothreitol

Escherichia coli

Ethylendiamintetraacetat-Dinatriumsalz

Ethylenglycol-bis-( $\beta$-Aminoethylether)-N,N,N',N'-Tetraacetat

Endkonzentration

Endoplasmatisches Retikulum 


EtOH Ethanol

GST Glutation-S-Transferase

$\mathrm{h}$

Stunde

HA Hämagluttinin

HEPES N-2-Hydroxyethylpiperazin-N'-2-ethansulfonsäure

HPLC High Pressure Liquid Chromatographie

HRP Horseradish-Peroxidase (Meerrettich-Peroxidase)

IgG Immunglobulin $\mathrm{G}$

IP Immunpräzipitation

IPTG Isopropyl- $\alpha-D-T h i o g a l a c t o p y r a n o s i d$

Kana Kanamycin

$\mathrm{kb} \quad$ Kilobasen

kDA Kilodalton

$1 \quad$ Liter

LB Luria Bertani

Lsg. $\quad$ Lösung

M molar

$\mathrm{mA} \quad$ Milliampere

$\mathrm{mF} \quad$ Millifarad

mg Milligramm

$\min \quad$ Minute

$\mathrm{ml} \quad$ Milliliter

$\mathrm{mM}$ millimolar

MW Molekulargewicht in Dalton

n.d. nicht determiniert

nm Nanometer

NSF $\quad N$-Ethylmaleimid-Sensitive-Factor

nt Nukleotide

$\mathrm{OD}_{600} \quad$ Optische Dichte bei einer Wellenlänge von $600 \mathrm{~nm}$

PAGE Polyacrylamid-Gelelektrophorese

PCR Polymerase-Ketten-Reaktion

PEP4 Gen, welches für die vakuoläre Proteinase A codiert 
Pfu Pyrococcus furiosus

$\mathrm{pH} \quad$ negativer dekadischer Logarithmus der $\mathrm{H}^{+}$-Ionenkonzentration

PMSF Phenylmethylsulfonylfluorid

RNA Ribonukleinsäure

RT Raumtemperatur

S. cerevisiae Saccharomyces cerevisiae

SDS Sodium Dodecyl Sulfate/Lauryl Sulfate (Natriumdodecylsulfat)

sec Sekunde

SNAP Soluble-NSF-Attachment-Protein

SNARE SNAP-Receptor

ss Einzelstrang-

Tab. Tabelle

TAE Tris-Acetat-EDTA-Puffer

Taq Thermus aquaticus

TCA Trichloressigsäure

TE Tris-EDTA-Puffer

TEMED N,N,N',N'-Tetramethylethylendiamin

TGN Trans-Golgi-Netzwerk

Tm Schmelztemperatur

Tris Tris-(hydroxymethyl)-aminomethan

ts temperatursensitiv

U Unit

üN über Nacht

UpM Umdrehungen pro Minute

UV Ultraviolett

V Volt

v/v Volumenverhältnis (volume/volume)

w/v Gewichtsverhältnis (weight/volume)

WT Wildtyp

z.B. zum Beispiel

$\mu \quad$ Mikro-

Die chemischen Elemente wurden mit den üblichen Symbolen abgekürzt 



\section{$1 \quad$ Einleitung}

\subsection{Intrazelluläre Transportprozesse}

Der Besitz membranumschlossener Kompartimente (auch Organellen genannt), welche unterschiedliche Funktionen erfüllen und voneinander abgegrenzte Reaktionsräume bilden, ist ein wesentliches Merkmal von eukaryonten Zellen (de Duve, 1975; Palade, 1975). Beispiele für solche Kompartimente sind der Zellkern, das endoplasmatische Retikulum (ER), der Golgi-Apparat, Endosomen, Lysosomen (in Hefe: Vakuolen) und im weitesten Sinne das Cytosol und die Plasmamembran. Jedes Organell besitzt seine eigene, charakteristische Ausstattung an Proteinen, Lipiden und anderen Makromolekülen, welche über komplizierte Transportwege zu diesem Organell befördert werden. Die Zielsteuerung der Proteine erfolgt dabei anhand von molekularen Markierungen wie Signalsequenzen und Glykosylierungsmustern die als Adressierungssignale dienen (Blobel, 1980). Generell muss zwischen zwei grundsätzlich verschiedenen Transportarten unterschieden werden, durch die Proteine von einem Kompartiment zum anderen gelangen. Sie können entweder direkt durch eine Membran hindurch transportiert werden, wozu jedoch ein spezifischer, porenförmiger Protein-Translokator erforderlich ist und sich das Protein meist entfalten muss, um hindurch zu gelangen. Diese Art des Proteintransportes findet z.B. während der Translokation von Proteinen ins Lumen des ER (Rapoport, 1992), in die Matrix von Mitochondrien und Chloroplasten (Neupert, 1997; May and Soll, 1999) sowie beim Import von Proteinen in den Kern (Görlich and Laskey, 1995) statt. Oder aber sie werden von Transportvesikeln, die sich von einem Donor-Organell abschnüren und mit einem Akzeptor-Organell verschmelzen, von einem Kompartiment zum anderen befördert (Palade, 1975; Übersicht in: Rothman, 1994; Mellman and Warren, 2000).

Durch die Fusion der Lipiddoppelschichten des Transportvesikels und des Zielorganells werden dabei jedoch nicht nur lösliche Proteine befördert, sondern gleichzeitig auch die Membranen selbst und darin integrierte Membranproteine und Lipide. Dieser sogenannte vesikelvermittelte Membrantransport ist daher auch an der Bildung neuer Plasmamembranen während Zellwachstum und Zellteilung und an der Entstehung von Lysosomen (Vakuolen) und Endosomen durch homotypische Fusion beteiligt. 
Grundsätzlich erfolgt der Vesikeltransport über zwei Hauptwege, den biosynthetischsekretorischen Transportweg und den endozytotischen Transportweg:

- Für lysosomale (vakuoläre) und sekretorische Proteine sowie Proteine der Plasmamembran stellt die Translokation ins ER erst den Beginn ihrer Reise dar. Nach Faltung und Assemblierung erhalten die Proteine eine sogenannte Kern- oder „Core“-Glykosylierung. Sie treten nun in den biosynthetisch-sekretorischen Transportweg ein indem sie in Transportvesikel eingeschlossen werden, die sich vom ER abschnüren und zum cis-Golgi transportiert werden. Beim Durchtritt durch den Golgi-Apparat, der vermutlich nach dem Modell der Zisternenprogression erfolgt (Bonfanti et al., 1998), erhalten die Proteine ihre terminale Glykosylierung. Im trans-Golgi-Netzwerk (TGN) verzweigen sich nun die Transportrouten (Griffiths and Simons, 1986). Integrale Membranproteine und sekretorische Proteine werden in Transportvesikeln über den sekretorischen Weg zur Plasmamembran transportiert. Lösliche lysosomale Enzyme werden in höheren Eukaryonten anhand einer Mannose-6-Phosphat-Markierung durch einen spezifischen Rezeptor erkannt und weiter im biosynthetischen Transportweg über das späte Endosom zum Lysosom befördert (Traub and Kornfeld, 1997), wo sie an der Degradierung von extrazellulären und intrazellulären Substanzen beteiligt sind. Letztere erreichen das Lysosom durch Autophagozytose indem sie in von einer Doppelmembran umgrenzte Vesikel (sogenannte Autophagosomen) eingeschlos-sen werden, die daraufhin mit dem Lysosom fusionieren. Autophagozytose ist ein nichtselektiver Transport der durch Nährstoffmangel induziert wird. Durch die im Lysosom degradierten Proteine werden in Hungerphasen Aminosäuren für die Neusynthese von Proteinen zur Verfügung gestellt.

- Extrazelluläre Substanzen werden im endozytotischen Transportweg über frühe Endosomen und späte Endosomen zum Lysosom transportiert. Dieser Transportweg wird auch von einigen Viren benutzt, um in die Wirtszelle einzudringen.

In Hefe sind daneben noch zwei zusätzliche Transportwege zur Vakuole (Lysosom) identifiziert worden, auf die später eingegangen werden soll (siehe Kap.1.7.1). 


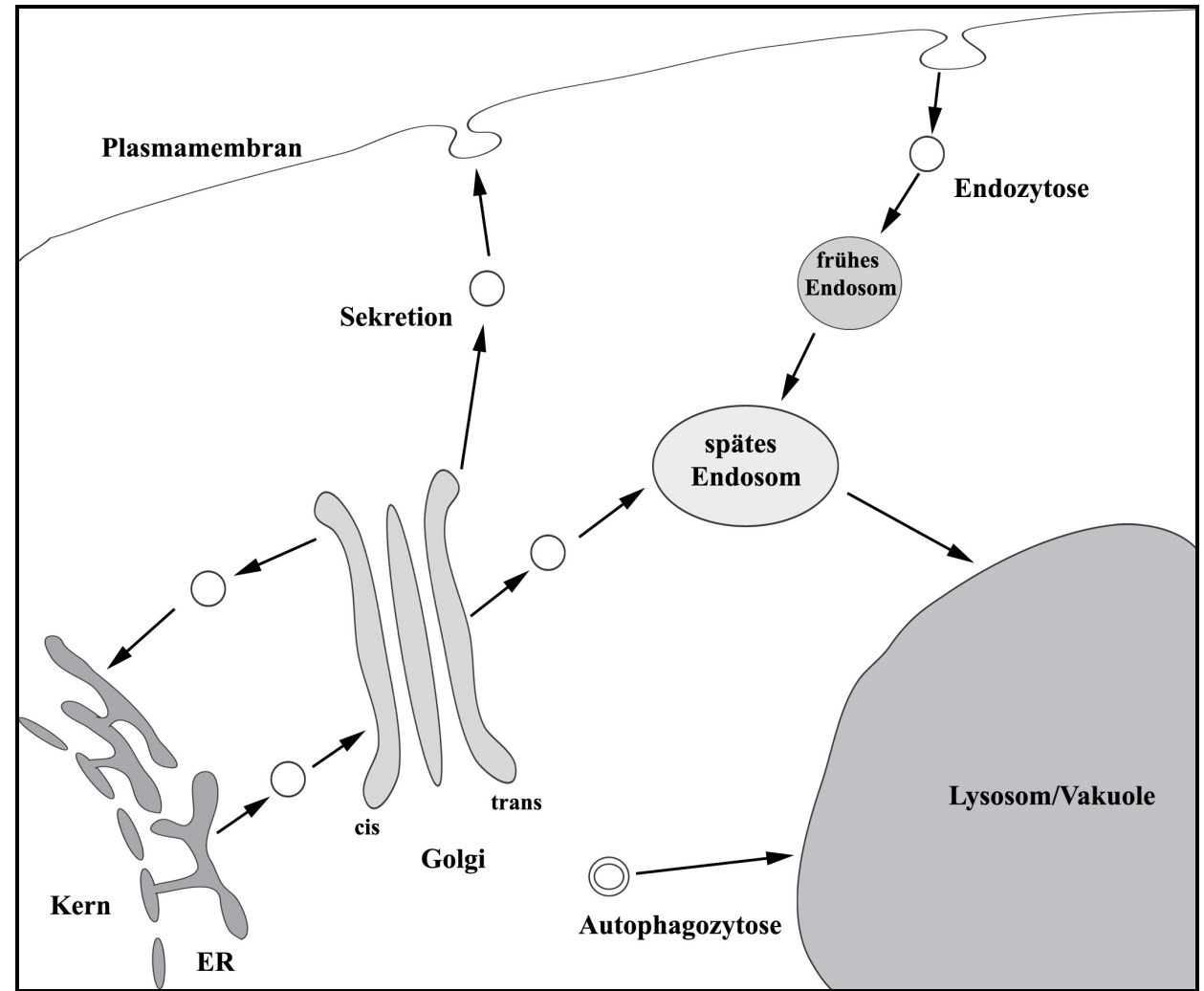

Abb. 1.1: Schematische Darstellung der vesikulären Transportprozesse in einer eukaryonten Zelle.

Bei diesen zahlreichen vesikulären Transportprozessen zwischen den unterschiedlichen Kompartimenten muss die strukturelle und funktionelle Integrität der Organellen bewahrt werden, d.h. es muss die Möglichkeit bestehen, dass Organell-spezifische Proteine, die aus Versehen von einem Transportvesikel zum nächsten Organell transportiert wurden, erkannt und wieder zurückbefördert werden können. Daher existiert neben den anterograden Transportwegen vom ER über den Golgi-Apparat zum Lysosom auch noch ein gegenläufiger, retrograder Transport von frühen und späten Endosomen zum TGN, innerhalb des Golgi-Apparates, sowie vom cis-Golgi zum ER. Außerdem muss die Spezifität und Direktionalität des Transportes gewährleistet sein, d.h. dass ein vom ER abgeschnürtes Vesikel seine Fracht nur zum cis-Golgi transportiert und nicht zum TGN oder zum Lysosom. Viele der am Vesikeltransport beteiligten Proteine, Lipide und Enzymkomplexe sind mittlerweile identifiziert und charakterisiert worden, wobei man erkannte, dass sie sowohl innerhalb der Zelle vom ER zur Plasmamembran als auch phylogenetisch von der Hefe zum Menschen hochgradig konserviert sind (Bennett and Scheller, 1993; Ferro-Novick and Jahn, 1994; Bock et al., 2001). Da ein fehlerhafter 
Transport von Proteinen innerhalb der Zellen zu Fehlfunktionen und Krankheiten führen kann, wie dies z.B. bei der Entstehung lysosomaler Speicherkrankheiten der Fall ist (Übersicht in: Kornfeld and Mellman, 1989; Amara et al., 1992), trägt die Identifizierung und Charakterisierung der Komponenten des Membrantransportsystems zur Aufklärung der zugrundeliegenden Mechanismen bei. Die Hefe Saccharomyces cerevisiae erweist sich hierbei als ideales Modellsystem, da der Membrantransport in Hefe und Säugern große Ähnlichkeiten aufweist, die genetische Manipulation und biochemische Analyse in Hefe jedoch erheblich vereinfacht ist.

\subsection{Prinzip des Vesikeltransportes}

Für die Entstehung von Transportvesikeln an der Membran des Donor-Organells ist eine Interaktion verschiedener Proteine erforderlich. Zuerst erfolgt eine Anhäufung kleiner GTPasen der Arf- oder Sar1-Familie in ihrer GTP-gebundenen Form in einem bestimmten Bereich der dem Cytosol zugewandten Membranoberfläche. Sie rekrutieren lösliche Hüllproteine (englisch: coat proteins) die sich auf der Membran zu einem Netzwerk zusammenlagern, welches eine Krümmung der Lipiddoppelschicht bewirkt. Bislang sind drei Arten von Hüllproteinen identifiziert worden: COPI, COPII und Clathrin. COPI besteht aus 7 Proteinuntereinheiten (Coatomere) und ist am retrograden Transport zwischen den einzelnen Golgi-Zisternen, sowie dem Rücktransport vom cisGolgi zum ER beteiligt (Letourneur et al., 1994). Es erkennt und bindet spezifische ERRetentionssignale in ER-Transmembranproteinen (KKXX/RRXX-Motiv). Außerdem interagieren COPI-Coatomere mit einem Transportrezeptor für luminale lösliche ERProteine (KDEL-Rezeptor in Säugern; HDEL-Rezeptor in Hefe). COPII besteht aus 5 Untereinheiten und ist für den anterograden Transport zwischen ER und cis-Golgi verantwortlich (Barlowe et al., 1994), der überwiegend nach dem „bulk-flow“-Prinzip erfolgt, d.h. unselektiv ohne Erkennung und Sortierung von Frachtproteinen. Clathrin besteht aus Trimeren (Triskelions) die zu Penta- und Hexagonen polymerisieren und ist sowohl am Transport vom TGN zu Endosomen als auch an der Endozytose beteiligt. In Hefe stellt möglicherweise das Protein Vps41p/Vam2p ein weiteres Hüllprotein dar, das am Clathrin-unabhängigen direkten Transport vom TGN und Cytosol zur Vakuole beteiligt ist (Harding et al., 1995; Rehling et al., 1999). 
Die Hüllproteine interagieren entweder direkt, oder indirekt über Adapterkomplexe, mit Transmembranproteinen, die zum Teil als Rezeptoren für lösliche Frachtproteine dienen. Außerdem werden durch Interaktion mit den Hüll- und Adapterproteinen auch integrale Membranproteine in die Vesikelmembran eingebaut, die für die Zielsteuerung und die Fusion des Vesikels mit dem Akzeptor-Organell verantwortlich sind.

Eine Gruppe von heterotetrameren Adapterkomplexen (AP) ist sowohl am post-Golgi Proteintransport zu Endosomen und zum Lysosom als auch an der Endozytose beteiligt. Sie decodieren Tyrosin- und Dileucin-Sortierungssignale in der cytosolischen Domäne von Plasmamembran-Rezeptoren und anderen Transmembranproteinen. Bislang sind 4 APs identifiziert worden. AP-1 ist in Säugern an der Sortierung und dem Clathrinabhängigen Export lysosomaler Enzyme aus dem TGN durch Bindung an den Mannose6-Phosphat-Rezeptor (MPR) beteiligt (Übersicht in: Le Borgne and Hoflack, 1998). Daneben wird für AP-1 aber auch eine Rolle im retrograden Transport von MPRs zum TGN diskutiert (Meyer et al., 2000). In Hefe scheint AP-1 ebenfalls am Transport vom TGN zum frühen Endosom beteiligt zu sein (Stepp et al., 1995). AP-2 ist an der Clathrinvermittelten Endozytose plasmamembranständiger Rezeptorproteine involviert (Schmid, 1997). AP-3 ist in der Hefe im direkten Clathrin-unabhängigen Transport vom TGN zur Vakuole beteiligt (Übersicht in: Odorizzi et al., 1998). Das vakuoläre Membranprotein Alkalische Phosphatase (ALP) und die SNARE-Proteine Vam3p und Nyv1p werden über diese als ALP-Weg bezeichnete Transportroute befördert (siehe Kap. 1.7.1). Im Gegensatz zur Hefe bindet AP-3 in Säugern an Clathrin (Dell'Angelica et al., 1998). Hier ist es an der Sortierung von lysosomalen Transmembranproteinen und der Bildung spezieller Speicherlysosomen wie Melanosomen und Thrombocytenspeichervesikeln beteiligt. Mutationen in AP-3-Untereinheiten rufen daher eine anomale Haut- und Haarpigmentierung und Blutgerinnungsstörungen hervor. Diese AP-3-Mutationen konnten Patienten mit Hermansky-Pudlak-Syndrom zugeordnet werden (Dell'Angelica et al., 1999). AP-4 ist ebenfalls mit dem TGN assoziiert, bindet jedoch kein Clathrin. Über seine Funktion ist bisher noch nichts bekannt.

Neben den heterotetrameren Adapterkomplexen existiert noch eine zweite Gruppe von monomeren Adapterproteinen, die GGA-Proteine (Boman et al., 2000). Bislang sind 3 Mitglieder dieser Proteinfamilie bekannt, GGA1, GGA2 und GGA3. Sie besitzen Sequenzhomologien zur Clathrin-bindenden Untereinheit der heterotetrameren Adapter- 
komplexe und sind alle im TGN lokalisiert. GGAs scheinen in Säugern am Export von MPRs aus dem TGN (Puertollano et al., 2001) und der Sortierung von SortilinRezeptoren (Nielsen et al., 2001) beteiligt zu sein. GGA1/GGA2-Doppeldeletionsmutanten zeigen in Hefe eine Fehlsortierung von Carboxypeptidase Y (CPY), welches durch Vps10p, einen dem Sortilin-Rezeptor homologen Transportrezeptor, sortiert wird (Hirst et al., 2000; Mullins and Bonifacino, 2001). Außerdem wird für GGA-Proteine eine Funktion am Transport von Pep12p, einem prävakuolären SNARE-Protein, vom TGN zur Prävakuole diskutiert (Black and Pelham, 2000).

Nachdem sich die mit Frachtproteinen beladenen Transportvesikel von der Membran des Donor-Organells abgeschnürt haben (Budding), dissoziieren die Hüllproteine in ihre Monomere und werden abgeworfen. Dieser Prozess wird durch die GTP-Hydrolyse an Arf bzw. Sarlp katalysiert. Hierdurch wird gewährleistet, dass die Sortierungs- und Fusionsproteine auf der Vesikelmembran mit korrespondierenden Proteinen auf der Membran des Akzeptor-Organells interagieren können. Der Transport der Vesikel zu den Zielorganellen erfolgt teilweise unter Beteiligung von Cytoskelett-Elementen und Motorproteinen (Govindan et al., 1995).

Sobald das Transportvesikel die Zielmembran erreicht, wird eine lockere Bindung (Tethering) zwischen den Membranen ausgebildet. Die Interaktion zwischen einer kleinen GTPase der Ypt/Rab-Familie auf der Vesikelmembran und einem faserartigen coiled-coilProtein (Tether-Protein) auf der Membran des Akzeptor-Organells ist hierfür verantwortlich (TerBush et al., 1996; Cao et al., 1998; Sacher et al., 1998; Übersicht in: Pfeffer, 1999 und Guo et al., 2000). Das Tethering des Vesikels an die Zielmembran ist zeitlich limitiert. GTP-Hydrolyse durch das Ypt/Rab-Protein führt zur Dissoziation der Bindung (Stahl et al., 1996). Hefe besitzt 11 Ypt-Proteine (Lazar et al., 1997), in Säugerzellen kommen 60 verschiedene Rab-Proteine vor (Bock et al., 2001). Jedes Ypt/Rab-Protein ist funktionell auf einen bestimmten vesikulären Transportschritt spezialisiert (Übersicht in: (Martinez and Goud, 1998). Die Tether-Proteine besitzen ebenfalls eine spezifische Lokalisation. So ist das Tether-Protein EEA1 (bzw. sein Hefehomolog Vac1p) z.B. mit frühen Endosomen assoziiert (Mu et al., 1995). Hierdurch könnte die Spezifität des Vesikeltransportes gewährleistet werden. Im nächsten Schritt interagieren spezielle Membranproteine der SNARE-Familie (siehe Kap. 1.3), welche auf allen Membranen intrazellulärer Kompartimente $\mathrm{zu}$ finden sind, miteinander. Auf der Vesikelmembran 
lokalisierte v-SNAREs (vesicular) bilden einen Komplex mit passenden t-SNAREs (target) auf der Membran des Zielorganells, was zur festen Bindung des Vesikels an die Zielmembran führt (Docking). Dieses Docking erfolgt möglicherweise nur dann, wenn sich in der durch die GTP-Hydrolyse am Ypt/Rab-Protein festgelegten Zeitspanne passende SNARE-Proteine finden und miteinander interagieren (Clague, 1999). Die Ausbildung eines trans-SNARE-Komplexes zwischen SNARE-Proteinen auf der Vesikelund Zielmembran führt zur Annäherung beider Membranen und stellt die Energie zur Verfügung, die benötigt wird, um die elektrostatischen Abstoßungskräfte zwischen den Membranen zu überwinden (Hanson et al., 1997; Sutton et al., 1998; Ungermann et al., 1998). Hierdurch kommt es zur Fusion des Transportvesikels mit der Membran des Akzeptor-Organells. Da alle SNARE-Proteine des SNARE-Komplexes nun in derselben Membran lokalisiert sind, spricht man jetzt von einem cis-SNARE-Komplex. Das akzessorische Protein $\alpha$-SNAP (Clary et al., 1990) und die ATPase NSF (Wilson et al., 1989), bzw. die Hefehomologen Sec17p und Sec18p (Novick et al., 1981), dissoziieren nun den cis-SNARE-Komplex unter ATP-Hydrolyse in die einzelnen SNARE-Proteine (Priming), wodurch die v-SNAREs zum Donor-Organell zurücktransportiert werden und an weiteren Vesikelfusionen teilnehmen können (Mayer et al., 1996; Weber et al., 1998; Grote et al., 2000).

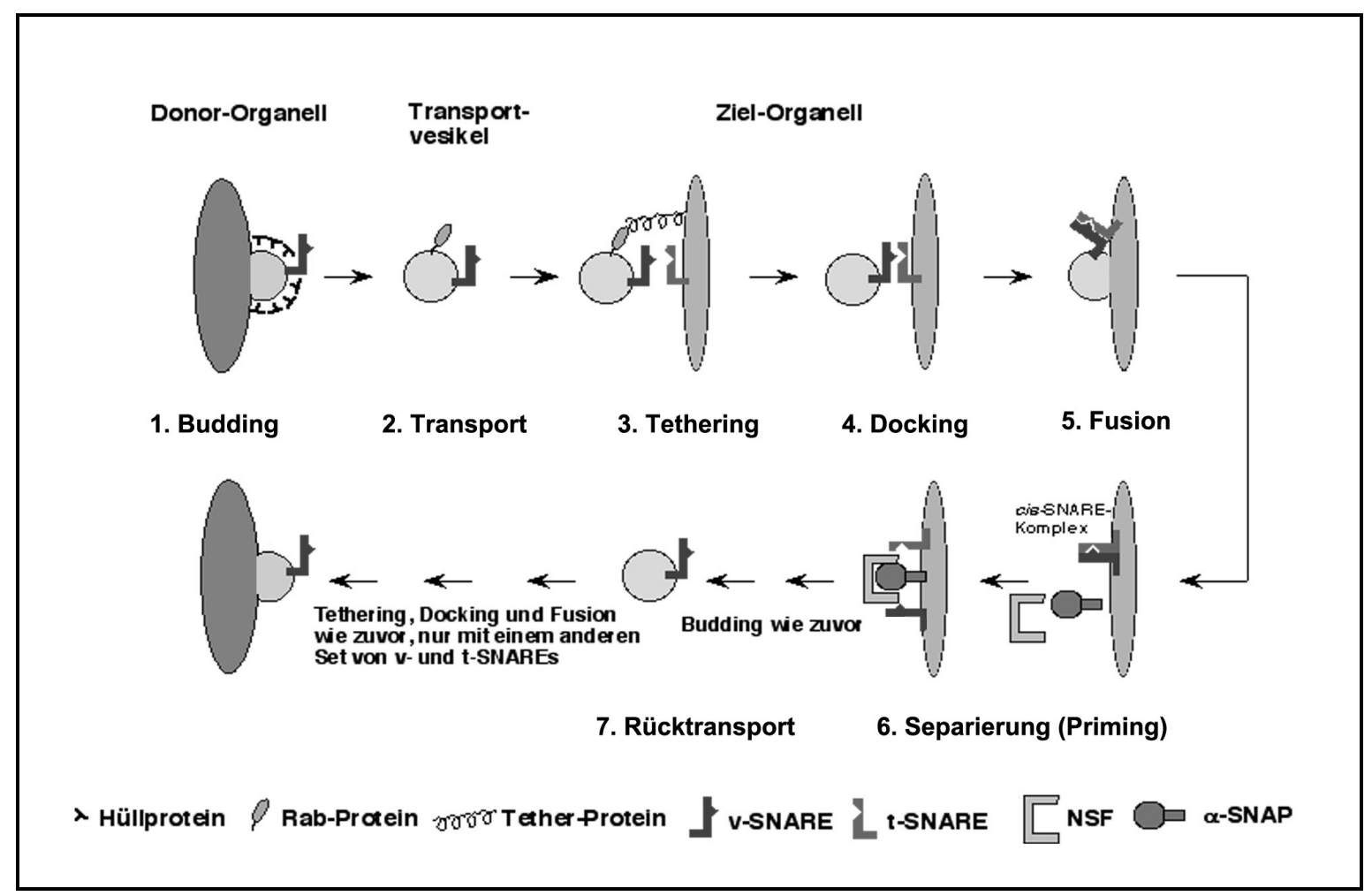

Abb. 1.2: Prinzip des Vesikeltransportes zwischen Donor- und Zielorganell. 


\subsection{SNARE-Proteine und ihre Funktion}

James Rothman und seinen Mitarbeitern gelang es 1987 den Vesikeltransport zwischen Golgi-Membranen in einem zellfreien System durch die Gabe von N-Ethylmaleimid (NEM) zu blockieren (Glick and Rothman, 1987). Ein Jahr später isolierten sie den NEMsensitiven Faktor (NSF), eine lösliche ATPase (Block et al., 1988). Daraufhin wurden weitere lösliche Proteine isoliert, die mit NSF interagieren, die sogenannten SNAPs (soluble NSF attachment protein), von denen 3 Isoformen $\alpha, \beta$ und $\gamma$ existieren (Clary et al., 1990; Clary and Rothman, 1990; Whiteheart et al., 1993). Rothman und Mitarbeiter beschrieben daraufhin erstmalig SNAREs (= SNAP-Rezeptoren) als Proteine, welche die Bindung der löslichen Faktoren NSF und $\alpha$-SNAP an Membranen aus RinderhirnHomogenaten vermitteln (Söllner et al., 1993b). Hierbei identifizierten sie einen SNAREKomplex aus 3 Proteinen, welche schon zuvor beschrieben wurden und von denen man wusste, dass sie an der regulierten Exozytose von Neurotransmittern aus Synapsen beteiligt waren (Trimble et al., 1988; Baumert et al., 1989; Bennett et al., 1992) (Malhotra et al., 1988; Oyler et al., 1989). Bei den Proteinen handelte es sich um Synaptobrevin 2 (auch VAMP-2 = vesicle- $\underline{\text { associated }}$ membrane protein $\underline{2}$ genannt), Syntaxin 1 und SNAP-25 (synaptosome-associated protein of $\underline{25} \mathrm{kDa}$ ). Synaptobrevin 2verwandte Proteine waren bereits in S. cerevisiae beschrieben worden (Dascher et al., 1991). Homologe aller drei neuronalen SNARE-Proteine sind bislang in allen Eukaryonten identifiziert worden, weshalb SNAREs in die Syntaxin-, SNAP-25 und VAMP-Familie untergliedert wurden. Synaptobrevin 2 ist mit der Membran synaptischer Vesikel assoziiert, während Syntaxin 1 und SNAP-25 an der präsynaptischen Plasmamembran lokalisiert sind. Diese funktionelle Verbindung zwischen SNARE-Proteinen und der Membranfusion wurde durch die Entdeckung unterstützt, dass SNAREs die alleinigen Substrate clostridialer Neurotoxine wie Tetanustoxin und Botulinumtoxin sind, welche durch spezifische Spaltung der SNARE-Proteine die Neurotransmission blockieren (Jahn and Niemann, 1994; Montecucco and Schiavo, 1995). Befinden sich die SNARE-Proteine in einem Komplex, so sind sie nicht mehr für die Neurotoxine zugänglich (Hayashi et al., 1994). Die Spaltung freier SNARE-Proteine verhindert jedoch die Entstehung neuer SNARE-Komplexe und führt so zur Inhibierung der Exozytose von synaptischen Vesikeln. 
Nach der von James Rothman und seinen Kollegen postulierten „SNARE-Hypothese“ (Söllner et al., 1993a; Rothman, 1994) könnte durch die spezifische Interaktion von zusammenpassenden v- und t-SNARE-Proteinen die Spezifität im Membrantransport erreicht werden. Dies würde jedoch bedeuten, dass spezielle SNARE-Proteine nur an einem bestimmten Transportschritt beteiligt sind. Zwar besitzen viele SNARE-Proteine, ähnlich wie Ypt/Rab-Protein und Tether-Proteine, eine Kompartiment-spezifische Lokalisation, einige SNARE-Proteine sind jedoch in mehreren unterschiedlichen Fusionsprozessen involviert. So bindet das Hefe-t-SNARE Sed5p z.B. mindestens 7 unterschiedliche SNAREs in 3 verschiedenen Komplexen (Nichols and Pelham, 1998) und das Hefe-v-SNARE Vtilp 4 unterschiedliche Syntaxin-verwandte SNAREs (Fischer von Mollard et al., 1997; Lupashin et al., 1997; Holthuis et al., 1998; Fischer von Mollard and Stevens, 1999). Daher scheint es, dass ein t-SNARE eine Zielmembran definiert und mit mehreren v-SNAREs an verschiedenen Populationen von Transportvesikeln interagieren kann. Die unterschiedliche Kombination von v-SNAREs könnte so die Spezifität des Transportes bestimmen, was auch dadurch unterstrichen wird, dass es viel mehr v-SNAREs als t-SNAREs gibt.

Bei den meisten SNARE-Proteinen handelt es sich um kleine (18 - $42 \mathrm{kDa})$ Typ-IIintegrale Membranproteine mit einer relativ kurzen luminalen Domäne (die auch vollkommen fehlen kann) und einer hochkonservierten cytoplasmatischen Domäne von ca. 60 Aminosäuren Länge, die sich zu einer $\alpha$-Helix falten kann und als SNARE-Motiv bezeichnet wird (Jahn and Südhof, 1999). Über diese SNARE-Motive interagieren verschiedene SNARE-Proteine miteinander und bilden Komplexe. Einige SNAREProteine besitzen keine Transmembrandomäne, sondern sind durch posttranslationale Modifikationen wie Palmitoylierung oder Isoprenylierung in der Membran verankert. Ein Beispiel hierfür ist SNAP-25, dessen zwei unterschiedliche SNARE-Motive durch eine cysteinreiche Sequenz getrennt sind, welche durch Acylreste mit der Membran verbunden ist (Hess et al., 1992). Das SNARE-Motiv wird bei einigen SNAREs von einer variablen N-terminalen Domäne gefolgt, die anscheinend regulatorische Funktionen besitzt (Nicholson et al., 1998; Munson et al., 2000). In Syntaxinen wird diese N-terminale Domäne aufgrund ihrer 3-Helix-Struktur als $\mathrm{H}_{\mathrm{A}, \mathrm{B}, \mathrm{C}}$ bezeichnet (Fernandez et al., 1998; Nicholson et al., 1998; Fiebig et al., 1999). $\mathrm{H}_{\mathrm{A}, \mathrm{B}, \mathrm{C}}$ führt durch Bindung an das als H3Helix bezeichnete SNARE-Motiv zur Abschirmung dieser Domäne, wodurch die 
Interaktion mit SNARE-Motiven anderer SNARE-Proteine inhibiert wird (Munson et al., 2000). Diese fusionsinkompetente Konformation (,closed“) wird vermutlich durch Bindung von Sec1/Munc18-homologen Proteinen (SM-Proteine) stabilisiert. Durch Bindung von Munc13 an das SM-Protein wird dessen Konformation geändert, was sich in der Folge auch auf die $\mathrm{H}_{\mathrm{A}, \mathrm{B}, \mathrm{C}}$-Domäne auswirkt, wodurch diese sich von der H3-Helix trennt (Brose et al., 2000). In dieser fusionskompetenten Konformation („open“) kann Syntaxin nun mit anderen SNARE-Proteinen interagieren und einen SNARE-Komplex bilden (Misura et al., 2000). Möglicherweise sind die variablen N-terminalen Domänen von SNARE-Proteinen aber auch für die Spezifität des Transportes verantwortlich. So sind diese Regionen in unterschiedlichen Syntaxinen, die im gleichen Transportschritt agieren, konserviert, während sie sich in Syntaxinen, die an unterschiedlichen Transporten beteiligt sind, unterscheiden (Weimbs et al., 1997).

In welchem Umfang SNARE-Proteine alleine die Spezifität des Transportes bestimmen können ist noch nicht mit entgültiger Sicherheit geklärt. Mehrere Experimente haben gezeigt, dass rekombinante SNARE-Motive von Mitgliedern der Syntaxin-, SNAP-25 und VAMP-Familie in vitro miteinander in unterschiedlichen Kombinationen unspezifisch SDS-resistente Komplexe bilden können, solange jede der vier Helices von einem unterschiedlichen Mitglied der Familien zur Verfügung gestellt wurde (Fasshauer et al., 1999; Yang et al., 1999). Außerdem konnte gezeigt werden, dass auch rekombinante 6xHis- bzw. GST-verlängerte Fragmente der gesamten cytosolischen Domänen von ERGolgi-SNARE-Proteinen miteinander unspezifische binäre Interaktionen ausbilden (Tsui and Banfield, 2000). Da diese in vitro-Bindeexperimente jedoch nur mit den löslichen Domänen der SNARE-Proteine durchgeführt wurden, könnte es sein, dass sie die tatsächlichen Verhältnisse in vivo während der Membranfusion nicht korrekt widerspiegeln (Hay, 2001). Andere Experimente deuten z.B. darauf hin, dass die Ausbildung von SNARE-Komplexen nur durch Interaktion passender SNARE-Proteine erfolgt. So konnten Rothman und Kollegen in einer abgewandelten Version ihres in vitroLiposomenfusions-Experimentes zeigen, dass SNAREs nur in einer bestimmten Anordnung die Fusion katalysierten. Nur wenn sich die SNARE-Proteine des exozytotischen SNARE-Komplexes Sso1p und Sec9p in der Membran der einen Liposomenpopulation befanden, während das passende v-SNARE Snc2p mit der anderen Liposomenmembran assoziiert war, erfolgte eine Fusion. Ein Austausch von Snc2p gegen 
das ER-Golgi-v-SNARE Betlp führte zur Inhibierung der Fusion (McNew et al., 2000). Ähnliche Einschränkungen beobachtete man auch beim Austausch des SNARE-Motivs von Vam3p gegen das von Sed5p oder Pep12p, was zur Inhibierung der Vakuolenfusion in vitro führte (Wang et al., 2001). Umgekehrt kann Vam3p Pep12p jedoch funktionell ersetzen (Darsow et al., 1997; Götte and Gallwitz, 1997). Zudem beobachtete man im Falle der SNARE-Proteine des an der homotypischen Vakuolenfusion beteiligten Komplexes, dass eine Kombination der für diesen Schritt spezifischen SNAREs Vam3p, Vam7p, Vtilp und Nvy1p ein höheres Maß an Liposomenfusion erzielte, als wenn man Nvylp gegen die an anderen Transportschritten beteiligten v-SNAREs Snclp oder Sec22p ersetzte (Fukuda et al., 2000). Die Aussagen der Liposomenfusions-Experimente sind jedoch dadurch limitiert, dass andere Faktoren wie Tether- und Rab-Proteine, welche möglicherweise an der primären Spezifitätsprüfung beteiligt sind, fehlen (Hay, 2001). In einem Transport-Experiment, in welchem die Fusion zwischen isolierten COPII-Vesikeln und Golgi-Membranen aus temperatursensitiven Stämmen mit Mutationen in den ERGolgi-SNAREs Sed5p, Bet1p, Bos1p und Sec22p gemessen wurde zeigte sich, dass Vesikel, die Mutationen in Betlp oder Boslp besaßen, nicht mit WT-Akzeptormembranen fusionieren konnten (Cao and Barlowe, 2000). Umgekehrt konnten Akzeptormembranen aus diesen temperatursensitiven Stämmen jedoch mit WT-COPII-Vesikeln fusionieren. Vesikel aus einer Sec22p-Mutante besaßen keinen Defekt, vermutlich deshalb weil Ykt6p Sec22p substituieren kann (Liu and Barlowe, 2002). Darüber hinaus konnten Akzeptormembranen einer Sed5p-Mutante nicht mit WT-COPII-Vesikeln fusionieren, während COPII-Vesikel aus der Sed5p-Mutante dazu fähig waren. Somit scheint es eine topologische Einschränkung für die Funktion eines SNARE-Proteins zu geben: Sed5p ist nur in Assoziation mit Golgi-Membranen funktionell, während Bet1p und Bos1p nur als v-SNAREs agieren.

\subsection{Struktur von SNARE-Komplexen}

Der bislang am besten charakterisierte SNARE-Komplex ist der exozytotische SNAREKomplex in Synapsen, der an der Fusion synaptischer Vesikel mit der präsynaptischen Plasmamembran beteiligt ist. Er besteht - wie erwähnt - aus den Plasmamembranassoziierten SNARE-Proteinen Syntaxin 1 und SNAP-25 sowie dem mit der Vesikelmembran verbundenen SNARE Synaptobrevin 2/VAMP-2 (Söllner et al., 1993b). 
Während monomeres Syntaxin eine definierte Sekundärstruktur mit hohem $\alpha$-helikalen Gehalt besitzt, sind die SNARE-Motive von monomerem SNAP-25 und Synaptobrevin eher unstrukturiert. Erst wenn sie miteinander Interagieren und sich zu einem Komplex assemblieren, bilden sie eine $\alpha$-helikale Struktur aus (Fasshauer et al., 1997a; Fasshauer et al., 1997b). Zu Beginn lagern sich vermutlich die SNARE-Motive von Syntaxin 1 und SNAP-25 zu einem Komplex mit einer 2:1-Stöchiometrie zusammen (Fasshauer et al., 1997b; Xiao et al., 2001). Während der Bindung von Synaptobrevin 2 an diesen vorgeformten Komplex wird ein Syntaxin 1-Molekül durch Synaptobrevin 2 ersetzt (Fasshauer et al., 1997b), was zur festen Assoziation zwischen Vesikel und Plasmamembran führt. Die Verkürzung von Synaptobrevin 2 durch die Ausbildung der $\alpha$-Helix verringert daraufhin die Distanz zwischen Vesikel- und Plasmamembran, was eine Grundvoraussetzung für die Fusion darstellt (Fasshauer et al., 1997b; Hanson et al., 1997). Das beschriebene Prinzip ähnelt dem Mechanismus mit dem virale Fusionsproteine, wie das HA2-Protein des Influenzavirus oder das gp41-Protein des HIV-Virus Virus- und Wirtsmembran miteinander verbinden und beide Membranen so dicht aneinander ziehen, dass die Energiebarriere der Membranfusion überwunden wird (Jahn and Südhof, 1999). Der so entstandene trans-SNARE-Komplex besitzt in Bezug auf die SNARE-Proteine eine 1:1:1-Stöchiometrie, setzt sich jedoch aus $4 \alpha$-Helices zusammen, da SNAP-25 zwei SNARE-Motive zur Verfügung stellt. Die Ausbildung dieses ternären Komplexes ist thermodynamisch begünstigt. Er ist extrem stabil, was seine Resistenz gegen Hitze (bis zu $90^{\circ} \mathrm{C}$ ), SDS-Behandlung und Proteasen darlegt (Hayashi et al., 1994; Fasshauer et al., 1997b). Die über den trans-SNARE-Komplex mit der präsynaptischen Plasmamembran verbundenen synaptischen Vesikel bleiben jedoch zunächst arretiert (Präfusion). Erst eine Erhöhung der cytosolischen $\mathrm{Ca}^{2+}$-Konzentration infolge eines Nervenimpulses führt zur Fusion der Vesikel mit der Plasmamembran und zur Ausschüttung des Neurotransmitters. Das $\mathrm{Ca}^{2+}$-bindende Protein Synaptotagmin scheint an diesem Prozess beteiligt zu sein, da es mit Syntaxin 1 und SNAP-25 $\mathrm{Ca}^{2+}$-abhängig interagiert (Chapman et al., 1995; Li et al., 1995; Gerona et al., 2000).

1998 gelang es durch Röntgenstrukturanalyse des kritallisierten Kernbereichs des neuronalen SNARE-Komplexes die Struktur bis ins Detail aufzuklären (Sutton et al., 1998) (Abb. 1.3). Dieser Kern- oder „Core“-Komplex besteht nur aus den rekombinanten SNARE-Motiven der drei beteiligten SNARE-Proteine, ähnelt jedoch dem ternären 
SNARE-Komplex in Bezug auf Assemblierung, Deassemblierung und biophysikalischen Eigenschaften (Fasshauer et al., 1997b; Fasshauer et al., 1998a). Die Kristallstruktur des SNARE-Komplexes zeigt wahrscheinlich die Anordnung der Proteine nach der Fusion der Membranen (cis-SNARE-Komplex). Man erkannte, dass in diesem Kernkomplex die $4 \alpha$-helikalen SNARE-Motive parallel in einem Bündel umeinander gedreht sind, welches strukturell klassischen coiled coil-Strukturen ähnelt (Crick, 1953).

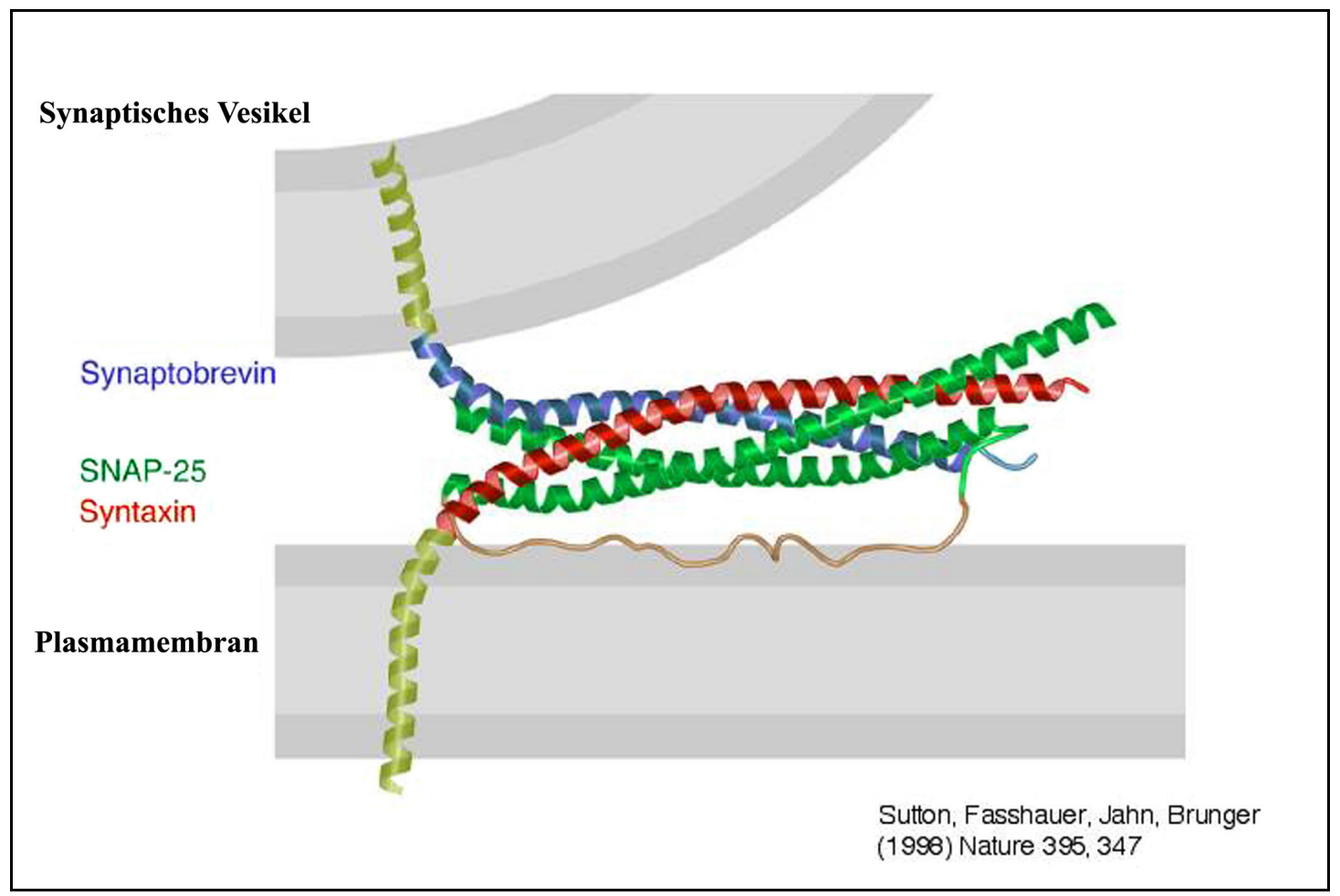

Abb. 1.3: Struktur des neuronalen SNARE-Komplexes basierend auf der Analyse der Kristallstruktur.

Die Interaktion zwischen den 4 SNARE-Motiven erfolgt hauptsächlich über hydrophobe Wechselwirkungen der Aminosäureseitenketten entlang der Achse der Superhelix. Jede 3. und darauffolgend 4. Aminosäure der $\alpha$-Helices jedes SNARE-Proteins weisen dabei ins Innere des Bündels und interagieren miteinander (Heptad-Repeat). Hierdurch entstehen 16 planare Schichten, die senkrecht zur Achse des 4-Helix-Bündels stehen und so der Struktur von Leucin-Zipper-Transkriptionsfaktoren ähneln. Ungefähr in der Mitte des Komplexes befindet sich eine asymmetrische Ebene, in der ein positiv geladenes Arginin (R) der Synaptobrevin 2-Helix mit drei hochpolaren Glutaminen (Q) der SNARE-Motive von Syntaxin 1 und SNAP-25 eine hydrophile Interaktion ausbildet. Diese auch als 0Ebene (englisch: 0-Layer) bezeichnete Schicht ist für die Stabilität des Komplexes von 
erheblicher Bedeutung. Sie wird durch die benachbarten hydrophoben Schichten von der wässrigen Phase abgeschirmt. Neben der Stabilisierung des Komplexes besteht eine weitere mögliche Funktion des 0-Layers darin, die $4 \alpha$-Helices in der korrekten Ausrichtung aneinander zu reihen. Des weiteren wurde eine Funktion des 0-Layers in der Deassemblierung des SNARE-Komplexes durch NSF und $\alpha$-SNAP beschrieben (Scales et al., 2001). Die restlichen Ebenen des 4-Helix-Bündels werden ausgehend vom 0-Layer in C-terminaler Richtung positiv (bis +8 ) und in N-terminaler Richtung negativ (bis -7) durchnummeriert. Die Aminosäurekomposition der einzelnen Ebenen, und besonders die des 0-Layers, ist dabei innerhalb der gesamten SNARE-Superfamilie konserviert (Weimbs et al., 1998). Die Bedeutung der hochkonservierten Aminosäurereste in den Ebenen des SNARE-Komplexes wird dadurch unterstrichen, dass Mutationen in SNAREProteinen, die zu Defekten im Membrantransport führen, generell Aminosäuren dieser Ebenen betreffen (Fasshauer et al., 1998b). Eine weitere für Sequenzvergleiche bedeutsame Ebene ist der ebenfalls asymmetrische -3-Layer, der im neuronalen SNAREKomplex aus 2 großen (Methionin und Phenylalanin) und zwei kleinen (Glycin und Alanin) Aminosäuren besteht. Es zeigte sich, dass die -3-Layer in anderen SNAREKomplexen eine ähnliche Aminosäurezusammensetzung besitzen, wobei die großen Aminosäuren immer von Synaptobrevin- und Syntaxin 1-verwandten SNAREs und die kleinen Aminosäuren jeweils von SNAP-25-homologen Proteinen stammen (Fasshauer et al., 1998b).

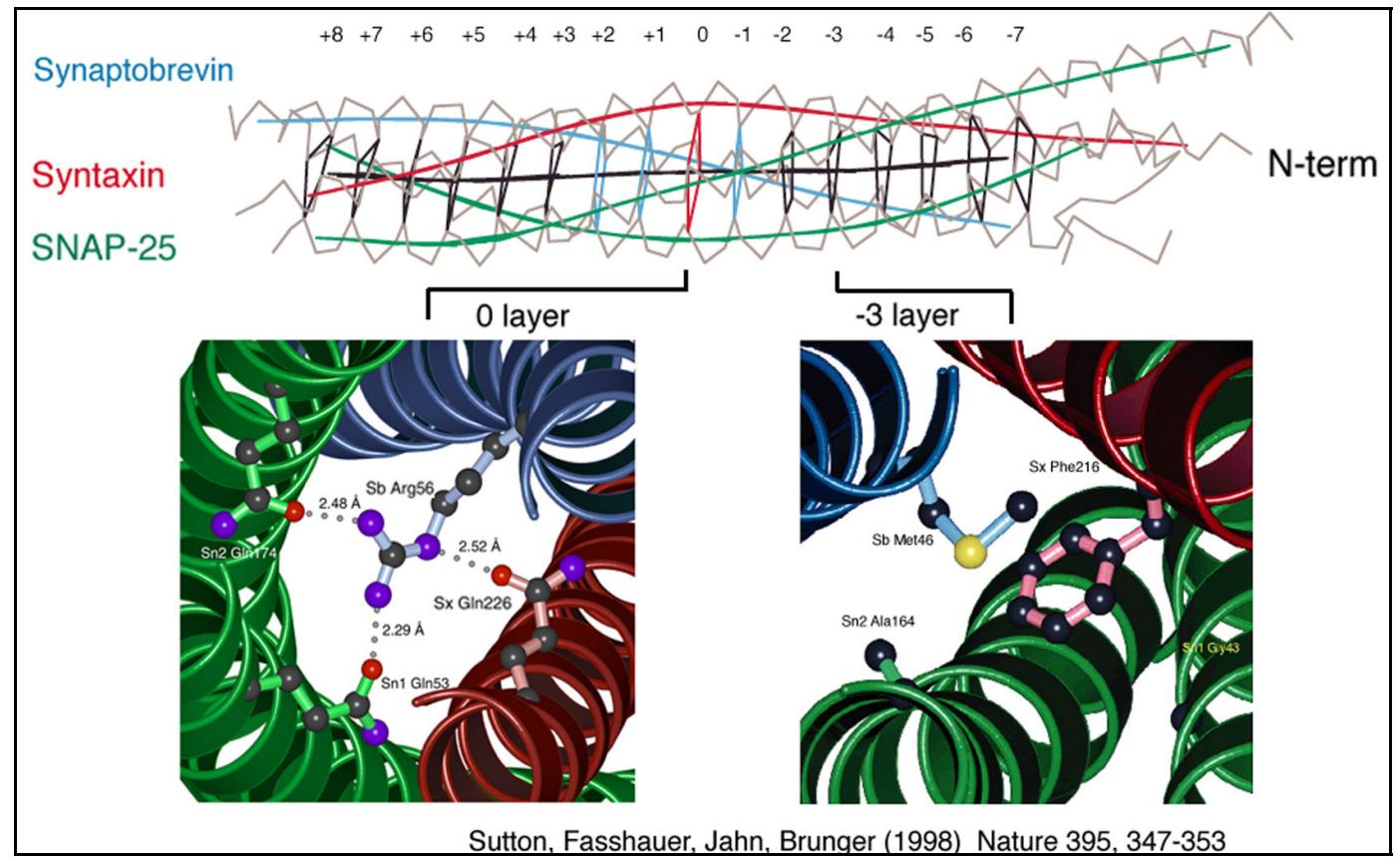

Abb. 1.4: Aufbau der Interaktionsebenen (Layer) der 4- $\alpha$-Helices des neuronalen SNARE-Komplexes. 
Kürzlich konnte die Kristallstruktur eines zweiten SNARE-Komplexes aufgeklärt werden (Antonin et al., 2002). Dieser SNARE-Komplex des späten Endosoms besteht aus den SNARE-Proteinen Syntaxin 7, Syntaxin 8, Vtilb und Endobrevin/VAMP-8 und weist eine signifikante Ähnlichkeit mit dem neuronalen SNARE-Komplex auf, wobei die beiden SNARE-Motive von SNAP-25 hier von Vtilb und Syntaxin 8 ersetzt werden. Auch in diesem Komplex besteht der 0-Layer aus einem Arginin und 3 Glutaminen (1R:3Q-Verhältnis). Der exozytotische SNARE-Komplex in Hefe, bestehend aus den Proteinen Sec9p (homolog zu SNAP-25), Snc1p/Snc2p (homolog zu Synaptobrevin 2) und Sso1p/Sso2p (homolog zu Syntaxin 1), weist ebenfalls viele Gemeinsamkeiten mit dem neuronalen SNARE-Komplex auf (Brennwald et al., 1994; Gerst, 1997; Rice et al., 1997; Katz et al., 1998; Fiebig et al., 1999). Experimente zeigten, dass ein Austausch von Glutamin gegen Arginin in Sso1p, was zu einem 2R:2Q-Verhältnis im 0-Layer führt, das Zellwachstum und die Proteinsekretion drastisch inhibierten, bis hin zu lethalen oder konditional-lethalen Phänotypen (Katz and Brennwald, 2000; Ossig et al., 2000). Eine Wiederherstellung des 1R:3Q-Verhältnisses durch eine Arginin-gegen-GlutaminSubstitution in Snc1p resultierte in einer Restauration des WT-Phänotyps, was darauf hin deutet, dass es egal ist, welche Helix des Bündels das Arginin im 0-Layer trägt. Diese Ergebnisse sprechen dafür, dass die verschiedenen SNARE-Komplexe anderer Membrantransportschritte ebenfalls coiled-coil-Strukturen aus vier parallel angeordneten $\alpha$-Helices ausbilden, die möglicherweise alle eine 1R:3Q-Komposition des 0-Layers aufweisen. Überraschenderweise führte eine Arginin-zu-Glutamin-Mutation in der 0-Layer-Position von Snc1p, welches in der Ausbildung von SNARE-Komplexen mit 4 Glutaminen im 0Layer resultierte, jedoch zu keinem Defekt der Zellen (Katz and Brennwald, 2000; Ossig et al., 2000). Die gleiche 0R:4Q-Komposition des 0-Layers existiert auch in biochemisch isolierten Komplexen aus einem SNAP-25-Molekül und zwei Syntaxin 1-Molekülen, die sich möglicherweise auf der präsynaptischen Plasmamembran bilden, bevor eine Interaktion mit Synaptobrevin 2 stattfindet (s.o.) (Fasshauer et al., 1997b; Fasshauer et al., 1998b; Fiebig et al., 1999). Daher scheint das 1R:3Q-Verhältnis des 0-Layers möglicherweise keine generelle Regel für die SNARE-Komplex-Assemblierung darzustellen. 


\subsection{Molekulare Mechanismen der Membranfusion}

Ergebnisse aus Experimenten zur homotypischen Vakuolenfusion und aus einem in vitroER-Golgi-Transportexperiment zeigen, dass Ypt/Rab-Proteine und Tether-Proteine nur an der lockeren Bindung (Tethering) der Transportvesikel an die Zielmembran beteiligt sind, während SNARE-Proteine erst in einem späteren Schritt agieren wo sie essentiell für die Membranfusion sind (Mayer and Wickner, 1997; Cao et al., 1998; Ungermann et al., 1998). Außerdem zeigten Rothman und Kollegen in einem in vitro-LiposomenfusionsExperiment mit in der Liposomenmembran rekonstituierten SNARE-Proteinen, dass diese alleine die Fusion der Lipidschichten vermitteln können und somit als minimale Fusionsmaschinerie agieren (Weber et al., 1998). Allerdings erfolgte die Fusion um ein Vielfaches langsamer als in der Zelle, was die physiologische Relevanz dieser Ergebnisse in Frage stellt. Die durch die trans-SNARE-Komplex-Bildung vermittelte Annäherung der Membranen von Transportvesikel und Zielorganell könnte die elektrostatischen Abstoßungskräfte zwischen den Membranen überwinden und die Fusion der Lipiddoppelschichten einleiten (Hanson et al., 1997; Sutton et al., 1998). Hierbei vermischen sich zunächst die proximalen Schichten der gegenüberliegenden Membranen (Hemifusion). Durch anschließende Fusion der distalen Schichten bildet sich eine Fusionspore aus, die sich daraufhin erweitert (Jahn and Südhof, 1999).

Daneben deuten andere Experimente darauf hin, dass es nach der trans-SNAREKomplex-Bildung noch weitere Faktoren gibt, die Einfluss auf das Fusionsereignis haben. So zeigten Ungermann et al. in einem in vitro-Vakuolenfusions-Experiment, dass die Fusion eines Vesikels mit der Zielmembran nach Ausbildung eines trans-SNAREKomplexes durch Phosphataseinhibitoren und amphiphile Peptide wie Mastoparan inhibiert werden kann, was darauf hin deutet, dass zusätzliche unbekannte Proteine für den letzten Schritt der Vesikelfusion verantwortlich sind (Ungermann et al., 1998). Wie zuvor beschrieben, sind die synaptischen Vesikel nach trans-SNARE-Komplex-Bildung zunächst in einem fusionsinkompetenten Stadium arretiert. Erst eine Erhöhung der cytosolischen $\mathrm{Ca}^{2+}$-Konzentration führt zur Fusion mit der Plasmamembran. Auch für andere Fusionsereignisse wurde eine $\mathrm{Ca}^{2+}$-Abhängigkeit aufgezeigt (Porat and Elazar, 2000; Pryor et al., 2000). Daneben wurde dem $\mathrm{Ca}^{2+}$-bindenen Protein Calmodulin eine Funktion im terminalen Schritt der Vakuolenfusion zugeschrieben (Peters and Mayer, 1998). Calmodulin bindet an den V0-Protonenkanal der vakuoläre $\mathrm{H}^{+}$-ATPase, welcher 
wiederum mit dem SNARE-Protein Vam3p interagiert (Peters et al., 2001). Durch Dimerisierung von einzelnen V0-Segmenten der gegenüberliegenden Membranen könnte sich eine Fusionspore ausbilden (Peters et al., 2001). Bislang ist allerdings noch unklar ob dieses Modell auch auf andere intrazelluläre Fusionsereignisse übertragen werden kann.

\subsection{Klassifizierung von SNARE-Proteinen}

SNARE-Proteine besitzen untereinander, abgesehen vom SNARE-Motiv, nur eine relativ geringe Sequenzhomologie, weshalb es schwierig ist sie in Subgruppen einzuordnen und neue Mitglieder dieser Familie zu identifizieren. Bislang sind im humanen Genom 35 SNARE-Gene identifiziert worden, während in Hefe 22 SNAREs bekannt sind (Bock et al., 2001; Pelham, 2001).

Wie zuvor beschrieben, wurden SNARE-Proteine ursprünglich in v-SNAREs und $\mathrm{t}$ SNAREs unterteilt, je nachdem ob sie auf der Membran des Transportvesikels oder des Zielorganells lokalisiert waren (Söllner et al., 1993a). Allerdings sind auch häufig tSNAREs mit Transportvesikeln assoziiert und bewegen sich so zwischen verschiedenen Kompartimenten, da auch sie über vesikulären Transport zu den Membranen der Zielorganellen transportiert werden müssen. Daneben ist es im Falle von homotypischen Fusionsereignissen nicht möglich zwischen v- und t-SNAREs zu unterscheiden. Deshalb ist es nicht ausreichend, alleine die Lokalisation eines SNARE-Proteins festzustellen, um dessen Funktion zu bestimmen (Jahn and Südhof, 1999). Aufgrund von Sequenzhomologien $\mathrm{zu}$ den synaptischen SNARE-Proteinen erfolgte daraufhin eine Klassifizierung der t-SNAREs in Syntaxine und SNAP-25-verwandte Proteine, sowie der vSNAREs in Synaptobrevine/VAMPs. Es wird angenommen, dass es in Hefe nicht mehr als 7 Syntaxine gibt (Übersicht in: Pelham, 1999; Bock et al., 2001). Mitglieder der SNAP-25-Familie sind anscheinend ausschließlich an der Fusion mit Plasmamembranen beteiligt (Weimbs et al., 1998). So fand man im Hefegenom nur zwei SNAP-25homologe Proteine, Sec9p und Spo20p, die beide eine Funktion in Plasmamembranassoziierten SNARE-Komplexen während Exozytose bzw. Sporulation besitzen (Weimbs et al., 1997; Neiman, 1998). In Säugern gibt es neben dem mit der präsynaptischen Plasmamembran assoziierten SNAP-25 nur zwei weitere homologe Proteine: SNAP-23, welches konstitutiv exprimiert wird und daher an Plasmamembranen in allen nichtneuronalen Geweben zu finden ist (Low et al., 1998) und SNAP-29, welches mit 
intrazellulären Membranen assoziiert ist, allerdings weder eine Transmembrandomäne noch eine Palmitoylierungssequenz besitzt und dessen Funktion und Partner-Proteine bislang noch unbekannt sind (Steegmaier et al., 1998). Da man davon ausgeht, dass alle SNARE-Komplexe dahingehend strukturell gleich sind, dass sie aus 4 SNARE-Motiven aufgebaut sind, scheint es so $\mathrm{zu}$ sein, dass SNAP-25 in intrazellulären SNAREKomplexen von zwei SNARE-Proteinen ersetzt wird, die jeweils zum N- bzw. Cterminalen SNARE-Motiv von SNAP-25 homolog sind.

Die Aufklärung der Kristallstruktur des neuronalen SNARE-Komplexes (Sutton et al., 1998) und die damit verbundene Entdeckung, dass die Aminosäurekomposition des 0Layers innerhalb der gesamten SNARE-Familie hochgradig konserviert ist (Weimbs et al., 1998), führte zu einer Reklassifizierung der SNARE-Proteine in R-SNAREs und QSNAREs (Fasshauer et al., 1998b). Alle Syntaxin- und SNAP-25-verwandten SNAREs sind Q-SNAREs, während es sich bei Synaptobrevin-verwandten SNAREs immer um RSNAREs handelt. Einige wenige SNARE-Proteine, z.B. Maus- und Ratten Vtila, besitzen allerdings anstelle des Glutamins ein Aspartat (D) in der 0-Layer-Position. Aspartat kann Glutamin jedoch funktionell ersetzen (Antonin et al., 2000c).

Eine weitere Unterteilung der Q-SNAREs wurde nötig, als man entdeckte, dass sich kein SNARE-Komplex formte, wenn alle drei Q-SNARE-Helices von Syntaxin-verwandten SNARE-Proteinen zur Verfügung gestellt wurden (McNew et al., 2000). SNAREKomplexe formten sich nur dann, wenn je eine der drei Q-SNARE-Helices dem SNAREMotiv von Syntaxin 1, bzw. den C- und N-terminalen SNARE-Motiven von SNAP-25 homolog waren. Daher werden Syntaxin 1-homologe Q-SNAREs nun als $\mathrm{Q}_{\mathrm{a}}$-SNAREs bezeichnet während Q-SNAREs, die zur N- bzw. C-terminalen Helix von SNAP-25 homolog sind als $\mathrm{Q}_{\mathrm{b}}$ - bzw. Q $\mathrm{Q}_{\mathrm{c}}$ SNAREs klassifiziert werden (Bock et al., 2001).

\subsection{SNARE-Proteine in der Hefe Saccharomyces cerevisiae}

In Hefe wurden bislang 22 SNARE-Proteine identifiziert, darunter 5 R-SNAREs (Snc1p und Snc2p besitzen redundante Funktionen), 7 Syntaxin-verwandte Q-SNAREs (Sso1p und Sso2p sind ebenfalls redundant) sowie 10 SNAP-25-homologe Q-SNAREs (Pelham, 2001). Einige Hefe-SNAREs, darunter Sed5p, Ykt6p und Vtilp, sind in mehreren Transportschritten involviert (Fischer von Mollard et al., 1997; Lupashin et al., 1997; Holthuis et al., 1998; Fischer von Mollard and Stevens, 1999). Außerdem sind für einige 
Transportschritte bislang noch nicht alle an der SNARE-Komplex-Assemblierung beteiligten SNARE-Proteine identifiziert worden. Fast von allen Hefe-SNARE-Proteinen sind bisher Homologe in Säugern identifiziert worden, deren intrazelluläre Lokalisation und Funktion der ihrer Hefependants vergleichbar ist (Pelham, 1999). Die humanen Homologen von Vtilp und Ykt6p können sogar korrespondierende Hefemutanten komplementieren (Lupashin et al., 1997; McNew et al., 1997; Fischer von Mollard and Stevens, 1998).

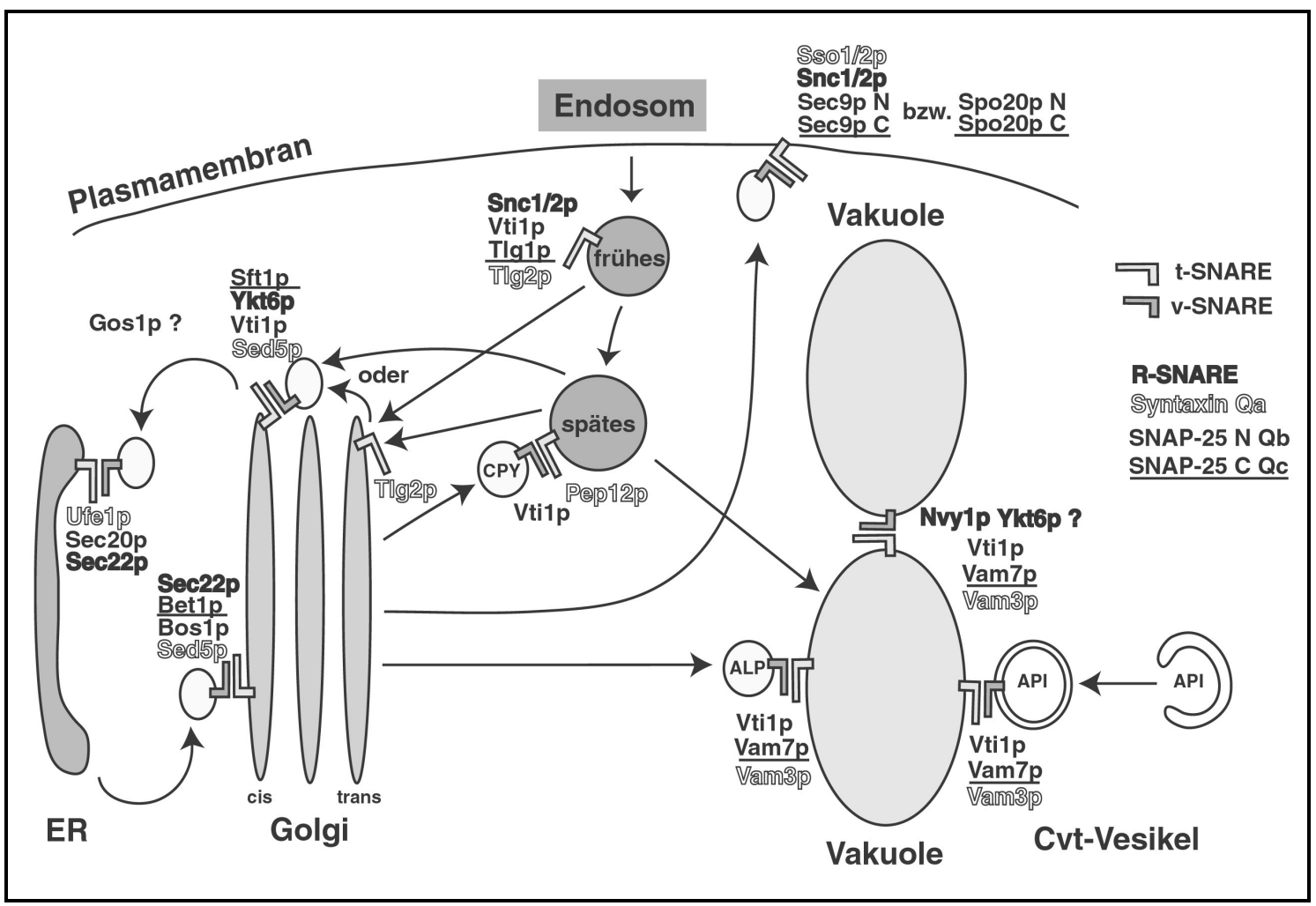

Abb. 1.5: SNARE-Proteine der Hefe Saccharomyces cerevisiae und ihre Beteiligung am Aufbau unterschiedlicher SNARE-Komplexe.

\subsubsection{Biosynthetische Transportwege zur Hefe-Vakuole}

Ein besonderes Charakteristikum des Transportes zur Hefevakuole, welches S. cerevisiae generell zu einem attraktiven Modelsystem zur Untersuchung des Proteintransportes macht, sind eine Reihe praktischer Markerproteine deren Beförderung zur Vakuole leicht verfolgt werden kann. Sie werden in einer inaktiven Precursor-Form synthetisiert und teilweise während des Transportes in unterschiedlicher Art und Weise modifiziert. Sobald sie die Vakuole erreichen, werden sie zur maturen, aktiven Form prozessiert, wobei die Precursor-Sequenz durch vakuoläre Proteasen abgespalten wird. Diese wiederum werden 
durch die Proteinase A (PrA), welche vom PEP4-Gen codiert wird, aktiviert. Die Abspaltung der Precursor-Sequenz resultiert in einer Verkürzung des Proteins, wodurch die mature Form in einer SDS-Polyacrylamid-Gelelektrophorese von der Precursor-Form unterschieden werden kann. Aufgrund dieser Eigenschaften können in Hefe 3 verschiedene Transportwege vom TGN zur Vakuole unterschieden und in ihren Teilschritten analysiert werden (siehe Abb. 1.5).

Die meisten löslichen Proteine und integrale Membranproteine der Hefevakuole werden nach Translokation ins ER und Transport durch den Golgi-Komplex im biosynthetischsekretorischen Transportweg über die Prävakuole (spätes Endosom) zur Vakuole befördert. Die lösliche vakuoläre Hydrolase Carboxypeptidase Y (CPY) dient für diese Transportroute als Markerprotein, weshalb dieser Weg auch als CPY-Weg bezeichnet wird (Bryant and Stevens, 1998; Conibear and Stevens, 1998). Die inaktive PrecursorForm von CPY (Prepro-CPY) wird nach Synthese ins Lumen des ER transportiert. Nach Entfernung der Signalsequenz erhält das Protein eine „Core“-Glykosylierung, wodurch die $67 \mathrm{kDa}$ große p1CPY-Form entsteht. Diese wird daraufhin zum Golgi-Apparat transportiert, wo durch weitere Oligosaccharid-Modifikationen die 69 kDa große p2CPYForm entsteht. Im TGN bindet p2CPY dann an den CPY-Transportrezeptor Vps10p (Marcusson et al., 1994). Dieser Komplex wird daraufhin in Vesikeln zur Prävakuole befördert, wo er dissoziiert. p2CPY wird weiter zur Vakuole transportiert, während Vps10p zum Golgi-Apparat zurückbefördert wird (Cereghino et al., 1995; Piper et al., 1995; Cooper and Stevens, 1996). In der Vakuole wird p2CPY anschließend durch vakuoläre Proteasen zur maturen $61 \mathrm{kDa}$ großen mCPY-Form prozessiert. Bislang wurden über 50 Gene identifiziert, die für den CPY-Transport vom Golgi zur Vakuole benötigt werden, und in unterschiedliche Gen-Familien unterteilt: VPS (vacuolar protein sorting), PEP (peptidase deficient) und VAM (vacuolar morphology) (Jones, 1977; Bankaitis et al., 1986; Rothman and Stevens, 1986; Bryant and Stevens, 1998).

Neben dem CPY-Weg existiert noch ein zweiter, direkter Transportweg vom TGN zur Vakuole, ohne den Umweg über die Prävakuole. Für diese als ALP-Weg bezeichnete Transportroute dient das vakuoläre Membranprotein Alkalische Phosphatase (ALP) als Markerprotein (Piper et al., 1997). ALP wird nach Translokation ins ER zur 76 kDa großen Proform glykosyliert (pALP), die sich während des Transportes durch den Golgi- 
Apparat nicht in ihrer Größe verändert. Scott Emr und Kollegen zeigten in einem genetischen Screen, dass der Adapterkomplex AP-3 am Transport von ALP vom TGN zur Vakuole beteiligt ist. Außerdem akkumulieren AP-3-defiziente Stämme pALP (Cowles et al., 1997a). Im TGN wird pALP durch Interaktion seines N-terminalen Dileucin-Signals mit AP-3 in Transportvesikel sortiert, die von einem bislang unbekannten Hüllprotein umgeben sind (Cowles et al., 1997b; Vowels and Payne, 1998). Clathrin ist an der Ausbildung dieser Transportvesikel nicht beteiligt, da es in Hefe weder biochemisch noch genetisch mit AP-3 interagiert (Simpson et al., 1996; Panek et al., 1997). Möglicherweise handelt es sich bei dem Hüllprotein um Vps41p/Vam2p (Harding et al., 1995; Rehling et al., 1999). In der Vakuole wird pALP zur maturen $72 \mathrm{kDa}$ großen mALP-Form prozessiert. Neben ALP werden noch die vakuolären SNARE-Protein Vam3p und Nyv1p über diese direkte Transportroute befördert (Cowles et al., 1997b; Reggiori et al., 2000). Emr und Kollegen fanden heraus, dass Vam3p ebenfalls anhand eines Dileucin-Motivs von AP-3 erkannt und sortiert wird. Mutationen in diesem Motiv resultierten in einer Fehlsortierung von Vam3p (Darsow et al., 1998).

Der dritte biosynthetische Transportweg zur Hefevakuole wird von der löslichen vakuolären Hydrolase Aminopeptidase I (API) benutzt (Klionsky et al., 1992). Diese Route wird als API-Weg oder Cvt-Weg (cytoplasm-to-vacuole-targeting) bezeichnet. API wird im Cytosol als inaktives Precursor-Protein von 61 kDa Größe synthetisiert. Nach Oligomerisierung wird es in Vesikel eingeschlossen, die von einer Doppelmembran umgeben sind. Diese sogenannten Cvt-Vesikel werden daraufhin zur Vakuole transportiert, wo zunächst die äußere Membran des Vesikels mit der Vakuolenmembran fusioniert. Die innere Membran wird erst später abgebaut und das freigesetzte pAPI zur maturen $50 \mathrm{kDa}$ großen mAPI-Form prozessiert. Dieser Prozess ähnelt der Autophagozytose, erfolgt jedoch konstitutiv unter allen Wachstumsbedingungen, während Autophagozytose nur durch Nährstoffmangel induziert wird (Übersicht in: Klionsky, 1998).

\subsubsection{Funktion von Vti1p und seinen Homologen in höheren Eukaryonten}

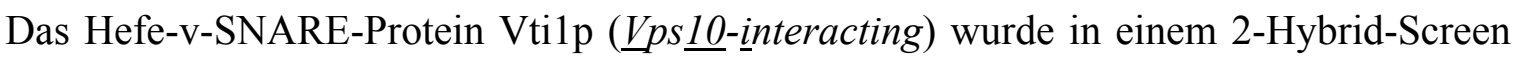
identifiziert, in dem nach Bindungspartnern der cytosolischen Domäne des CPYTransportrezeptors Vps10p gesucht wurde (Fischer von Mollard et al., 1997). Eine spezifische biochemische Interaktion zwischen Vtilp und Vps10p konnte allerdings nicht ermittelt werden. Das essentielle VTI1-Gen codiert für ein 217 Aminosäuren langes Protein mit einer C-terminalen Transmembrandomäne, die luminal von 4 Aminosäuren 
gefolgt wird. Das N-terminal vor der Transmembrandomäne liegende SNARE-Motiv enthält ein Glutamin im 0-Layer, weshalb Vtilp zur Familie der Q-SNAREs gezählt wird. Sequenzvergleiche zeigten außerdem, dass das SNARE-Motiv von Vtilp mit dem der Nterminalen Helix von SNAP-25 verwandt ist ( $\left.\mathrm{Q}_{b}-\mathrm{SNARE}\right)$. Vtilp interagiert mit dem Syntaxin (Qa-SNARE) Sed5p im retrograden Transport zum cis-Golgi (Lupashin et al., 1997), mit dem Qa-SNARE Pep12p im Transport vom Golgi zur Prävakuole (Fischer von Mollard et al., 1997) und mit dem vakuolären Syntaxin Vam3p im biosynthetischen Transport von CPY, ALP und API zur Vakuole (Fischer von Mollard and Stevens, 1999). Außerdem ist Vtilp über Interaktion mit Vam3p an der homotypischen Vakuolenfusion beteiligt (Ungermann et al., 1999). Daneben konnte gezeigt werden, dass Vtilp biochemisch mit dem Syntaxin Tlg2p (TGN) interagiert (Holthuis et al., 1998).

Vtil-homologe Proteine wurden in C. elegans, Drosophila, Arabidopsis und Säugern gefunden. In Arabidopsis wurden bislang 3 Vtil-homologe Proteine identifiziert (Zheng et al., 1999; Sanderfoot et al., 2000). In Säugern existieren zwei Vti1-Proteine, Vtila (27 $\mathrm{kDa}$ ) und Vtilb (29 kDa), die untereinander nur zu $30 \%$ identisch sind (Lupashin et al., 1997; Fischer von Mollard and Stevens, 1998). Außerdem wurde eine hirnspezifische Spleißvariante von Vtila, Vtila- $\beta$ (29 kDa) identifiziert, welche eine Insertion von 7 Aminosäuren enthält (Antonin et al., 2000c). Anscheinend besitzen die zwei Säuger- bzw. drei Pflanzen-Homologen von Vtilp keine redundante Funktion, sondern sind auf unterschiedliche Transportwege spezialisiert, was auch durch ihre unterschiedliche subzelluläre Lokalisation zum Ausdruck kommt. In der indirekten Immunfluoreszenz wurde Vtila an Golgi- und TGN-Strukturen lokalisiert, während Vtilb mit frühen und späten Endosomen assoziiert zu sein scheint (Kreykenbohm et al., 2002). Vtilb bildet während der homotypischen Fusion später Endosomen mit den SNARE-Proteinen Syntaxin 7, Syntaxin 8 und Endobrevin/VAMP-8 einen SNARE-Komplex, dessen Kristallstruktur ermittelt werden konnte (Antonin et al., 2000a; Antonin et al., 2000b). Vtilb-Knock-out-Mäuse sind vital, zeigen jedoch phänotypische Heterogenität. Die Proteinlevel des SNARE-Partners Syntaxin 8 sind in diesen Mäusen erniedrigt. Hepatozyten kleiner Knock-out-Mäuse zeigten außerdem einen verlangsamten lysosomalen Abbau von endozytiertem Material (Atlashkin et al., Manuskript in Vorbereitung). Vtila bildet einen SNARE-Komplex mit VAMP-4, Syntaxin 6 und Syntaxin 16, der an der Fusion von frühen Endosomen und am retrograden Transport vom frühen Endosom zum TGN beteiligt ist (Kreykenbohm et al., 2002; Mallard et al., 2002). Es konnte gezeigt werden, dass humanes Vtilb das Hefe-Vtilp im Transport zum cis-Golgi sowie im 
Transport vom Golgi zur Prävakuole funktionell ersetzen kann, jedoch nicht im ALPWeg (Fischer von Mollard and Stevens, 1998). Wie bereits beschrieben, besitzen Maus-, Ratten- und Mensch-Vtila anstelle des Glutamins ein Aspartat in der 0-Layer-Position (Antonin et al., 2000c).

\subsubsection{Temperatursensitive Mutanten von Vti1p}

Über ungerichtete Mutagenese des VTI1-Genes und Analyse der Zellen, die bei erhöhter Temperatur Defekte im Wachstum oder Proteintransport zeigten, wurden drei unterschiedliche temperatursensitive (ts) VTI1-Mutanten identifiziert: vti1-1, vti1-2 und vti1-11 (Fischer von Mollard et al., 1997). ts-mutierte Proteine sind bei Raumtemperatur funktionsfähig, während eine Temperaturerhöhung z.B. auf $37^{\circ} \mathrm{C}$ aufgrund einer Änderung der Raumstruktur zu einem Defekt der Proteine führt. Es zeigte sich, dass die Mutationen in allen vtil-ts-Mutanten Aminosäuren des SNARE-Motivs betreffen, insbesondere konservierte Aminosäuren an den Interaktionspunkten (Layern) über die Vtilp mit anderen SNARE-Proteinen einen SNARE-Komplex bildet. Die Mutanten vtil1, vtil-2 und vtil-11 zeigen nach Temperaturerhöhung alle einen Defekt im CPYTransport vom Golgi zur Prävakuole, was nach radioaktiver „Pulse-Chase“-Markierung durch Sekretion der Golgi-modifizierten p2CPY-Form und Fehlen der vakuolären mCPYForm zum Ausdruck kommt. vti1-11-Zellen besitzen darüber hinaus eine Blockierung im retrograden Transport zum cis-Golgi, der aufgrund eines indirekten Effektes auf den ERGolgi-Transport zur Akkumulierung der ER-modifizierten p1CPY-Form führt. vtil-2Zellen zeigen im Unterschied zu vtil-1-Zellen einen Defekt im Transport von ALP vom TGN zur Vakuole und akkumulieren deshalb pALP (Fischer von Mollard and Stevens, 1999). In vti1-11-Zellen kann dieser Transportweg nicht untersucht werden, da man nicht unterscheiden kann, ob pALP im ER, Golgi oder TGN akkumuliert. vtil-1-Zellen zeigen keinen Defekt im API-Transport zur Vakuole, während dieser Weg in vti1-11-Zellen nach Temperaturerhöhung vollständig blockiert ist. Auch vti1-2-Zellen zeigen einen partiellen Defekt in diesem Transportschritt. vtil-1- und vtil-2-Mutanten besitzen außerdem einen Defekt in der homotypischen Vakuolenfusion (Ungermann et al., 1999). Während vtil-1Zellen bei $37^{\circ} \mathrm{C}$ mit annähernd WT-Verdopplungszeiten wachsen, zeigen vtil-2- und vtil11-Zellen einen Wachstumsdefekt bei $37^{\circ} \mathrm{C}$ (Fischer von Mollard et al., 1997). 


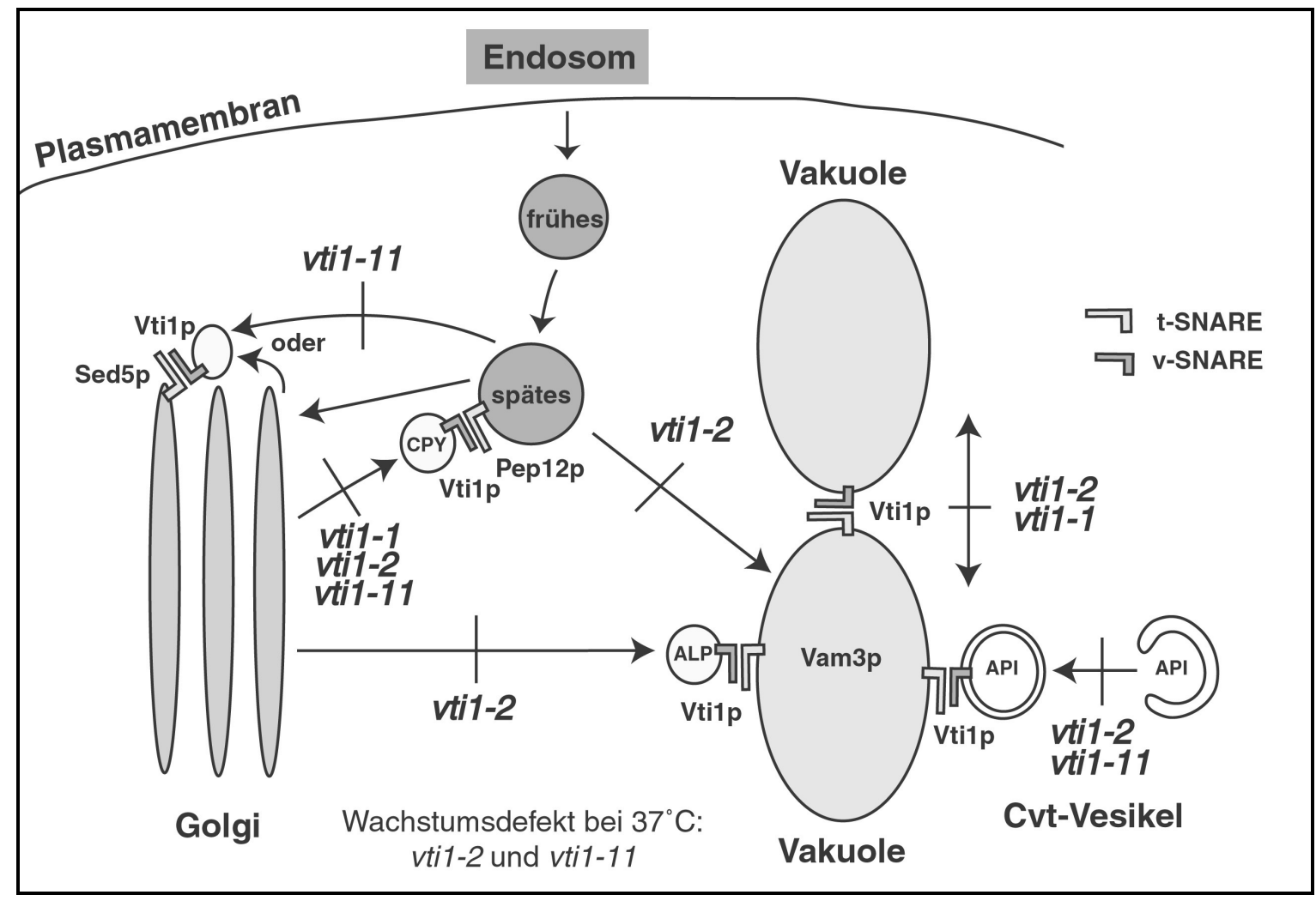

Abb. 1.6: Temperatursensitive Mutanten des SNAREs Vtilp und ihre Defekte.

Mit Hilfe von temperatursensitiven Hefemutanten ist es möglich Partner-Proteine zu identifizieren, die mit dem mutierten Protein interagieren, da eine Überproduktion des Partner-Proteins den Defekt der ts-Mutante unterdrücken (supprimieren) kann. Möglicherweise wird hierbei das mutierte Protein stabilisiert, so dass seine Restaktivität besser genutzt wird. ts-mutierte Zellen werden dabei mit einer cDNA-Bibliothek in Plasmiden, welche für eine Überexpression der Gene sorgen, transformiert und die Transformanten anschließend auf Suppression des Defektes der ts-Mutante untersucht (Multicopy-Suppressor-Screen). Daneben kann man auch gezielt Kandidaten für PartnerProteine in den ts-Mutanten überproduzieren um anhand ihrer Suppressionseffekte herauszufinden, ob sie mit den ts-mutierten Proteinen genetisch interagieren. Eine weitere Form der Identifizierung von genetischen Interaktionen stellt die Analyse synthetischer Phänotypen dar. Hierbei verschlimmert sich der Defekt einer ts-Mutante, wenn man das Partner-Protein in dieser Mutante ebenfalls mutiert oder deletiert. Ist die ts-Mutante danach nicht mehr lebensfähig, so spricht man von synthetisch-lethalem Phänotyp. 


\subsubsection{Das SNARE-Protein Ykt6p}

Das v-SNARE-Protein Ykt6p wurde ursprünglich nach Inaktivierung von Sec18p (NSF) zusammen mit den Proteinen Sft1p und Gos1p als Interaktionspartner des cis-Golgi-tSNAREs Sed5p biochemisch isoliert (Søgaard et al., 1994). Das essentielle YKT6-Gen codiert für ein $23 \mathrm{kDa}$ großes Protein, das aufgrund seiner Homologie zu Synaptobrevinen und dem Besitz eines Arginins in der 0-Layer-Position seines SNARE-Motivs zur Familie der R-SNAREs zählt. Ykt6p besitzt eine variable N-terminale Domäne (Tochio et al., 2001) und anstelle einer C-terminalen Transmembrandomäne eine CAAXBox-Sequenz, welche die posttranslationale Anheftung eines Farnesylrestes bewirkt, der als Membrananker dient (Søgaard et al., 1994). Ykt6p-homologe Proteine wurden in $C$. elegans und Mensch gefunden. Humanes YKT6 kann einen Verlust des essentiellen YKT6-Genes in Hefe funktionell komplementieren (McNew et al., 1997). Außerdem konnten Lupashin et al. zeigen, dass Ykt6p am retrograden Transport zum cis-Golgi involviert ist, und sowohl genetisch als auch biochemisch mit Vtilp interagiert (Lupashin et al., 1997). Wickner und Kollegen fanden zudem heraus, dass Ykt6p Bestandteil eines vakuolären SNARE-Komplexes ist, in welchem es biochemisch mit Vtilp interagiert, und möglicherweise an der homotypischen Vakuolenfusion beteiligt ist (Ungermann et al., 1999).

\subsubsection{SNARE-Proteine des anterograden und retrograden ER-Golgi-Transportes in Hefe}

In Hefe wurden bislang 6 SNARE-Proteine identifiziert, die am anterograden bzw. retrograden Transport zwischen ER und cis-Golgi beteiligt sind. Darunter befinden sich die zwei Syntaxine (Qa-SNAREs) Sed5p und Ufelp, die SNAP-25-homologen Proteine Bos1p (Qb), Bet1p (Qc) und Sec20p (Qb?), sowie das Synaptobrevin-verwandte RSNARE Sec22p.

Das Qa-SNARE Sed5p ist ein evolutionär konserviertes Syntaxin des cis-GolgiKompartimentes, wo es mit mindestens 7 unterschiedlichen SNAREs in verschiedenen Komplexen assoziiert ist (Hardwick and Pelham, 1992; Nichols and Pelham, 1998). Zwei SNARE-Komplexe, die Sed5p enthalten, konnten durch Immunpräzipitation identifiziert werden. Der eine enthält neben Sed5p Vti1p und Ykt6p, und ist am retrograden Transport von späten Golgi-Kompartimenten zum cis-Golgi-Kompartiment beteiligt (Fischer von Mollard et al., 1997; Lupashin et al., 1997; McNew et al., 1997). Das SNARE-Protein 
Sft1p ist ebenfalls in diesem Transportschritt involviert (Banfield et al., 1995). In einem zweiten SNARE-Komplex interagiert Sed5p mit Bet1p, Bos1p und Sec22p im anterograden Transport vom ER zum cis-Golgi (Newman et al., 1990; Søgaard et al., 1994).

Das ER-Syntaxin Ufelp vermittelt den retrograden Transport vom cis-Golgi zum ER (Lewis and Pelham, 1996). Ufe1p wurde in einem Komplex mit den SNAREs Sec20p und Sec22p gefunden (Lewis et al., 1997). Bei Sec20p handelt es sich um ein recht ungewöhnliches SNARE-Protein, welches nur geringe Sequenzhomologien mit anderen SNARE-Proteinen aufweist und darüber hinaus das einzige ER-Transmembranprotein ist, welches eine HDEL-Retentionssequenz enthält (Sweet and Pelham, 1992). Das cytosolische Protein Tip20p interagiert ebenfalls biochemisch mit Sec20p (Sweet and Pelham, 1993) und scheint eine Funktion im retrograden Golgi-ER-Transport zu besitzen (Lewis and Pelham, 1996). Tip20p wiederum interagiert mit dem periphären Membranprotein Dsl1p, welches vermutlich als Tethering-Protein für den retrograden Transport zum ER dient (Andag et al., 2001; Reilly et al., 2001). Sec22p scheint sowohl am anterograden als auch retrograden ER-Golgi-Transport beteiligt zu sein. Es interagiert biochemisch mit Sed5p, Bos1p und Bet1p, was auf eine Rolle im anterograden Transport hindeutet (Lewis and Pelham, 1996; Cosson et al., 1997; Lewis et al., 1997). Außerdem wurde eine Interaktion zwischen Sec22p und Gos1p beobachtet (Pelham, 1999). In vitro-Experimente zeigten überraschenderweise, dass auch Betlp am retrograden Transport beteiligt ist (Spang and Schekman, 1998). Betlp wurde allerdings nicht in einem Komplex zusammen mit Ufe1p gefunden (Lewis et al., 1997). In einem zellfreien ER-Golgi-Transportexperiment wurde gezeigt, dass Sec22p für den anterograden Transport benötigt wird, jedoch durch Ykt6p ersetzt werden kann (Liu and Barlowe, 2002). In vitro-Experimente mit permeabilisierten sec22-3-Mutantenzellen zeigten, dass der retrograde Transport inhibiert wurde (Spang and Schekman, 1998; Cao and Barlowe, 2000). Daneben zeigt Sec22p eine starke genetische Interaktion mit Genen die für Proteine codieren, welche im Golgi-ER-Retrogradtransport beteiligt sind (Ossig et al., 1991; Andag et al., 2001). 
Tab. 1.1: SNARE-Proteine des anterograden und retrograden ER-Golgi-Transportes.

\begin{tabular}{|c|c|}
\hline \multicolumn{2}{|c|}{ ER-Golgi-SNARE-Komplex (anterograd) } \\
\hline SNARE-Protein & Familie \\
\hline Sed5p & Syntaxin/Qa-SNARE \\
\hline Bos $1 p$ & SNAP-25-N-Terminus/Qb-SNARE \\
\hline Bet1p & SNAP-25-C-Terminus/Qc-SNARE \\
\hline Sec $22 p$ & Synaptobrevin/R-SNARE \\
\hline
\end{tabular}

\begin{tabular}{|c|c|}
\hline \multicolumn{2}{|c|}{ Golgi-ER-SNARE-Komplex (retrograd) } \\
\hline SNARE-Protein & Familie \\
\hline Ufe1p & Syntaxin/Qa-SNARE \\
\hline Sec $20 \mathrm{p}$ & SNAP-25-N-Terminus/Qb-SNARE $?$ \\
\hline Sec $22 \mathrm{p}$ & Synaptobrevin/R-SNARE \\
\hline
\end{tabular}

\subsection{Zielsetzung}

\section{Projekt 1:}

Das Qb-SNARE Vtilp ist an drei unterschiedlichen Transportwegen zur Hefe-Vakuole beteiligt, wobei es mit den vakuolären SNARE-Proteinen Vam3p (Qa) und Vam7p (Qc), sowie dem prävakuolären SNARE Pep12p (Qa) interagiert. Da es scheint, dass alle SNARE-Komplexe aus 4 SNARE-Motiven aufgebaut sind, würde dies bedeuten, dass im Falle der vakuolären SNARE-Komplexe noch jeweils ein weiterer SNARE-Partner (RSNARE) unidentifiziert ist, während im prävakuolären SNARE-Komplex noch zwei weitere SNARE-Proteine (R- und Qc-SNARE) unbekannt sind. Zudem ist bislang noch kein Protein identifiziert worden, das die Aktivität von Vtilp in diesen Transportschritten reguliert und dadurch für die Spezifität des Transportes sorgen könnte. Aufgrund ihrer unterschiedlichen Transportdefekte in verschiedenen Transportwegen können tsMutanten von VTII dazu benutzt werden, weitere Proteine zu identifizieren, die mit Vtilp in diesen Transportschritten interagieren. Hierbei macht man sich das Prinzip der genetischen Interaktion zu Nutze. So können in Hefe die Defekte von ts-Mutationen durch Überexpression eines Partner-Proteins supprimiert werden.

Da die VTI1-Mutante vtil-2 bei der restriktiven Temperatur einen Defekt sowohl im Transport vom Golgi zur Prävakuole als auch in allen biosynthetischen Transportwegen zur Vakuole zeigt, während der retrograde Transport zum cis-Golgi-Kompartiment nicht betroffen ist, und vtil-2 darüber hinaus einen Wachstumsdefekt bei $37^{\circ} \mathrm{C}$ besitzt, sollte 
diese Mutante für einen Multicopy-Suppressor-Screen verwendet werden. Durch Transformation einer $2 \mu$-Hefe-Genbibliothek in die temperatursensitive Mutante vtil-2 und anschließender Analyse der Transformanten auf Suppression des Wachstumsdefektes sollten so Gene identifiziert werden, die mit VTI1 in diesen Transportschritten interagieren und die Genprodukte anschließend charakterisiert werden.

\section{Projekt 2:}

In einem alternativen Ansatz sollten neue SNARE-Proteine durch eine Datenbanksuche identifiziert werden. Mit der Hilfe von Prof. Enno Hartmann gelang es uns mit Sequenzabschnitten, welche für SNARE-Proteine charakteristisch sind, über einen Vergleich mit der Hefe-Genom-Datenbank die Sequenz eines bislang uncharakterisierten offenen Leserahmens zu identifizieren, welcher eine ähnliche Domänenstruktur wie SNARE-Proteine aufweist. Daher sollte nun untersucht werden, ob es sich hierbei tatsächlich um ein neues, bislang unidentifiziertes SNARE-Protein handeln könnte. Hierzu sollte die subzelluläre Lokalisation des Proteins, mögliche SNARE-Partner sowie durch Erzeugung und Untersuchung von Mutanten die Funktion des Proteins analysiert werden. 


\section{Material und Methoden}

\subsection{Material}

\subsubsection{Geräte und Verbrauchsmaterial}

\begin{tabular}{|c|c|}
\hline Gerät/Material & Bezugsquelle/Hersteller \\
\hline Allgemeine Glaswaren & Schütt, Göttingen \\
\hline Autoklav Typ Tecnoclav 50 & Tecnomara, Zürich (Schweiz) \\
\hline $\begin{array}{l}\text { CCD-Kamera LAS-1000 Intelligent Dark } \\
\text { Box II }\end{array}$ & Fuji, Tokyo (Japan) \\
\hline Corex $^{\circledR}$-Röhrchen $15 \mathrm{ml}$ & Corning Inc., NY (USA) \\
\hline DNA-Sequenzierer, Typ 310 & ABI, PE Biosystems \\
\hline Drehrad (Eigenbau) & Werkstatt des Institutes \\
\hline Einmalspitzen & Sarstedt, Braunschweig \\
\hline Eismaschine & Ziegra, Isernhagen \\
\hline $\begin{array}{l}\text { Elektrophoresekammern für Agarosegele } \\
\text { und Polyacrylamidgele (Eigenbau) }\end{array}$ & Werkstatt des Institutes \\
\hline Elektroporationsgerät & Stratagene, Cortland NY (USA) \\
\hline Elektroporationsküvetten & Invitrogen, Leek (Niederlande) \\
\hline $\begin{array}{l}\text { Eppendorf-Tischzentrifugen } \\
5415 \mathrm{C} \text { und } 5804 \mathrm{R}\end{array}$ & Schütt Labortechnik, Göttingen \\
\hline Filmentwicklungsmaschine Gevamatic 60 & Agfa-Gevaert, Leverkusen \\
\hline $\begin{array}{l}\text { Fluoreszenzmikroskop Olympus IX50 mit } \\
\text { Photonics Polychrome II und UPlanApo } \\
\text { 100x/1,35 Öl-Objektiv }\end{array}$ & Olympus, Hamburg \\
\hline Flüssigkeitsszintillationszähler 1900TR & Packard, Frankfurt/Main \\
\hline French $^{\circledR}$ Pressure Cell Press, SLM-Minco ${ }^{\circledR}$ & Spectronic Instruments \\
\hline Geldokumentationsanlage Cybertech CS1 & Intas, Göttingen \\
\hline Geltrockner & BioRad, München \\
\hline $\begin{array}{l}\text { Heraeus-Tischzentrifugen: } \\
\text { Biofuge fresco und Biofuge pico }\end{array}$ & Schütt Labortechnik, Göttingen \\
\hline $\begin{array}{l}\text { Inkubationsschüttler: } \\
\text { G25 } \\
\text { Innova } 4230 \\
\text { Innova } 4330\end{array}$ & $\begin{array}{l}\text { New Brunswick Scientific, Edison, New } \\
\text { Jersey (USA) }\end{array}$ \\
\hline Inkubator $\left(37^{\circ} \mathrm{C}\right)$ & Heraeus, Osterode \\
\hline Inkubator Friocell $\left(30^{\circ} \mathrm{C}\right)$ & MM Medcenter \\
\hline Mikromanipulator & Zeiss, Jena \\
\hline Mikrowelle & Bosch, Stuttgart \\
\hline Nitrozellulose Blotting Membran 0,2 $\mu \mathrm{m}$ & Sartorius, Göttingen \\
\hline PAP-PEN $^{(}$ & Kisker-Biotech, Steinfurt \\
\hline
\end{tabular}




\begin{tabular}{|c|c|}
\hline Gerät/Material & Bezugsquelle/Hersteller \\
\hline Parafilm ${ }^{\circledR}$ & American National Can ${ }^{\mathrm{TM}}$, Neenah (USA) \\
\hline Phosphoimager FUJIX BAS 1000 & Fuji, Tokyo (Japan) \\
\hline Pipetman $20,200,1000 \mu \mathrm{l}$ & $\begin{array}{l}\text { Gilson Medical Electronics, Villers-le-bel } \\
\text { (Frankreich) }\end{array}$ \\
\hline Plastikröhrchen, klein $(15 \mathrm{ml})$, groß $(50 \mathrm{ml})$ & Sarstedt, Braunschweig \\
\hline $\begin{array}{l}\text { Polyallomer Zentrifugationsgefäße } 1.5 \mathrm{ml} \\
\text { für TLA 100.3-Rotor }\end{array}$ & Beckmann, München \\
\hline Reaktionsgefäße $0.2 \mathrm{ml}$ und $0.5 \mathrm{ml}$ & Perkin-Elmer Cetus, Norwalk (USA) \\
\hline Reaktionsgefäße $1,5 \mathrm{ml}$ & Sarstedt, Braunschweig \\
\hline Röntgenfilme X-Omat AR 13 x $18 \mathrm{~cm}$ & Kodak, Stuttgart \\
\hline Semi Dry Blotsystem & CTI GmbH, Idstein/Taunus \\
\hline $\begin{array}{l}\text { SMART }^{\circledR} \text {-System mit folgenden Säulen: } \\
\text { Superdex }{ }^{\circledR} 75 \text { PC 3.2/30-Gelfiltrationssäule } \\
\text { MonoS }^{\circledR} \text { PC 1.6/5-Kationenaustauschersäule }\end{array}$ & Pharmacia, Uppsala (Schweden) \\
\hline Sonicator, Typ SONIFIER 450 & Heinemann, Schwäbisch Gmünd \\
\hline Spektralphotometer CARY 50 BIO & VARIAN, Darmstadt \\
\hline Spektralphotometer Uvikon 932 & Kontron Instruments, Neufahrn \\
\hline $\begin{array}{l}\text { Sterilbank } \\
\text { Microflow Biological Safety Cabinet }\end{array}$ & Nunc, Wiesbaden \\
\hline Sterilfilter Minisart NML, $\varnothing 0,2 \mu \mathrm{m}$ & Sartorius, Göttingen \\
\hline $\begin{array}{l}\text { Tabletop Ultrazentrifuge und entsprechender } \\
\text { Rotor TLA-100.3, bis } 430,000 \times \mathrm{g}\end{array}$ & Beckmann, München \\
\hline Thermocycler GeneAmp PCR System 9600 & Perkin-Elmer Cetus, Norwalk (USA) \\
\hline Transilluminator IL-400-M & Bachofer, Reutlingen \\
\hline Vortex Genie $^{\mathrm{TM}}$ & Bender \& Holbein, Zürich (Schweiz) \\
\hline Whatmann GB002-Papier & Schleicher \& Schuell, Dassel \\
\hline Whatmann GB003-Papier, extra dick & Schleicher \& Schuell, Dassel \\
\hline $\begin{array}{l}\text { Zentrifugen Sorvall RC-5B, RC-3B und } \\
\text { entsprechende Rotoren } \\
\text { JA 10, bis } 17.680 \times \mathrm{g} \\
\text { JA 20, bis } 48.300 \times \mathrm{g}\end{array}$ & $\begin{array}{l}\text { DuPont Instruments, Bad Homburg } \\
\text { Beckmann, München } \\
\text { Beckmann, München }\end{array}$ \\
\hline $\begin{array}{l}\text { Zentrifugenbecher: JA-10 und JA-20, } \\
\text { Polyprophylen }\end{array}$ & SCI Science Service, München \\
\hline
\end{tabular}

\subsubsection{Chemikalien}

Die verwendeten Chemikalien wurden im Reinheitsgrad pro analysis (p.a.) bezogen.

Aceton

Agarose

Aminosäuren

APNE (N-Acetyl-Phenylalanin- $\beta$-Naphtylester) APS (Ammoniumperoxodisulfat) $\beta$-Mercaptoethanol

$\begin{array}{ll}\text { Merck } & \text { Darmstadt } \\ \text { Roth } & \text { Karlsruhe } \\ \text { Biomol, } & \text { Hamburg, Heidelberg, } \\ \text { Serva, } & \text { München, } \\ \text { Sigma, ICN } & \text { Meckenheim } \\ \text { Sigma } & \text { München } \\ \text { Merck } & \text { Darmstadt } \\ \text { Merck } & \text { Darmstadt }\end{array}$




\begin{tabular}{|c|c|c|}
\hline Bacto-Agar & DIFCO & Detroid (USA) \\
\hline Bacto-Pepton & DIFCO & Detroid (USA) \\
\hline Bacto-Trypton & DIFCO & Detroid (USA) \\
\hline Bromphenolblau & BioRad & München \\
\hline Calziumchlorid $\left(\mathrm{CaCl}_{2}\right)$ & Merck & Darmstadt \\
\hline Chloroform & Merck & Darmstadt \\
\hline Coomassie Brilliant Blue & Serva & Heidelberg \\
\hline DAPI (4'-6-Diamino-2-phenylindoldihydrochlorid) & Sigma & München \\
\hline Dimethyl-pimelinediimidat-dihydrochlorid (DMP) & Fluka & Buchs (Schweiz) \\
\hline dNTPs & Amersham & Braunschweig \\
\hline Dimethylsulfoxid, ultrarein (DMSO) & Merck & Darmstadt \\
\hline Dithiothreitol, ultrarein (DTT) & Serva & Heidelberg \\
\hline Ethylendiamintetraacetat-Dinatriumsalz (EDTA), & Merck & Darmstadt \\
\hline Ethylenglycol-bis-( $\beta$-Aminoethylether)-N,N,N',N'- & Sigma & München \\
\hline Tetraacetat (EGTA) & & \\
\hline Ethanol & Roth & Karlsruhe \\
\hline Ethidiumbromid & Serva & Heidelberg \\
\hline Fast Carnet GBC Salt & Sigma & München \\
\hline Flüssigszintillator Lumasafe Plus & Packard & Groningen \\
\hline Formaldehyd (37\%) & Merck & Darmstadt \\
\hline Glycin & Roth & Karlsruhe \\
\hline Harnstoff & Serva & Heidelberg \\
\hline $\mathrm{HCl}$ & Roth & Karlsruhe \\
\hline Hefeextrakt & DIFCO & Detroid (USA) \\
\hline $\begin{array}{l}\text { HEPES (N-2-Hydroxyethylpiperazin-N'-2- } \\
\text { ethansulfonsäure) }\end{array}$ & Serva & Heidelberg \\
\hline Isopropyl- $\alpha$-D-Thiogalactopyranosid (IPTG) & BTS & St. Leon-Rot \\
\hline Methanol & Roth & Karlsruhe \\
\hline Natriumacetat & Merck & Darmstadt \\
\hline Ni-NTA-Sepharose & Qiagen & Hilden \\
\hline Pansorbin ${ }^{\circledR}$ Cells, Standardized & Calbiochem & Bad Soden \\
\hline Paraformaldehyd & Sigma & München \\
\hline Phenol:Chloroform:Isoamylalkohol (25:24:1) & Fluka & Buchs (Schweiz) \\
\hline Poly-L-Lysin Hydrobromid MW > 300,000 & Sigma & München \\
\hline Ponceau-S & Serva & Heidelberg \\
\hline Protein-A-Sepharose / Protein-G-Sepharose & Pharmacia & Freiburg \\
\hline Rinderserumalbumin & Serva & Heidelberg \\
\hline SDS (Lauryl Sulfate, Natriumdodecylsulfat) & Sigma & München \\
\hline Sorbitol & Roth & Karlsruhe \\
\hline TEMED (N,N,N',N'-Tetramethylethylendiamin) & Sigma & München \\
\hline Trichloressigsäure (TCA) & Merck & Darmstadt \\
\hline Tris-(hydroxymethyl)-aminomethan (Tris) & $\mathrm{ICN}$ & Aurora, Ohio (USA) \\
\hline Triton X-100 & Serva & Heidelberg \\
\hline Tween-20 & Serva & Heidelberg \\
\hline Wasser, HPLC-Reinheitsgrad & Baker & Deventer (Holland) \\
\hline Yeast-Nitrogene-Base & DIFCO & Detroid (USA) \\
\hline $30 \%(\mathrm{w} / \mathrm{v})$ Acrylamid $/ 0.8 \%(\mathrm{w} / \mathrm{v})$ Bisacrylamid & Roth & Karlsruhe \\
\hline
\end{tabular}




\subsubsection{Proteaseinhibitoren}

Leupeptin

Pepstatin A

Phenylmethylsulfonylfluorid (PMSF)
Biomol, Hamburg

Biomol, Hamburg

Serva, Heidelberg

$100 \mu 1$ 100x Proteaseinhibitor-Mix setzen sich zusammen aus:

$50 \mu 1100 \mathrm{mM}$ PMSF $(17.4 \mathrm{mg} / \mathrm{ml}$ in Ethanol)

$1 \mu \mathrm{l}$ Leupeptin $\left(10 \mathrm{mg} / \mathrm{ml}\right.$ in $\left.\mathrm{H}_{2} \mathrm{O}\right)$

$10 \mu \mathrm{l}$ Pepstatin $(1 \mathrm{mg} / \mathrm{ml}$ in Methanol)

$39 \mu \mathrm{l}$ Methanol

benötigte Menge jeweils frisch ansetzen, Leupeptin zum Schluss hinzugeben, da der Proteaseinhibitor-Mix in Wasser instabil ist.

\subsubsection{Enzyme, Nukleotide und Standards}

1 kb-DNA-Ladder

Alkalische Phosphatase (Calf Intestine)

Prestained Protein Molecular Weight

Markers High Range (14 - 200 kDa)

Restriktionsendonukleasen

RNAse A

T4-DNA-Ligase

T4-Polynukleotid-Kinase

Taq-DNA-Polymerase

$P f u$-DNA-Polymerase

PfuTurbo ${ }^{\circledR}$-DNA-Polymerase

Ultrapure dNTP Set

Zymolyase ${ }^{\circledR}-20 \mathrm{~T}$
Gibco BRL, Eggenstein

Roche, Mannheim

Oncogene, Boston (USA)

New England Biolabs, Bad Schwalbach

Boehringer, Mannheim

New England Biolabs, Bad Schwalbach

New England Biolabs, Bad Schwalbach

Pharmacia, Freiburg

Stratagene, Heidelberg

Stratagene, Heidelberg

Pharmacia, Freiburg

Seikagaku, Tokyo (Japan)

\subsubsection{Antibiotika}

Ampicillin Trihydrat

Serva, Heidelberg

Kanamycin A Monosulfat

Sigma, München 


\subsubsection{Kits zur Bearbeitung von DNA und Proteinen}

ABI PRISM Dye Terminator Cycle

Sequencing Ready Reaction Premix

Perkin Elmer Cetus, Norwalk (USA)

BioRad Protein Assay

Bio-Rad, München

QIAEX $^{\circledR}$ II Agarose Gel Extraction Kit

Qiagen, Hilden

QIAprep Spin Miniprep Kit

Qiagen, Hilden

SuperSignal ${ }^{\circledR}$ West Pico

Chemiluminescent Substrate

PIERCE, Rockford (USA)

\subsubsection{Radiochemikalien}

L- $\left[{ }^{35} \mathrm{~S}\right]-$ Methionin/Cystein, wässrige Lösung, $14 \mathrm{mCi} / \mathrm{mmol}$ von Amersham-Buchler, Braunschweig.

\subsubsection{Häufig verwendete Puffer und Stammlösungen}

\begin{tabular}{llr}
$10 x \mathrm{PBS}(1 \mathrm{~L}):$ & Endkonz.: \\
\hline $87.70 \mathrm{~g}$ & $\mathrm{NaCl}$ & $1.5 \mathrm{M}$ \\
$28.48 \mathrm{~g}$ & $\mathrm{Na}_{2} \mathrm{HPO}_{4}$ & $160 \mathrm{mM}$ \\
$5.52 \mathrm{~g}$ & $\mathrm{NaH}_{2} \mathrm{PO}_{4}$ & $40 \mathrm{mM}$
\end{tabular}

in $\mathrm{ddH}_{2} \mathrm{O}$ lösen, $\mathrm{pH}-$ Wert mit $\mathrm{NaOH}$ auf 7.4 einstellen, Volumen auf $1000 \mathrm{ml}$ auffüllen.

50x TAE (1L):

$242 \mathrm{~g}$ Tris

$37 \mathrm{~g} \quad \mathrm{Na}_{2}$ EDTA (Titriplex III)

mit 100 \% Essigsäure (Eisessig) auf pH 8.0 einstellen.
$\underline{\mathrm{TE}}(100 \mathrm{ml}):$

$1 \mathrm{ml} 1 \mathrm{M}$ Tris-HCl, $\mathrm{pH} 7.5$

$20 \mu 1 \quad 0.5$ M EDTA

$\underline{\operatorname{TE} \beta(10 \mathrm{ml}):}$

$1 \mathrm{ml} 1 \mathrm{M}$ Tris-HCl, $\mathrm{pH} 8.0$

$200 \mu \mathrm{l} \quad 0.5 \mathrm{M}$ EDTA

$50 \mu 1 \quad \beta$-Mercaptoethanol

jeweils frisch ansetzen.
Endkonz.:

$2 \mathrm{M}$

$0.1 \mathrm{M}$

Endkonz.:

$10 \mathrm{mM}$

$0.1 \mathrm{mM}$

Endkonz.:

$200 \mathrm{mM}$

$20 \mathrm{mM}$

$1 \%$ 
Sphäroplast-Puffer $(10 \mathrm{ml})$ :

$$
\begin{array}{rl}
6 \mathrm{ml} & 2 \mathrm{M} \text { Sorbitol } \\
500 \mu \mathrm{l} & 1 \mathrm{M} \mathrm{KPO}_{4}, \mathrm{pH} 7.3 \\
100 \mu \mathrm{l} & 0.1 \mathrm{M} \mathrm{MgCl}_{2}
\end{array}
$$

Endkonz.:

$50 \mathrm{mM}$

$1 \mathrm{mM}$

\section{$10 \%$ SDS:}

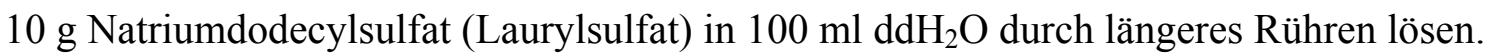

\section{$\underline{0.5 \mathrm{M} \text { EDTA: }}$}

$14.61 \mathrm{~g}$ Ethylendiamintetraacetat (Titriplex II) mit $\mathrm{ddH}_{2} \mathrm{O}$ auf $60-70 \mathrm{ml}$ auffüllen (bleibt trübe), mit $10 \mathrm{~N} \mathrm{NaOH}$ auf pH 8.0 einstellen (löst sich erst jetzt).

\section{$1 \mathrm{M}$ Tris-HCl:}

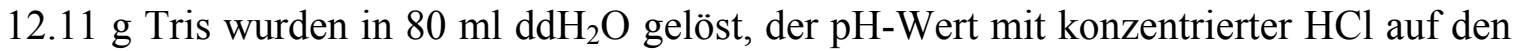
gewünschten Wert (zwischen 7.0 und 9.5) eingestellt und schließlich das Volumen auf $100 \mathrm{ml}$ aufgefüllt.

\begin{tabular}{|c|c|c|}
\hline Stamm & Genotyp & Quelle \\
\hline SEY6210 & $\begin{array}{l}\text { MATa leu2-3,112 ura3-52 his3- } \Delta 200 \text { trp1- } \Delta 901 \\
\text { lys2-801 suc2- } \Delta 9 \text { mel- }\end{array}$ & (Robinson et al., 1988) \\
\hline SEY6211 & $\begin{array}{l}\text { MATa leu2-3,112 ura3-52 his3- } \Delta 200 \text { ade2-101 } \\
\text { trp1- } \Delta 901 \text { suc2- } \Delta 9 \text { mel- }\end{array}$ & (Robinson et al., 1988) \\
\hline SEY5186 $\alpha$ & MAT $\alpha$ ura3-52 leu2-3,112 gal2 sec18-1 & S. Emr \\
\hline RPY10 & MAT $\alpha$ ura3-52 leu2-3,112 his4-519 ade6 gal2 & (Piper et al., 1994) \\
\hline FvMY7 & $\begin{array}{l}\text { MATa leu2-3,112 ura3-52 his3- } \Delta 200 \text { ade2-101 } \\
\text { trp1- } \Delta 901 \text { suc2- } \Delta 9 \text { mel-vtil-1 }\end{array}$ & $\begin{array}{l}\text { G. Fischer von Mollard, } \\
\text { diese Abteilung }\end{array}$ \\
\hline FvMY21 & $\begin{array}{l}\text { MATa leu2-3,112 ura3-52 his3- } \Delta 200 \text { ade2-101 } \\
\text { trp1- } \Delta 901 \text { suc2- } \Delta 9 \text { mel- vtil-11 }\end{array}$ & $\begin{array}{l}\text { G. Fischer von Mollard, } \\
\text { diese Abteilung }\end{array}$ \\
\hline FvMY24 & $\begin{array}{l}\text { MATa leu2-3,112 ura3-52 his3- } \Delta 200 \text { ade2-101 } \\
\text { trp1- } \Delta 901 \text { suc2- } \Delta 9 \text { mel- vtil-2 }\end{array}$ & $\begin{array}{l}\text { G. Fischer von Mollard, } \\
\text { diese Abteilung }\end{array}$ \\
\hline FvMY22 & $\begin{array}{l}\text { MATa ura3-52 leu2-3,112 his4-519 ade6 gal2 } \\
\text { vtil-2 }\end{array}$ & $\begin{array}{l}\text { G. Fischer von Mollard, } \\
\text { diese Abteilung }\end{array}$ \\
\hline MDY1 & $\begin{array}{l}\text { MATa leu2-3,112 ura3-52 his3- } \Delta 200 \text { trp1- } \Delta 901 \\
\text { lys2-801 suc2- } \Delta 9 \text { mel- vts } 1 \Delta:: H I S 3\end{array}$ & diese Arbeit \\
\hline MDY4 & $\begin{array}{l}\text { MATa leu2-3,112 ura3-52 his3- } \Delta 200 \text { ade2-101 } \\
\text { trp1- } \Delta 901 \text { suc2- } \Delta 9 \text { mel- vtil-1 vts } 1 \Delta:: H I S 3\end{array}$ & diese Arbeit \\
\hline
\end{tabular}

\subsubsection{Hefe- und Bakterienstämme}

Saccharomyces cerevisiae: 


\begin{tabular}{|c|c|c|}
\hline Stamm & Genotyp & Quelle \\
\hline MDY5 & $\begin{array}{l}\text { MATa leu2-3,112 ura3-52 his3- } \Delta 200 \text { ade2-101 } \\
\text { trp1- } \Delta 901 \text { suc2- } \Delta 9 \text { mel- vtil-2 vts } 1 \Delta:: H I S 3\end{array}$ & diese Arbeit \\
\hline MDY6 & 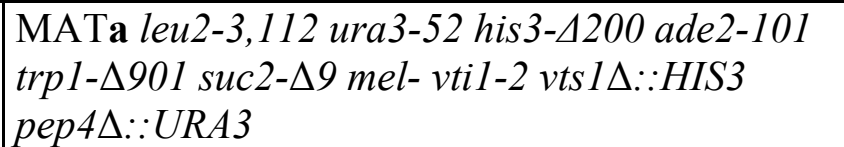 & diese Arbeit \\
\hline MDY7 & $\begin{array}{l}\text { MATa leu2-3,112 ura3-52 his3- } \triangle 200 \text { ade2-101 } \\
\text { trp1- } \Delta 901 \text { suc2- } \Delta 9 \text { mel-vtil-2 pep } 4 \Delta:: U R A 3\end{array}$ & diese Arbeit \\
\hline MDY8 & 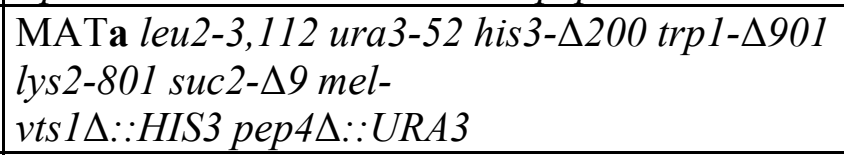 & diese Arbeit \\
\hline MDY9 & 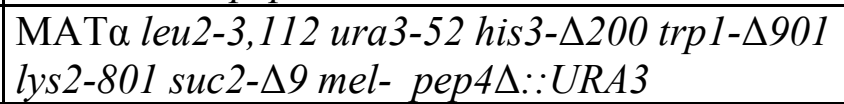 & diese Arbeit \\
\hline BKY3 & 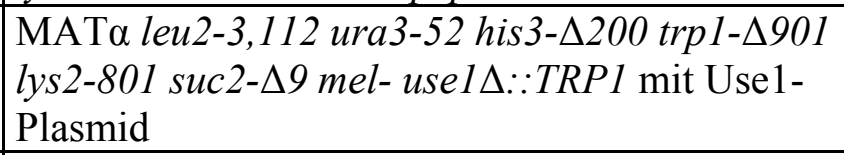 & $\begin{array}{l}\text { Beate Veith, } \\
\text { diese Abteilung }\end{array}$ \\
\hline BKY4 & $\begin{array}{l}\text { MATa leu2-3,112 ura3-52 his3- } \triangle 200 \text { ade2-101 } \\
\text { trp1- } \triangle 901 \text { suc2- } \triangle 9 \text { mel- } \text { use1 } \triangle:: T R P 1 \text { mit Use1- } \\
\text { Plasmid }\end{array}$ & $\begin{array}{l}\text { Beate Veith, } \\
\text { diese Abteilung }\end{array}$ \\
\hline BKY10 & 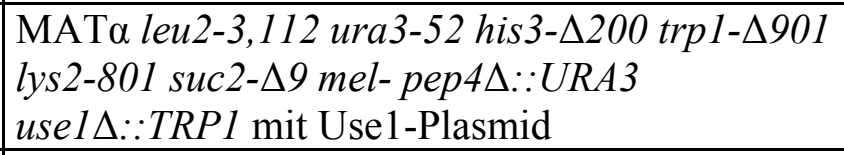 & $\begin{array}{l}\text { Beate Veith, } \\
\text { diese Abteilung }\end{array}$ \\
\hline BKY12 & $\begin{array}{l}\text { MATa leu2-3,112 ura3-52 his3- } \Delta 200 \text { trp1- } \Delta 901 \\
\text { lys2-801 suc2- } \triangle 9 \text { mel-pep } 4 \Delta:: U R A 3\end{array}$ & $\begin{array}{l}\text { Beate Veith, } \\
\text { diese Abteilung }\end{array}$ \\
\hline RH236-3A & MAT $\alpha$ ura3 leu2 lys 2 sec20-1 & H. Riezman \\
\hline
\end{tabular}

\section{Escherichia coli:}

\begin{tabular}{|c|c|c|}
\hline Stamm & Genotyp & Quelle \\
\hline DH5 $\alpha$ & $\begin{array}{l}\text { supE44, thi-1, recA1, relA1, hsdR17(rK-mK }+) \text {, thi- } \\
1, \Delta \text { lacU169 }(\Phi 80 \text { lacZ } \Delta M 15) \text {, endA1, gyrA }\left(\mathrm{Nal}^{\mathrm{r}}\right)\end{array}$ & Gibco BRL, Eggenstein \\
\hline XL1-Blue & $\begin{array}{l}\text { recA1, endA1, gyrA96, thi-1, hsdR17, supE44, } \\
\left.\text { relA1, lac [F', proAB, lacl }{ }^{\mathrm{q}} \mathrm{Z} \Delta \mathrm{M} 15, \mathrm{Tn} 10\left(\mathrm{Tet}^{\mathrm{r}}\right)\right]^{\mathrm{c}}\end{array}$ & Stratagene, Heidelberg \\
\hline $\begin{array}{l}\text { BL21- } \\
\text { (D3)-RIL }\end{array}$ & 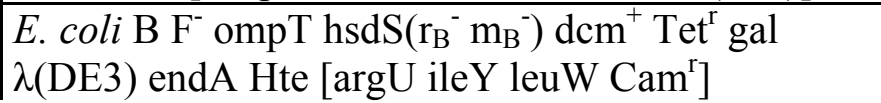 & Stratagene, Heidelberg \\
\hline
\end{tabular}

\subsubsection{Verwendete Plasmide}

\begin{tabular}{l|l|l} 
Plasmid & Beschreibung & Quelle \\
\hline pFvM104 & $\begin{array}{l}\text { 2.9 kb EcoRI-SnaBI SUC2-Fragment in EcoRI- } \\
\text { SmaI pRS316 (CEN-URA3) }\end{array}$ & $\begin{array}{l}\text { G. Fischer von Mollard, } \\
\text { diese Abteilung }\end{array}$ \\
\hline pBK24 & $\begin{array}{l}\text { 4.4 kb Chrom. XV (nt 1009767-1014198) VTS1 } \\
\text { in YEp24 }\end{array}$ & $\begin{array}{l}\text { B. Veith, } \\
\text { diese Abteilung }\end{array}$ \\
\hline pBK25 & $\begin{array}{l}\text { 11 kb Chrom. XI (nt 69529-80400) YKT6 in } \\
\text { YEp24 }\end{array}$ & $\begin{array}{l}\text { B. Veith, } \\
\text { diese Abteilung }\end{array}$
\end{tabular}




\begin{tabular}{|c|c|c|}
\hline Plasmid & Beschreibung & Quelle \\
\hline pBK55 & $\begin{array}{l}\text { 1.0 kb Chrom. VII (nt 317239-318228) USE1 mit } \\
\text { N-terminalem 3xHA-Tag, F242S, in pRS315 } \\
\text { (CEN6) }\end{array}$ & $\begin{array}{l}\text { B. Veith, } \\
\text { diese Abteilung }\end{array}$ \\
\hline pBK64 & $\begin{array}{l}1.0 \mathrm{~kb} \text { Chrom. VII (nt 317239-318228) USE1 mit } \\
\text { Mutation F242S und N-terminalem 3xHA-Tag in } \\
\text { YEp352 }(2 \mu)\end{array}$ & $\begin{array}{l}\text { B. Veith, } \\
\text { diese Abteilung }\end{array}$ \\
\hline pBK83 & $\begin{array}{l}\text { 1.0 kb use1-10AA-Mutante mit Mutationen } \\
\text { Q18R, Q132R, E139D, Q156R, S168G, G177R, } \\
\text { D183G, Q185R, F220Y, F242S in pRS315 }\end{array}$ & $\begin{array}{l}\text { B. Veith, } \\
\text { diese Abteilung }\end{array}$ \\
\hline $\mathrm{pBK} 85$ & $\begin{array}{l}1.0 \mathrm{~kb} \text { Chrom. VII (nt 317239-318228) USE1 mit } \\
\text { Mutation F242S in pRS315 (CEN6-LEU2) }\end{array}$ & $\begin{array}{l}\text { B. Veith, } \\
\text { diese Abteilung }\end{array}$ \\
\hline pMD1 & $1.1 \mathrm{~kb} Y K T 6$ in YEp352 $(2 \mu-U R A 3)$ & diese Arbeit \\
\hline pMD3 & $2.3 \mathrm{~kb}$ ClaI-SpeI VTS1 in YEp352 $(2 \mu-U R A 3)$ & diese Arbeit \\
\hline pMD8 & $\begin{array}{l}\text { VTS1 mit N-terminalem 3xHA-Tag in pRS316 } \\
(C E N 6-U R A 3)\end{array}$ & diese Arbeit \\
\hline pMD9 & $\begin{array}{l}2.3 \mathrm{~kb} \text { KpnI-SpeI VTS1 in pRS316 (CEN6- } \\
\text { URA3) }\end{array}$ & diese Arbeit \\
\hline pMD10 & $\begin{array}{l}\text { VTS1 mit N-terminalem 3xHA-Tag in YEp352 } \\
(2 \mu-U R A 3)\end{array}$ & diese Arbeit \\
\hline pMD16 & $\begin{array}{l}1.0 \mathrm{~kb} \text { use } 1-2 A A \text {-Mutante mit KpnI-Schnittstelle } \\
\text { und Mutationen D183G, K184T, F242S in } \\
\text { pRS313 (CEN6-HIS3) }\end{array}$ & diese Arbeit \\
\hline $\begin{array}{l}\text { pMD19 } \\
\text { (6xHis- } \\
\text { Use1p) }\end{array}$ & $\begin{array}{l}\text { PCR-amplifizierte lösliche Domäne von USE1 } \\
\text { (AA 1-215, Primer 98-Nde und 98-Sol) über } \\
\text { NdeI/EcoRI-Verdau in E. coli-Expressions- } \\
\text { vektor pET-28b }\end{array}$ & diese Arbeit \\
\hline pMD21 & $1.1 \mathrm{~kb}$ YKT6 in pRS316 (CEN6-URA3) & diese Arbeit \\
\hline pMD23 & $\begin{array}{l}1.0 \mathrm{~kb} \text { use l-2AA-Mutante mit KpnI-Schnittstelle } \\
\text { und Mutationen D183G, K184T, F242S in } \\
\text { pRS313 (CEN6-HIS3) }\end{array}$ & diese Arbeit \\
\hline pMD25 & $\begin{array}{l}1.0 \mathrm{~kb} \text { use 1-Olayer-Mutante mit Mutationen } \\
\mathrm{D} 183 \mathrm{G}, \mathrm{F} 242 \mathrm{~S} \text { in pRS315 (CEN6-LEU2) }\end{array}$ & diese Arbeit \\
\hline pMD26 & $\begin{array}{l}\text { 1.0 kb use1-10AA-Mutante mit Mutationen } \\
\text { Q18R, Q132R, E139D, Q156R, S168G, G177R, } \\
\text { D183G, Q185R, F220Y, F242S in pRS313 } \\
(C E N 6-H I S 3)\end{array}$ & diese Arbeit \\
\hline pUA20 & pRS315-SEC22 (CEN6-LEU2) & (Andag et al., 2001) \\
\hline $2 \mu-\mathrm{SEC} 22$ & $S E C 22$ in YEp511 $(2 \mu-L E U 2)$ & H. D. Schmitt \\
\hline pUA37 & pRS315-BOS1 (CEN6-LEU2) & (Andag et al., 2001) \\
\hline $2 \mu-\mathrm{BOS} 1$ & pRS323-BOS1 $(2 \mu-H I S 3)$ & H. D. Schmitt \\
\hline pUA39 & pRS315-UFE1 (CEN6-LEU2) & (Andag et al., 2001) \\
\hline $2 \mu$-UFE1 & pRS323-UFE1 $(2 \mu-H I S 3)$ & H. D. Schmitt \\
\hline CEN-BET1 & BET1 in pRS316 (CEN6-URA3) & H. D. Schmitt \\
\hline $2 \mu$-BET1 & $B E T 1$ in YEp511 $(2 \mu-L E U 2)$ & H. D. Schmitt \\
\hline pBK124 & $S E C 20$ in pRS315 (CEN6-LEU2) & $\begin{array}{l}\text { B. Veith, } \\
\text { diese Abteilung }\end{array}$ \\
\hline
\end{tabular}




\begin{tabular}{l|l|l} 
Plasmid & Beschreibung & Quelle \\
\hline $2 \mu$-SEC20 & $\begin{array}{l}\text { 1.5 kb PCR-amplifiziertes } S E C 20 \text { XhoI-blunt } \\
\text { geschnitten in pRS323 (HIS3) }\end{array}$ & H. D. Schmitt \\
\hline pUF5 & $\begin{array}{l}\text { PCR-amplifiziertes SNARE-Motiv von SEC20 } \\
\text { (AA 201-274, Primer Sec20-201 und Sec20-Sol) } \\
\text { über NdeI/EcoRI-Verdau in E. coli-Expressions- } \\
\text { vektor pET-28b }\end{array}$ & U. Ferch \\
\hline pUF6 & $\begin{array}{l}\text { PCR-amplifiziertes SNARE-Motiv von SEC22 } \\
\text { (AA 121-188, Primer Sec22-121 und Sec22-Sol) }\end{array}$ & U. Ferch \\
& $\begin{array}{l}\text { über NdeI/EcoRI-Verdau in E. coli-Expressions- } \\
\text { vektor pET-28b }\end{array}$ & \\
\hline pUF7 & $\begin{array}{l}\text { PCR-amplifiziertes SNARE-Motiv von USE1 } \\
\text { (AA 147-215, Primer 098-147 und 098-Sol) über } \\
\text { NdeI/EcoRI-Verdau in E. coli-Expressions- } \\
\text { vektor pET-28b }\end{array}$ & U. Ferch \\
\hline pUF8 & $\begin{array}{l}\text { PCR-amplifiziertes SNARE-Motiv von UFE1 } \\
\text { (AA 253-326, Primer Ufe1-253 und Ufe1-Sol) } \\
\text { über NdeI/EcoRI-Verdau in E. coli-Expressions- } \\
\text { vektor pET-28b }\end{array}$ & U. Ferch \\
&
\end{tabular}

\subsubsection{Verwendete Oligonukleotide}

\begin{tabular}{|c|c|c|}
\hline Name & Sequenz & Zweck \\
\hline 098DR & 5'-AAA GTT AGT CGT GAA CTA CTT CCA-3' & $\begin{array}{l}\text { Herstellung von } \\
\text { pMD15 / pMD24 }\end{array}$ \\
\hline 098DF & 5'-AAC CAA GTT CTT GGA GCT GCA G-3' & $\begin{array}{l}\text { Herstellung von } \\
\text { pMD15 }\end{array}$ \\
\hline 098-Sol & $\begin{array}{l}\text { 5'-GGA ATT CTA TTT ACT CTT GTC ATA TTT } \\
\text { CC-3' }\end{array}$ & $\begin{array}{l}\text { Herstellung von } \\
\text { pMD19 und } \\
\text { pUF7 }\end{array}$ \\
\hline 098-Nde & 5'-CCA TAT GGC TGA AAC TTC CAA CG-3' & $\begin{array}{l}\text { Herstellung von } \\
\text { pMD19 }\end{array}$ \\
\hline 098DK & 5'-AAA CAA GTT CTT GGA GCT GCA G-3' & $\begin{array}{l}\text { Herstellung von } \\
\text { pMD24 }\end{array}$ \\
\hline SUKO5' & $\begin{array}{l}\text { 5'-GAA AAA CTG TTC ATA TAA AGT AAT TGT } \\
\text { CAG CAA AGA AAT CTT GTA CTG AGA GTG CAC } \\
\text { CAT-3' }\end{array}$ & $\begin{array}{l}\text { Herstellung von } \\
\text { MDY1 }\end{array}$ \\
\hline SUKO3’ & $\begin{array}{l}\text { 5'-CTT TAT GCA ACG TCA AGA CAA TCA ACT } \\
\text { TTA TTA TGC CAG ATT GGT ATT TCA CAC CGC } \\
\text { ATA-3' }\end{array}$ & $\begin{array}{l}\text { Herstellung von } \\
\text { MDY1 }\end{array}$ \\
\hline SU5' & $\begin{array}{l}\text { 5'-CCC CAA GCT TGT AAT TGT CAG CAA AGA } \\
\text { AAT C-3' }\end{array}$ & $\begin{array}{l}\text { Nachweis von } \\
\text { vts } 1 \Delta\end{array}$ \\
\hline SU3' & $\begin{array}{l}\text { 5'-CCC GCT CGA GAC AAT CAA CTT TAT TAT } \\
\text { GCC-3' }\end{array}$ & $\begin{array}{l}\text { Nachweis von } \\
v t s 1 \Delta\end{array}$ \\
\hline SUBam3' & 5'-ATG GAT CCA AAA CAT CCG TAT GAG-3' & $\begin{array}{l}\text { Herstellung von } \\
\text { pMD8/pMD10 }\end{array}$ \\
\hline
\end{tabular}




\begin{tabular}{|c|c|c|}
\hline Name & Sequenz & Zweck \\
\hline SUBam5 & 5'-CAT TAA CAG TCG TTT CTT TAG TAC CTA-3' & $\begin{array}{l}\text { Herstellung von } \\
\text { pMD8/pMD10 }\end{array}$ \\
\hline 359ATG & $\begin{array}{l}\text { 5'-CGG GAT CCA TGA AAC ATC CGT ATG AGG- } \\
3 \text {, }\end{array}$ & $\begin{array}{l}\text { Herstellung von } \\
\text { GST-Vtslp }\end{array}$ \\
\hline 359Stop & $\begin{array}{l}\text { 5'-CCC GCT CGA GTT AAT AAG CAG ATC TAT } \\
\text { CAA TTA-3' }\end{array}$ & $\begin{array}{l}\text { Herstellung von } \\
\text { GST-Vtslp }\end{array}$ \\
\hline $98-5$ & 5'-CGG GAT CCA AGC TAG CTT TTC C-3' & $\begin{array}{l}\text { Herstellung von } \\
\text { pBK85 }\end{array}$ \\
\hline $98-3$ & 5'-GCT CTA GAG TAT CAT CAT AAT GCG TTC-3' & $\begin{array}{l}\text { Herstellung von } \\
\text { pBK85 }\end{array}$ \\
\hline $\mathrm{T} 7$ & 5'-TAA TAC GAC TCA CTA TAG GG-3' & Sequenzierung \\
\hline T3 & 5'-ATT AAC CCT CAC TAA AG-3' & Sequenzierung \\
\hline YEP35 5 & 5'-CGG GAT CCA ACT GAA CGA AAA ATG C-3' & $\begin{array}{l}\text { Herstellung von } \\
\text { pBK83 }\end{array}$ \\
\hline YEP35 3' & 5'-GCT CTA GAG CAT TGG ATG ACT CCT G-3' & 3 \\
\hline YKT6 5 & 5'-CGG GAT CCT ACT TCC AGT TGG TAA TTG-3' & $\begin{array}{l}\text { Herstellung von } \\
\text { pMD1 }\end{array}$ \\
\hline YKT6 3' & $\begin{array}{l}\text { 5'-GGA AAT CAC TGA AGA AAC AAA TCA ATT } \\
\text { CT-3' }\end{array}$ & $\begin{array}{l}\text { ellung von } \\
1\end{array}$ \\
\hline $\begin{array}{l}\text { Sec20- } \\
201\end{array}$ & $\begin{array}{l}\text { 5'-GCA TAT GAA GCT TTT GAG CAA AAC AAA } \\
\text { AC-3' }\end{array}$ & $\begin{array}{l}\text { Herstellung von } \\
\text { pUF5 }\end{array}$ \\
\hline $\begin{array}{l}\text { Sec20- } \\
\text { Sol }\end{array}$ & $\begin{array}{l}\text { 5'-GGA ATT CTA TCG TTT CTC TTG ATG GGA G- } \\
3 \text { ', }\end{array}$ & $\begin{array}{l}\text { Herstellung von } \\
\text { pUF5 }\end{array}$ \\
\hline $\begin{array}{l}\text { Sec22- } \\
121\end{array}$ & $\begin{array}{l}\text { 5'-GCA TAT GAA AAA GTC ATA CAG TGA TAA } \\
\text { G-3' }\end{array}$ & $\begin{array}{l}\text { Herstellung von } \\
\text { pUF6 }\end{array}$ \\
\hline $\begin{array}{l}\text { Sec22- } \\
\text { Sol }\end{array}$ & $\begin{array}{l}\text { 5'-GGA ATT CTA ATC GAA GTT GAT CTT TTG } \\
\text { CG-3' }\end{array}$ & $\begin{array}{l}\text { Herstellung von } \\
\text { pUF6 }\end{array}$ \\
\hline 098-147 & 5'-GCA TAT GCA AAT TGA GGA CCA GGA C-3' & $\begin{array}{l}\text { Herstellung von } \\
\text { pUF7 }\end{array}$ \\
\hline Ufe1-253 & $\begin{array}{l}\text { 5'-GCA TAT GGA ACT GCT AAA TCA AAA AAA } \\
\text { TG-3' }\end{array}$ & $\begin{array}{l}\text { Herstellung von } \\
\text { pUF8 }\end{array}$ \\
\hline Ufe1-Sol & $\begin{array}{l}\text { 5'-GGA ATT CTA TTT AGC AGT TCT TCC AGC } \\
\text { AG-3' }\end{array}$ & $\begin{array}{l}\text { Herstellung von } \\
\text { pUF8 }\end{array}$ \\
\hline
\end{tabular}

\subsubsection{Nährmedien zur Kultivierung von Bakterien}

Alle Medien wurden für 20 min bei $120^{\circ} \mathrm{C}$ autoklaviert. Medien für Agarplatten wurde vor dem Autoklavieren Bacto-Agar in einer Endkonzentration von $1.5 \%$ (w/v) zugesetzt. Nach Abkühlen auf ca. $50^{\circ} \mathrm{C}$ wurde den Platten-Medien $100 \mathrm{mg} / 1$ Ampicillin (Stock: 25 $\mathrm{mg} / \mathrm{ml}$ ) oder $50 \mathrm{mg} / \mathrm{l} \mathrm{Kanamycin} \mathrm{(Stock:} 50 \mathrm{mg} / \mathrm{ml}$ ) zugesetzt, Platten gegossen und bei $4^{\circ} \mathrm{C}$ gelagert. 
$\underline{\text { LB (Luria Bertani)-Medium: }}$

$\begin{array}{rl}5 \mathrm{~g} / 1 & \text { Yeast Extract } \\ 5 \mathrm{~g} / 1 & \mathrm{NaCl} \\ 1 \mathrm{~g} / 1 & \text { Glucose } \\ 10 \mathrm{~g} / 1 & \text { Bacto-Trypton }\end{array}$

2xYT-Medium:

$\begin{array}{rl}10 \mathrm{~g} / 1 & \text { Yeast Extract } \\ 5 \mathrm{~g} / 1 & \mathrm{NaCl} \\ 16 \mathrm{~g} / 1 & \text { Bacto-Trypton }\end{array}$

SOC-Medium:

$\begin{array}{rl}5 \mathrm{~g} / \mathrm{l} & \text { Yeast Extract } \\ 0.6 \mathrm{~g} / \mathrm{l} & \mathrm{NaCl} \\ 0.19 \mathrm{~g} / 1 & \mathrm{KCl} \\ 2 \mathrm{~g} / 1 & \mathrm{MgCl}_{2} * 6 \mathrm{H}_{2} \mathrm{O} \\ 20 \mathrm{~g} / 1 & \text { Bacto-Trypton }\end{array}$

\subsubsection{Nährmedien für Hefekulturen}

Alle Medien wurden für 20 min bei $120^{\circ} \mathrm{C}$ autoklaviert. Medien für Agarplatten wurde vor dem Autoklavieren Bacto-Agar in einer Endkonzentration von 1.5 \% (w/v) zugesetzt. YEPD: $10 \mathrm{~g} / 1 \quad$ Hefeextrakt $20 \mathrm{~g} / 1 \quad$ Bacto-Pepton

nach Autoklavieren

und Abkühlen: $\quad 40 \mathrm{ml} / 1 \quad 50 \%$ Glukose (Endkonz.: $2 \%(\mathrm{w} / \mathrm{v})$ )

SD-Minimalmedium: $\quad 6.7 \mathrm{~g} / 1 \quad$ Yeast Nitrogen Base (w/o amino acids)

nach Autoklavieren

und Abkühlen:

$$
\begin{array}{rl}
40 \mathrm{ml} / 1 & 50 \% \text { Glucose (Endkonz.: 2\% (w/v)) } \\
100 \mathrm{ml} / 1 & \text { entsprechender 10x Aminosäuremix }
\end{array}
$$

10x Aminosäuremix:

Für den jeweiligen 10x Aminosäuremix wurden die entsprechenden Purin-/Pyrimidinbasen bzw. Aminosäuren nach folgendem Schema eingewogen, mit $\mathrm{ddH}_{2} \mathrm{O}$ auf 1 Liter aufgefüllt und autoklaviert. Diejenige Base bzw. Aminosäure, die zur Selektion dienen soll, wurde dabei jeweils weggelassen, so dass z.B. ein 10x-Leu-Medium alle folgenden 
Bestandteile bis auf L-Leucin enthielt. Allen 10x Aminosäuremix-Medien fehlte außerdem Methionin und somit eine Schwefelquelle, da die Hefezellen für „PulseChase“-Experimente mit radioaktiv markiertem Methionin gefüttert werden.

\begin{tabular}{|c|c|}
\hline $\begin{array}{c}\text { Purin-/Pyrimidinbase } \\
\text { bzw. Aminosäure }\end{array}$ & g/l \\
\hline Adenin & 0.2 \\
\hline L-Arginin & 0.2 \\
\hline L-Histidin & 0.2 \\
\hline L-Leucin & 1.2 \\
\hline L-Lysin/HCl & 0.6 \\
\hline L-Phenylalanin & 0.5 \\
\hline L-Threonin & 2.0 \\
\hline L-Tryptophan & 0.2 \\
\hline L-Tyrosin & 0.3 \\
\hline Uracil & 0.2 \\
\hline
\end{tabular}

Sporulationsplatten: $10 \mathrm{~g} / 1 \quad$ Kaliumacetat (Endkonz.: $1 \%(\mathrm{w} / \mathrm{v})$ )

1g/1 Hefeextrakt (Endkonz.: 0.1\%(w/v))

$15 \mathrm{~g} / 1 \quad$ Agar (Endkonz.: $1.5 \%(\mathrm{w} / \mathrm{v}))$

nach Autoklavieren

und Abkühlen: $\quad 1 \mathrm{ml} / 1 \quad 50 \%$ Glukose (Endkonz.: $0.05 \%(\mathrm{w} / \mathrm{v})$ )

$25 \mathrm{ml} / 1$ 10x Aminosäuremix - Methionin (Endkonz.: 0.25x)

\subsubsection{EDV}

Hardware:

Apple Power Mac G3

Apple Macintosh

PC Type Pentium IV

IBM-kompatibel

Laser Jet $4050 \mathrm{~N}$

Hewlett Packard, Palo Alto (USA)

Scanner ScanJet 4C/T

Hewlett Packard, Palo Alto (USA)

Software:

Windows 98SE/Windows XP

Microsoft

Word 2000

Microsoft

Adobe Photoshop 6.0

Adobe Systems Inc.

Adobe Illustrator 8.0

Adobe Systems Inc. 
Mac Draw Pro

Image Reader

Image Gauge

AIDA Image Analyzer Vers. 3.10

Image Reader LAS-1000 Pro Vers. 2.1
Apple Macintosh

Fuji, Tokyo (Japan)

Fuji, Tokyo (Japan)

raytest, Straubenhardt

raytest, Straubenhardt

\subsection{Methoden}

\subsubsection{Allgemeine Methoden}

\subsubsection{Kultivierung von $E$. coli}

\subsection{Nährmedien für $E$. coli}

LB-Medium wurde für die Vermehrung von Plasmiden und 2xYT-Medium für die Produktion von Proteinen in E. coli eingesetzt (siehe Nährmedien).

\subsection{Anzucht von $E$. coli-Kulturen}

\section{Flüssigkultur:}

Ein Teil einer Dauerkultur oder eine Einzelkolonie von einer Transformationsplatte wurde mit einem sterilen Zahnstocher in einem Reagenzglas mit $2 \mathrm{ml}$ LB-Medium, welchem zur Selektion der Transformanten ein Antibiotikum z.B. Ampicillin (Endkonz.: $0.1 \mathrm{mg} / \mathrm{ml}$ ) oder Kanamycin (Endkonz.: $50 \mu \mathrm{g} / \mathrm{ml}$ ) hinzugesetzt wurde, inokuliert. Die Flüssigkulturen wurden mit ca. $210 \mathrm{UpM}$ bei $37^{\circ} \mathrm{C}$ geschüttelt.

\section{$\underline{\text { Kultur auf Agarplatte: }}$}

Hierzu wurde ein Teil einer Dauerkultur mit einem sterilen Zahnstocher auf einer LB $_{\text {Amp- }}$ Platte $(0.1 \mathrm{mg}$ Ampicillin/ml) bzw. LB Kana-Platte (50 $\mu \mathrm{g}$ Kanamycin/ml) ausgestrichen. Diese wurde anschließend bei $37^{\circ} \mathrm{C}$ inkubiert.

\subsection{Anlegen von Bakteriendauerkulturen}

Hierzu wurden mehrere Zahnstocherspitzen einer frisch auf einer $\mathrm{LB}_{\mathrm{Amp}}$ - bzw. $\mathrm{LB}_{\mathrm{Kana}}{ }^{-}$ Platte hochgewachsenen Kultur in einem Einfrier-Eppendorf-Gefäß mit $0.7 \%$ DMSO in sterilem Wasser vermischt und anschließend bei $-80^{\circ} \mathrm{C}$ eingefroren. Die Bakterien können so über mehrere Jahre konserviert werden. 


\subsection{Herstellung elektrokompetenter Bakterien}

Zur Einschleusung fremder Plasmid-DNA in E. coli (Cohen et al., 1972) müssen Bakterien entsprechend vorbereitet werden. Dazu wurden XL1-Blue-, DH5 $\alpha$ - oder BL21Zellen ohne die Verwendung von Kationen für die Elektroporation vorbereitet.

$10 \mathrm{ml}$ LB-Medium wurden mit einer Bakterienkultur inokuliert und üN bei $37^{\circ} \mathrm{C}$ wachsen gelassen. Am nächsten Morgen wurde die Übernachtkultur in 1 Liter frisches LBMedium überführt und auf zwei $500 \mathrm{ml}$-Kolben aufgeteilt. Die Kulturen wurden bei $37^{\circ} \mathrm{C}$ bis zu einer $\mathrm{OD}_{600}$ von $0.3-0.35$ wachsen gelassen (etwa für $2 \mathrm{~h}$ ). Die Kolben wurden daraufhin für 15 - 30 min auf Eis abgekühlt. Es folgte eine Zentrifugation für 15 min mit $5000 \mathrm{UpM}$ bei $4^{\circ} \mathrm{C}$ in einem JA-10-Rotor. Das Pellet wurde in 1 Liter kaltem, sterilen Wasser resuspendiert und erneut für 15 min mit $5000 \mathrm{UpM}$ bei $4^{\circ} \mathrm{C}$ zentrifugiert. Nun wurde das Pellet in 0.5 Liter kaltem, sterilen $\mathrm{ddH}_{2} \mathrm{O}$ resuspendiert und erneut für $15 \mathrm{~min}$ mit $5000 \mathrm{UpM}$ bei $4^{\circ} \mathrm{C}$ zentrifugiert. Daraufhin wurde das Pellet in $20 \mathrm{ml}$ kaltem, sterilen 10 \%igen Glycerol resuspendiert. Es folgte eine Zentrifugation für 15 min mit $6000 \mathrm{UpM}$ bei $4^{\circ} \mathrm{C}$ in einem JA-20-Rotor. Das Pellet wurde schließlich in $2 \mathrm{ml}$ kaltem, sterilen 10 \%igen Glycerol resuspendiert und anschließend Aliquots zu $40 \mu \mathrm{l}, 80 \mu \mathrm{l}$ oder $160 \mu \mathrm{l}$ in sterile Eppendorf-Gefäße pipettiert und sofort auf Trockeneis eingefroren. Diese Aliquots wurden daraufhin bei $-80^{\circ} \mathrm{C}$ gelagert.

\subsection{Transformation von $E$. coli-Zellen durch Elektroporation}

Die Elektroporation ist eine sehr effiziente Methode zum Transfer von DNA (z.B. ein bei einer Ligation entstandenes rekombinantes, zirkuläres Plasmid) in gram-negative und gram-positive Bakterienzellen. Die Methode beruht auf der Beobachtung, dass kurze Hochspannungspulse „Löcher“ in der Zellhülle verursachen, durch welche dann exogene DNA in die Zelle aufgenommen werden kann. Die zu transformierende DNA muss sich zur Vermeidung eines elektrischen Kurzschlusses in einer weitgehend von Ionen befreiten Lösung befinden.

Für die Transformation wurden $40 \mu \mathrm{l}$ der elektrokompetenten Zellen auf Eis aufgetaut und mit $1.2 \mu$ l Ligationsansatz (oder ca. 50 ng Plasmid-DNA) versetzt und vorsichtig gemischt. Dieser Ansatz wurde in eine sterile, eiskalte Elektroporationsküvette überführt und mit $1800 \mathrm{~V}$ und $25 \mathrm{mF}$ im Elektroporator (Stratagene 1000) sofort elektroporiert. Die Zellen wurden anschließend mit $500 \mu \mathrm{l}$ SOC-Medium versetzt, in ein Eppendorf-Gefäß überführt und zur Regeneration $20-40 \mathrm{~min}$ bei $37^{\circ} \mathrm{C}$ im Wasserbad inkubiert. Danach 
wurde der gesamte Ansatz je nach vorhandenem Resistenzgen auf eine LB $_{\text {Amp }}$ bzw. $\mathrm{LB}_{\text {Kana }}-\mathrm{Platte}$ ausplattiert und üN bei $37^{\circ} \mathrm{C}$ inkubiert.

\subsubsection{Kulturbedingungen für Saccharomyces cerevisiae}

\subsection{Nährmedien für S. cerevisiae}

Wildtyp-Stämme bzw. Stämme mit genomischen Mutationen wurden in YEPD-Medium inkubiert. Zur Selektion von Plasmiden wurde ein SD-Minimalmedium verwendet, welchem die entsprechende(n) Purin-/ Pyrimidinbase bzw. Aminosäure(n) fehlte(n) für dessen Synthese das Plasmid ein Auxotrophiegen besaß (siehe Nährmedien).

\subsection{Anzucht von Hefekulturen}

Anzucht auf Agarplatte:

Hefekulturen wurden entweder aus einer Dauerkultur oder von einer Einzelkolonie auf eine entsprechende Agarplatte (YEPD-Vollmedium oder SD-Minimalmedium) ausgestrichen und bei $30^{\circ} \mathrm{C}$, bzw. $24^{\circ} \mathrm{C}$ für temperatursensitive Stämme, inkubiert. Als Kohlenstoffquelle wurde Glukose verwendet. Zur Induktion der Sporulation wurden diploide Stämme 3-5 Tage auf Sporulationsplatten inkubiert, welche $1 \%$ Kaliumacetat enthielten.

Anzucht in Flüssigkultur:

Vollmedium (YEPD) oder SD-Minimalmedium zu Selektion von Plasmiden wurde von einer Agarplatte mit dem entsprechenden Hefestamm inokuliert und bei $30^{\circ} \mathrm{C}$, bzw. $24^{\circ} \mathrm{C}$ für temperatursensitive Stämme mit 200 UpM inkubiert.

\subsubsection{Molekularbiologische Methoden}

\subsubsection{Minipräparation von Plasmid-DNA (Alkalische Lyse)} (modifiziert nach Birnboim and Doly, 1979)

Eine Plasmid-Minipräparation wird meist in Kombination mit einem anschließenden Restriktionsverdau zur Fragmentlängen-Charakterisierung angewendet, um die aus einer Transformation gewonnenen Klone zu testen. Bei der Minipräparation von Plasmid-DNA wird die chromosomale DNA durch Alkalibehandlung mit $\mathrm{NaOH}$ denaturiert und nach anschließender Neutralisierung ausgefällt. Die zirkuläre Plasmid-DNA denaturiert zunächst ebenfalls, renaturiert aber unter hohen Salzkonzentrationen wieder vollständig 
und bleibt daher gelöst. Durch Zugabe von SDS und einer nachfolgenden Zentrifugation werden die chromosomale DNA, ein großer Teil der RNA und die Proteine sedimentiert. Die Plasmid-DNA im Überstand wird daraufhin mit 100 \% Ethanol präzipitiert und durch einen anschließenden Waschschritt mit 70 \%igem Ethanol von Salz befreit. Anwesende RNAs werden durch RNase A-Behandlung gespalten.

\section{Prozedur:}

Rekombinante Einzelkolonien wurden in $2 \mathrm{ml} 2 \mathrm{xYT}+\mathrm{Amp}$ in sterilen Reagenzgläsern angeimpft und üN bei $37^{\circ} \mathrm{C}$ unter Schütteln inkubiert. Am nächsten Tag wurden jeweils $1,5 \mathrm{ml}$ (die restlichen $0.5 \mathrm{ml}$ wurden aufgehoben und dienten der Sicherung der Klone) in ein Eppendorf-Reaktionsgefäß überführt und für 1 min bei RT mit 13000 UpM zentrifugiert. Der Überstand wurde verworfen und die Pellets in $100 \mu 1$ „Lysozyme-Lösung“ resuspendiert wodurch die Zellen lysierten. Anschließend wurden jeweils $200 \mu \mathrm{l} \mathrm{NaOH}-$ SDS hinzugegeben und die Reaktionsgefäße vorsichtig durch Umdrehen gemischt. Es folgte eine Inkubation für 5 min bei RT. Nun wurden $150 \mu 13 \mathrm{M}$ Natriumacetat (pH 5,2) hinzugegeben und die Ansätze erneut vorsichtig durch Umdrehen gemischt. Es folgte eine weitere Inkubation für 5 min bei RT. Danach wurden die Ansätze für 9 min bei RT mit 13000 UpM zentrifugiert. Die klaren Überstände wurden in ein neues Eppendorfgefäß überführt. [Zur Herstellung besonders reiner Plasmid-DNA wurde dieser Überstand nun mit $150 \mu \mathrm{l}$ eine Phenol-Chloroform-Isoamylalkohol-Gemisches (25:24:1) versetzt, gut gemischt und für 5 min bei RT mit $13000 \mathrm{UpM}$ zentrifugiert. Die obere Phase wurde weiterverwendet]. Der klare Überstand wurde nun mit $875 \mu \mathrm{l} 100 \%$ Ethanol (unvergällt, $-20^{\circ} \mathrm{C}$ ) versetzt und durchgemischt. Die Ansätze wurden nun für 10 min bei $4^{\circ} \mathrm{C}$ mit $13000 \mathrm{UpM}$ zentrifugiert. Die Überstände wurden verworfen und die Pellets mit $500 \mu 1$ $70 \%$ Ethanol $\left(-20^{\circ} \mathrm{C}\right)$ versetzt und einmal vorsichtig umgedreht. Anschließend wurden die Ansätze für $1 \mathrm{~min}$ bei $4^{\circ} \mathrm{C}$ und $13000 \mathrm{UpM}$ zentrifugiert, die Überstände erneut verworfen und die Pellets ca. $30 \mathrm{~min}$ im $37^{\circ} \mathrm{C}$-Schrank getrocknet. Danach wurden die Pellets in je $20 \mu \mathrm{TE} / \mathrm{RNase}(100 \mu \mathrm{g} / \mathrm{ml})$ resuspendiert und bis zur weiteren Verwendung (z.B. Restriktionsverdau) bei $-20^{\circ} \mathrm{C}$ gelagert. 


\section{„Lysozyme-Lösung“:}

50 mM Glukose

10 mM EDTA

25 mM Tris- $\mathrm{HCl}, \mathrm{pH} 8,0$

$\rightarrow$ Lagerung bei $4^{\circ} \mathrm{C}$ für $100 \mathrm{ml}$

$$
93,7 \mathrm{ml} \mathrm{ddH_{2 }} \mathrm{O}
$$

$$
\begin{aligned}
& \text { 1,8 ml 2,78 M (50\%) Glukose } \\
& \text { 2,0 ml 0.5 M EDTA } \\
& \text { 2,5 ml } 1 \text { M Tris-HCl, pH 8,0 }
\end{aligned}
$$

$\underline{\mathrm{NaOH}-\mathrm{SDS}:}$

$0,2 \mathrm{M} \mathrm{NaOH}$

$1 \%(\mathrm{w} / \mathrm{v}) \mathrm{SDS}$ für $10 \mathrm{ml}$

$8,6 \mathrm{ml} \mathrm{ddH} \mathrm{H}_{2} \mathrm{O}$

$0,4 \mathrm{ml} 5 \mathrm{M} \mathrm{NaOH}$

$1,0 \mathrm{ml} 10 \%(\mathrm{w} / \mathrm{v}) \mathrm{SDS}$

$\rightarrow$ Lagerung bei RT

RNase A- Stammlösung (10 mg/ml):

$10 \mathrm{mg}$ RNase A in $1 \mathrm{ml} \mathrm{TE}$ lösen. $30 \mathrm{~min}$ bei $95^{\circ} \mathrm{C}$ inkubieren.

$\rightarrow$ Lagerung bei $-20^{\circ} \mathrm{C}$

$\underline{\mathrm{TE} / \mathrm{RNase}(100 \mu \mathrm{g} / \mathrm{ml}):}$

$5 \mu \mathrm{l} 10 \mathrm{mg} / \mathrm{ml}$ RNAse A-Stammlösung auf $500 \mu \mathrm{l}$ TE.

$\rightarrow$ Lagerung bei $4^{\circ} \mathrm{C}$

Zur Präparation besonders reiner Plasmid-DNA z.B. für eine nachfolgende Sequenzierung wurde das Qiaprep-Spin-Miniprep-Kit der Firma Qiagen (Hilden) verwendet.

\subsubsection{Photometrische Konzentrations- und Reinheitsbestimmung von Nukleinsäuren}

Die Konzentration wässriger DNA- und RNA-Lösungen kann durch Messung der Absorption von UV-Licht bei der Wellenlänge $260 \mathrm{~nm}$ in einer Quarzküvette im Spektralphotometer bestimmt werden, da Nukleotide hier ein Absorptionsmaximum besitzen. Eine $\mathrm{OD}_{260}$ von 1,0 entspricht einer Konzentration von

$$
\begin{aligned}
& 50 \mu \mathrm{g} / \mathrm{ml} \text { dsDNA } \\
& 40 \mu \mathrm{g} / \mathrm{ml} \text { ssDNA/RNA } \\
& 20 \mu \mathrm{g} / \mathrm{ml} \text { ss Oligonucleotide }
\end{aligned}
$$


Aromatische Aminosäuren und Phenole absorbieren Lichtwellen bei $280 \mathrm{~nm}$, so dass durch die $\mathrm{OD}_{280}$ eine Abschätzung der Reinheit der Nukleinsäurelösung möglich ist. Der Quotient $\mathrm{OD}_{260} / \mathrm{OD}_{280}$ sollte für relativ proteinfreie DNA- bzw. RNA-Präparationen zwischen 1,8 und 2,0 liegen (Sambrook et al., 1989).

\subsubsection{Enzymkatalysierte Reaktionen an DNA}

\subsection{Restriktionsverdau}

(Sambrook et al., 1989)

Zur Spaltung von dsDNA, z.B. um ein DNA-Fragment (Insert) in ein Plasmid (Vektor) zu klonieren, oder um das Restriktionsmuster des entstandenen rekombinanten Plasmides, welches über eine Plasmid-Minipräparation gewonnen wurde zu analysieren, werden Restriktionsendonukleasen des Typs II verwendet. Diese werden von verschiedenen Bakterienstämmen synthetisiert und katalysieren die spezifische hydrolytische Spaltung der Phosphodiesterbindungen der DNA innerhalb ihrer palindromischen Erkennungssequenzen. Je nach Enzym entstehen dabei Fragmente mit glatten Enden („blunt ends“), oder mit 3'- bzw. 5' - überhängenden, kohäsiven Enden (,sticky ends“'). Dabei ist immer das 3'-Hydroxylende frei, während das 5'-Ende die verbleibende Phosphatgruppe trägt. Aktivität und Spezifität der Restriktionsenzyme werden durch Salzkonzentration, Temperatur, pH-Wert und den Gehalt an zweiwertigen Kationen (besonders $\mathrm{Mg}^{2+}$ ) beeinflusst. Entsprechende Puffer werden jeweils nach Angaben des Herstellers verwendet. Bei 1 Erkennungssequenz pro DNA-Molekül spaltet 1 Unit (U) eines Restriktionsenzyms $1 \mu \mathrm{g}$ Lambda-Phagen-DNA in $1 \mathrm{~h}$ in einem $50 \mu \mathrm{l}$-Ansatz bei der für das Enzym optimalen Temperatur. Dies ist jedoch stark von dem Reinheitsgrad der DNA abhängig, da eine Kontamination mit Salzen, Polysacchariden oder Proteinen die Enzymwirkung herabsetzt. Deshalb wählt man in der Regel einen $2-5$ fachen Überschuss an Enzym, um Plasmid-DNA mit 1 - 3 Schnittstellen pro Molekül in $1 \mathrm{~h} \mathrm{zu}$ schneiden. Nach Spaltung mit nur einer Restriktionsendonuklease ist anschließend eine Behandlung mit alkalischer Phosphatase notwendig (siehe Kap. 2.2.2.3.2) um die Religation des Vektors zu verhindern. Die nach dem Restriktionsverdau erhaltenen Fragmente lassen sich anschließend durch eine Gelelektrophorese auftrennen, wodurch ihre Länge näherungsweise bestimmt werden kann. 
Beispiel 1: Analytischer Doppelverdau von rekombinanten Plasmiden

Hierzu werden in einem Eppendorf-Reaktionsgefäß zu $9 \mu$ l eines RestriktionsverdauMixes $1 \mu$ einer Plasmid-Minipräparations-DNA gegeben, gemischt und für mindestens 1 $\mathrm{h}$ bei $37^{\circ} \mathrm{C}$ im Wasserbad inkubiert.

\section{$\underline{\text { Restriktionsverdau-Mix: }}$}

(entsprechend mit der Anzahl der Ansätze multiplizieren + 1 Ansatz extra)

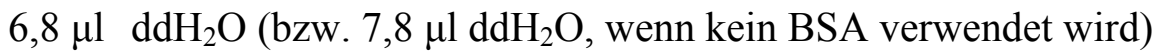

1,0 $\mu 1 \quad$ 10x Enzympuffer (entsprechend den Angaben des Enzymherstellers)

$1,0 \mu 1 \quad 10 x \operatorname{BSA}(1 \mathrm{mg} / \mathrm{ml})$ [falls notwendig]

mischen

$0,1 \mu 1$ Restriktionsenzym A

$0,1 \mu 1$ Restriktionsenzym B (bei Doppelverdau)

mischen

$\mathrm{Zu}$ einem $10 \mu \mathrm{l}$-Restriktionsansatz werden nun $2 \mu \mathrm{l}$ 6x Auftragspuffer gemischt und anschließend je $6 \mu \mathrm{l}$ in einem analytischen Agarosegel elektrophoretisch aufgetrennt (siehe Kap. 2.2.2.4).

Beispiel 2: Präparativer Verdau zur Linearisierung von Vektor-DNA für die Subklonierung von DNA-Fagmenten

a) Linearisierung des Vektors (60 $\mu 1$-Ansatz)

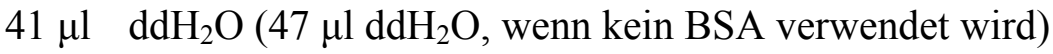

$5 \mu \mathrm{l}$ Plasmid-DNA

$6 \mu 1$ 10x Enzympuffer (entsprechend den Angaben des Enzymherstellers)

$6 \mu \mathrm{l} \quad 10 \mathrm{x}$ BSA $(1 \mathrm{mg} / \mathrm{ml})$ [falls notwendig]

mischen

$1 \mu \mathrm{l} \quad$ Restriktionsenzym A

$1 \mu \mathrm{l}$ Restriktionsenzym B (bei Doppelverdau)

Inkubation für $2-3 \mathrm{~h}$ bei $37^{\circ} \mathrm{C}$ 
b) Spaltung des Inserts (100 $\mu \mathrm{l}$-Ansatz)

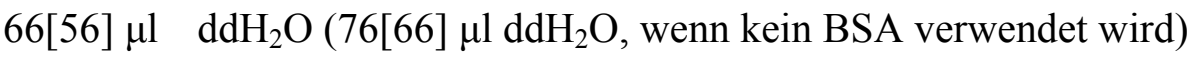

$10 \mu \mathrm{l}$ Plasmid-DNA [oder $20 \mu \mathrm{l}$ PCR-Produkt]

$10 \mu 1$ 10x Enzympuffer (entsprechend den Angaben des Enzymherstellers)

$10 \mu 1$ 10x BSA (1 mg/mg) [falls notwendig]

mischen

$2 \mu 1 \quad$ Restriktionsenzym A

$2 \mu \mathrm{l}$ Restriktionsenzym B (bei Doppelverdau)

Inkubation mindestens $2 \mathrm{~h}$ bei $37^{\circ} \mathrm{C}$ [Inkubation üN bei $37^{\circ} \mathrm{C}$ für PCR-Produkte].

Die Restriktionsenzyme in den Vektor- und Insert-Restriktionsansätzen werden anschließend durch eine meist 20 -minütige Inkubation bei $80^{\circ} \mathrm{C}$ im Heizblock inaktiviert (Dauer und Temperatur der Inaktivierung hängen von den verwendeten Enzymen ab). Die Produkte werden daraufhin in einem präparativen Agarosegel elektrophoretisch aufgetrennt (siehe Kap. 2.2.2.4). Es folgt eine QiaexII-DNA-Extraktion wie in Kap. 2.2.2.5 beschrieben. Daraufhin werden je $1 \mu \mathrm{l}$ der extrahierten DNA mit $5 \mu \mathrm{l} 1 \mathrm{x}$ Auftragspuffer gemischt und in einem analytischen Agarosegel (siehe Kap. 2.2.2.4) elektrophoretisch aufgetrennt, um die DNA-Konzentrationen für die anschließende Ligation abschätzen zu können (siehe Kap. 2.2.2.3.3).

\section{Beispiel 3: Verdau von PCR-Produkten zur Klonierung in einen Vektor}

Soll ein PCR-Produkt einer Restriktionsspaltung unterzogen werden, so müssen zuvor die Primer durch Phenolextraktion und Ethanolpräzipitation (siehe Kap. 2.2.2.3.5) entfernt werden.

Prozedur:

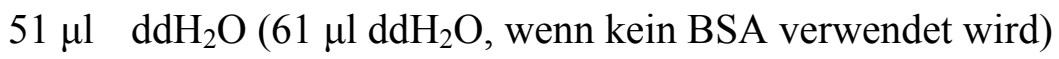

$25 \mu \mathrm{l}$ präzipitiertes PCR-Produkt

$10 \mu \mathrm{l}$ 10x Enzympuffer (entsprechend den Angaben des Herstellers)

$10 \mu \mathrm{l}$ 10x BSA $(1 \mathrm{mg} / \mathrm{ml})$ [falls notwendig]

mischen

$2 \mu \mathrm{l}$ Restriktionsenzym A

$2 \mu \mathrm{l}$ Restriktionsenzym B

Inkubation üN im $37^{\circ} \mathrm{C}$-Wasserbad 


\subsection{Behandlung von linearisierter DNA mit alkalischer Phosphatase}

Die alkalische Phosphatase (Calf Intestinal, Roche) katalysiert die Abspaltung der endständigen 5'-Phosphatgruppe von DNA- und RNA-Fragmenten. Das Enzym wurde bei einigen Klonierungen verwendet, um eine Religation des Vektors mit glatten oder kompatiblen kohäsiven Enden ohne ein eingefügtes DNA-Fragment zu verhindern und somit die Effizienz einer nachfolgenden Ligation von Vektor- und Insert-DNA zu erhöhen (Ullrich et al., 1977). Während der Ligation bildet die T4-DNA-Ligase nun zwar nur zwei Phosphodiesterbindungen zwischen der Plasmid-DNA und dem einzuführenden DNA-Fragment aus, während noch zwei Einzelstrangbrüche bestehen bleiben, diese Bindungen reichen jedoch aus um beide Moleküle vorübergehend zusammenzuhalten. Nach der Transformation werden diese Einzelstrangbrüche durch das DNA-Ligasesystem der Wirtszelle verschlossen. RNA-Fragmente, die durch RNAse A-Behandlung von Plasmid-Miniprep-DNA entstanden sind, stören die Phosphatase-Behandlung, weshalb die Plasmid-DNA-Minipräparation des Vektor-Plasmides zuvor mit Hilfe des QiaprepSpin-Miniprep-Kits der Firma Qiagen durchgeführt wurde.

Prozedur:

Das aufgereinigte Vektor-Plasmid wurde in einem $50 \mu$ Reaktionsansatz für 2-3 h bei $37^{\circ} \mathrm{C}$ mit dem entsprechenden Restriktionsenzym verdaut. Bei Verwendung des NEPuffers 1 (New England Biolabs Restriktionspuffer 1) wurden anschließend $5 \mu$ 10x NEPuffer 3 (New England Biolabs Restriktionspuffer 3) hinzugegeben (um den pH-Wert auf 7.9 einzustellen) und gemischt. In allen anderen NE-Puffern sowie den spezifischen Restriktionspuffern für EcoRI, BamHI und SalI ist die alkalische Phosphatase ebenfalls aktiv. Der Ansatz wurde nun mit $2 \mu$ alkalischer Phosphatase (1 $\mathrm{U} / \mu \mathrm{l})$ versetzt und für 1 $\mathrm{h}$ bei $37^{\circ} \mathrm{C}$ inkubiert. Die alkalische Phosphatase wurde anschließend durch Zugabe von $0.5 \mu 1500 \mathrm{mM}$ EDTA, pH 8.0 (Endkonz. $=5 \mathrm{mM}$ ) und Erhitzen für $20 \mathrm{~min}$ auf $75^{\circ} \mathrm{C}$ inaktiviert. Das inaktivierte Enzym wurde daraufhin mit Hilfe eines präparativen Agarosegeles und anschließender QiaexII-DNA-Extraktion (siehe Kap. 2.2.2.5) von der DNA getrennt. 


\subsection{Ligation von DNA-Doppelstrang-Fragmenten}

Bei der Ligasereaktion werden DNA-Enden miteinander verknüpft. Hierbei gibt es zwei verschiedene Fälle zu unterscheiden:

1) Die DNA-Fragmente, die miteinander verknüpft werden sollen, besitzen an ihren Enden kurze, überhängende Einzelstrangbereiche, die zueinander vollständig komplementär sind (,cohesive“ oder ,sticky ends“).

2) Die beiden Stränge sind bis zu den Enden basengepaart, d.h. gleich lang, so dass stumpfe Enden entstehen (,,blunt ends“).

Das verwendete Enzym für die Ligasereaktion ist meistens die DNA-Ligase des Bakteriophagen T4 (T4-DNA-Ligase), da sie im Gegensatz zur E. coli-DNA-Ligase sowohl überhängende Enden als auch stumpfe Enden ligieren kann. Notwendiger Kofaktor für die Reaktion ist bei der T4-DNA-Ligase ATP.

Für die Ligation ist es notwendig, dass zumindest eines der beteiligten 5'-Enden eine Phosphatgruppe trägt. Dies ist z.B. der Fall, wenn man die Fragmente durch Restriktionsspaltung erzeugt hat. Die T4-DNA-Ligase katalysiert die Bildung von Phosphodiesterbindungen zwischen einem 5'-Phospat und einer benachbarten 3'Hydroxylgruppe in der DNA. Während das Temperaturoptimum für die T4-DNA-Ligase bei $37^{\circ} \mathrm{C}$ liegt, weshalb ,blunt-end“-Ligationen bei dieser Temperatur inkubiert werden, kann es für „sticky-end“-Ligationen hilfreich sein, die Reaktion bei $16^{\circ} \mathrm{C}$ zu inkubieren, da dadurch die Hybridisierung der Enden verbessert wird.

Für die Konstruktion eines rekombinanten Plasmides werden zwischen 20 und 100 ng linearisierte Vektor-DNA und ein ca. 10-facher molarer Überschuss an zu integrierendem Insert eingesetzt.

Ligationsansatz:

$\mathrm{x} \mu \mathrm{l}$ linearisierte Vektor-DNA

y $\mu 1$ Insert-DNA (ca. 10-fach mehr Insert-DNA als Vektor-DNA)

1,5 $\mu 1$ 10x Ligasepuffer

1,0 $\mu \mathrm{l}$ T4-DNA-Ligase (400 U/ $\mu \mathrm{l})$

mit $\mathrm{ddH}_{2} \mathrm{O}$ auf $15 \mu$ auffüllen.

$\rightarrow$ Inkubation üN im Wasserbad bei $16^{\circ} \mathrm{C}$.

Danach können die Ansätze direkt zur Transformation von kompetenten E. coli eingesetzt werden (siehe Kap. 2.2.1.1.5). 


\subsection{Polymerase-Ketten-Reaktion (PCR)}

(Mullis and Faloona, 1987)

Die Polymerase-Ketten-Reaktion (englisch: polymerase chain reaction, PCR) ist eine sehr effektive Methode, um in vitro große Mengen einer spezifischen DNA-Sequenz (Template) zu amplifizieren. Die Vervielfältigung der DNA-Sequenz erreicht man durch einen dreistufigen zyklischen Prozess. Notwendige Voraussetzungen für die PCR sind:

1) Zwei synthetische Oligonukleotidprimer, die $\mathrm{zu}$ Regionen auf einander gegenüberliegenden Strängen komplementär sind, welche die gesuchte DNASequenz flankieren. Die freien 3'-OH-Gruppen der Oligonukleotidprimer sind nach der Anlagerung an diese Bereiche der Ausgangs-DNA einander zugewandt und dienen als Startpunkt für eine DNA-Polymerase-Reaktion. Die DNAPolymerase verknüpft die OH-Gruppe durch eine Phosphodiesterbindung mit einem freien Nukleotid, wodurch der Primerstrang in 3'-Richtung verlängert wird. Die Primer sollten ca. 20 - 30 Nukleotide lang sein, einen möglichst hohen GC-Gehalt besitzen (40 - $60 \%$ ) und am 3'-Ende mit einem $\mathrm{C}$ oder $\mathrm{G}$ enden. Außerdem sollten beide Primer eine ähnliche Schmelztemperatur $\left(\mathrm{T}_{\mathrm{m}}=\right.$ Temperatur, bei der unter den Pufferbedingungen $50 \%$ der Oligonukleotide dissoziieren) von mindestens $55^{\circ} \mathrm{C}$ besitzen, welche nach folgender Formel berechnet werden kann. Hierbei werden nur die zur Matrizen-DNA komplementären Nukleotide berücksichtigt.

$\mathrm{T}_{\mathrm{m}}=69.3+0.41 *(\mathrm{G}+\mathrm{C}[\%])-650 /$ Primerlänge $\left[{ }^{\circ} \mathrm{C}\right]$

näherungsweise:

$\mathrm{T}_{\mathrm{m}}=4 *$ Anzahl der G/C-Basen $+2 *$ Anzahl der A/T-Basen $\left[{ }^{\circ} \mathrm{C}\right]$

Die Annealing-Temperatur liegt im allgemeinen $3-4^{\circ} \mathrm{C}$ unterhalb der berechneten $\mathrm{T}_{\mathrm{m}}$. Je höher die Annealing-Temperatur, desto spezifischer erfolgt die Hybridisierung der Primer mit dem DNA-Template.

2) Geringe Mengen einer DNA-Probe mit einer Zielsequenz, die zwischen dem Primerpaar liegt und 100 bis 5000 bp lang ist. Als DNA-Matrize diente in dieser Arbeit entweder Vektor-DNA oder genomische Hefe-DNA.

3) Eine thermostabile DNA-Polymerase, die eine Temperatur von $95^{\circ} \mathrm{C}$ oder mehr standhält. Hierzu wird zumeist die DNA-Polymerase aus dem thermophilen 
Bakterium Thermus aquaticus (Taq-Polymerase) eingesetzt. Da diese Polymerase jedoch keine Korrekturlesefunktion (,proof-reading“) besitzt, wird häufig zur Optimierung der Amplifikationsgenauigkeit $P f u$-DNA-Polymerase aus Pyrococcus furiosus im Verhältnis Taq:Pfu $=10: 1$ hinzugefügt. PfuTurbo ${ }^{\circledR}{ }_{-}$ DNA-Polymerase wurde zur Amplifikation besonders großer DNA-Proben (große Plasmide, genomische DNA) verwendet.

4) Die 4 Desoxyribonukleotide (dNTPs).

Ein typischer PCR-Prozeß zur Amplifikation einer spezifischen DNA-Sequenz erfordert mehrere Zyklen. Jeder Zyklus besteht aus drei aufeinanderfolgenden Schritten:

\section{Denaturierung:}

Der erste Schritt bei der DNA-Amplifikation ist die thermische Denaturierung der DNAProbe durch Erhöhung der Temperatur im Reaktionsgefäß auf $95^{\circ} \mathrm{C}$, wobei sich die beiden DNA-Doppelstränge voneinander trennen. Das Reaktionsgemisch enthält zusätzlich zur Ausgangs-DNA einen beträchtlichen molaren Überschuss an beiden Oligonukleotidprimern, die Taq-Polymerase und die vier Desoxyribonukleotide.

\section{Renaturierung („Annealing"):}

Für den zweiten Schritt lässt man die Temperatur auf ungefähr $55^{\circ} \mathrm{C}$ absinken. Während der Temperatursenkung paaren die Primer mit komplementären Sequenzen in der DNAProbe. Die effektive Stringenz des Annealing-Schrittes kann durch Zugabe von Denaturierungsmitteln wie DMSO zum PCR-Ansatz erhöht werden.

\section{Synthese (Elongation):}

Bei dem dritten Schritt liegt die Temperatur bei $72^{\circ} \mathrm{C}$, dem optimalen Bereich für die katalytische Funktion der Taq-Polymerase. Die DNA-Synthese beginnt an den 3'-OHEnden der Primer. Die Taq-Polymerase verlängert in Gegenwart von dNTPs die Primer entlang der einzelsträngigen denaturierten DNA-Matrize und synthetisiert so neue DNAStränge, deren Sequenz komplementär zum Template ist. Hierbei amplifiziert die TaqPolymerase in etwa $1 \mathrm{~kb}$ DNA pro Minute.

Jede zusätzliche Strangsynthese bedeutet eine neue Vermehrungsrunde, wobei auch die neusynthetisierten DNA-Stränge als Matrize dienen. So steigt mit jedem neuen Zyklus die Konzentration der amplifizierten Ziel-Sequenzen exponentiell an. Die optimalen 
Reaktionsbedingungen müssen für jeden Ansatz individuell ermittelt werden. Besonders die $\mathrm{MgCl}_{2}$-Konzentration und die Annealing-Temperatur müssen optimiert werden.

In dieser Arbeit wurde die PCR-Reaktion für die Einführung spezifischer Restriktionsstellen in DNA, für die Durchführung von gerichteten Mutagenesen (Austausch von Aminosäuren an bestimmten Stellen der codierenden DNA-Sequenz), für die Klonierung von DNA-Fragmenten in Plasmide, für die Identifizierung von rekombinanten E. coliKlonen, für die Identifizierung von Deletionsmutationen im Hefegenom, sowie für die Sequenzierungsreaktion (siehe Kap. 2.2.2.3.8) verwendet.

Beispiel: PCR für die Klonierung eines Fragmentes in einen Vektor

\begin{tabular}{|c|c|}
\hline \multicolumn{2}{|l|}{ PCR-Ansatz: } \\
\hline $10 \mu \mathrm{l}$ & 10x Taq-Puffer (100mM Tris/HCL pH 9.0; 500 mM KCl) \\
\hline $10 \mu \mathrm{l}$ & $2.5 \mathrm{mM}$ dNTPs (Amersham, Stock 100mM) \\
\hline $5 \mu \mathrm{l}$ & $25 \mathrm{mM} \mathrm{MgCl}_{2}$ \\
\hline $2 \mu \mathrm{l}$ & 5'-Primer (Stock $100 \mathrm{pmol} / \mu \mathrm{l})$ \\
\hline $2 \mu \mathrm{l}$ & 3'-Primer $($ Stock $100 \mathrm{pmol} / \mu \mathrm{l})$ \\
\hline Rest in Pipettenspitze & DNA-Template (Plasmid-Miniprep-DNA) \\
\hline $1 \mu \mathrm{l}$ & $\begin{array}{l}\text { Taq-Polymerase }+1 / 10 \text { Pfu-Polymerase } \\
\text { (für analytische PCR wird nur Taq-Polymerase verwendet) }\end{array}$ \\
\hline ad $100 \mu 1$ & $\mathrm{HPLC}-\mathrm{H}_{2} \mathrm{O}$ \\
\hline \multicolumn{2}{|l|}{ Temperaturprogramm: } \\
\hline $40 \mathrm{sec}$ & $95^{\circ} \mathrm{C}$ \\
\hline $40 \mathrm{sec}$ & $50^{\circ} \mathrm{C}$ (hängt von Primern $\mathrm{ab}$ ) \\
\hline $1 \mathrm{~min}$ & $72^{\circ} \mathrm{C}$ (Dauer hängt von der Länge des Templates ab) \\
\hline 30 Zyklen & \\
\hline
\end{tabular}

Die Reaktion erfolgte in dünnwandigen $0.5 \mathrm{ml}$ Reaktionsgefäßen in einem automatischen Thermocycler mit beheizbarem Deckel. Die Amplifikationsprodukte konnten daraufhin durch TAE-Agarose-Gelelektrophorese (siehe Kap. 2.2.2.4) analysiert werden. Wenn das PCR-Produkt danach einer Restriktionsspaltung unterzogen werden soll, um es anschließend in einen Vektor $\mathrm{zu}$ klonieren, müssen zuvor die Primer durch Phenolextraktion und Ethanolpräzipitation entfernt werden (siehe Kap. 2.2.2.3.5).

\subsection{Phenolextraktion und Ethanolpräzipitation von DNA}

$100 \mu \mathrm{l}$ PCR-Produkt wurden mit $10 \mu \mathrm{l} 3 \mathrm{M}$ Natriumacetat, pH 5.2 (generell 1/10 Volumen) und $30 \mu \mathrm{l}$ Phenol-Chloroform-Isoamylalkohol (25:24:1) versetzt und gemischt. Der Ansatz wurde nun für 2 min bei 13000 UpM zentrifugiert. Die obere, wässrige Phase 
wurde in ein neues Eppendorf-Gefäß transferiert und mit $250 \mu \mathrm{l}-20^{\circ} \mathrm{C}$ kaltem $100 \%$ igen Ethanol (generell 2.5-faches Volumen) versetzt und gemischt. Der Ansatz wurde nun für $10 \mathrm{~min}$ auf Trockeneis inkubiert. Es folgte eine Zentrifugation für $10 \mathrm{~min}$ bei $13000 \mathrm{UpM}$ und $4^{\circ} \mathrm{C}$. Der Überstand wurde vorsichtig abgesaugt und mit $250 \mu 1-20^{\circ} \mathrm{C}$ kaltem 70 \%igen Ethanol versetzt. Es folgte eine Zentrifugation für 1 min bei $13000 \mathrm{UpM}$ und $4^{\circ} \mathrm{C}$. Der Überstand wurde vorsichtig abgesaugt und das Pellet ca. 30 min im $37^{\circ} \mathrm{C}$-Schrank getrocknet. Anschließend wurde das Pellet in $50 \mu \mathrm{TE}$ durch Vortexen gelöst.

\subsection{Gerichtete in vitro-Mutagenese über PCR}

Um gerichtete Mutationen, z.B. Basen-Deletionen oder neue Restriktionsstellen, in Plasmid-DNA einzuführen wurde die „Rapid PCR Site-directed Mutagenesis“-Methode (Stratagene Cloning Systems, La Jolla, USA) benutzt. Die Primerpaare wurden dabei so konstruiert, dass sie am 5'-Ende die einzuführende Mutation besitzen, während das 3'Ende komplementär zur Plasmid-DNA ist. Außerdem sollten zusätzlich während der Amplifikation neue Restriktionsstellen erzeugt, oder alte zerstört werden, um die Mutanten über einen Restriktionsverdau nachweisen zu können. Um die linearen Amplifikationsprodukte anschließend wieder zu einem zirkulären Plasmid ligieren zu können, müssen die Primer außerdem vorher an ihren 5'-Enden phosphoryliert werden.

\section{Phosphorylierung der Primer:}

$1 \mu \mathrm{l} \quad$ Primer 1 bzw. 2

$1 \mu \mathrm{l} \quad$ 10x T4-Polynukleotid-Kinase-Puffer

$1 \mu \mathrm{l} \quad 10 \mathrm{mM}$ АТP

$6 \mu \mathrm{HPLC}-\mathrm{H}_{2} \mathrm{O}$

$1 \mu \mathrm{l}$ T4-Polynukleotid-Kinase $(10 \mathrm{U} / \mu \mathrm{l})$

$\rightarrow 30 \mathrm{~min} \mathrm{im} \mathrm{Wasserbad} \mathrm{bei} 37^{\circ} \mathrm{C}$ inkubieren

\section{$\underline{\text { PCR: }}$}

Für die PCR-Reaktion wird diesmal ausschließlich die $P f u$-Polymerase verwendet, da diese eine geringere Fehlerrate als die Taq-Polymerase besitzt. Bei der Bestimmung der Elongationszeit muss jedoch beachtet werden, dass die $P f u$-Polymerase knapp 2 min für die Amplifikation von $1 \mathrm{~kb}$ DNA benötigt. 
$1 \mu 1$ verdünntes Plasmid (1:10 bis 1:50)

$5 \mu 1$ 10x Pfu-Puffer

$5 \mu \mathrm{dNTPs}$

$1.5 \mu \mathrm{l}$ phosphorylierter Primer 1 ( $3 \mu \mathrm{l}$ bei Verwendung der PfuTurbo ${ }^{\circledR}$-Polymerase)

$1.5 \mu \mathrm{l}$ phosphorylierter Primer 2 ( $3 \mu \mathrm{l}$ bei Verwendung der PfuTurbo ${ }^{\circledR}$-Polymerase)

$35 \mu \mathrm{HPLC}-\mathrm{H}_{2} \mathrm{O}$ (32 $\mu \mathrm{l}$ bei Verwendung der PfuTurbo ${ }^{\circledR}$-Polymerase)

$\rightarrow$ Denaturierung für 4 min bei $95^{\circ} \mathrm{C}$

$\rightarrow$ Start durch Zugabe von $1 \mu$ Pfu-Polymerase

Beispielprogramm:

$1 \mathrm{~min}$ bei $95^{\circ} \mathrm{C}$

$1 \mathrm{~min}$ bei $52^{\circ} \mathrm{C}$ (Temperatur richtet sich nach $\mathrm{T}_{\mathrm{m}}$ der verwendeten Primer)

$10 \min$ bei $72^{\circ} \mathrm{C}$

10 Zyklen (maximal 12)

Um das Ausgangsplasmid welches die eingefügte Mutation nicht besitzt zu entfernen, wird der PCR-Ansatz nun mit dem Enzym DpnI verdaut, welches nur methylierte und hemimethylierte DNA, d.h. DNA die in Bakterien $\left(\mathrm{dam}^{+}\right)$amplifiziert wurde, spaltet.

\section{DpnI-Verdau:}

PCR-Ansatz + $1 \mu \mathrm{l}$ DpnI $(20 \mathrm{U} / \mu \mathrm{l})$

$\rightarrow$ Inkubation für $1 \mathrm{~h} \mathrm{im} 37^{\circ} \mathrm{C}$-Wasserbad

$\rightarrow$ Inaktivierung des Enzyms durch 30 min Inkubation bei $80^{\circ} \mathrm{C}$

$2 \mu \mathrm{l}$ des Ansatzes können nun in einem analytischen Agarosegel auf Verlust des zirkulären Ausgangsplasmides und Vorhandensein des linearen PCR-Produktes hin untersucht werden.

\section{Ligation:}

$12.5 \mu \mathrm{D} \quad D p n \mathrm{I}$-verdauter Ansatz

$1.5 \mu \mathrm{l}$ 10x T4-DNA-Ligase-Puffer

$1.0 \mu \mathrm{l}$ T4-DNA-Ligase $(400 \mathrm{U} / \mu \mathrm{l})$

$\rightarrow$ Inkubation üN bei $16^{\circ} \mathrm{C}$ im Wasserbad.

Das Ligationsprodukt kann danach in kompetente E. coli elektroporiert werden. 


\subsection{Ungerichtete in vitro-Mutagenese über PCR zur Herstellung von ts- Mutanten}

(nach Muhlrad et al., 1992)

Das Prinzip zur Einführung zufälliger Mutationen über eine PCR-Reaktion beruht darauf, dass man in Gegenwart von $\mathrm{Mn}^{2+}$ die Konzentration eines der dNTPs stark verringert. Dies hat zur Folge, dass die Taq-Polymerase während der Amplifikation vermehrt falsche Nukleotide einfügt, die in höherer Konzentration vorliegen. Da die Taq-Polymerase keine Korrekturlesefunktion besitzt, werden diese Fehler nicht behoben.

PCR:

$10 \mu \mathrm{l}$ 10x Taq-Puffer

$10 \mu \mathrm{l} 2.5 \mathrm{mM}$ dATP, dCTP, dTTP, $0.25 \mathrm{mM}$ dGTP (= low G)

bzw. $\quad 2.5 \mathrm{mM}$ dGTP, dCTP, dTTP, $0.25 \mathrm{mM}$ dATP (= low A)

$12 \mu \mathrm{l} 25 \mathrm{mM} \mathrm{MgCl}{ }_{2}$

$1 \mu \mathrm{l} \quad 25 \mathrm{mM} \mathrm{MnCl}_{2}$

$2 \mu \mathrm{l} \quad$ YEP35 5'-Primer $(5 \mathrm{pmol} / \mu \mathrm{l})$

$2 \mu \mathrm{l} \quad$ YEP35 3'-Primer $(5 \mathrm{pmol} / \mu \mathrm{l})$

$62 \mu \mathrm{l} \quad \mathrm{HPLC}-\mathrm{H}_{2} \mathrm{O}$

$1 \mu 1 \quad$ Taq-Polymerase

+ Rest aus Pipettenspitze eines Plasmides mit dem zu mutagenisierenden Gen, welches von YEP35 5'- und YEP35 3'-komplementären Sequenzen flankiert wird (z.B. Multicloning-Site der Vektoren pRS313 - pRS316 bzw. pBlueskript).

Temperaturprogramm:

$\left.\begin{array}{l}95^{\circ} \mathrm{C} \Rightarrow 40 \mathrm{sec} \\ 55^{\circ} \mathrm{C} \Rightarrow 40 \mathrm{sec} \\ 72^{\circ} \mathrm{C} \Rightarrow 1 \mathrm{~min} 30 \mathrm{sec}\end{array}\right\} 30 x$

Parallel hierzu wurde der Hefe-Shuttle-Vektor pRS315(LEU2) mit zwei unterschiedlichen Restriktionsenzymen innerhalb der Multi-Cloning-Site geschnitten (siehe Kap. 2.2.2.3.1), so dass dieser nicht wieder religieren konnte. Der geschnittene Vektor sowie das PCRProdukt wurden nun gemeinsam mittels Lithiumacetat-Transformation (siehe Kap. 
2.2.3.3) in einen kompetenten Hefestamm transformiert, welcher eine Deletion des zu mutagenisierenden Genes besitzt (im Falle eines essentiellen Genes muss der Deletionsstamm außerdem eine WT-Kopie des Genes auf einem Plasmid besitzen, welches einen zum pRS315-Vektor verschiedenen Auxotrophiemarker besitzt, z.B. $U R A 3)$.

\section{DNA-Mix:}

$7.5 \mu \mathrm{l} \quad$ Heringssperma-DNA $(10 \mathrm{mg} / \mathrm{ml})$

$50 \mu \mathrm{l}$ präzipitiertes PCR-Produkt (low G oder low A)

$200 \mu$ Lithium-Sorbitol

$2.5 \mu \mathrm{l}$ geschnittener pRS315-Vektor

$\rightarrow$ Lithiumacetat-Transformation (siehe Kap. 2.2.3.3)

$\rightarrow$ Ausplattierung auf SD-LEU, Inkubation bei RT.

Innerhalb der Zelle erfolgt eine homologe Rekombination der YEP35 5'- und YEP35 3'Sequenzbereiche des PCR-Produktes mit homologen Bereichen des geschnittenen pRS315-Vektors, wodurch dieser wieder geschlossen wird.

Die Transformanten werden daraufhin gepoolt und auf Platten ausplattiert, welche 5-FOA (5-fluoroorotic acid) in einer Konzentration von $1 \mathrm{mg} / \mathrm{ml}$ enthalten. Das URA3Genprodukt konvertiert 5-FOA in eine toxische Verbindung, wodurch nur solche Transformanten überleben welche das URA3-Plasmid und damit die WT-Kopie verloren haben. Um ts-Mutanten zu identifizieren wurden Transformanten, die auf 5-FOA-Platten wachsen konnten, daraufhin auf Wachstumsdefekt bei $37^{\circ} \mathrm{C}$ untersucht.

\subsection{Sequenzierung}

Die Sequenzanalyse von DNA-Fragmenten erfolgte nach dem Prinzip von (Sanger et al., 1977) mittels einer Kapillarelektrophorese in einem Sequenzierautomaten Typ 310 der Firma PE Biosystems, Norwalk/USA. Hierzu wurde das Kit ABI PRISM Dye Terminator Cycle Sequencing Ready Reaction verwendet.

Vorbereitung:

Zuerst muss die Plasmid-DNA, in welcher die zu sequenzierende DNA als Insert vorliegt, mit dem QIAprep-Spin-Miniprep-Kit der Firma Qiagen aufgereinigt werden. Danach wird die Plasmid-DNA einer PCR-Reaktion unterzogen, wobei die Template-DNA unter Verwendung fluoreszenzmarkierter Basen amplifiziert wird. Als Sequenzierungs-Primer 
dienten Abschnitte auf den jeweiligen Vektoren, die in der Nähe der Insertionsstelle lagen (z.B. T3, T7).

\section{PCR-Ansatz:}

vorwärts-Reaktion

$\mathrm{x} \mu \mathrm{l}$ Plasmid-DNA $(0.2-0.5 \mu \mathrm{g})$

$3.2 \mu 1$ vorwärts-Primer $(1 \mathrm{pmol} / \mu \mathrm{l})$

$2.0 \mu 1$ ABI PRISM Dye Terminator Cycle Sequencing Ready Reaction Premix x $\mu \mathrm{l}$ HPLC- $\mathrm{H}_{2} \mathrm{O}($ ad $20 \mu \mathrm{l})$

rückwärts-Reaktion

x $\mu 1$ Plasmid-DNA $(0.2-0.5 \mu \mathrm{g})$

$3.2 \mu \mathrm{l}$ rückwärts-Primer $(1 \mathrm{pmol} / \mu \mathrm{l})$

$2.0 \mu \mathrm{l}$ ABI PRISM Dye Terminator Cycle Sequencing Ready Reaction Premix $x \mu \mathrm{HPLC}-\mathrm{H}_{2} \mathrm{O}(\mathrm{ad} 20 \mu \mathrm{l})$

Temperaturprogramm:

$\left.\begin{array}{l}96^{\circ} \mathrm{C} \Rightarrow 10 \mathrm{sec} \\ 50^{\circ} \mathrm{C} \Rightarrow 5 \mathrm{sec} \\ 60^{\circ} \mathrm{C} \Rightarrow 4 \mathrm{~min}\end{array}\right\} 25 x$

\section{Aufreinigung der DNA:}

Nach der Sequenzreaktion mussten die nicht eingebauten, fluoreszenzmarkierten ddNTPs durch eine Ethanolfällung entfernt werden. Hierzu wurden in ein $500 \mu$ Eppendorf-Gefäß $2 \mu \mathrm{l} 3 \mathrm{M}$ Natriumacetat (pH 5.2) und $50 \mu \mathrm{l} 95 \%$ EtOH (RT) vorgelegt. Der PCR-Ansatz wurde hinzupipettiert, gemischt und für $10 \mathrm{~min}$ bei RT inkubiert. Es folgte eine Zentrifugation für 20 min bei $13000 \mathrm{UpM}$ und RT. Das Pellet wurde mit $250 \mu 170 \%$ EtOH (RT) vorsichtig gewaschen. Nach 10 min Zentrifugation bei 13000 UpM und RT wurde das Pellet für mindestens $30 \mathrm{~min}$ im $37^{\circ} \mathrm{C}$-Schrank getrocknet. Anschließend wurde es in $25 \mu \mathrm{l}$ HPLC- $\mathrm{H}_{2} \mathrm{O}$ resuspendiert und konnte nun im Sequenzierautomaten kapillarelektrophoretisch analysiert werden. 


\subsubsection{Gelelektrophoretische Auftrennung von DNA}

Die Agarose-Gelelektrophorese wurde zur Reinigung, Trennung und Analyse von zirkulärer Plasmid-DNA und linearen DNA-Fragmenten benutzt. Aufgrund der negativen Ladung ihrer Phosphatgruppen wandern DNA-Moleküle im elektrischen Feld zur Anode. Wird die angelegte Spannung gering gehalten, so ist die Wanderungsgeschwindigkeit von linearer, doppelsträngiger DNA in einem Agarosegel umgekehrt proportional zum Logarithmus ihres Molekulargewichtes (Helling et al., 1974). Die Größe der DNAFragmente kann durch Vergleich mit Standard-DNA-Fragmenten definierter Größe abgeschätzt werden. Die Menge der aufgetrennten DNA konnte durch Vergleich der Intensität der Ethidiumbromidfärbung abgeschätzt werden.

\subsection{Analytische und präparative Agarose-Gelelektrophorese}

Zur analytischen und präparativen Trennung von DNA-Fragmenten wurden AgaroseFlachbettgele benutzt. Je nach Größe der zu trennenden DNA-Moleküle wurde eine Agarosekonzentration von $0.7-2.0 \%$ (w/v) Agarose gewählt.

\begin{tabular}{|c|c|}
\hline Agarosekonzentration & Größe der DNA-Fragmente \\
\hline $0.7 \%$ & $12 \mathrm{~kb}-800 \mathrm{bp}$ \\
\hline $1.0 \%$ & $10 \mathrm{~kb}-500 \mathrm{bp}$ \\
\hline $1.5 \%$ & $3 \mathrm{~kb}-200 \mathrm{bp}$ \\
\hline $2.0 \%$ & $2 \mathrm{~kb}-50 \mathrm{bp}$ \\
\hline
\end{tabular}

Die Agarose wurde durch Aufkochen in TAE-Puffer gelöst und in eine entsprechende Gelkammer gegossen. Durch das Aufsetzen eines Kammes wurden Taschen für den Probenauftrag freigehalten. Die Proben wurden mit 1/6 Volumen 6x Auftragspuffer versetzt und in die Taschen des mit TAE-Laufpuffer bedeckten Gels pipettiert. Durch die in dem Auftragspuffer enthaltene Saccharose wird die DNA-Probe beschwert, so dass sie in die Geltasche sinkt. Außerdem enthält der Auftragspuffer noch zwei Farbmarker, wodurch man die Wanderung der Probe durch das Gel verfolgen kann. Zusätzlich wurde ein Molekulargewichts-Standard (EcoRI/HindIII-geschnittene DNA des Phagen Lambda, $1 \mathrm{~kb}-$ Standard) aufgetragen. Die Elektrophorese erfolgte in 1x TAE-Puffer bei einer konstanten Spannung von $70 \mathrm{~V}$ für präparative Gele und maximal $95 \mathrm{~V}$ für analytische Gele. Die Gelkammern wurden während der Elektrophorese mit einem Ventilator 
gekühlt. Anschließend wurde das Agarosegel in einem Ethidiumbromidbad für 15 - 30 min inkubiert. Da Ethidiumbromid in die DNA interkaliert, konnten die DNA-Fragmente danach durch Bestrahlung mit UV-Licht (302 nm) sichtbar gemacht werden. Präparative Gele wurden für möglichst kurze Zeit langwelligerem UV-Licht (366 nm) ausgesetzt, um Schäden in der DNA-Struktur zu vermeiden. Die Nachweisgrenze Ethidiumbromidgefärbter Gele liegt bei ca. 10 ng DNA pro Bande. Das Agarosegel wurde auf dem UVTransilluminator mit Hilfe eines Videosystems dokumentiert.

50x TAE-Puffer (1 Liter):

$242 \mathrm{~g}$ Tris

$37 \mathrm{~g} \mathrm{Na}_{2}$ EDTA (Titriplex III)

mit Eisessig auf $\mathrm{pH} 8.0$ einstellen 6x Auftragspuffer:

$0.15 \%$ (w/v) Bromphenolblau (ca. bei 400 bp)

$0.15 \%(\mathrm{w} / \mathrm{v})$ Xylencyanat FF (ca. bei $4 \mathrm{~kb}$ )

$40 \%(w / v)$ Saccharose

Ethidiumbromidbad:

ca. $20 \mu \mathrm{l} \mathrm{konz}$. Ethidiumbromid in $200 \mathrm{ml} \mathrm{1x} \mathrm{TAE}$

\subsubsection{QIAEX ${ }^{\circledR}$ II-DNA-Extraktion aus präparativen Agarosegelen}

Zur Isolierung von DNA aus Agarosegelen wurde das QIAEX ${ }^{\circledR} I I$ Agarose Gel Extraction Kit der Firma Qiagen (Hilden) verwendet. Das DNA-Fragment wurde unter UV-Licht (Handlampe, $366 \mathrm{~nm}$ ) mit einem Skalpell aus dem Agarosegel herausgeschnitten und in ein Eppendorf-Reaktionsgefäß überführt. Nach Auswiegen des ausgeschnittenen Agarosestückchens wurde pro $100 \mathrm{mg}$ Gel $300 \mu \mathrm{l}$ Puffer QX1 hinzugegeben. Die QIAEX $^{\circledR}$ II-Glasmilchsuspension wurden resuspendiert und $10 \mu$ pro Verdau hinzugegeben. Der Ansatz wurde nun für $10 \mathrm{~min}$ bei $50^{\circ} \mathrm{C}$ im Heizblock inkubiert, wobei etwa alle 2 min gemischt wurde. In diesem Schritt wird die Agarose aufgeschmolzen und die DNA bindet an die QIAEX ${ }^{\circledR} I I-G l a s m i l c h$. Diese wurden daraufhin durch $30 \mathrm{sec}$ Zentrifugation bei 13000 UpM pelletiert. Der Überstand wurde vorsichtig abgesaugt und das Pellet in $500 \mu \mathrm{l}$ QX1-Puffer resuspendiert. Es folgte eine weitere Zentrifugation für $30 \mathrm{sec}$ bei 13000 UpM. Der Überstand wurde wieder verworfen und das Pellet 2x mit 500 $\mu 1$ PE-Puffer gewaschen. Danach wurde das Pellet für $10-15$ min an der Luft getrocknet und die DNA anschließend 5 min mit $20 \mu 1$ 10mM Tris, pH 8.0 eluiert (bei RT für DNA unter $4 \mathrm{~kb}$ bzw. bei $50^{\circ} \mathrm{C}$ für DNA von $4-10 \mathrm{~kb}$ ). Es folgte eine Zentrifugation für $30 \mathrm{sec}$ bei 13000 UpM. Der Überstand mit der eluierten DNA wurde in ein neues Eppendorf- 
Gefäß pipettiert. $1 \mu \mathrm{l}$ der eluierten DNA wurden daraufhin mit $5 \mu 1$ x Auftragspuffer versetzt und die DNA-Konzentrationen für die anschließende Ligation in einem analytischen Agarosegel abgeschätzt.

\subsubsection{Klonierung rekombinanter DNA in E. coli}

Die Vektor-DNA wurde für die Ligation durch geeignete Restriktionsendonukleasen linearisiert. Wurde nur ein Restriktionsenzym verwendet, so wurden die 5'-Phosphatreste an den glatten oder kompatiblen kohäsiven Enden durch Behandlung mit alkalischer Phosphatase entfernt, um eine Religation der Vektor-DNA zu verhindern. Die zu klonierende DNA wurde ebenfalls mit geeigneten Restriktionsendonukleasen geschnitten. Die DNA wurde daraufhin elektrophoretisch aufgetrennt und durch QIAEX ${ }^{\circledR}$ II-DNAExtraktion aus dem Agarosegel isoliert. Die Insert-DNA wurde anschließend in die linearisierte Vektor-DNA ligiert. Danach erfolgte die Transformation des Ligationsproduktes in kompetente E. coli-Zellen durch Elektroporation. Nach Selektion der Transformanten aufgrund ihrer Antibiotikaresistenz wurden die Plasmide durch eine Plasmid-DNA-Minipräparation isoliert und rekombinante Plasmide über einen analytischen Restriktionsverdau identifiziert.

\subsubsection{Methoden zur Hefegenetik}

\subsubsection{PLATE-Hefetransformation}

Die PLATE-Hefetransformation wurde dazu benutzt, reine Plasmide in Hefezellen zu transformieren. Das im PLATE-Medium enthaltene Lithiumacetat macht die Zellwand für DNA-Moleküle durchlässig, so dass die Hefezellen Plasmid-DNA aufnehmen können. Das ebenfalls im PLATE-Medium enthaltene PEG 4000 bewirkt durch seine hohe Viskosität eine stärkere Annäherung von DNA und Zellen.

Prozedur:

Die zu transformierenden Hefezellen wurden von einer frisch inkubierten Platte abgekratzt und in $500 \mu \mathrm{l}$ PLATE-Medium mit der Pipette resuspendiert, so dass das Medium milchig-trüb wurde (alternativ kann eine $1.5 \mathrm{ml}$ Übernachtkultur (ca. 1 OD) zentrifugiert und das Pellet in $500 \mu$ PLATE-Medium resuspendiert werden). Danach werden $2 \mu \mathrm{l}$ des entsprechenden Plasmides zugesetzt und mit der Pipette durchmischt. Es folgt ein Hitzeschock für $30 \mathrm{~min}$ im $42^{\circ} \mathrm{C}$-Wasserbad (temperatursensitive Stämme 
werden alternativ 1-2 Tage bei RT auf der Wippe langsam bewegt). Die Ansätze werden danach für $15 \mathrm{sec}$ bei $6500 \mathrm{UpM}$ zentrifugiert, die Überstände abgenommen und die Pellets in $200 \mu \mathrm{l}$ SOS-Medium resuspendiert. Zur Regeneration der Zellen folgt eine Inkubation für $20-30 \mathrm{~min}$ bei $30^{\circ} \mathrm{C}$ im Wasserbad (temperatursensitive Stämme alternativ bei RT). Danach werden die Ansätze jeweils auf die Hälfte einer entsprechenden SD-Minimalmedium-Agarplatte, die gegen das vom Plasmid codierte Auxotrophiegen selektioniert, ausplattiert und bis zur Entstehung von Kolonien bei $30^{\circ} \mathrm{C}$ (bzw. $24^{\circ} \mathrm{C}$ ) inkubiert.

\begin{tabular}{rlr} 
PLATE-Medium $(100 \mathrm{ml}):$ & Endkonz.: \\
\hline $40 \mathrm{~g}$ & PEG 4000 & $40 \%$ \\
$10 \mathrm{ml}$ & $1 \mathrm{M}$ Lithiumacetat & $0.1 \mathrm{M}$ \\
$1 \mathrm{ml}$ & $1 \mathrm{M} \mathrm{Tris} / \mathrm{HCl}, \mathrm{pH} 7.5$ & $10 \mathrm{mM}$ \\
$0.2 \mathrm{ml}$ & $0.5 \mathrm{M}$ EDTA & $1 \mathrm{mM}$ \\
$\rightarrow$ autoklavieren &
\end{tabular}

$\underline{\text { SOS-Medium (wird jeweils frisch angesetzt): }}$

$500 \mu \mathrm{l} \quad$ YEPD

$500 \mu \mathrm{l} 2 \mathrm{M}$ Sorbitol

$6.5 \mu \mathrm{l} \quad 1 \mathrm{M} \mathrm{CaCl}_{2}$

\subsubsection{Klassische Hefetransformation}

\subsection{Herstellung transformationskompetenter Hefezellen}

\section{- Alle Arbeitsschritte und Materialien müssen steril sein ! -}

Eine Hefekultur wird in $100 \mathrm{ml}$ YEPD verdünnt und üN bei $30^{\circ} \mathrm{C}$ inkubiert. Am nächsten Morgen sollte die $\mathrm{OD}_{600}$ zwischen 1 und 1.3 liegen. Die Zellen werden nun in einem JA20-Rotor für 5 min mit $5000 \mathrm{UpM}$ zentrifugiert. Das Pellet wird in $5 \mathrm{ml} \mathrm{Li-TE-Sorbitol}$ resuspendiert, welches dazu dient, die Zellwand für DNA-Moleküle durchlässig zu machen, und anschließend in ein $15 \mathrm{ml}$ Falcon-Röhrchen überführt. Der Ansatz wird nun für 5 min mit $3000 \mathrm{UpM}$ zentrifugiert. Mit einer Glaspipette wird das Pellet in $1 \mathrm{ml} \mathrm{Li}$ TE-Sorbitol resuspendiert. Die Zellen werden daraufhin für $60 \mathrm{~min}$ im $30^{\circ} \mathrm{C}$-Wasserbad unter Schütteln inkubiert. Danach werden die Zellen mindestens 10 min (bis. maximal 1 
h) auf Eis inkubiert. Zu dem Ansatz wird nun $1 \mathrm{ml} 40 \%$ (v/v) Glycerol + $0.05 \%$ (8.6 $\mathrm{mM}) \mathrm{NaCl}$ hinzugefügt und gemischt. Es werden sofort $200 \mu$ l-Aliquots in sterile Eppendorf-Gefäße überführt und auf Trockeneis eingefroren. Die aliquotierten kompetenten Zellen werden danach bei $-70^{\circ} \mathrm{C}$ gelagert.

\begin{tabular}{rlr} 
Li-TE-Sorbitol $(100 \mathrm{ml}):$ & Endkonz.: \\
\hline $50 \mathrm{ml}$ & 2 M Sorbitol & $1 \mathrm{M}$ \\
$5 \mathrm{ml}$ & $1 \mathrm{M}$ Lithiumacetat & $50 \mathrm{mM}$ \\
$1 \mathrm{ml}$ & $1 \mathrm{M}$ Tris/HCl, pH 7.5 & $500 \mu \mathrm{mM}$ \\
$100 \mu \mathrm{l}$ & $0.5 \mathrm{M} \mathrm{EDTA}$ & $200 \mu \mathrm{M}$ \\
$20 \mu \mathrm{l}$ & $1 \mathrm{M} \mathrm{CaCl}_{2}$ & \\
$\rightarrow$ autoklavieren &
\end{tabular}

$\underline{40 \%(\mathrm{v} / \mathrm{v}) \text { Glycerol }+0.05 \%(\mathrm{w} / \mathrm{v}) \mathrm{NaCl}(100 \mathrm{ml})}$ :

$\begin{array}{cc}50.2 \mathrm{~g} & \text { Glycerol } \\ 172 \mu \mathrm{l} & 5 \mathrm{M} \mathrm{NaCl} \text { (Endkonz.: } 8.6 \mathrm{mM}) \\ \rightarrow & \text { autoklavieren }\end{array}$

\subsection{Klassische Transformation von Hefezellen}

Die klassische Hefetransformation mit transformationskompetenten Hefezellen zeichnet sich durch eine höhere Transformationseffizienz als die PLATE-Hefetransformation aus. Auch lineare DNA-Fragmente können auf diese Weise in Hefezellen transformiert und durch homologe Rekombination in das Hefegenom integriert werden (Rothstein, 1983).

\section{- Alle Arbeitsschritte und Materialien müssen steril sein ! -}

Ein $200 \mu$ l-Aliquot transformationskompetenter Hefezellen wird auf Eis aufgetaut. $100 \mu 1$ Zellen werden mit $1 \mu$ Plasmid-DNA (bzw. $5 \mu$ PCR-Produkt) und $5 \mu$ l HeringsspermaDNA $(10 \mathrm{mg} / \mathrm{ml})$ versetzt und gemischt. Die gleiche Menge (100 $\mu \mathrm{l}) 70 \%$ (w/v) PEG 4000 wird mit einer blauen Spitze hinzugegeben und durch rauf und runter pipettieren gemischt. Die Zellen werden nun für $30 \mathrm{~min}$ im $30^{\circ} \mathrm{C}$-Wasserbad (temperatursensitive Stämme bei $24^{\circ} \mathrm{C}$ ) inkubiert. Danach erfolgt ein Hitzeschock für 15 min im $42^{\circ} \mathrm{C}$ Wasserbad. Der Ansatz wird nun für $20 \mathrm{sec}$ bei $6500 \mathrm{UpM}$ zentrifugiert und das Pellet in $300 \mu \mathrm{l}$ sterilem SOS-Medium resuspendiert. Zur Regeneration werden die Zellen für 30 min bis $1 \mathrm{~h} \mathrm{im} 30^{\circ} \mathrm{C}$-Wasserbad (bzw. $24^{\circ} \mathrm{C}$ ) inkubiert. Die Ansätze werden daraufhin auf 
der entsprechenden SD-Minimalmedium-Agarplatte, die gegen das vom Plasmid codierte Auxotrophiegen selektioniert, ausplattiert und im $30^{\circ} \mathrm{C}$-Brutschrank (bzw. $24^{\circ} \mathrm{C}$-Brutschrank) für 2 - 3 Tage inkubiert, bis sich Kolonien gebildet haben.

$\underline{\text { SOS-Medium (wurde jeweils frisch angesetzt): }}$

$500 \mu \mathrm{Y}$ YEPD

$500 \mu 12$ M Sorbitol

$6.5 \mu 11 \mathrm{M} \mathrm{CaCl}_{2}$

\subsubsection{Lithiumacetat-Transformation von Hefezellen}

Für diese äußerst effiziente Transformation werden die Hefezellen zuvor frisch kompetent gemacht. Diese Methode wurde dazu verwendet DNA-Bibliotheken für einen MulticopySuppressor-Screen (ts-Screen) in Hefezellen zu transformieren.

\section{- Alle Arbeitsschritte und Materialien müssen steril sein !-}

\section{Herstellung kompetenter Hefezellen:}

Eine Hefekultur wird in $100 \mathrm{ml}$ YEPD verdünnt und üN bei $30^{\circ} \mathrm{C}$ inkubiert. Am nächsten Morgen sollte die $\mathrm{OD}_{600}$ zwischen 0.5 und 0.8 liegen. Die Zellen wurden nun im JA20Rotor für $5 \mathrm{~min}$ bei $5000 \mathrm{UpM}$ zentrifugiert. Das Pellet wurde in $50 \mathrm{ml}$ sterilem Wasser resuspendiert und die Zellen erneut für $5 \mathrm{~min}$ bei $5000 \mathrm{UpM}$ zentrifugiert. Nun wurde das Pellet in $25 \mathrm{ml}$ LiSorb resuspendiert und für $15-30 \mathrm{~min}$ bei $30^{\circ} \mathrm{C}$ inkubiert. Die Zellen wurden daraufhin erneut im JA20-Rotor für $5 \mathrm{~min}$ bei $5000 \mathrm{UpM}$ zentrifugiert. Schließlich wurde das Pellet in $300 \mu \mathrm{L}$ LiSorb resuspendiert und auf Eis aufbewahrt.

\section{Transformation:}

Zuerst wird der DNA-Mix vorbereitet:

$100 \mu \mathrm{l}$ Heringssperma-DNA $(10 \mathrm{mg} / \mathrm{ml})$ werden für $7-10 \mathrm{~min}$ bei $95^{\circ} \mathrm{C}$ im Heizblock inkubiert. Anschließend werden $400 \mu \mathrm{l}$ LiSorb zugesetzt und durch rauf und runter pipettieren gemischt. Man lässt das Gemisch nun auf RT abkühlen und fügt danach $10 \mu 1$ der DNA-Bibliothek hinzu.

Je $100 \mu \mathrm{l}$ der frisch kompetent gemachten Hefezellen werden nun im EppendorfReaktionsgefäß mit $100 \mu \mathrm{l}$ DNA-Mix versetzt und durch rauf und runter pipettieren gemischt. Nun werden $900 \mu \mathrm{l} 40$ \% (w/v) PEG 3350 in LiAc/TE hinzugefügt und erneut gemischt. Der Ansatz wird daraufhin für $30 \mathrm{~min}$ bei $30^{\circ} \mathrm{C}$ inkubiert. Danach erfolgt ein 
Hitzeschock für $15 \mathrm{~min}$ im $42^{\circ} \mathrm{C}$-Wasserbad. Die Ansätze werden nun für $20 \mathrm{sec}$ bei 6500 UpM zentrifugiert und das Pellet anschließend in $300 \mu \mathrm{l}$ sterilem SOS-Medium resuspendiert. Es folgt eine Inkubation für $30 \mathrm{~min}$ bis $1 \mathrm{~h}$ im $30^{\circ} \mathrm{C}$-Wasserbad. Der gesamte Ansatz wird danach auf eine SD-Minimalmedium-Agarplatte ausplattiert (im Falle der YEp24-DNA-Bibliothek handelte es sich um eine SD-Ura-Platte) und zur Expression der transformierten Plasmide üN im $30^{\circ} \mathrm{C}$-Brutschrank inkubiert. Zur Identifizierung von Suppressoren temperatursensitiver Stämme wurden die Transformationsplatten anschließend bei $37^{\circ} \mathrm{C}$ inkubiert.

LiSorb (100 ml):

$$
18.2 \mathrm{~g} \text { Sorbitol }
$$

$10 \mathrm{ml} 1 \mathrm{M}$ Lithiumacetat

$1 \mathrm{ml} 1 \mathrm{M}$ Tris/HCl, $\mathrm{pH} 8.0$

$200 \mu 1 \quad 0.5$ M EDTA

$\rightarrow$ autoklavieren

40\% (w/v) PEG 3350 in LiAc/TE $(50 \mathrm{ml})$ :

$20 \mathrm{~g}$ Polyethylenglykol MW 3350

$5 \mathrm{ml} 1 \mathrm{M}$ Lithiumacetat

$0.5 \mathrm{ml} 1 \mathrm{M}$ Tris/HCl, $\mathrm{pH} 8.0$

$100 \mu \mathrm{l} \quad 0.5 \mathrm{M}$ EDTA

$\rightarrow$ autoklavieren
Endkonz.:

$1 \mathrm{M}$

$100 \mathrm{mM}$

$10 \mathrm{mM}$

$1 \mathrm{mM}$
Endkonz.:

$40 \%(\mathrm{w} / \mathrm{v})$

$100 \mathrm{mM}$

$10 \mathrm{mM}$

$1 \mathrm{mM}$

\subsubsection{Plasmidisolation aus $S$. cerevisiae}

$2 \mathrm{ml}$ stationär in Selektionsmedium gewachsene Hefekultur wurden für $30 \mathrm{sec}$ bei 6500 UpM zentrifugiert und das Zellenpellet in $200 \mu$ l Lyse-Puffer durch Vortexen resuspendiert. Es wurden nun ca. $100 \mu 1$ säuregewaschene Glasperlen und $200 \mu 1$ PhenolChloroform (1:1) hinzugegeben und für 2 min gevortext. Zur Trennung der wässrigen Phase von der organischen Phase, den Glasperlen und den unaufgeschlossenen Zellen werden die Ansätze für 5 min bei $13000 \mathrm{UpM}$ zentrifugiert. Die wässrige Phase wurde vorsichtig abgenommen und die DNA durch Zugabe von $20 \mu 13 \mathrm{M}$ Natriumacetat (pH 5.2) und $550 \mu 100 \% \mathrm{EtOH}\left(-20^{\circ} \mathrm{C}\right)$ ausgefällt. Das Präzipitat wurde nun für $10 \mathrm{~min}$ bei $4^{\circ} \mathrm{C}$ mit $13000 \mathrm{UpM}$ zentrifugiert und Salze durch Waschen mit $250 \mu \mathrm{l}$ kaltem $70 \%$ igem 
EtOH entfernt. Der Ansatz wurde erneut für 1 min bei $4^{\circ} \mathrm{C}$ und $13000 \mathrm{UpM}$ zentrifugiert und das Pellet anschließend im $37^{\circ} \mathrm{C}$-Schrank getrocknet. Danach wurde das DNA-Pellet in $20 \mu \mathrm{l}$ TE-Puffer durch vortexen resuspendiert. Jeweils $1.2 \mu \mathrm{l}$ dieser Plasmid-DNA wurden anschließend in kompetente E. coli elektroporiert, um das Plasmid für weitere Analysen zu amplifizieren.

Lyse-Puffer (50 ml):

$4 \mathrm{ml} 25 \%(\mathrm{w} / \mathrm{v})$ Triton X-100

$5 \mathrm{ml} \quad 10 \%(\mathrm{w} / \mathrm{v})$ SDS

$1 \mathrm{ml} \quad 5 \mathrm{M} \mathrm{NaCl}$

$500 \mu \mathrm{l} \quad 1 \mathrm{M}$ Tris/HCl, $\mathrm{pH} 8.0$

$100 \mu \mathrm{l} \quad 0.5 \mathrm{M}$ EDTA
Endkonz.:

$2 \%$

$1 \%$

$100 \mathrm{mM}$

$10 \mathrm{mM}$

$1 \mathrm{mM}$

\subsubsection{Präparation von genomischer Hefe-DNA}

Die Hefen werden in $8 \mathrm{ml}$ YEPD-Medium inokuliert und bis zur stationären Phase wachsen gelassen. Danach werden sie für 3 min bei 3000 UpM zentrifugiert. Das Pellet wird in $500 \mu \mathrm{l}$ Wasser resuspendiert und in ein Eppendorf-Reaktionsgefäß überführt. Die Zellen werden nun für $30 \mathrm{sec}$ bei $13000 \mathrm{UpM}$ zentrifugiert und das Pellet anschließend in $200 \mu 1$ Lyse-Puffer durch vortexen resuspendiert. Pro Ansatz werden ca. $100 \mu 1$ säuregewaschene Glasperlen und $200 \mu$ Phenol-Chloroform (1:1) zugegeben und anschließend für 2 min gevortext. Nun werden $200 \mu$ TE-Puffer zugesetzt, gemischt und $5 \mathrm{~min}$ bei 13000 UpM zentrifugiert. Die obere wässrige Phase wird in ein neues Eppendorf-Gefäß überführt und mit $1 \mathrm{ml} 100 \%$ igen $-20^{\circ} \mathrm{C}$ kalten $\mathrm{EtOH}$ versetzt und gemischt um die DNA und RNA auszufällen. Es folgt eine Zentrifugation für 2 min mit $13000 \mathrm{UpM}$ bei $4^{\circ} \mathrm{C}$. Das Pellet wird daraufhin in $400 \mu \mathrm{l}$ TE-Puffer mit $100 \mu \mathrm{g} / \mu \mathrm{l}$ RNase A gelöst und für 5 min bei $37^{\circ} \mathrm{C}$ im Wasserbad inkubiert um die mitgefällte RNA abzubauen. Um die DNA erneut zu präzipitieren werden nun $20 \mu \mathrm{l} 3 \mathrm{M}$ Natriumacetat ( $\mathrm{pH}$ 5.2) sowie $1 \mathrm{ml}$ $100 \%$ iges EtOH zugesetzt, gemischt und anschließend 2 min mit $13000 \mathrm{UpM}$ bei $4^{\circ} \mathrm{C}$ zentrifugiert. Der Überstand wird vorsichtig abgesaugt und das Pellet mit $250 \mu 1$ kaltem 70 \%igem EtOH versetzt. Es folgt eine Zentrifugation für 1 min mit $13000 \mathrm{UpM}$ bei $4{ }^{\circ} \mathrm{C}$. Das DNA-Pellet wird für ca. $30 \mathrm{~min}$ im $37^{\circ} \mathrm{C}$-Schrank getrocknet und anschließend in 50 $\mu 1$ TE-Puffer durch vortexen gelöst. 
Lyse-Puffer $(50 \mathrm{ml})$ :

$\begin{array}{rl}4 \mathrm{ml} & 25 \%(\mathrm{w} / \mathrm{v}) \text { Triton X-100 } \\ 5 \mathrm{ml} & 10 \%(\mathrm{w} / \mathrm{v}) \mathrm{SDS} \\ 1 \mathrm{ml} & 5 \mathrm{M} \mathrm{NaCl} \\ 500 \mu \mathrm{l} & 1 \mathrm{M} \text { Tris/HCl, } \mathrm{pH} 8.0 \\ 100 \mu \mathrm{l} & 0.5 \mathrm{M} \mathrm{EDTA}\end{array}$

Endkonz.:

$2 \%$

$1 \%$

$100 \mathrm{mM}$

$10 \mathrm{mM}$

$1 \mathrm{mM}$

\subsubsection{Herstellung von Deletionsmutanten}

(nach Baudin et al., 1993)

Um ein Gen in S. cerevisiae zu deletieren wird es in der Regel mittels homologer Rekombination durch ein Auxotrophiegen ersetzt. Hierzu werden verschiedene Methoden verwendet, wovon hier nur eine exemplarisch beschrieben werden soll. $\mathrm{Zu}$ Beginn konstruiert man sich zwei Oligonukleotid-Hybridprimer. Diese sind jeweils ca. 60 Nukleotide lang und bestehen aus ca. 40 Nukleotiden einer komplementären Sequenz zum 5'- bzw. 3'-flankierenden Bereich des zu deletierenden Genes gefolgt von ca. 20 Nukleotiden einer komplementären Sequenz zum 5'- bzw. 3'-flankierenden Bereich (z.B. aus der Multicloning-Site) eines in einem Vektor klonierten Auxotrophiegenes (z.B. LEU2, URA3, HIS3, TRP1). Über eine PCR-Reaktion mit diesem Vektor als Matrize entsteht so ein lineares Deletionskonstrukt, welches aus dem Auxotrophiegen flankiert von Sequenzen des zu deletierenden Genes besteht. Dieses lineare Deletionskonstrukt wird daraufhin in einen kompetenten diploiden WT-Hefestamm transformiert (SEY6210xSEY6211). Mittels homologer Rekombination der zum 5'- und 3'flankierenden Bereich des zu deletierenden Genes homologen Sequenzen des Deletionskonstruktes erfolgt nun ein Austausch von einer der chromosomalen Gensequenzen gegen das Auxotrophiegen. Handelt es sich bei dem zu deletierenden Gen um ein nichtessentielles Gen, so erhält man bei der anschließenden Sporulation 4 Sporen (2 WTSporen und 2 Deletionsmutanten-Sporen), wobei letztere durch Selektion gegen das Auxotrophiegen identifiziert werden können (der WT-Stamm SEY6211 ist auxotroph für Leucin, Uracil, Histidin und Tryptophan; der Stamm SEY6210 zusätzlich noch für Lysin). Erhält man nach der Sporulation nur 2 WT-Sporen, so bedeutet dies, das es sich bei dem Gen um ein essentielles Gen handelt. In diesem Fall muss man das Deletionskonstrukt in einen diploiden Hefestamm transformieren, welcher zusätzlich noch eine Kopie des zu deletierenden Genes auf einem Plasmid (mit zum Deletionskonstrukt 
unterschiedlichem Auxotrophiemarker) enthält. Aufgrund dieser zusätzlichen extrachromosomalen Kopie des Genes überleben nun bei der Sporulation die Deletionsmutanten-Sporen, weshalb wieder 4 Sporen entstehen. Die Deletionsmutanten können daraufhin durch Selektion gegen das Auxotrophiegen identifiziert werden (eine zusätzliche Selektion gegen das Plasmid ist nicht nötig, da sie das Plasmid nicht verlieren können). Um auszuschließen, dass die homologe Rekombination an einer anderen Stelle stattgefunden hat, sollte die Deletion außerdem immer über eine PCR-Reaktion mit isolierter genomischer DNA überprüft werden. Hierbei ist es wichtig, dass das Auxotrophiegen eine andere Größe besitzt als das zu deletierende Gen, da sie sonst in der PCR-Reaktion nicht voneinander unterschieden werden können. Es werden Primer benutzt, die Sequenzen erkennen, welche jeweils dem 5'- bzw. 3'-flankierenden Genbereich des zu deletierenden Genes entsprechen. Da diese Sequenzbereiche bei korrekter homologer Rekombination auch das Auxotrophiegen flankieren, kann dieses über die PCR-Reaktion identifiziert werden.

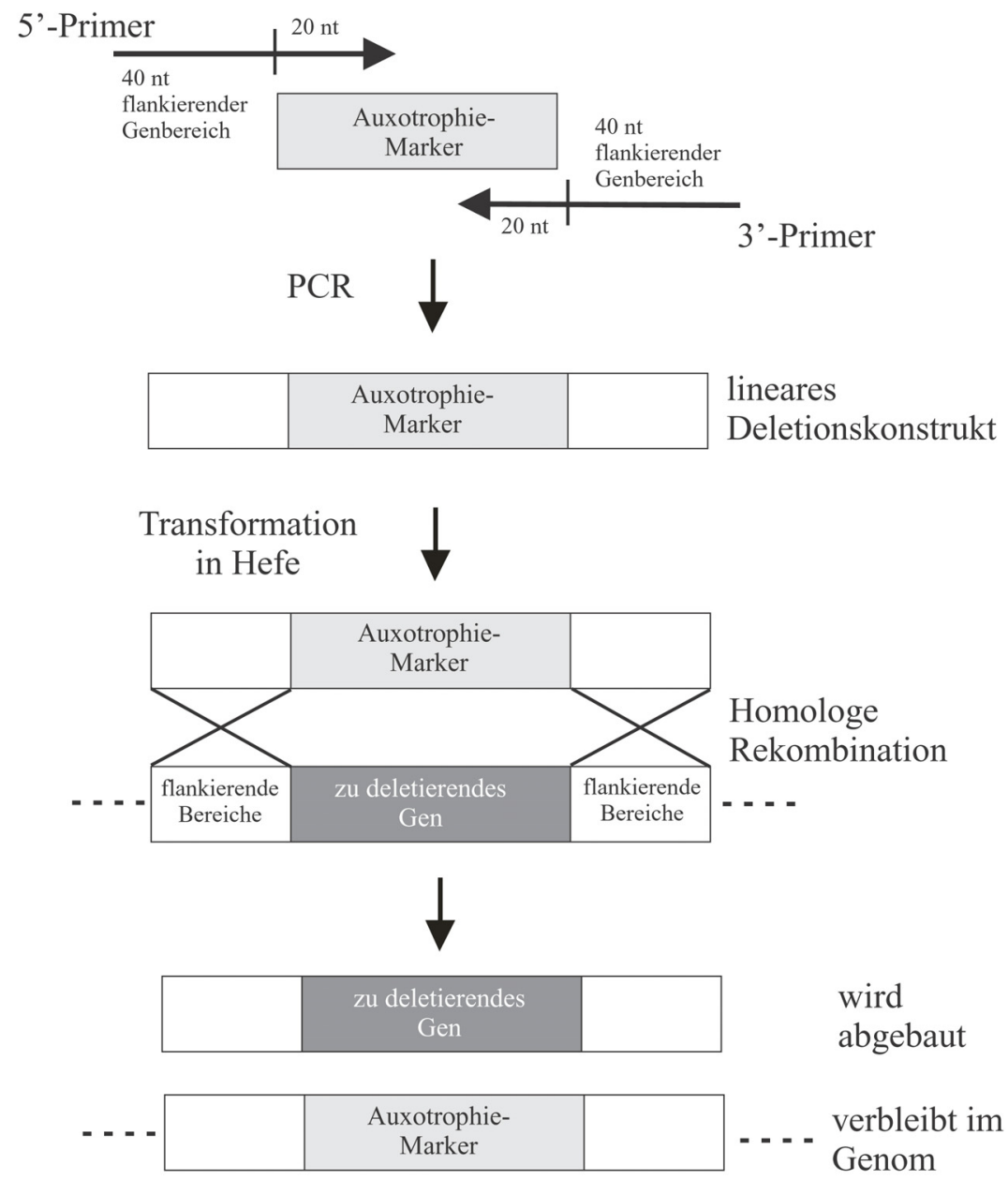

Abb. 2.1: Schema der Deletierung eines Genes in Hefe. 


\subsubsection{Kreuzung von Hefezellen}

S. cerevisiae-Hefestämme können sich unter optimalen Wachstumsbedingungen sowohl als diploide, als auch als haploide Zellen vegetativ vermehren. Haploide Zellen treten in zwei unterschiedlichen Paarungstypen auf: a (MATa) und $\alpha$ (MAT $\alpha$ ). Eine Konjugation von haploiden Hefezellen erfolgt nur bei einer Mischung von Zellen mit unterschiedlichen Paarungstypen. Die Verschmelzung der Zellen führt zur Bildung einer diploiden Zygote. Die im Labor verwendeten heterothallischen Hefestämme behalten ihren Paarungstyp stabil bei und können daher dauerhaft als haploide Kulturen gezüchtet werden.

Prozedur:

Hefestämme mit unterschiedlichen Paarungstypen wurden linienförmig auf einer YEPDPlatte über Kreuz ausgestrichen und für $12-15 \mathrm{~h}$ bei $30^{\circ} \mathrm{C}$ inkubiert. Aus dem Mischbereich beider Stämme wurden daraufhin mehrere Zahnstocherspitzen auf eine SDMinimalmediumplatte ausgestrichen, welche nur auf diploide Zellen selektioniert. Hochwachsende Kolonien wurden gesichert.

\subsubsection{Sporulation von Hefezellen}

Wird eine diploide Hefekultur unter Stickstoff-Mangelbedingungen inkubiert, so treten die Hefezellen in den meiotischen Zyklus ein. Dabei wird ein Ascus mit vier haploiden Sporen gebildet, der auch als Tetrade bezeichnet wird. Zerlegt man die Tetrade durch Mikromanipulation in vier voneinander getrennte Sporen, können diese als haploide Kulturen weiterwachsen. Nachdem die Sporen zu Zellkolonien herangewachsen sind, kann der Genotyp analysiert werden.

\section{Prozedur:}

Ein diploider Stamm wurde auf einer SD-Minimalmediumplatte frisch wachsen gelassen, anschließend dick auf einer Sporulationsplatte (siehe Kap. 2.1.13) ausgestrichen und für 3 - 5 Tage bei $30^{\circ} \mathrm{C}$ inkubiert. Die Ausbildung der Tetraden konnte daraufhin mit einem Lichtmikroskop kontrolliert werden.

\subsubsection{Analyse von Hefetetraden}

Sporulierte Hefezellen werden mit einem sterilen Zahnstocher von einer Sporulationsplatte abgekratzt und in $50 \mu 11 \mathrm{M}$ Sorbitol $+2.5 \mu 110 \mathrm{mg} / \mathrm{ml}$ Zymolyase in $1 \mathrm{M}$ Sorbitol resuspendiert. Es folgt eine Inkubation für $7 \mathrm{~min}$ bei $30^{\circ} \mathrm{C}$ im Wasserbad, wodurch die 
Ascuswand partiell abgebaut wurde. Nun werden $25 \mu \mathrm{l}$ herauspipettiert, mit $200 \mu 11 \mathrm{M}$ Sorbitol versetzt und auf Eis aufgehoben. Die restlichen $25 \mu \mathrm{l}$ werden für weitere $7 \mathrm{~min}$ bei $30^{\circ} \mathrm{C}$ inkubiert. Danach werden sie ebenfalls mit $200 \mu 11$ M Sorbitol versetzt und auf Eis überführt. Schließlich werden $10 \mu \mathrm{l}$ jeder Lösung auf die Hälfte der Mittellinie einer YEPD-Platte ausgestrichen.

Unter einem Lichtmikroskop konnten nun die 4 Meiosporen eines Ascus mit der feinen Glasspitze eines Mikromanipulators isoliert werden und einzeln in einer Linie auf der YEPD-Platte abgelegt werden. Die YEPD-Platte wurde daraufhin bei $30^{\circ} \mathrm{C}$ (bzw. $24^{\circ} \mathrm{C}$ für temperatursensitive Sporen) inkubiert. Nachdem die Sporen zu Zellkolonien herangewachsen waren, konnte der Genotyp der jeweiligen vier zusammengehörenden Meioseprodukte bestimmt werden, indem diese z.B. auf Selektionsplatten ausgestrichen wurden um die Verteilung der Auxotrophiegene zu analysieren, indem der Paarungstyp bestimmt wurde, oder indem das Wachstum auf YEPD-Platten bei unterschiedlichen Temperaturen überprüft wurde, um temperatursensitive Mutanten zu identifizieren.

\subsubsection{Bestimmung des Paarungstyps durch den „Halo“-Test}

Die zu untersuchenden Stämme, sowie a- und $\alpha$-Kontrollstämme [z.B. die WT-Stämme SEY6210( $\alpha$ ) und SEY6211(a)] wurden als Flecken mit mindestens $2 \mathrm{~cm}$ Abstand auf einer YEPD-Platte ausgestrichen und üN im Brutschrank inkubiert. Die a- und $\alpha$ Testerstämme $[\mathrm{RC} 828(\mathbf{a})$ bzw. $\operatorname{sst}(\alpha)]$ wurden üN in YEPD-Flüssigmedium bis zu einer $\mathrm{OD}_{600}$ von 0.1 - 0.5 wachsen gelassen. Die Zellen wurden daraufhin mit YEPD-Medium auf $0.01 \mathrm{OD} / \mathrm{ml}$ verdünnt. $1.5 \%$ iger steriler Agar wurde in der Mikrowelle aufgeschmolzen und im Wasserbad auf $55^{\circ} \mathrm{C}$ temperiert. $1.5 \mathrm{ml}$ Agar wurden daraufhin mit 1.5 ml verdünnten Testerstämmen sanft gevortext und auf eine YEPD-Platte ausgegossen. Nach ca. 20 min konnte die Platte mit den zu testenden Stämmen auf die Platten mit den a- und $\alpha$-Testerstämmen überstempelt werden. Die Platten wurden daraufhin für $1-2$ Tage bei $30{ }^{\circ} \mathrm{C}$ inkubiert bis die Testerstämme einen Zellrasen ausgebildet haben. Das Wachstum des Testerstamms wird in der Nähe des zu untersuchenden Stammes gehemmt, falls beide einen unterschiedlichen Paarungstyp haben. Hierdurch entsteht ein klarer Halo im Rasen des Testerstamms. 


\subsubsection{Identifizierung PEP4-defizienter Stämme durch den APNE-Test}

(Wolf and Fink, 1975)

Der APNE-Test ist ein schnelles und einfaches Verfahren um Stämme auf das Vorhandensein oder den Verlust des PEP4-Genes, welches für die vakuoläre Proteinase A codiert, zu untersuchen.

Prozedur:

Die zu untersuchenden Stämme sowie ein PEP4-positiver (WT) bzw. ein PEP4defizienter Kontrollstamm werden in Sektoren auf einer YEPD-Platte ausgestrichen und üN im Brutschrank bei $30^{\circ} \mathrm{C}$ inkubiert. Am nächsten Tag wird der APNE-Mix hergestellt:

für $25 \mathrm{ml}$ APNE-Mix:

$\begin{array}{rl}0.175 \mathrm{~g} & \text { Agar } \\ 17.5 \mathrm{ml} & \mathrm{ddH}_{2} \mathrm{O} \\ 5.0 \mathrm{ml} & 1 \mathrm{M} \text { Tris-HCl, } \mathrm{pH} 7.4\end{array}$

werden in einem $50 \mathrm{ml}$ Falcon-Gefäß in der Mikrowelle durch Erhitzen gelöst und danach im Wasserbad auf $55^{\circ} \mathrm{C}$ temperiert. Nun werden $2.5 \mathrm{ml}$ frisch hergestellte APNE-Lösung ( $2 \mathrm{mg} / \mathrm{ml}$ in DMF) und $20 \mathrm{mg}$ Fast Garnet GBC Salt hinzugegeben und gemischt. Es werden nun ca. $6 \mathrm{ml}$ des APNE-Mixes auf die YEPD-Platte mit den zu testenden Stämmen gegossen und ca. 5 min gewartet bis sich der APNE-Mix verfestigt hat. Anschließend kann aufgrund der unterschiedlichen Färbung der Hefestämme eine PEP4Defizienz ermittelt werden, da diese Stämme weiß bleiben, während PEP4-positive Stämme (WT) rot werden.

$\mathrm{Da}$ der APNE-Test teilweise nicht ganz eindeutige Ergebnisse liefert, oder die zu testenden Stämme aufgrund einer Mutation im AMP-Biosyntheseweg (ade-Mutanten) das Zwischenprodukt AIR (p-Ribosylaminoimidazol) akkumulieren, welches unter aeroben Bedingungen zu einem roten Pigment oxidiert wird, und die Stämme daher von sich aus rot sind, kann in solchen Fällen eine PEP4-Defizienz auch über das Fehlen der maturen CPY-Form nachgewiesen werden. Proteinase A wird nämlich in der Vakuole zur Prozessierung der CPY-Proform p2CPY in die mature Form mCPY benötigt.

Hierzu werden Proteinextrakte der zu untersuchenden Hefestämme hergestellt und die Proteine danach durch SDS-PAGE und Immunoblot mit anti-CPY-Antikörper analysiert. 


\subsubsection{Bestimmung des Wachstums von Hefezellen auf Agarplatten}

Zur Untersuchung des Wachstumsverhaltens wurden die Hefestämme zunächst in Flüssigkultur in YEPD-Vollmedium oder SD-Minimalmedium bei $24^{\circ} \mathrm{C}$ angezüchtet. Anschließend wurden die Kulturen mit sterilem Wasser auf eine $\mathrm{OD}_{600}$ von $0.01 / \mathrm{ml}$ bzw. 0.05/ml verdünnt und nun jeweils $10 \mu \mathrm{l}$ im Raster auf eine auf die jeweilige Temperatur $\left(24^{\circ} \mathrm{C}, 30^{\circ} \mathrm{C}, 37^{\circ} \mathrm{C}\right)$ vorgewärmte YEPD-Platte aufgetropft. Die Platten wurden daraufhin für 1 - 2 Tage bei der jeweiligen Temperatur inkubiert und das Wachstumsverhalten in regelmäßigen Abständen durch Fotografie der Platten dokumentiert.

\subsubsection{Biochemische Methoden}

\subsubsection{Herstellung von Proteinextrakten aus Hefezellen}

$10 \mathrm{ml}$ Hefekultur wurden $\mathrm{u} N$ bis zu einer $\mathrm{OD}_{600}$ von maximal 1.0 wachsen gelassen. 1 10 OD Zellen werden für 3 min bei 3000 UpM zentrifugiert. Der Überstand wird verworfen und das Pellet in $1 \mathrm{ml}$ Wasser resuspendiert und in ein Eppendorf-Reaktionsgefäß transferiert. Die Zellen werden nun für $30 \mathrm{sec}$ bei $6500 \mathrm{UpM}$ zentrifugiert. Der Überstand wird abgesaugt und das Hefepellet mit ca. $50 \mu$ säuregewaschener Glasperlen versetzt. Eine entsprechende Menge Thorner-Puffer $+5 \% \beta$-Mercaptoethanol wird im Heizblock auf $70^{\circ} \mathrm{C}$ temperiert und direkt vor dem Gebrauch mit 1/100 einer $100 \mathrm{x}$ Proteaseinhibitorlösung versetzt. Pro 1 OD Zellen werden nun $40 \mu 1$ dieses Gemisches hinzugegeben, gevortext und für $10 \mathrm{~min}$ bei $70^{\circ} \mathrm{C}$ inkubiert. Danach werden die Ansätze für $2 \mathrm{~min}$ im automatischen Vortex geschüttelt. Es folgt eine Zentrifugation für $5 \mathrm{~min}$ mit $13000 \mathrm{UpM}$ bei $4^{\circ} \mathrm{C}$. Die Überstände werden abgenommen und bis zum Auftragen auf das SDS-Gel eingefroren.

Durch diese Methode ist es möglich, von verschieden dicht gewachsenen Kulturen gleiche ODs in einem SDS-PAGE auftrennen zu können. Aufgrund des im ThornerPuffer vorhandenen Harnstoffs ist es jedoch nicht möglich, eine Proteinkonzentrationsbestimmung nach Bradford anzuschließen.

\section{Auftrag auf das SDS-Gel:}

$10 \mu 1$ Proteinextrakt mit $10 \mu \mathrm{l} 2 \mathrm{x}$ Probenpuffer mischen, für 5 min bei $95^{\circ} \mathrm{C}$ erhitzen, danach $15 \mu \mathrm{l}$ auf das SDS-Gel auftragen. 
Thorner-Puffer:

$\begin{aligned} 8 \mathrm{M} & \text { Harnstoff } \\ 5 \% & \text { SDS } \\ 50 \mathrm{mM} & \text { Tris-HCl, pH } 6.8\end{aligned}$

\subsubsection{Kar2p/BiP-Sekretionsexperiment}

(nach Boehm et al., 1994)

Diese Methode wurde dazu verwendet, um festzustellen, ob die use1-Mutanten Kar2p/BiP ins Medium sezernieren, wie dies bei Mutanten der Fall ist, die einen Defekt im retrograden Transport vom cis-Golgi zum ER besitzen.

Die zu untersuchenden Hefestämme wurden in dem entsprechenden Selektionsmedium bis zu einer Dichte von 0.3 bis $0.5 \mathrm{OD} / \mathrm{ml}$ wachsen gelassen, danach $15 \mathrm{ml}$ für $5 \mathrm{~min}$ mit 3000 UpM zentrifugiert und das Pellet in $15 \mathrm{ml}$ frischem YEPD-Medium resuspendiert. Danach wurden die Stämme für $2 \mathrm{~h}$ bei der entsprechenden Temperatur inkubiert. Die Dichte der Kulturen wurde nun erneut bestimmt und die Zellen daraufhin durch 5 min Zentrifugation bei $3000 \mathrm{UpM}$ vom Medium getrennt. Aus den Zellpellets wurden Proteinextrakte wie in Kap. 2.2.4.1 beschrieben hergestellt, um den Gehalt an nichtsezerniertem Kar2p/BiP zu determinieren. Der Überstand (Medium) wurde in auf Eis gekühlte Corex $^{\circledR}$-Röhrchen überführt und mit 1/10 Volumen $100 \%$ (w/v) TCA (Endkonz.: $10 \%$ ) versetzt, gut gemischt und anschließend für 10 min auf Eis inkubiert, wodurch die ins Medium sezernierten Proteine präzipitierten. Es folgte eine Zentrifugation für 15 min mit $10000 \mathrm{UpM}$ bei $4^{\circ} \mathrm{C}$ im JA20-Rotor mit Gummiadaptoren. Das Pellet wurde mit $1 \mathrm{ml}-20^{\circ} \mathrm{C}$ kaltem Aceton von der Corex ${ }^{\circledR}$-Röhrchenwand gelöst und in ein Eppendorf-Reaktionsgefäß überführt. Es folgte eine Ultraschallbehandlung für $20 \mathrm{sec}$ und eine anschließende Zentrifugation für $5 \mathrm{~min}$ mit $13000 \mathrm{UpM}$ bei $4^{\circ} \mathrm{C}$. Das Pellet wurde daraufhin nochmals mit $1 \mathrm{ml}-20^{\circ} \mathrm{C}$ kaltem Aceton gewaschen und sonifiziert um die Säure zu entfernen und danach bei RT im offenen EppendorfReaktionsgefäß getrocknet. Anschließend wurde das Pellet in $8.3 \mu 12$ x Probenpuffer pro 1 OD Zellen resuspendiert und die im Pellet verbliebene TCA durch Zugabe von $5 \mu 11 \mathrm{M}$ Tris, $\mathrm{pH} 9.5$ pro $100 \mu \mathrm{l}$ Probenpuffer neutralisiert. Um das Pellet vollständig zu resuspendieren folgte eine zusätzliche Ultraschallbehandlung für $20 \mathrm{sec}$. 


\section{$\underline{\text { Auftrag auf das SDS-Gel: }}$}

Von den Proteinextrakten der Zellpellets wurde eine 1:2-Verdünnung hergestellt, indem $10 \mu$ Proteinextrakt mit $10 \mu$ Thorner-Puffer und $20 \mu 1$ 2x Stop-Puffer versetzt wurden. Diese Ansätze wurden nun zusammen mit den TCA-präzipitierten Proteinen des Mediums für 5 min bei $95^{\circ} \mathrm{C}$ inkubiert und anschließend je $30 \mu \mathrm{l}$ (entspricht $0.19 \mathrm{OD}_{600}$ der Pellet-Fraktionen bzw. $3.6 \mathrm{OD}_{600}$ der externen Fraktionen der sezernierten Proteine) in einem $8 \%$ igen SDS-PAGE und anschließendem Immunoblot mit anti-Kar2p-Antikörper analysiert.

\subsubsection{Bestimmung der Proteinkonzentration}

(Bradford, 1976)

Die Messung der Proteinkonzentration nach Bradford beruht auf der Eigenschaft des Coomassie-G-250-Farbstoffes, sein Absorptionsmaximum durch Bindung an Proteine von $465 \mathrm{~nm}$ auf $595 \mathrm{~nm} \mathrm{zu}$ verschieben, wobei die Erhöhung der Absorption direkt proportional zum Proteingehalt der Lösung ist. Die quantitative Bestimmung erfolgte mit der Färbelösung und nach der Vorschrift des „BioRad Protein Assay“ (Richmond, USA) spektrophotometrisch bei $595 \mathrm{~nm}$. Eichkurven wurden unter Verwendung definierter Konzentrationen von Rinderserumalbumin (BSA) hergestellt.

\subsubsection{Trennung von Proteinen durch SDS-Polyacrylamid-Gelelektrophorese} (Laemmli, 1970)

Die $\underline{\text { SDS}}$ - Polya Molekulargewicht aufzutrennen. Die elektrophoretische Beweglichkeit von Proteinen in einer Polyacrylamid-Gelmatrix ist von ihrer Größe und Form abhängig und wird durch die Nettoladung des Proteins bestimmt. Das anionische Detergenz Natriumlaurylsulfat (englisch: sodium dodecyl sulfate, SDS) wird von Proteinen quantitativ gebunden und bewirkt in Gegenwart von Thiolreagenzien wie $\beta$-Mercaptoethanol oder Dithiothreitol (DTT) zumeist eine vollständige Denaturierung der Proteine. Die Sulfatgruppen des SDS verleihen den Proteinen eine stark negative Gesamtladung, die der Masse des jeweiligen komplexierten Proteins proportional ist. Die durch das gebunden SDS erworbene negative Ladung ist meist wesentlich größer als die ursprüngliche Ladung des nativen Proteins, die damit vernachlässigbar wird. Die Wanderungsgeschwindigkeit der Proteine wird somit hauptsächlich durch den Molekularsiebeffekt der Gelmatrix und die angelegte Strom- 
stärke bestimmt. Generell lässt sich sagen, dass für die Trennung von Proteinen im Bereich von $200 \mathrm{kDa}$ bis $10 \mathrm{kDa}$ Gelkonzentrationen zwischen $8 \%$ und $12.5 \%$ Acrylamid eingesetzt werden.

\begin{tabular}{|c|c|}
\hline Acrylamid-Konzentration & Molekulargewicht \\
\hline $8 \%$ & $200-40 \mathrm{kDa}$ \\
\hline $11 \%$ & $100-20 \mathrm{kDa}$ \\
\hline $12.5 \%$ & $40-10 \mathrm{kDa}$ \\
\hline
\end{tabular}

Die SDS-PAGE wurde als diskontinuierliche Gelelektrophorese mit Trenn- und Sammelgel mit unterschiedlicher Konzentrations- und Pufferzusammensetzung in einem System mit vertikal ausgerichteten Glasplatten (kleine Gele: 16 x 16 cm; große Gele: 18 x 17.5; $1 \mathrm{~mm}$ Abstandhalter) durchgeführt. Die Kanten der Glasplatten wurden vor dem Eingießen des Gels mit 1 \% Agarose in Wasser abgedichtet. Das frisch gemischte Trenngel wurde bis ca. $3 \mathrm{~cm}$ unterhalb des Glasplattenrandes zwischen die beiden Glasplatten gegossen und mit Wasser überschichtet, um eine glatte Oberfläche zu erhalten. Nach 30 min Polymerisation wurde das überschichtete Wasser abgesaugt, das Sammelgel eingegossen und sofort der Probenkamm eingesetzt. Nach 15 min Polymerisation wurde der Probenkamm sowie der untere Abstandhalter entfernt, die Probentaschen mit Wasser gespült und die Glasplatten mit dem Gel in einer Elektrophoresekammer fixiert. Der obere und untere Gelrand wurden mit 1x Laufpuffer überschichtet. Die Proteinproben wurden 1: 1 mit 2x Probenpuffer (bzw. 2: 1 mit 3x Probenpuffer) gemischt und zur vollständigen Denaturierung für $5 \min$ bei $95^{\circ} \mathrm{C} \mathrm{im}$ Heizblock inkubiert. Nach Anzentrifugieren wurden die Proben in die mit 1x Laufpuffer überschichteten Taschen aufgetragen. Als Molekulargewichtsmarker wurden $5 \mu 1$ Calbiochem Rainbow-Marker aufgetragen. In die leeren Probentaschen wurden $15 \mu \mathrm{l}$ 1x Probenpuffer gegeben. Die Elektrophorese erfolgte für kleine Gele mit $30 \mathrm{~mA}$ für ca. $2 \mathrm{~h}$ bzw. für große Gele bei $13 \mathrm{~mA}$ für ca. 5 - 6 h unter Kühlung durch einen Ventilator. Die Elektrophorese wurde beendet, sobald der im Probenpuffer enthaltene Farbmarker Bromphenolblau die untere Kante des Gels erreicht hatte. Das Gel wurde daraufhin entweder einer Coomassie-Färbung oder einem Western-Blot unterzogen. Radioaktive Gele von „Pulse-Chase“-Experimenten (siehe Kap. 2.2.4.10) wurden nach Fixierung und 
Trocknung entweder auf einer „Phospho-Imaging-Plate“ oder einem Röntgenfilm exponiert (siehe Kap. 2.2.4.6).

$\underline{3 x}$ Probenpuffer $(45 \mathrm{ml})$ :

$\begin{array}{rl}4.5 \mathrm{~g} & \text { SDS } \\ 18.8 \mathrm{ml} & 1 \mathrm{M} \text { Tris-HCl, pH } 6.8 \\ 15 \mathrm{~g} & \text { Saccharose }\end{array}$

1 Spatelspitze Bromphenolblau

$26.2 \mathrm{ml} \quad \mathrm{ddH}_{2} \mathrm{O}$

Vor dem Gebrauch werden pro $900 \mu \mathrm{l} 3 \mathrm{x}$ Probenpuffer $100 \mu \mathrm{l} \beta$-Mercaptoethanol hinzugegeben.

10x Laufpuffer:

$30.2 \mathrm{~g} / \mathrm{L} \quad$ Tris

$144 \mathrm{~g} / \mathrm{L} \quad$ Glycin

$10 \mathrm{~g} / \mathrm{L} \quad$ SDS

Acrylamidlösung:

$30 \%(w / v)$ Acrylamid

$0.8 \%(\mathrm{w} / \mathrm{v})$ Bisacrylamid

Ammoniumpersulfat (APS):

$10 \%(\mathrm{w} / \mathrm{v})$ Ammoniumpersulfat in $\mathrm{ddH}_{2} \mathrm{O}$

\begin{tabular}{|l|c|c|c|}
\hline \multicolumn{4}{|c|}{ Trenngel (15 ml) } \\
\hline Acrylamidkonzentration & $8 \%$ & $11 \%$ & $12.5 \%$ \\
\hline $1.5 \mathrm{M}$ Tris-HCl, $\mathrm{pH} 8.8$ & & $3.75 \mathrm{ml}$ \\
\hline Acrylamidlösung & $4.0 \mathrm{ml}$ & $5.5 \mathrm{ml}$ & $6.25 \mathrm{ml}$ \\
\hline $\mathrm{ddH}_{2} \mathrm{O}$ & $6.9 \mathrm{ml}$ & $5.45 \mathrm{ml}$ & $4.65 \mathrm{ml}$ \\
\hline $10 \%(\mathrm{w} / \mathrm{v}) \mathrm{SDS}$ & \multicolumn{4}{|c|}{$150 \mu \mathrm{l}$} \\
\hline $10 \%(\mathrm{w} / \mathrm{v})$ APS & $150 \mu \mathrm{l}$ \\
\hline TEMED & \multicolumn{4}{|c|}{$7.5 \mu \mathrm{l}$} \\
\hline
\end{tabular}




\begin{tabular}{|l|c|}
\hline \multicolumn{2}{|c|}{ Sammelgel (7.5 ml) } \\
\hline Acrylamidkonzentration & $5.6 \%$ \\
\hline $1 \mathrm{M}$ Tris-HCl, pH 6.8 & $936 \mu \mathrm{l}$ \\
\hline Acrylamidlösung & $1.39 \mathrm{ml}$ \\
\hline $\mathrm{ddH}_{2} \mathrm{O}$ & $4.95 \mathrm{ml}$ \\
\hline $10 \%(\mathrm{w} / \mathrm{v}) \mathrm{SDS}$ & $75 \mu \mathrm{l}$ \\
\hline $10 \%(\mathrm{w} / \mathrm{v})$ APS & $150 \mu \mathrm{l}$ \\
\hline TEMED & $7.5 \mu \mathrm{l}$ \\
\hline
\end{tabular}

\subsubsection{Färbung mit Coomassie-Blau}

Mit der Coomassie-Färbung können in Polyacrylamidgelen aufgetrennte Proteine mit einer Nachweisgrenze von $0.1 \mu \mathrm{g}$ detektiert werden. Die Gele wurden dazu für $1 \mathrm{~h}$ in der Coomassie-Färbelösung geschwenkt. Danach wurden sie für mehrere Stunden in Entfärber inkubiert und anschließend $\ddot{\mathrm{N}}$ in $\mathrm{ddH}_{2} \mathrm{O}$ äquilibriert. Die Gele wurden daraufhin für ca. $1.5 \mathrm{~h}$ zwischen Cellophan-Folie im Geltrockner getrocknet

Coomassie-Färbelösung:

$0.1 \%(\mathrm{w} / \mathrm{v}) \quad$ Serva blue R (Coomassie brilliant blue R-250)

$25 \%(\mathrm{v} / \mathrm{v}) \quad$ Isopropanol

$10 \%(\mathrm{v} / \mathrm{v}) \quad$ Essigsäure

$65 \%(\mathrm{v} / \mathrm{v}) \quad \mathrm{ddH}_{2} \mathrm{O}$

\section{Entfärber:}

$\begin{array}{ll}50 \%(\mathrm{v} / \mathrm{v}) & \text { Methanol } \\ 10 \%(\mathrm{v} / \mathrm{v}) & \text { Essigsäure } \\ 40 \%(\mathrm{v} / \mathrm{v}) & \mathrm{ddH}_{2} \mathrm{O}\end{array}$

\subsubsection{Nachweis radioaktiv markierter Proteine}

Zur Visualisierung radioaktiv markierter Proteine wurden die Polyacrylamidgele für 30 min in Entfärber fixiert und anschließend einige min in $\mathrm{ddH}_{2} \mathrm{O}$ äquilibriert. Danach wurden die Gele für ca. $1.5 \mathrm{~h}$ zwischen Cellophan-Folie im Geltrockner getrocknet. Zur Quantifizierung der inkorporierten radioaktiven Markierung wurde das Gel schließlich auf einer „Phospho-Imaging-Plate“ (Fuji) für 1-2 Tage bei RT exponiert und mit dem Programm „Image Reader“ (Juji-Film, Vers. 1.4 E) in einem „Phosphor-Imager“ (BAS 2000) analysiert. 


\subsubsection{Transfer von Proteinen auf Nitrozellulose-Membranen („Western-Blot"}

(Towbin et al., 1979)

Für einen nachfolgenden immunologischen Nachweis wurden die Proteine nach der elektrophoretischen Auftrennung im SDS-PAGE im sogenannten „semi-dry“-Verfahren auf eine Nitrozellulose-Membran (Sartorius, $0.2 \mu \mathrm{m}$ ) transferiert. Hierzu wurde die Nitrozellulose-Membran und 6 Filterpapierstücke (Whatman, $3 \mathrm{~mm}$ ) entsprechend der Gelgröße zurechtgeschnitten und zusammen mit dem ungefärbten Gel im Semi-DryBlotpuffer getränkt. Der Blot wurde nun luftblasenfrei in einer speziellen Blotkammer wie folgt aufgebaut:

\section{Kathodenseite}

$3 \times$ Filterpapier

Gel

Nitrozellulose-Membran

3 x Filterpapier

\section{Anodenseite}

Auf die Blotvorrichtung wurde ein Gewicht von ca. 750 g gestellt. Der Transfer erfolgte für $1 \mathrm{~h}$ bei einer konstanten Stromstärke von $1.0 \mathrm{~mA} / \mathrm{cm}^{2}$. Um den Transfer $\mathrm{zu}$ kontrollieren wurden die Proteine anschließend ca. 5 - 10 min durch Ponceau-S $(0.2 \%$ in $3 \%$ TCA, Serva) reversibel angefärbt und durch Entfärben der Membran mit Wasser sichtbar gemacht. Die Membran wurde nun zurechtgeschnitten, zum vollständigen Entfärben mit Wasser gewaschen und bis zur Immunodetektion (siehe Kap. 2.2.4.8) im Dunkeln gelagert.

Semi-Dry-Blotpuffer:

$5.80 \mathrm{~g} / \mathrm{L} \quad$ Tris

$2.92 \mathrm{~g} / \mathrm{L} \quad$ Glycin

$3.7 \mathrm{ml} / \mathrm{L} \quad 10 \%(\mathrm{w} / \mathrm{v}) \mathrm{SDS}$

$x \quad \mathrm{ml} / \mathrm{L} \quad \mathrm{ddH}_{2} \mathrm{O}$

$\mathrm{pH} \quad 9.2(\mathrm{NaOH})$

$200 \mathrm{ml} / \mathrm{L} \quad$ Methanol (zum Schluss hinzugeben) 


\subsubsection{Immunologischer Nachweis von Proteinen auf Nitrozellulose-Membranen (Immunoblot-Analyse)}

Auf Nitrozellulose-Membranen immobilisierte Proteine (Antigene) können mit sehr hoher Sensitivität mit spezifischen Primärantikörpern und gegen diese gerichteten Sekundärantikörpern detektiert werden. Die Primärantikörper binden mit ihren $\mathrm{F}_{\mathrm{ab}}$-Regionen an die Proteine, die Sekundärantikörper binden daraufhin an die $\mathrm{F}_{\mathrm{c}}$-Region des Pimärantikörpers. Durch das an den Sekundärantikörper gekoppelte Enzym MeerrettichPeroxidase (englisch: horseradish-peroxidase, HRP) kann der Sekundärantikörper durch das Reaktionssystem zur „Enhanced Chemiluminescence“ (ECL-System, Amersham) nachgewiesen werden. Unter alkalischen Bedingungen katalysiert die Peroxidase die Oxidation von Luminol durch $\mathrm{H}_{2} \mathrm{O}_{2}$, wodurch Luminol zur Lichtemission angeregt wird. Verstärkt wird diese Reaktion durch Phenole wie p-Cumarsäure. Die Halbwertszeit der Reaktion beträgt ca. $1 \mathrm{~h}$.

\section{PBS-T:}

$0.1 \%(\mathrm{w} / \mathrm{v})$ Tween $-20^{\circledR}$ in PBS

Blotto:

$2 \%(\mathrm{w} / \mathrm{v})$ Milchpulver in PBS-T

\section{ECL-Lösung:}

SuperSignal $^{\circledR}$ West Pico Chemiluminescent Substrate (PIERCE), bestehend aus StablePeroxide-Lösung und Luminol/Enhancer-Lösung

$\rightarrow$ vor dem Gebrauch gleiche Mengen beider Lösungen zusammenmischen

\section{Prozedur:}

Zur Absättigung von unspezifischen Bindungsstellen wurde die Nitrozellulose-Membran für 30 min in Blotto auf der Wippe inkubiert. Anschließend wurde die Membran mit dem in Blotto verdünnten Primärantikörper (polyklonal aus Kaninchen bzw. monoklonal aus Maus) in Plastikfolie eingeschweißt und für $1-2 \mathrm{~h}$ auf der Wippe inkubiert (bei erwartetem schwachen Signal kann die Inkubation mit dem Primärantikörper auch üN bei $4^{\circ} \mathrm{C}$ auf der Wippe durchgeführt werden). Nachdem die Membran 3 x mindestens 5 min mit PBS-T gewaschen wurde, folgte die Inkubation mit dem in PBS-T verdünnten 
Sekundärantikörper (Ziege-anti-Kaninchen-HRP bzw. Ziege-anti-Maus-HRP), ebenfalls für $1-2 \mathrm{~h}$ auf der Wippe. Die Membran wurde nun $5 \mathrm{x}$ mindestens 5 min mit PBS-T gewaschen und anschließend in 1x PBS transferiert. Die Membran wurde anschließend mit einem 1:1-Gemisch der beiden ECL-Lösungen für ca. 5 min inkubiert. Zur Detektion und Quantifizierung wurde eine CCD-Kamera der Firma Fuji mit der Software AIDAImage-Reader und AIDA-Image-Analyzer verwendet.

\begin{tabular}{|l|l|l|l|l|l|}
\hline \multicolumn{5}{|c|}{ Primärantikörper } \\
\hline Protein & MG & Reinigung & Herkunft & Verdünnung & Referenz \\
\hline Vti1p & $29 \mathrm{kDa}$ & Serum & Kaninchen & $1: 2000$ & $\begin{array}{l}\text { G. Fischer von } \\
\text { Mollard }\end{array}$ \\
\hline Vph1p & $\begin{array}{l}100 \\
\mathrm{kDa}\end{array}$ & $\begin{array}{l}\text { Gewebekultur- } \\
\text { Überstand }\end{array}$ & Maus & $1: 100$ & T. Stevens \\
\hline ALP & $72 \mathrm{kDa}$ & $\begin{array}{l}\text { Gewebekultur- } \\
\text { Überstand }\end{array}$ & Maus & $1: 50$ & T. Stevens \\
\hline PGK & $45 \mathrm{kDa}$ & $\begin{array}{l}\text { Gewebekultur- } \\
\text { Überstand }\end{array}$ & Maus & $1: 200$ & T. Stevens \\
\hline Sec22p & $25 \mathrm{kDa}$ & Serum & Kaninchen & $1: 1000$ & H.D. Schmitt \\
\hline Bet1p & $16 \mathrm{kDa}$ & Serum & Kaninchen & $1: 1000$ & H.D. Schmitt \\
\hline Bos1p & $28 \mathrm{kDa}$ & Serum & Kaninchen & $1: 1000$ & H.D. Schmitt \\
\hline Use1p & $35 \mathrm{kDa}$ & Serum & Kaninchen & $1: 1000$ & diese Arbeit \\
\hline BiP/Kar2p & $74 \mathrm{kDa}$ & Serum & Kaninchen & $1: 1000$ & H.D. Schmitt \\
\hline HA & n.d. & $\begin{array}{l}\text { Gewebekultur- } \\
\text { Überstand }\end{array}$ & Maus & $1: 100$ & $\begin{array}{l}\text { BabCo, Richmond } \\
\text { (USA) }\end{array}$ \\
\hline $\begin{array}{l}\text { c-Myc- } \\
\text { Epitop } \\
\text { (9E10) }\end{array}$ & n.d. & $\begin{array}{l}\text { Aszites, } \\
\text { affinitätsgereinigt }\end{array}$ & Maus & $1: 2000$ & (Evan et al., 1985) \\
\hline
\end{tabular}

\begin{tabular}{|l|l|l|}
\hline Sekundärantikörper & Verdünnung & Referenz \\
\hline $\begin{array}{l}\text { Ziege-anti-Maus-HRP } \\
\text { IgG (,whole molecule })\end{array}$ & $\begin{array}{l}1: 10000 \\
(1: 5000 \text { bei anti-HA- } \\
\text { Primärantikörper) }\end{array}$ & Sigma, München \\
\hline $\begin{array}{l}\text { Ziege-anti-Kaninchen-HRP } \\
\text { IgG (,whole molecule“) }\end{array}$ & $1: 10000$ & Sigma, München \\
\hline
\end{tabular}

\subsubsection{Proteolytische Prozessierung von $\alpha$-Faktor-erweitertem Sec22p (Sec22 $\alpha-$ Western)}

(nach Boehm et al., 1997 und Ballensiefen et al., 1998)

Eine wichtige Voraussetzung für dieses Experiment ist, dass man nur Stämme mit Paarungstyp $\alpha$ verwendet, da diesen Zellen die im ER lokalisierte Protease Barlp fehlt. 
MATa-Zellen, welche Barlp besitzen, zeigen nämlich eine sehr schnelle Prozessierung von Sec22- $\alpha$ im ER (Ballensiefen and Schmitt, 1997).

PEP4-positive und PEP4-defiziente Hefestämme mit Paarungstyp $\alpha$, welche ein Sec22 $\alpha$ Plasmid enthielten, wurden in $45 \mathrm{ml}$ SD-Medium üN bei $24^{\circ} \mathrm{C}$ bis zur frühen logarithmischen Phase wachsen gelassen. $15 \mathrm{ml}$ jedes Stammes wurden daraufhin für 30 min entweder bei $24^{\circ} \mathrm{C}, 30^{\circ} \mathrm{C}$ oder $37^{\circ} \mathrm{C}$ im Wasserbad inkubiert und bis zu einer $\mathrm{OD}_{600}$ zwischen 0.5 und 1.0/ml wachsen gelassen. $1-10 \mathrm{OD}_{600}$ wurden durch 3 min Zentrifugation bei $3000 \mathrm{UpM}$ geerntet und anschließend Proteinextrakte hergestellt (siehe Kap. 2.2.4.1). $10 \mu$ Proteinextrakt (0.25 OD) wurden mit $10 \mu 1$ 2x Probenpuffer versetzt, für $5 \mathrm{~min}$ bei $95^{\circ} \mathrm{C}$ erhitzt und anschließend $15 \mu$ (entsprechen $0.19 \mathrm{OD}$ ) in einem langen 12.5 \%igen SDS-PAGE elektrophoretisch aufgetrennt, wobei die Lauffront herauslaufen gelassen wurde. Es folgte ein Western-Blot (siehe Kap. 2.2.4.7) und Antikörperinkubation mit einem anti-c-Myc-Antikörper ( siehe Kap. 2.2.4.8).

\subsubsection{Immunpräzipitation radioaktiv markierter Proteinen aus Zellextrakten (,Pulse-Chase“"Immunpräzipitation)}

Um den Transport und die spezifische Prozessierung eines Proteins innerhalb einer Zelle zu verfolgen, wurden „Pulse-Chase“-Experimente durchgeführt. Hierbei wurden Hefezellen, die in einem Methionin- und Cysteinfreien Medium wuchsen, während eines definierten Zeitraumes mit radioaktivem $\left[{ }^{35} \mathrm{~S}\right]$-Methionin und $\left[{ }^{35} \mathrm{~S}\right]$-Cystein markiert (,Pulse“). Der Einbau der radioaktiv markierten Aminosäuren in neusynthetisierte Proteine wurde durch Zugabe einer hohen Konzentration unmarkierter Aminosäuren in den Reaktionsansatz beendet, und die Eigenschaften des radioaktiv markierten Proteinpools nach unterschiedlichen Zeitpunkten untersucht („Chase“). Um den Transport bzw. die Prozessierung eines spezifischen Proteins verfolgen zu können, wurde es durch Immunpräzipitation (IP) isoliert. „Pulse-Chase“-Immunpräzipitationen wurden für die Proteine Carboxypeptidase Y (CPY), Alkalische Phosphatase (ALP), Aminopeptidase I (API) sowie Invertase durchgeführt. Stämme in denen der Transport und die Prozessierung von Invertase verfolgt werden soll und denen das endogene Invertasegen SUC2 fehlt (suc2- $\Delta 9$ ), müssen zuvor zusätzlich noch mit dem Plasmid pFvM104 transformiert werden. 


\section{Prozedur:}

Die zu analysierenden Stämme wurden in Minimalmedium (SD-Met-Selektionsmarker) angeimpft und am Abend vor dem Experiment so in $8 \mathrm{ml}$ des entsprechenden Mediums verdünnt, dass die $\mathrm{OD}_{600}$ am nächsten Morgen zwischen 0.1 und 1.1/ml lag. Die Inkubation erfolgte üN bei $24^{\circ} \mathrm{C}$.

Im weiteren Ablauf unterscheiden sich die verschiedenen „Pulse-Chase“-Immunpräzipitationen:

Für die Invertase-IP wurden am nächsten Morgen pro „Chase“-Zeitpunkt je $0.5 \mathrm{OD}_{600}$ in einem 13 ml-Plastikröhrchen für 3 min bei $3000 \mathrm{UpM}$ geerntet und das Pellet

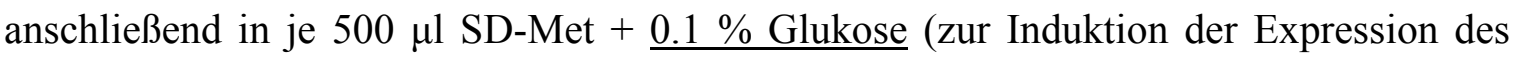
Invertasegenes $S U C 2$ auf dem Plasmid pFvM104) + $50 \mathrm{mM} \mathrm{KPO}_{4}, \mathrm{pH} 5.7+2 \mathrm{mg} / \mathrm{ml}$ BSA resuspendiert. Es folgte eine Vorinkubation für $45 \mathrm{~min}\left(30 \mathrm{~min}\right.$ bei $24^{\circ} \mathrm{C}$, danach genau 15 min Temperatur-Shift auf die jeweilige restriktive Temperatur). Nun wurden je $7 \mu \mathrm{l}$ radioaktiver L- $\left[{ }^{35} \mathrm{~S}\right]$-Label (Gemisch aus $\left[{ }^{35} \mathrm{~S}\right]$-Methionin und $\left[{ }^{35} \mathrm{~S}\right]$-Cystein, 14 $\mu \mathrm{Ci} / \mu \mathrm{l})$ hinzugegeben und die Kulturen für genau $10 \mathrm{~min}$ bei der restriktiven Temperatur im Schüttelwasserbad inkubiert („Pulse“). Danach wurden $50 \mu \mathrm{l}$ des Methionin/CysteinMixes (je $5 \mathrm{mg} / \mathrm{ml}$ ) hinzugegeben und für genau $30 \mathrm{~min}$ im Schüttelwasserbad bei der restriktiven Temperatur inkubiert („Chase“). Der Stoffwechsel der Zellen wurde danach durch Zugabe von je $5 \mu 11 \mathrm{M}$ Natriumazid (Endkonz.: $10 \mathrm{mM}$ ) abgestoppt und die Ansätze in Eppendorfgefäße mit Schraubdeckel überführt. Die Ansätze wurden nun für $20 \mathrm{sec}$ bei $13000 \mathrm{UpM}$ zentrifugiert. Die Überstände, welche sekretierte Proteine enthalten, wurden in ein neues Eppendorfgefäß überführt (E), mit $10 \mu$ l eines $100 x$ Proteaseinhibitor-Mixes versetzt und bis zur weiteren Verarbeitung auf Eis gelagert. Die Pellets wurden nun in je $1 \mathrm{ml}$ Tris-DTT-Azid resuspendiert und für $5 \mathrm{~min}$ bei $30^{\circ} \mathrm{C} \mathrm{im}$ Heizblock inkubiert. Die Ansätze wurden anschließend für $30 \mathrm{sec}$ bei $13000 \mathrm{UpM}$ zentrifugiert und die Überstände verworfen. Daraufhin wurden die Pellets in je $150 \mu 1$ Sphäroplast-Mix mit $250 \mu \mathrm{g} / \mathrm{ml}$ Zymolyase resuspendiert und für $30-45 \min$ bei $30^{\circ} \mathrm{C}$ im Heizblock sphäroplastiert. Es folgte eine Zentrifugation für $30 \mathrm{sec}$ bei $6500 \mathrm{UpM}$. Der Überstand, welcher periplasmatische Proteine enthält, wurde mit dem zuvor gewonnenen $\underline{\text { Überstand (E) der sekretierten Proteine kombiniert und jeweils } 50 \mu 1 \text { PBS }+2 \% \text { SDS }}$ zugesetzt. Die Pellets wurden ebenfalls in $50 \mu \mathrm{PBS}+2 \%$ SDS + Proteaseinhibitoren resuspendiert. Interne und externe Proben wurden nun für 5 min bei $95^{\circ} \mathrm{C}$ im Heizblock 
erhitzt. $\mathrm{Zu}$ den internen Proben wurden nun $200 \mu \mathrm{l}$ 5x Invertase-IP-Puffer $+740 \mu \mathrm{l}$ $\mathrm{ddH}_{2} \mathrm{O}+50 \mu \mathrm{l}$ gewaschenes Pansorbin $+10 \mu \mathrm{l} 100 \mathrm{x}$ Proteaseinhibitor-Mix hinzugefügt.

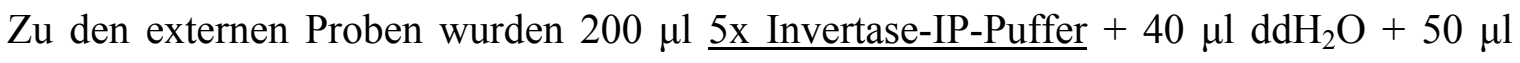
gewaschenes Pansorbin $+10 \mu \mathrm{l}$ 100x Proteaseinhibitor-Mix gegeben. Beide Ansätze wurden zur Präabsorption für 15 min auf Eis inkubiert. Die Ansätze wurden daraufhin für 5 min bei 13000 UpM zentrifugiert. Von den Überständen der Zellfraktionen wurden nun jeweils $5 \mu \mathrm{l}$ im Flüssig-Szintillationszähler zur Bestimmung der eingebauten Radioaktivität gezählt. Die restlichen Überstände wurden in neue Eppendorf-Gefäße mit Schraubdeckel überführt und mit je $1 \mu$ anti-Invertase-Antiserum versetzt. Es folgte eine Inkubation für $1 \mathrm{~h}$ auf Eis. Die gebildeten Antigen-Antikörper-Komplexe wurden nun durch Zugabe von $50 \mu$ gewaschenem Pansorbin und Inkubation für $\underline{1 \mathrm{~h}}$ auf Eis präzipitiert. Es folgte eine Zentrifugation für $30 \mathrm{sec}$ bei $13000 \mathrm{UpM}$. Die Pellets wurden $\underline{3 \mathrm{x}}$ mit je $1 \mathrm{ml}$ Invertase-Waschpuffer gewaschen (Inkubation für $5 \mathrm{~min}$ auf automatischem Schüttler). Die Pellets wurden daraufhin in $40 \mu \mathrm{l} 2 \mathrm{x}$ Probenpuffer resuspendiert und bis zum Auftragen aus das Gel bei $-20^{\circ} \mathrm{C}$ eingefroren.

Tris-DTT-Azid (frisch ansetzen):

$50 \mathrm{mM} \quad$ Tris, $\mathrm{pH} 9.5$

$10 \mathrm{mM} \quad$ DTT

$10 \mathrm{mM} \quad$ Natriumazid

Sphäroplast-Mix (frisch ansetzen):

$\begin{aligned} 1.2 \mathrm{M} & \text { Sorbitol } \\ 50 \mathrm{mM} & \text { KPO4, pH 7.3 } \\ 10 \mathrm{mM} & \text { Natriumazid }\end{aligned}$

5x Invertase-IP-Puffer:

$5 \times \quad$ PBS

$5 \% \quad$ Triton X-100

$1 \mathrm{mg} / \mathrm{ml} \quad$ BSA 
Waschen von Pansorbin:

Pansorbinzellen wurden 3 x mit $20 \mathrm{mM}$ Tris, pH $7.5+100 \mathrm{mM} \mathrm{NaCl}$ gewaschen (Zentrifugation für $30 \mathrm{sec}$ bei $11000 \mathrm{UpM}$ ) und auf das Ausgangsvolumen mit $20 \mathrm{mM}$ Tris, pH $7.5+100 \mathrm{mM} \mathrm{NaCl}$ aufgefüllt.

Invertase-Waschpuffer:

$\begin{aligned} 1 \mathrm{x} & \text { PBS } \\ 1 \% & \text { Triton X-100 } \\ 0.1 \% & \text { SDS }\end{aligned}$

Für die CPY- und ALP-IPs wurden am nächsten Morgen pro „Chase“-Zeitpunkt je 0.5 $\mathrm{OD}_{600}$ in einem 13 ml-Plastikröhrchen für 3 min bei $3000 \mathrm{UpM}$ geerntet und das Pellet anschließend in je $500 \mu \mathrm{l} \mathrm{SD-Met}+50 \mathrm{mM} \mathrm{KPO}_{4}, \mathrm{pH} 5.7+2 \mathrm{mg} / \mathrm{ml} \mathrm{BSA}$ resuspendiert. Es folgte eine Vorinkubation für $30 \mathrm{~min}\left(15 \mathrm{~min}\right.$ bei $24^{\circ} \mathrm{C}$, danach genau $15 \mathrm{~min}$ Temperatur-Shift auf die jeweilige restriktive Temperatur). Nun wurden je $\underline{7} \mu \mathrm{l}$ radioaktiver L- $\left[{ }^{35} \mathrm{~S}\right]$-Label (Gemisch aus $\left[{ }^{35} \mathrm{~S}\right]$-Methionin und $\left[{ }^{35} \mathrm{~S}\right]$-Cystein, $14 \mu \mathrm{Ci} / \mu \mathrm{l}$ ) hinzugegeben und die Kulturen für genau $10 \mathrm{~min}$ bei der restriktiven Temperatur im Schüttelwasserbad inkubiert („Pulse“). Danach wurden $50 \mu \mathrm{l}$ des Methionin/CysteinMixes (je $5 \mathrm{mg} / \mathrm{ml}$ ) hinzugegeben und für genau $30 \mathrm{~min}$ im Schüttelwasserbad bei der restriktiven Temperatur weiterinkubiert („Chase“). Der Stoffwechsel der Zellen wurde danach durch Zugabe von je $5 \mu 11 \mathrm{M}$ Natriumazid (Endkonz.: $10 \mathrm{mM}$ ) abgestoppt und die Ansätze in Eppendorfgefäße mit Schraubdeckel überführt. Die Ansätze wurden nun für $20 \mathrm{sec}$ bei $13000 \mathrm{UpM}$ zentrifugiert. Im Falle der CPY-IP wurden die Überstände, welche sekretierte Proteine enthalten, in ein neues Eppendorfgefäß überführt (E), mit 10 $\underline{\mu l \text { eines 100x Proteaseinhibitor-Mixes versetzt und bis zur weiteren Verarbeitung auf Eis }}$ gelagert. Die Überstände der ALP-IP wurden verworfen. Die Pellets wurden nun in je 1 $\mathrm{ml}$ Tris-DTT-Azid resuspendiert und für $5 \mathrm{~min}$ bei $30^{\circ} \mathrm{C}$ im Heizblock inkubiert. Die Ansätze wurden anschließend für $30 \mathrm{sec}$ bei $13000 \mathrm{UpM}$ zentrifugiert und die Überstände verworfen. Daraufhin wurden die Pellets in je $150 \mu \mathrm{l}$ Sphäroplast-Mix mit $250 \mu \mathrm{g} / \mathrm{ml}$ Zymolyase resuspendiert und für $30-45 \mathrm{~min}$ bei $30^{\circ} \mathrm{C}$ im Heizblock sphäroplastiert. Es folgte eine Zentrifugation für $30 \mathrm{sec}$ bei $6500 \mathrm{UpM}$. Die Überstände wurden verworfen

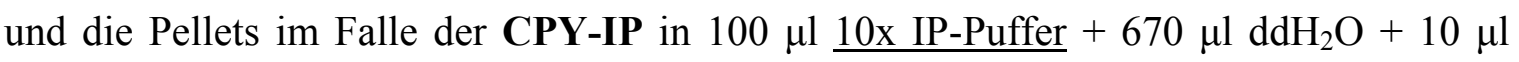


100x Proteaseinhibitor-Mix resuspendiert. $\mathrm{Zu}$ den externen Fraktionen der sekretierten Proteine (E) der CPY-IP wurden $100 \mu \mathrm{l}$ 10x IP-Puffer $+150 \mu 1 \mathrm{ddH}_{2} \mathrm{O}$ gegeben. Im Falle der ALP-IP wurden die Zellpellets in $50 \mu$ ALP-Mix resuspendiert. Die Ansätze wurden nun für 5 min bei $95^{\circ} \mathrm{C}$ inkubiert und danach einige Minuten auf Eis abgekühlt. Die Proben der CPY-IP wurden anschließend mit $270 \mu 1$ eines Gemisches aus $50 \mu 1$ gewaschenem Pansorbin und $220 \mu \mathrm{ldd}_{2} \underline{\mathrm{O}}$ versetzt. Die Proben der ALP-IP wurden mit $100 \mu \mathrm{l} \underline{\text { 10x IP-Puffer (ohne SDS) }}+840 \mu \mathrm{l} \mathrm{ddH}_{2} \mathrm{O}+50 \mu \mathrm{l}$ gewaschenem Pansorbin +10 $\mu l$ 100x Proteaseinhibitor-Mix versetzt. Es folgte eine Präabsorption für 15 min auf Eis. Die Ansätze wurden daraufhin für 5 min bei 13000 UpM zentrifugiert. Von den Überständen der Zellfraktionen wurden nun jeweils $5 \mu \mathrm{l}$ im Flüssig-Szintillationszähler zur Bestimmung der eingebauten Radioaktivität gezählt. Die restlichen Überstände wurden nun in neue Eppendorf-Gefäße mit Schraubdeckel überführt und mit je $1 \underline{\mu l}$ anti-

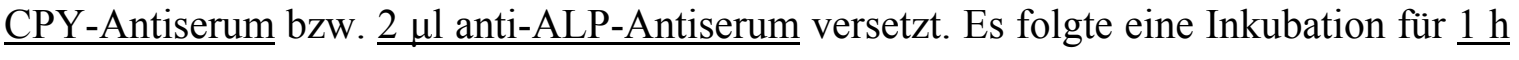
$\underline{30 \text { min }}$ auf Eis. Die gebildeten Antigen-Antikörper-Komplexe wurden nun durch Zugabe von $50 \mu \mathrm{l}$ gewaschenem Pansorbin und anschließender Inkubation für $\underline{1 \mathrm{~h} 30 \mathrm{~min}}$ auf Eis präzipitiert. Es folgte eine Zentrifugation für $30 \mathrm{sec}$ bei $13000 \mathrm{UpM}$. Die Ansätze der CPY-IP wurden $\underline{2 \times}$ mit je $1 \mathrm{ml}$ CPY+ALP-Waschpuffer gewaschen, wohingegen die

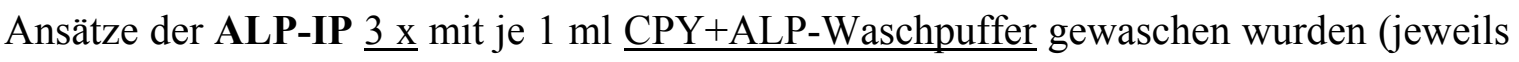
5 min Inkubation auf automatischem Schüttler). Die Pellets wurden daraufhin in $40 \mu \mathrm{l} 2 \mathrm{x}$ Probenpuffer resuspendiert und bis zum Auftragen aus das Gel bei $-20^{\circ} \mathrm{C}$ eingefroren.

10x IP-Puffer:

$\begin{aligned} 0.9 \mathrm{M} & \text { Tris-HCl, } \mathrm{pH} 8.0 \\ 1 \% & \text { SDS } \\ 1 \% & \text { Triton } \mathrm{X}-100 \\ 20 \mathrm{mM} & \text { EDTA }\end{aligned}$

10x IP-Puffer (ohne SDS):

$\begin{aligned} 0.9 \mathrm{M} & \text { Tris-HCl, pH } 8.0 \\ 1 \% & \text { Triton X-100 } \\ 20 \mathrm{mM} & \text { EDTA }\end{aligned}$


CPY+ALP-Waschpuffer:

$\begin{aligned} 10 \mathrm{mM} & \text { Tris, pH } 8.0 \\ 0.1 \% & \text { SDS } \\ 0.1 \% & \text { Triton } \mathrm{X}-100 \\ 2 \mathrm{mM} & \text { EDTA }\end{aligned}$

Für die $\underline{\text { API-IP }}$ wurden am nächsten Morgen pro „Chase“-Zeitpunkt je 0.25 OD $_{600}$ in einem 13 ml-Plastikröhrchen für $3 \mathrm{~min}$ bei $3000 \mathrm{UpM}$ geerntet und das Pellet anschließend in je $500 \mu \mathrm{l}$ SD-Met $+50 \mathrm{mM} \mathrm{KPO}_{4}, \mathrm{pH} 5.7+2 \mathrm{mg} / \mathrm{ml}$ BSA resuspendiert. Es folgte eine Vorinkubation für $30 \mathrm{~min}\left(15 \mathrm{~min}\right.$ bei $24^{\circ} \mathrm{C}$, danach genau $15 \mathrm{~min}$ Temperatur-Shift auf die jeweilige restriktive Temperatur). Nun wurden je $\underline{10} \mu 1$ radioaktiver L- $\left[{ }^{35} \mathrm{~S}\right]$-Label (Gemisch aus $\left[{ }^{35} \mathrm{~S}\right]$-Methionin und $\left[{ }^{35} \mathrm{~S}\right]$-Cystein, $14 \mu \mathrm{Ci} / \mu \mathrm{l}$ ) hinzugegeben und die Kulturen für genau $10 \mathrm{~min}$ bei der restriktiven Temperatur im Schüttelwasserbad inkubiert („Pulse“). Danach wurden $50 \mu \mathrm{l}$ des Methionin/CysteinMixes (je $5 \mathrm{mg} / \mathrm{ml}$ ) hinzugegeben und für genau $120 \mathrm{~min}$ im Schüttelwasserbad bei der restriktiven Temperatur weiterinkubiert („Chase“). Der Stoffwechsel der Zellen wurde danach durch Zugabe von je $5 \mu 11 \mathrm{M}$ Natriumazid (Endkonz.: $10 \mathrm{mM}$ ) abgestoppt und die Ansätze in Eppendorfgefäße mit Schraubdeckel überführt. Die Ansätze wurden nun für $20 \mathrm{sec}$ bei $13000 \mathrm{UpM}$ zentrifugiert. Die Überstände wurden verworfen und die Pellets in je $1 \mathrm{ml}$ Tris-DTT-Azid resuspendiert und für $5 \mathrm{~min}$ bei $30^{\circ} \mathrm{C}$ im Heizblock inkubiert. Die Ansätze wurden anschließend für $30 \mathrm{sec}$ bei $13000 \mathrm{UpM}$ zentrifugiert und die Überstände verworfen. Daraufhin wurden die Pellets in je $150 \mu$ l Sphäroplast-Mix mit $250 \mu \mathrm{g} / \mathrm{ml}$ Zymolyase resuspendiert und für $30-45$ min bei $30^{\circ} \mathrm{C}$ im Heizblock sphäroplastiert. Es folgte eine Zentrifugation für $30 \mathrm{sec}$ bei $6500 \mathrm{UpM}$. Die Überstände wurden verworfen und die Pellets in je $50 \mu \mathrm{A}$ API-Mix resuspendiert und für $5 \mathrm{~min}$ bei $95^{\circ} \mathrm{C}$ im Heizblock inkubiert. Zu jedem Ansatz wurden nun $940 \mu$ l $\underline{\text { API-IP-Puffer }}+50 \mu 1$ gewaschenes Pansorbin $+10 \mu 1$ 100x Proteaseinhibitor-Mix hinzugegeben und die Proben zur Präabsorption für 15 min auf Eis inkubiert. Die Ansätze wurden daraufhin für 5 min bei $13000 \mathrm{UpM}$ zentrifugiert. Von den Überständen der Zellfraktionen wurden nun jeweils $5 \mu \mathrm{l}$ im Flüssig-Szintillationszähler zur Bestimmung der eingebauten Radioaktivität gezählt. Die restlichen Überstände wurden nun in neue Eppendorf-Gefäße mit Schraubdeckel überführt und mit je $2.5 \mu$ anti-API-Antiserum versetzt. Es folgte eine 
Inkubation für $\underline{1 \mathrm{~h}}$ auf Eis. Die gebildeten Antigen-Antikörper-Komplexe wurden nun durch Zugabe von $50 \mu \mathrm{l}$ gewaschenem Pansorbin und anschließender Inkubation für $\underline{1 \mathrm{~h}}$ auf Eis präzipitiert. Es folgte eine Zentrifugation für $30 \mathrm{sec}$ bei $13000 \mathrm{UpM}$. Die Ansätze

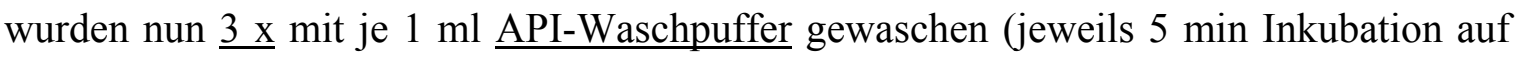
automatischem Schüttler). Die Pellets wurden daraufhin in $40 \mu \mathrm{l} 2 \mathrm{x}$ Probenpuffer resuspendiert und bis zum Auftragen aus das Gel bei $-20^{\circ} \mathrm{C}$ eingefroren.

API-Mix:

$\begin{array}{rl}50 \mathrm{mM} & \mathrm{NaPO}_{4}, \mathrm{pH} 7.0 \\ 1 \% & \mathrm{SDS} \\ 3 \mathrm{M} & \text { Harnstoff } \\ 1 \mathrm{x} & \text { Proteaseinhibitoren (frisch hinzugeben) }\end{array}$

API-IP-Puffer:

$\begin{array}{rl}50 \mathrm{mM} & \text { Tris, pH 7.5 } \\ 0.5 \% & \text { Triton X-100 } \\ 150 \mathrm{mM} & \mathrm{NaCl} \\ 0.1 \mathrm{mM} & \text { EDTA }\end{array}$

API-Waschpuffer:

$\begin{array}{rl}50 \mathrm{mM} & \text { Tris, pH } 7.5 \\ 0.1 \% & \text { SDS } \\ 0.5 \% & \text { Triton X-100 } \\ 150 \mathrm{mM} & \mathrm{NaCl} \\ 0.1 \mathrm{mM} & \text { EDTA }\end{array}$

$\underline{\text { Gel: }}$

Die Proben wurden für 5 min auf $95^{\circ} \mathrm{C}$ erhitzt, abgekühlt und für 2 min bei $13000 \mathrm{UpM}$ zentrifugiert. Von den Überständen wurden nun jeweils $20 \mu 1$ oder gleiche cpm in einem langen $8 \%$ igen SDS-PAGE mit 13 mA für 5 - 6 h elektrophoretisch aufgetrennt. Das Gel wurde daraufhin für 30 min in Entfärber fixiert und anschließend für einige Minuten in Wasser äquilibriert. Nach dem Trocknen wurde das Gel auf eine „Phospho-ImagingPlate“ oder einen Röntgenfilm exponiert und über Autoradiographie analysiert. 


\subsubsection{Reinigung eines 6xHis-Use1-Fusionsproteins zur Immunisierung und Gewinnung eines Antiserums}

Eine Möglichkeit größere Mengen eines definierten Proteins $\mathrm{zu}$ gewinnen, ist die heterologe Überexpression in E. coli-Zellen. Dazu wird der Leserahmen für das Protein in einen geeigneten Überexpressionsvektor hinter einen induzierbaren Promotor kloniert. Weiterhin enthält das Plasmid noch Sequenzen für ein Affinitätsepitop, welches die Reinigung des rekombinanten Proteins ermöglichen soll. Das hier verwendete Expressionssystem benutzt einen in WT-E. coli-Zellen nicht vorkommenden T7-Promotor zur Expression des Fusionsproteins und das 6xHis-Epitop zur Reinigung. Zur Überexpression wurde der proteasedefiziente E. coli-Stamm BL21-CodonPlus(D3)-RIL von Stratagene verwendet, der eine IPTG induzierbare T7-RNA-Polymerase besitzt. IPTG bindet an ein lac-Repressorprotein, welches dadurch seine DNA-Bindungseigenschaften verliert und die Transkription eines endogenen lac-Promotors nicht mehr inhibiert, welcher die Expression der T7-RNA-Polymerase kontrolliert. Diese bindet daraufhin an den T7-Promotor des Expresssionsvektors pET-28b, wodurch die Expression des nachgeschalteten rekombinanten Proteins induziert wird.

Die Gensequenz der cytosolischen Domäne des Use1-Proteins (Aminosäuren 1 - 215) wurde zunächst über eine PCR Reaktion in den Expressionsvektor pET-28b kloniert, was zur N-terminalen Anfügung einer 6xHis-Sequenz führt (pMD19). Nach Überexpression und Aufschluss der E. coli-Zellen wird das Fusionsprotein an einer Epitop-spezifischen Affinitätsmatrix (Ni-NTA-Agarose, Qiagen) gebunden, gewaschen und anschließend in reiner Form eluiert.

\subsection{Expression eines 6xHis-Use1-Fusionsproteins}

Der E. coli BL21-Stamm pMD19 wurde üN in $25 \mathrm{ml}$ 2xYT mit $50 \mu \mathrm{g} / \mathrm{ml}$ Kanamycin bei $37^{\circ} \mathrm{C}$ inkubiert. Am nächsten Morgen wurden $225 \mathrm{ml}$ 2xYT + Kanamycin hinzugegeben und die Kultur für weitere $1 \mathrm{~h} 30 \mathrm{~min}$ bei $37^{\circ} \mathrm{C}$ bis zu einer $\mathrm{OD}_{600}$ von $0.6-0.9$ inkubiert. Die Expression des rekombinanten 6xHis-Use1-Proteins wurde durch Zugabe von $476 \mu 1$

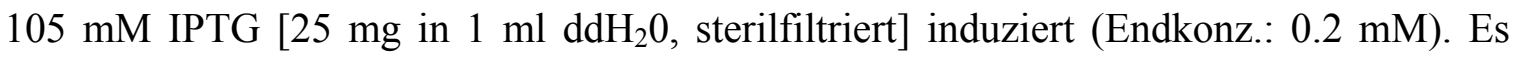
folgte eine Inkubation für $5 \mathrm{~h}$ bei $37^{\circ} \mathrm{C}$ (Temperatur und Induktionszeit für optimale Expression wurden zuvor in einem Vorversuch ausgetestet). Die Zellen wurden durch 15 min Zentrifugation bei $5000 \mathrm{UpM}$ und $4{ }^{\circ} \mathrm{C}$ geerntet. Das Pellet wurde in $20 \mathrm{ml} 1 \mathrm{x}$ PBS resuspendiert und konnte bis zur weiteren Verarbeitung bei $-20^{\circ} \mathrm{C}$ eingefroren werden. 


\subsection{Zell-Lyse durch „French Press“}

Die Lyse von rekombinanten E. coli-Zellen wurde mit Hilfe des „French Press“Verfahrens durchgeführt, da diese Methode schonender ist als ein Zellaufschluss mittels Ultraschall, und somit Protein-Degradierung weitgehend vermieden wird.

Das in 1x PBS resuspendierte Zellpellet wurden nach dem Auftauen mit $200 \mu 1$ 100x Proteaseinhibitor-Mix versetzt und in eine „French Press“-Zelle (French Pressure Cell Press, Specronic Instruments, USA) gefüllt. Es wurde ein Druck von maximal 1200 bar aufgebaut, welcher auch beim Öffnen des Auslassventils konstant blieb. Die Zellsuspension wurde 2 - 3 mal durch die Druckzelle geschickt.

\subsection{Reinigung des 6xHis-Use1-Fusionsproteins}

Das Lysat wurde nach dem Zellaufschluss für $10 \mathrm{~min}$ mit $12000 \mathrm{UpM}$ bei $4^{\circ} \mathrm{C}$ in einem JA20-Rotor zentrifugiert. Da in einem Vorversuch festgestellt wurde, dass das 6xHisUse1-Fusionsprotein in Proteineinschlusskörpern (,inclusion bodies“) aggregiert und sich somit im Pellet konzentriert, wurde der Überstand (enthält lösliche Proteine) weggefroren. Das Pellet wurde in $10 \mathrm{ml} \mathrm{7.2} \mathrm{M} \mathrm{Harnstoff} \mathrm{in} \mathrm{1x} \mathrm{PBS} \mathrm{resuspendiert} \mathrm{und} \mathrm{zur}$ Solubilisierung des rekombinanten Proteins für 30 min bei $4^{\circ} \mathrm{C}$ auf dem Drehrad inkubiert. Es folgte eine Zentrifugation für $15 \mathrm{~min}$ mit $15000 \mathrm{UpM}$ bei $4^{\circ} \mathrm{C}$. Das Pellet wurde in $10 \mathrm{ml} \mathrm{1x}$ PBS resuspendiert und weggefroren. Der Überstand wurde weiterverarbeitet. In der Zwischenzeit wurden $1 \mathrm{ml} \mathrm{Ni-NTA-Gel} 3$ x mit $10 \mathrm{ml} 1 \mathrm{x}$ PBS gewaschen (Zentrifugation für 2 min bei $2000 \mathrm{UpM}$ ). Danach wurde das Ni-NTA-Gel mit dem Überstand, welcher das solubilisierte 6xHis-Use1-Fusionsprotein enthält, versetzt und für 30 min bei $4^{\circ} \mathrm{C}$ auf der Wippe inkubiert. Die Lösung wurde danach in eine mit einer Fritte verschlossene Säule gegeben und der Durchlauf (ungebundene Proteine) zur späteren Analyse aufgefangen und weggefroren. Die Säule wurde nun wie folgt gewaschen:

$5.0 \mathrm{ml} 7.2 \mathrm{M}$ Harnstoff in 1x PBS, pH 7.4

$5.0 \mathrm{ml}$ 7.2 M Harnstoff in $0.1 \mathrm{M} \mathrm{NaPO}_{4}, \mathrm{pH} 7.0$

Die Elution erfolgte mit:

$1.5 \mathrm{ml}$ 6.4 M Harnstoff in $0.1 \mathrm{M} \mathrm{NaPO}_{4}, \mathrm{pH} 5.9$-> Eluat 1

$2.0 \mathrm{ml}$ 6.4 M Harnstoff in $0.1 \mathrm{M} \mathrm{NaPO}_{4}, \mathrm{pH} 4.5$-> Eluat 2

Um den Harnstoff zu entfernen wurden die Eluate üN gegen 3 M Harnstoff in 1x PBS und anschließend für $5 \mathrm{~h}$ gegen 1x PBS dialysiert. 
Die einzelnen Fraktionen wurden zur Analyse in einem 11 \%igen SDS-PAGE elektrophoretisch aufgetrennt. Danach wurde vom Eluat 2 eine Proteinbestimmung durchgeführt (siehe Kap. 2.2.4.3). Das Eluat 2 wurde daraufhin Aliquotiert und bei $-20^{\circ} \mathrm{C}$ weggefroren.

\subsection{Immunisierung eines Kaninchens}

Zur Gewinnung eines Antiserums gegen Use1p wurde ein Kaninchen (New Zealand, white) mit dem in E. coli überexprimierten Protein immunisiert. Für die Primärinjektionen wurden je 2 x $300 \mu \mathrm{g}$ gereinigtes Protein mit PBS auf ein Endvolumen von $500 \mu \mathrm{l}$ aufgefüllt und in eine $2 \mathrm{ml}$ Luer-Lock Spritze aufgezogen. In eine entsprechende zweite Spritze wurde das gleiche Volumen an Adjuvans (Specol) vorgelegt. Zum Mischen von Antigen und Specol wurde eine dünne Plastikkapillare, die an beiden Enden mit Luer-Anschlüssen versehen war, an die Spritzen gekoppelt. Durch das mehrmalige Pressen des Gemisches durch die Kapillare von der einen in die andere Spritze, wurde eine weiße Emulsion hergestellt. Für die Injektion wurde der gesamte frisch emulgierte Ansatz verwendet, wobei dem Kaninchen $1-2$ Depots subkutan in die Hautpolster der Hüften injiziert wurden. Drei Wochen nach der Primärinjektion wurde das Antigen erneut verabreicht $(300 \mu \mathrm{g}), 10$ Tage danach wurde dem Kaninchen Blut entnommen. Weitere Injektionen wurden alle 4 Wochen durchgeführt, wobei die Blutentnahme jeweils 10 Tage später erfolgte. Serum, das vor der Primärinjektion entnommen wurde, diente als Präimmunserum in Kontrollexperimenten.

\subsection{Gewinnung, Aufarbeitung und Lagerung des Antiserums}

Für die Gewinnung des Serums wurde dem Kaninchen Blut an der Ohrvene abgenommen. Störende Haare wurden vorsichtig abgezupft und der Venenbereich mit Alkohol desinfiziert. Eine dünne Kanüle, die mit einer Plastikkapillare verbunden war, wurde behutsam in die Vene eingebracht. Es wurden jeweils 20 bis $30 \mathrm{ml}$ Blut entnommen. Das Blut wurde anschließend für ca. $2 \mathrm{~h}$ bei RT stehen gelassen. Der Blutkuchen wurde mit einer Pasteurpipette vom Gefäß gelöst und das Serum üN bei $4^{\circ} \mathrm{C}$ inkubiert. Durch die sich anschließende Zentrifugation für $10 \mathrm{~min}$ mit $4000 \mathrm{UpM}$ bei $4^{\circ} \mathrm{C}$ wurde das geronnene Blut abgetrennt. Das Serum wurde in Schraubdeckel-Eppendorfgefäße pipettiert und in Aliquots bei $-80^{\circ} \mathrm{C}$ gelagert. 


\subsubsection{Koimmunpräzipitationen}

\subsection{Kopplung von Antikörpern und Präimmunserum an Protein-A-bzw. Protein-G-Sepharose}

(nach Harlow and Lane, 1988)

In vier Eppendorf-Gefäßen werden je $300 \mu \mathrm{l}$ Protein-A/G-Sepharose Fast Flow (Pharmacia) 4 x mit je $1 \mathrm{ml} \mathrm{KPi-Puffer}$ gewaschen $(5 \mathrm{~min}$ auf dem Drehrad bei RT, danach 15 sec Zentrifugation bei 4000 UpM). Die Protein-A/G-Sepharose-Pellets wurden anschließend in je $200 \mu \mathrm{KPi}$-Puffer resuspendiert.

anti-Use1-Beads:

$200 \mu \mathrm{l}$ gewaschene Protein-A-Sepharose $+30 \mu$ anti-Use1-Antikörper (773.t) $+95 \mu 1$ KPi-Puffer

Use1-Präimmun-Beads:

$200 \mu \mathrm{l}$ gewaschene Protein-A-Sepharose $+30 \mu$ Use1-Präimmunserum (773.pre) $+95 \mu 1$ KPi-Puffer

anti-HA-Beads:

$400 \mu \mathrm{l}$ gewaschene Protein-G-Sepharose $+250 \mu$ anti-HA-Antikörper (monoklonaler Gewebekulturüberstand)

Die Bindung der Antikörper an die Protein-A/G-Sepharose fand für $1 \mathrm{~h}$ bei RT auf dem Drehrad statt. Die Beads wurden daraufhin 2 x 3 min mit je $0.5 \mathrm{ml}$ Natriumborat-Puffer gewaschen. Vor dem letzten Waschen wurden die Ansätze auf je 2 Eppendorf-Gefäße aufgeteilt. Pro Gefäß wurden die Sepharose-Beads mit $1 \mathrm{ml}$ Natriumborat-Puffer, welchem der Crosslinker Dimethyl-pimelinediimidat-dihydrochlorid (DMP) in einer Endkonzentration von $4 \mathrm{mg} / \mathrm{ml}$ frisch hinzugefügt wurde, versetzt und für $30 \mathrm{~min}$ auf dem Drehrad bei RT inkubiert. Danach wurden die Ansätze für $15 \mathrm{sec}$ bei $4000 \mathrm{UpM}$ zentrifugiert. Nach einmaligem Waschen mit je $1 \mathrm{ml} 1 \mathrm{M}$ Tris- $\mathrm{HCl}, \mathrm{pH} 7.5$ wurden die Beads in $1 \mathrm{ml} 1 \mathrm{M}$ Tris-HCl, pH 7.5 für $2 \mathrm{~h}$ bei RT auf dem Drehrad inkubiert. Die zusammengehörigen Ansätze wurden nun wieder vereinigt und einmal mit PBS gewaschen. Daraufhin wurden die Beads im gleichen Volumen (ca. $100 \mu \mathrm{l}$ ) PBS resuspendiert, Natriumazid in einer Endkonzentration von $10 \mathrm{mM}$ hinzugefügt und bei $4^{\circ} \mathrm{C}$ gelagert. 
KPi-Puffer:

$100 \mathrm{mM} \quad \mathrm{KPO}_{4}, \mathrm{pH} 7.4$

Natriumborat-Puffer:

$0.1 \mathrm{M} \quad$ Natriumborat, $\mathrm{pH} 7.5$

\subsection{Versuch zur Koimmunpräzipitation von HA-Vts1p und Vti1p}

Ziel: Über einen an Protein-G-Sepharose-Beads gekoppelten anti-HA-Antikörper soll HA-Vts1p aus einem MDY1-pMD8-Homogenat gebunden werden. Falls Vti1p und Vts $1 p$ biochemisch interagieren, sollte Vtilp koimmunpräzipitiert werden.

Der Stamm MDY1-pMD8 wurde in SD-Ura-Met-Medium bei $30^{\circ} \mathrm{C}$ bis zu einer $\mathrm{OD}_{600}$ von $0.5-0.8$ inkubiert. Es wurden $10 \mathrm{OD}_{600}$ durch 5 min Zentrifugation bei $3000 \mathrm{UpM}$ geerntet. Das Pellet wurde in $1 \mathrm{ml}$ TE $\beta$ resuspendiert und für $10 \mathrm{~min}$ im $30^{\circ} \mathrm{C}$-Wasserbad inkubiert. Die Zellen wurden danach erneut zentrifugiert und in $1 \mathrm{ml}$ Sphäroplast-Puffer mit $30 \mu 110 \mathrm{mg} / \mathrm{ml}$ Zymolyase (Endkonz.: $300 \mu \mathrm{g} / \mathrm{ml}$ ) resuspendiert und für $1 \mathrm{~h}$ bei $30^{\circ} \mathrm{C}$ unter langsamen Schütteln sphäroplastiert. Anschließend wurde die Kultur für $30 \mathrm{sec}$ bei 6500 UpM zentrifugiert und das Pellet 3 x mit je $1 \mathrm{ml}$ Sphäroplast-Puffer gewaschen. Das Pellet wurde nun in $500 \mu \mathrm{l}$ (Konzentrierung) kaltem Lysepuffer + Proteaseinhibitoren resuspendiert und $5 \mathrm{x}$ im Glaspotter (,tight“) auf Eis homogenisiert. Zum Homogenat wurden $15 \mu \mathrm{l} 5 \mathrm{M} \mathrm{NaCl}$ und $20 \mu 125 \%$ Triton-X100 hinzugefügt und für $30 \mathrm{~min}$ bei $4^{\circ} \mathrm{C}$ auf dem Drehrad inkubiert. Es folgte eine Zentrifugation für 13,000 UpM bei $4^{\circ} \mathrm{C}$. Das Pellet wurde in $500 \mu \mathrm{l}$ Lyse-Puffer resuspendiert und weggefroren. Je $200 \mu \mathrm{l}$ des Überstandes (Homogenat) wurde in ein neues Eppendorf-Gefäß überführt:

$$
\begin{aligned}
& 200 \mu \mathrm{l} \text { Homogenat }+400 \mu \mathrm{l} \text { TBS/Triton }+60 \mu \mathrm{l} \text { HA-Protein-G-Beads } \\
& \text { bzw. als Kontrolle } \\
& 200 \mu \mathrm{l} \text { Homogenat }+400 \mu \mathrm{lBS} / \text { Triton }+60 \mu \mathrm{l} \text { gewaschene Protein-G-Beads }
\end{aligned}
$$

Nach Inkubation für $1 \mathrm{~h} 30 \mathrm{~min}$ bei $4^{\circ} \mathrm{C}$ auf dem Drehrad wurden die Ansätze für $20 \mathrm{sec}$ bei 6500 UpM zentrifugiert. Die Überstände wurden gesichert (ungebunden) und die Beads 3 x für 5 min mit $1 \mathrm{ml}$ TBS/Triton gewaschen und anschließend in $50 \mu 1$ x StopPuffer resuspendiert und weggefroren. 
Von den Homogenat-, Überstand- und 13,000 UpM-Pellet-Fraktionen wurden je $25 \mu 1$ mit $12.5 \mu \mathrm{l} 3 \mathrm{x}$ Stop-Puffer versetzt, zusammen mit den Beads für 5 min bei $95^{\circ} \mathrm{C}$ erhitzt und anschließend je $30 \mu \mathrm{im} \mathrm{Gel} \mathrm{aufgetrennt.}$

Lyse-Puffer wie in Kap. 2.2.5.3

\section{TBS/Triton:}

TBS $+1 \%$ Triton-X100

\subsection{Kreuzvernetzung („Crosslinking“) von Proteinen mit DSP und anschließende Immunpräzipitation}

Ablauf bis zum Waschen in Sphäroplast-Puffer wie unter 2.2.4.12.2 beschrieben. Anschließend werden $10 \mathrm{OD}_{600}$ pelletiert und in $2.5 \mathrm{ml} 50 \mathrm{mM} \mathrm{KPO}$, pH $7.5+$ Proteaseinhibitoren resuspendiert. $0.5 \mathrm{ml}$ werden abgenommen und weggefroren (Rest). Je $1 \mathrm{ml}$ wird nun mit $20 \mu \mathrm{l}$ frisch hergestelltem $10 \mathrm{mg} / \mathrm{ml}$ (DSP) in DMSO versetzt und für $1 \mathrm{~h}$ bei $4^{\circ} \mathrm{C}$ auf dem Drehrad inkubiert. Der Ansatz wird danach für $30 \mathrm{sec}$ bei 6500 UpM zentrifugiert und der Überstand verworfen. Zur Deaktivierung des Kreuzvernetzers und zur Solubilisierung der Proteine wird das Pellet nun in $1 \mathrm{ml} \mathrm{TBS/Triton} \mathrm{+}$ Proteaseinhibitoren resuspendiert und für weitere $15 \mathrm{~min}$ bei $4^{\circ} \mathrm{C}$ auf dem Drehrad inkubiert. Die Ansätze werden daraufhin für $5 \mathrm{~min}$ bei $70^{\circ} \mathrm{C}$ erhitzt und anschließend für 5 min mit $13000 \mathrm{UpM}$ bei $4^{\circ} \mathrm{C}$ zentrifugiert. Der Überstand (Homogenat) wird vorsichtig abgenommen.

$600 \mu 1$ Homogenat $+60 \mu 1$ Antikörper-gekoppelte-Protein-G-Beads

bzw. als Kontrolle

$600 \mu$ Homogenat $+60 \mu$ gewaschene Protein-G-Beads

Weiterer Ablauf wie unter 2.2.4.12.2 beschrieben.

\subsection{Native Immunpräzipitation von Use1-SNARE-Komplexen}

(abgewandelt nach Søgaard et al., 1994 und Lewis et al., 1997)

Für die Gewinnung der Membranextrakte wurde ein sec18-1-Stamm verwendet

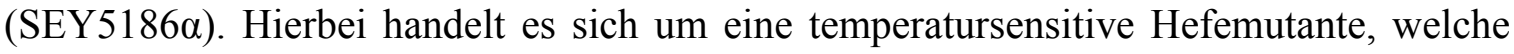
aufgrund einer Mutation im SEC18-Gen ein verändertes Sec18-Protein produziert, das 
nach Erhöhung der Temperatur auf $37^{\circ} \mathrm{C}$ nur noch eingeschränkt funktionsfähig ist. Sec18p ist das Hefehomolog zur ATPase NSF, die in Säugerzellen die Desassemblierung von cis-SNARE-Komplexen katalysiert. Wird in der Hefemutante die Funktion von Sec18p nach Erhöhung auf die restriktive Temperatur gestört, so müssten cis-SNAREKomplexe akkumulieren. Hierdurch soll erreicht werden, dass mögliche SNARE-Partner von Use1p an dieses gebunden bleiben, wodurch sie in einer darauffolgenden Immunpräzipitation detektiert werden können.

\section{Prozedur:}

Die sec18-1-Hefemutante wurde in $40 \mathrm{ml}$ YEPD-Medium angeimpft und üN bei $24^{\circ} \mathrm{C}$ bis $\mathrm{zu}$ einer $\mathrm{OD}_{600}$ zwischen 0.5 und 1.0 inkubiert. Es wurden nun $20 \mathrm{OD}_{600}$ durch $5 \mathrm{~min}$ Zentrifugation bei $3000 \mathrm{UpM}$ geerntet und das Pellet in $2 \mathrm{ml}$ TE $\beta$ resuspendiert und für 10 min unter langsamen Schütteln bei $24^{\circ} \mathrm{C}$ inkubiert. Der Ansatz wurde danach für 3 min bei $3000 \mathrm{UpM}$ zentrifugiert. Das Pellet wurde in $2 \mathrm{ml}$ Sphäroplast-Puffer mit $60 \mu 10$ $\mathrm{mg} / \mathrm{ml}$ Zymolyase (Endkonz. $300 \mu \mathrm{g} / \mathrm{ml}$ ) resuspendiert und für $1 \mathrm{~h}$ bei $24^{\circ} \mathrm{C}$ unter langsamen Schütteln sphäroplastiert. Der Ansatz wurde nun auf 2 Eppendorf-Gefäße aufgeteilt und 2 x mit je $1 \mathrm{ml}$ YEPD/Sorbitol gewaschen (Zentrifugation für $30 \mathrm{sec}$ bei $6500 \mathrm{UpM}$ ). Die Ansätze wurden wieder vereinigt, in $20 \mathrm{ml} \mathrm{YEPD/Sorbitol} \mathrm{resuspendiert}$ und nun auf zwei $50 \mathrm{ml}$-Inkubationskolben à $10 \mathrm{ml}$ aufgeteilt. Je ein Kolben wurde nun für $1 \mathrm{~h}$ bei $24^{\circ} \mathrm{C}$ bzw. $37^{\circ} \mathrm{C}$ unter langsamen Schütteln inkubiert. Die Ansätze wurden daraufhin in 15 ml-Falcon-Röhrchen überführt und für 2 min bei $2000 \mathrm{UpM}$ zentrifugiert. Die Pellets wurden in je $1 \mathrm{ml}$ kalten Lyse-Puffer + Proteaseinhibitoren resuspendiert und jeweils 20 x im eiskalten Potter (,loose“) homogenisiert. Danach wurde jeder Ansatz für 15 min bei $4^{\circ} \mathrm{C}$ auf dem Drehrad inkubiert. Es folgte eine Zentrifugation für 20 min mit $50000 \mathrm{UpM}$ bei $4^{\circ} \mathrm{C}$. Für das Gel wurden nun $40 \mu \mathrm{l}$ jedes Überstandes bei $-20^{\circ} \mathrm{C}$ gesichert (Membranextrakt). Je $450 \mu \mathrm{l}$ der Überstände wurden nun in zwei neue Eppendorf-Gefäße überführt:

A) $450 \mu \mathrm{l}$ Homogenat $+48 \mu \mathrm{l} \alpha$-Use1-Beads (siehe Kap. 2.2.4.12.1)

B) $450 \mu 1$ Homogenat $+48 \mu 1$ Use1-Präimmun-Beads (siehe Kap. 2.2.4.12.1)

Die Ansätze wurden nun üN bei $4^{\circ} \mathrm{C}$ auf dem Drehrad inkubiert. Am nächsten Tag wurden sie für $20 \mathrm{sec}$ bei $6500 \mathrm{UpM}$ zentrifugiert. Die Überstände (ungebunden) wurden für das Gel bei $-20^{\circ} \mathrm{C}$ gesichert. Die Beads wurden 3 x für 5 min bei $4^{\circ} \mathrm{C}$ mit je $1 \mathrm{ml}$ 
Lyse-Puffer gewaschen und anschließend in je $30 \mu \mathrm{l} 1 \mathrm{x}$ Probenpuffer ohne $\beta$ Mercaptoethanol resuspendiert und ebenfalls bei $-20^{\circ} \mathrm{C}$ gesichert.

$\underline{\text { Gel: }}$

Von den Fraktionen „Membranextrakt“ und ,ungebunden“" wurden je $25 \mu 1$ mit $12.5 \mu 1$ 3x Probenpuffer versetzt und zusammen mit den in 1x Probenpuffer resuspendierten Beads für 5 min bei $95^{\circ} \mathrm{C}$ erhitzt. Je $30 \mu \mathrm{l}$ wurden daraufhin in einem $11 \%$ igen SDS-PAGE elektrophoretisch aufgetrennt. Danach folgte ein Western-Blot und Antikörperinkubation mit gegen die jeweiligen SNARE-Proteine gerichteten Antiseren.

$\underline{\text { YEPD/Sorbitol: }}$

$$
\begin{aligned}
10 \mathrm{~g} / 1 & \text { Hefeextrakt } \\
20 \mathrm{~g} / 1 & \text { Bacto-Pepton } \\
182.2 \mathrm{~g} / 1 & \text { Sorbitol (Endkonz.: } 1 \mathrm{M})
\end{aligned}
$$

nach Autoklavieren

und Abkühlen: $\quad 40 \mathrm{ml} / 1 \quad 50 \%$ Glukose (Endkonz.: $2 \%(\mathrm{w} / \mathrm{v})$ )

\begin{tabular}{rlr}
\multicolumn{2}{c}{ Lyse-Puffer $(50 \mathrm{ml}):$} & $\underline{\text { Endkonz.: }}$ \\
$1 \mathrm{ml}$ & $1 \mathrm{M} \mathrm{HEPES-KOH}, \mathrm{pH} 7.0$ & $20 \mathrm{mM}$ \\
$5 \mathrm{ml}$ & $1 \mathrm{M} \mathrm{KCl}$ & $100 \mathrm{mM}$ \\
$0.2 \mathrm{ml}$ & $0.5 \mathrm{M} \mathrm{EDTA}$ & $2 \mathrm{mM}$ \\
$1 \mathrm{ml}$ & $25 \%$ Triton X-100 & $0.5 \%(\mathrm{w} / \mathrm{v})$
\end{tabular}

\subsubsection{Analyse der SNARE-Komplex-Assemblierung mittels Gelfiltration und Ionenaustausch-Chromatographie}

Die Gelfiltration über eine HPLC-Anlage (SMART ${ }^{\circledR}$-System, Pharmacia, Schweden) wurde verwendet, um SNARE-Proteine eines in vitro assemblierten Komplexes aufgrund ihres unterschiedlichen Molekulargewichtes $\mathrm{zu}$ trennen und so den Aufbau des Komplexes zu untersuchen. Hierzu wurde eine Superdex ${ }^{\circledR} 75$ PC 3.2/30-Säule mit einem Gelvolumen von $2.4 \mathrm{ml}$ verwendet, die eine optimale Separierung von Molekülen mit einem Molekulargewicht zwischen 3000 und 70,000 Dalton zeigt. Da sich kleine Moleküle aufgrund des ihnen zur Verfügung stehenden größeren Verteilungsvolumens länger in der Gelmatrix aufhalten, werden sie später als große Moleküle eluiert. Daher sollte es möglich sein mit dieser Methode einen in vitro assemblierten SNARE-Komplex 
von unassoziierten SNARE-Molekülen zu unterscheiden. Für die SNARE-KomplexAssemblierung wurden aufgereinigte, rekombinante, 6xHis-verlängerte SNARE-Motive der SNARE-Proteine verwendet. Diese wurden in einer Endkonzentration von je 12 $\mu \mathrm{g} / 100 \mu \mathrm{l}$ in Assemblierungspuffer $\mathrm{A}$ üN bei $4^{\circ} \mathrm{C}$ auf der Wippe inkubiert (nach Antonin et al., 2000a).

Assemblierungspuffer A $(250 \mathrm{ml})$ :

$5 \mathrm{ml} \quad 1 \mathrm{M}$ Tris, $\mathrm{pH} 7.4$

$7.5 \mathrm{ml} \quad 5 \mathrm{M} \mathrm{NaCl}$

$0.5 \mathrm{ml} \quad 0.5 \mathrm{M}$ EDTA

$\mathrm{x} \mathrm{ml} \quad \mathrm{HPLC}-\mathrm{H}_{2} \mathrm{O}$
Endkonz::

$20 \mathrm{mM}$

$150 \mathrm{mM}$

$1 \mathrm{mM}$

\section{$\rightarrow$ filtrieren und entgasen}

Die Auftrennung erfolgte mit einer Flussrate von $40 \mu$ l Assemblierungspuffer pro Minute. Die Eluate wurden über UV-Detektion bei den Wellenlängen $280 \mathrm{~nm}$ (aromatische Aminosäuren), $214 \mathrm{~nm}$ (Peptidbindung) und $340 \mathrm{~nm}$ (Verunreinigungen) analysiert.

Proteine könne auch aufgrund ihrer Nettoladung durch Ionenaustausch-Chromatographie getrennt werden. Diese Methode beruht auf dem reversiblen, elektrostatischen Austausch von in Lösung befindlichen Ionen gegen Ionen, die an ein unlösliches Trägermaterial gebunden sind. Ein Ionenaustauscher ist ein Polyelektrolyt, wobei der Kationenaustauscher kovalent negativ geladene, der Anionenaustauscher kovalent positiv geladene Gruppen enthält. Da der zu erwartende SNARE-Komplex eine andere Nettoladung besitzt, als die einzelnen SNARE-Proteine sollte somit eine Trennung stattfinden. Für die Ionenaustausch-Chromatographie wurde die gleiche HPLC-Anlage (SMART ${ }^{\circledR}$-System, Pharmacia, Schweden), diesmal jedoch mit der Kationenaustauschersäule Mono $\mathrm{S}^{\circledR} \mathrm{PC}$ 1.6/5 (Gelvolumen $100 \mu \mathrm{l}$ ) verwendet. Die SNARE-Komplex-Assemblierung erfolgte diesmal für $40 \mathrm{~h}$ bei $4^{\circ} \mathrm{C}$ auf der Wippe in Assemblierungspuffer B. Der Ansatz wurde daraufhin 1:5 mit $20 \mathrm{mM}$ Phosphatpuffer verdünnt um auf eine Salzkonzentration von 30 $\mathrm{mM}$ zu gelangen, danach auf die Säule geladen und mit einem $2 \mathrm{ml}$ Gradienten aus Startund Elutionspuffer (30 mM NaCl bis $0.5 \mathrm{M} \mathrm{NaCl}$, pH 7.4 bis 10.5) bei ansteigender Salzkonzentration und ansteigendem $\mathrm{pH}-$ Wert und einer Flussrate von $100 \mu 1 / \mathrm{min}$ von der Säule eluiert. Die Eluate wurden wieder über UV-Detektion bei den Wellenlängen 280 $\mathrm{nm}, 214 \mathrm{~nm}$ und $340 \mathrm{~nm}$ analysiert und zu jeweils $100 \mu$ fraktioniert. 
Assemblierungspuffer B $(250 \mathrm{ml})$ :

$10 \mathrm{ml} \quad 0.5 \mathrm{M} \mathrm{NaPO}_{4}, \mathrm{pH} 7.4$

$7.5 \mathrm{ml} \quad 5 \mathrm{M} \mathrm{NaCl}$

$\mathrm{x} \mathrm{ml}$ HPLC- $\mathrm{H}_{2} \mathrm{O}$

$\rightarrow$ filtrieren und entgasen

Start-Puffer $(250 \mathrm{ml})$ :

$10 \mathrm{ml} \quad 0.5 \mathrm{M} \mathrm{NaPO}_{4}, \mathrm{pH} 7.4$

$1.5 \mathrm{ml} \quad 5 \mathrm{M} \mathrm{NaCl}$

x ml HPLC- $\mathrm{H}_{2} \mathrm{O}$

$\rightarrow$ filtrieren und entgasen

Elutionspuffer $(250 \mathrm{ml})$ :

$10 \mathrm{ml} \quad 0.5 \mathrm{M} \mathrm{NaPO}_{4}, \mathrm{pH} 10.5$

$25 \mathrm{ml} \quad 5 \mathrm{M} \mathrm{NaCl}$

$x \mathrm{ml} \quad \mathrm{HPLC}-\mathrm{H}_{2} \mathrm{O}$

$\rightarrow$ filtrieren und entgasen
Endkonz.:

$20 \mathrm{mM}$

$150 \mathrm{mM}$

Endkonz.:

$20 \mathrm{mM}$

$30 \mathrm{mM}$

Endkonz.:

$20 \mathrm{mM}$

$0.5 \mathrm{M}$

\subsubsection{Zellbiologische Methoden}

\subsubsection{Indirekte Immunfluoreszenz mit Hefezellen}

(nach Pringle et al., 1989 und Roberts et al., 1991)

Die jeweiligen Hefestämme wurden in $10 \mathrm{ml}$ YEPD-Medium üN bei der entsprechenden Temperatur bis zu einer $\mathrm{OD}_{600}$ von max. 1 - 1.2 wachsen gelassen (zur Selektion von Plasmiden wurden die entsprechenden Stämme in SD-Minimalmedium hochgezogen, 2.5 $\mathrm{OD}_{600}$ zentrifugiert, in $10 \mathrm{ml}$ YEPD-Medium resuspendiert und für weitere $3-4 \mathrm{~h}$ bei der jeweiligen Temperatur inkubiert). $9 \mathrm{ml}$ der Kulturen wurden anschließend mit $1 \mathrm{ml} 37 \%$ Formaldehyd versetzt (Endkonz. Formaldehyd $=3.7 \%$ ) und für $30 \mathrm{~min}$ bei $30^{\circ} \mathrm{C}$ in 15 ml-Falcon-Röhrchen inkubiert. Die Zellen wurden danach für 3 min bei $3000 \mathrm{UpM}$ zentrifugiert und das Pellet in $2 \mathrm{ml}$ Fixative resuspendiert. Die Kulturen wurden nun üN auf der Wippe bei RT fixiert. Am nächsten Tag werden die Zellen wieder für 3 min bei 3000 UpM zentrifugiert und das Pellet in $1 \mathrm{ml}$ TE $\beta$ resuspendiert und für 10 min auf der Wippe inkubiert. Die Zellen werden erneut zentrifugiert und das Pellet in $1 \mathrm{ml}$ 
Sphäroplast-Puffer mit $450 \mu \mathrm{g} / \mathrm{ml}$ Zymolyase resuspendiert und für $30 \mathrm{~min}$ bei $30^{\circ} \mathrm{C}$ unter langsamem Schütteln sphäroplastiert. Die sphäroplastierten Zellen werden durch $30 \mathrm{sec}$ Zentrifugation bei $6500 \mathrm{UpM}$ pelletiert und anschließend vorsichtig in $1 \mathrm{ml}$ Sorbitol-Azid gewaschen. Die Zellen wurden erneut zentrifugiert und nun zur Permeabilisierung der Plasmamembran in $1 \mathrm{ml}$ Sorbitol-SDS resuspendiert und für genau 2 min bei RT inkubiert. Die Zellen wurden daraufhin erneut zentrifugiert und das Pellet zweimal mit je $1 \mathrm{ml} 1.2 \mathrm{M}$ Sorbitol gewaschen. Anschließend wurde das Pellet in ca. 100 - $500 \mu \mathrm{l}$ (hängt von der Größe des Pellets ab) 1.2 M Sorbitol resuspendiert. In jede Grube der Objektträger wurden $20 \mu$ Poly-L-Lysin $\left(1 \mathrm{mg} / \mathrm{ml}\right.$ in $\left.\mathrm{ddH}_{2} \mathrm{O}\right)$ gegeben und für ca. $1 \mathrm{~min}$

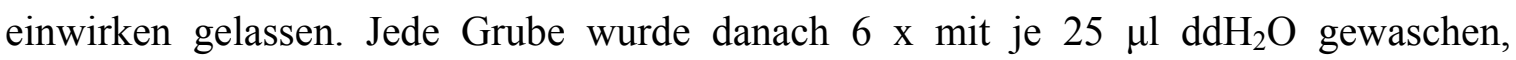
abgesaugt und trocknen gelassen. Pro Grube wurden nun $40 \mu \mathrm{l}$ Zellen gegeben und für 10 min an die Oberfläche binden gelassen. Die ungebundenen Zellen wurden danach abgesaugt, jede Grube 3 x mit je $25 \mu$ PBS-BSA-Azid gewaschen und anschließend zur Absättigung unspezifischer Bindungsstellen für 15 min bei RT mit PBS-BSA-Azid in einer Feuchthaltekammer inkubiert. $20 \mu \mathrm{l}$ des in PBS-BSA-Azid verdünnten Primärantikörpers wurden nun in jede Grube gegeben und für $1 \mathrm{~h}$ bei RT in der Feuchthaltekammer im Dunkeln inkubiert. Die Gruben wurden anschließend 6 x mit je 25 $\mu 1$ PBS-BSA-Azid gewaschen. Der Sekundärantikörper (Cy2- oder Cy3-konjugiertes Ziege-anti-Kaninchen- bzw. Ziege-anti-Maus-IgG, Dianova) wurde nun 1:200 in PBSBSA-Azid verdünnt und ebenfalls jeweils $20 \mu \mathrm{l}$ pro Grube aufgetragen. Es folgte eine erneute Inkubation für $1 \mathrm{~h}$ bei RT in der Feuchthaltekammer im Dunkeln. Die Gruben wurden anschließend 9 x mit je $25 \mu$ PBS-BSA-Azid gewaschen und anschließend mit einem kleinen Tropfen (ca. $8 \mu \mathrm{l}$ ) Einbett-Medium überschichtet und durch ein entsprechendes Deckglas abgedeckt. Überschüssiges Einbett-Medium wurde vorsichtig entfernt und nach dem Abtrocknen das Deckglas mit Nagellack umrandet und versiegelt. Die so behandelten Zellen wurden fluoreszenzmikroskopisch untersucht und danach bei $20^{\circ} \mathrm{C}$ im Dunkeln aufbewahrt. 


\begin{tabular}{|l|l|l|l|l|}
\hline \multicolumn{9}{|c|}{ Primärantikörper } \\
\hline Protein & Reinigung & Herkunft & Verdünnung & Referenz \\
\hline Emp47p & Serum & Kaninchen & $1: 200$ & H.D. Schmitt \\
\hline Vti1p & $\begin{array}{l}\text { Serum, } \\
\text { affinitätsgereinigt }\end{array}$ & Kaninchen & $1: 50$ & $\begin{array}{l}\text { G. Fischer von } \\
\text { Mollard }\end{array}$ \\
\hline Use1p & Serum & Kaninchen & $1: 10$ & $\begin{array}{l}\text { G. Fischer von } \\
\text { Mollard }\end{array}$ \\
\hline HA & $\begin{array}{l}\text { Gewebekultur- } \\
\text { Überstand }\end{array}$ & Maus & $1: 10$ & $\begin{array}{l}\text { BabCo, } \\
\text { Richmond (USA) }\end{array}$ \\
\hline
\end{tabular}

\begin{tabular}{|l|l|l|}
\hline \multicolumn{3}{|c|}{ Sekundärantikörper } \\
\hline Antikörper & Verdünnung & Referenz \\
\hline $\begin{array}{l}\text { Cyanin-(Cy2/Cy3)-konjugiertes } \\
\text { Ziege-anti-Kaninchen IgG }\end{array}$ & $1: 200$ & Dianova, Hamburg \\
\hline $\begin{array}{l}\text { Cyanin-(Cy2/Cy3)-konjugiertes } \\
\text { Ziege-anti-Maus IgG }\end{array}$ & $1: 200$ & Dianova, Hamburg \\
\hline
\end{tabular}

Fixative $(25 \mathrm{ml})$ :

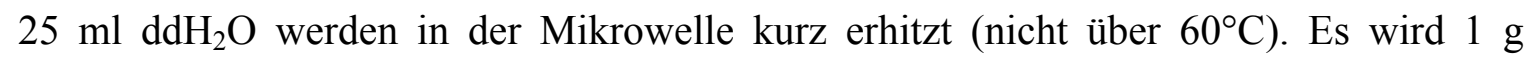
Paraformaldehyd hinzugegeben und gemischt (Lösung bleibt trübe). Nun werden $187.5 \mu 1$ $6 \mathrm{~N} \mathrm{NaOH}$ hinzupipettiert (Paraformaldehyd löst sich erst jetzt). Nach Lösen und Abkühlen werden $0.34 \mathrm{~g} \mathrm{KH}_{2} \mathrm{PO}_{4}$ hinzugegeben und gemischt. Der $\mathrm{pH}-$ Wert sollte bei ca. 6.5 liegen.

Sorbitol-Azid (10 ml):

Endkonz.:

$\begin{array}{rlr}6 \mathrm{ml} & 2 \mathrm{M} \text { Sorbitol } & 1.2 \mathrm{M} \\ 50 \mu \mathrm{l} & 1 \mathrm{M} \text { Natriumazid } & 5 \mathrm{mM}\end{array}$

Sorbitol-SDS $(5 \mathrm{ml})$ :

$$
\begin{array}{rl}
1 \mathrm{ml} & 10 \%(\mathrm{w} / \mathrm{v}) \mathrm{SDS} \\
3 \mathrm{ml} & 2 \mathrm{M} \text { Sorbitol } \\
25 \mu \mathrm{l} & 1 \mathrm{M} \text { Natriumazid }
\end{array}
$$

Endkonz.:

$$
2 \%
$$$$
1.2 \mathrm{M}
$$

$5 \mathrm{mM}$

$\begin{array}{rlr}\text { PBS-BSA-Azid }(50 \mathrm{ml}): & \underline{\text { Endkonz.: }} \\ 250 \mathrm{mg} & \text { BSA } & 5 \mathrm{mg} / \mathrm{ml} \\ 250 \mu \mathrm{l} & 1 \mathrm{M} \text { Natriumazid } & 5 \mathrm{mM} \\ 10 \mathrm{ml} & 10 x \text { PBS } & 1 \mathrm{x}\end{array}$




\section{Einbett-Medium:}

$50 \mathrm{mg}$ p-Phenylendiamin (licht- und sauerstoffempfindlich) werden in $5 \mathrm{ml} 1 \mathrm{x}$ PBS gelöst. Danach werden $45 \mathrm{ml} 100$ \% Glycerol und $2-3 \mu$ DAPI (1 mg/ml) hinzugegeben und vorsichtig durch schwenken gelöst (keine Luftblasen). Es werden sofort $0.5 \mathrm{ml}$ Aliquots bei $-80^{\circ} \mathrm{C}$ eingefroren.

\subsubsection{Indirekte Immunfluoreszenz für Emp47p in Hefezellen}

(nach Schröder et al., 1995)

Die jeweiligen PEP4-defizienten Hefestämme wurden in $30 \mathrm{ml}$ YEPD-Medium üN bei $24^{\circ} \mathrm{C}$ bis zu einer $\mathrm{OD}_{600}$ von ca. 0.4 wachsen gelassen. Die Kultur wurde daraufhin auf $2 \mathrm{x}$ $15 \mathrm{ml}$ aufgeteilt. Die eine Hälfte wurde weiter bei $24^{\circ} \mathrm{C}$ inkubiert. Die andere Hälfte wurde für $1 \mathrm{~h} 30 \mathrm{~min}$ bei der restriktiven Temperatur $\left(30^{\circ} \mathrm{C}\right.$ bzw. $\left.37^{\circ} \mathrm{C}\right)$ im Schüttelwasserbad inkubiert. Danach wurden jeweils $3.3 \mathrm{OD}_{600}$ durch 3 min Zentrifugation bei 3000 UpM geerntet. Die Pellets wurden nun in je $1 \mathrm{ml}$ Fixative resuspendiert und anschließend für $1 \mathrm{~h}$ bei der jeweiligen Temperatur $\left(24^{\circ} \mathrm{C}, 30^{\circ} \mathrm{C}\right.$ bzw. $\left.37^{\circ} \mathrm{C}\right)$ unter schütteln fixiert. Die Zellen wurden daraufhin für 3 min bei $3000 \mathrm{UpM}$ zentrifugiert und die Pellets in je $1 \mathrm{ml}$ Sphäroplast-Puffer mit $450 \mu \mathrm{g} / \mathrm{ml}$ Zymolyase resuspendiert. Die Sphäroplastierung erfolgte für alle Ansätze für $1 \mathrm{~h}$ im $30^{\circ} \mathrm{C}$-Wasserbad unter langsamem Schütteln. Anschließend wurden die Kulturen für $30 \mathrm{sec}$ bei $6500 \mathrm{UpM}$ zentrifugiert und $2 \mathrm{x}$ in je $1 \mathrm{ml} \mathrm{PBS} / 10 \%$ Sorbitol gewaschen. Die Pellets wurden daraufhin in je $40 \mu \mathrm{l}$ PBS/10 \% Sorbitol resuspendiert. In jede Grube eines Objektträgers wurden $20 \mu 1$ Poly-LLysin $\left(1 \mathrm{mg} / \mathrm{ml}\right.$ in $\left.\mathrm{ddH}_{2} \mathrm{O}\right)$ gegeben und für ca. 1 min einwirken gelassen. Die Gruben

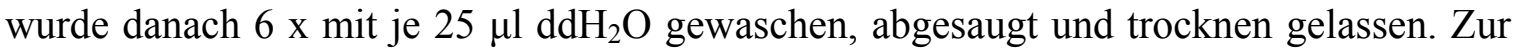
Errichtung einer wasserabweisenden Barriere wurden die mit Poly-L-Lysin behandelten Gruben nun mit einem PAP-PEN ${ }^{\circledR}$ umrandet und für 5 min abtrocknen gelassen. Pro Grube wurden nun $40 \mu \mathrm{l}$ Zellen gegeben und für $10 \mathrm{~min}$ an die Oberfläche binden gelassen. Die ungebundenen Zellen wurden danach abgesaugt und die Gruben mit je $20 \mu 1$ Quenching-Lösung gewaschen. Anschließend wurden je $20 \mu \mathrm{l}$ Quenching-Lösung pro Grube aufgetragen und für 10 min inkubiert. Danach wurden die Gruben abgesaugt und je $20 \mu 1$ eines 1:200 in Quenching-Lösung verdünnten anti-Emp47-Antikörper zugesetzt. Es folgte eine Inkubation für $1 \mathrm{~h}$ in einer Feuchthaltekammer im Dunkeln. Die Gruben wurden daraufhin $5 \mathrm{x}$ mit je $20 \mu \mathrm{PBS} / 10 \%$ Sorbitol gewaschen und anschließend mit je $20 \mu$ eines 1:200 in Quenching-Lösung verdünnten Cy2-konjugierten Ziege-anti- 
Kaninchen-Antikörpers (Dianova, Hamburg) versetzt. Es folgte eine Inkubation für 45 min in der Feuchthaltekammer im Dunkeln. Die Gruben wurden daraufhin 6 x mit je 20 $\mu \mathrm{lPBS} / 10 \%$ Sorbitol gewaschen. Nun wurden in jede Grube $20 \mu 1$ 1:8000 in PBS/10 \% Sorbitol verdünntes $1 \mathrm{mg} / \mathrm{ml}$ DAPI gegeben (Endkonz. $100 \mathrm{ng} / \mathrm{ml}$ ) und für $10 \mathrm{~min}$ in der Feuchthaltekammer im Dunkeln inkubiert. Jede Grube wurde daraufhin 3 x mit je $20 \mu 1$ PBS/10 \% Sorbitol gewaschen und anschließend mit einem kleinen Tropfen (ca. $8 \mu 1$ ) Einbett-Medium überschichtet und durch ein entsprechendes Deckglas abgedeckt. Überschüssiges Einbett-Medium wurde vorsichtig entfernt und nach dem Abtrocknen das Deckglas mit Nagellack umrandet und versiegelt. Die so behandelten Zellen wurden fluoreszenzmikroskopisch untersucht und danach bei $-20^{\circ} \mathrm{C}$ im Dunkeln aufbewahrt.

\section{Fixative:}

$3 \%(\mathrm{w} / \mathrm{v})$ Paraformaldehyd in PBS/10 \% Sorbitol

$\rightarrow$ löst sich nach üN-Inkubation auf der Wippe

\begin{tabular}{rlr} 
PBS $/ 10 \%$ Sorbitol $(100 \mathrm{ml}):$ & Endkonz.: \\
\hline $10 \mathrm{ml}$ & 10x PBS & $1 \mathrm{x}$ \\
$27.5 \mathrm{ml}$ & $2 \mathrm{M}$ Sorbitol $(36.44 \%)$ & $10 \%(\mathrm{w} / \mathrm{v})$ \\
& & \\
\hline Quenching-Lösung $(20 \mathrm{ml}):$ & Endkonz.: \\
\hline $2 \mathrm{ml}$ & $10 \mathrm{x}$ PBS & $10 \%(\mathrm{w} / \mathrm{v})$ \\
$5.49 \mathrm{ml}$ & $2 \mathrm{M}$ Sorbitol $(36.44 \%)$ & $1 \%(\mathrm{w} / \mathrm{v})$ \\
$0.8 \mathrm{ml}$ & $25 \%$ Triton X-100 & $1 \%(\mathrm{w} / \mathrm{v})$
\end{tabular}

Einbett-Medium (siehe 2.2.5.1)

\subsubsection{Subzelluläre Fraktionierung von Hefekompartimenten}

(nach Paravicini et al., 1992)

Der entsprechende Hefestamm (z.B. ein Stamm, welcher ein HA-erweitertes Use1Protein expremiert) wurde bis zu einer $\mathrm{OD}_{600}$ von 0.5 bis 1.0 wachsen gelassen und nun $20 \mathrm{OD}_{600}$ durch $5 \mathrm{~min}$ Zentrifugation bei $3000 \mathrm{UpM}$ geerntet. Das Pellet wurde in $2 \mathrm{ml}$ $\mathrm{TE} \beta$ resuspendiert und für $10 \mathrm{~min}$ im $30^{\circ} \mathrm{C}$-Wasserbad unter leichtem Schütteln inkubiert. Die Zellen wurden daraufhin für 3 min bei 3000 UpM zentrifugiert und das Pellet in $2 \mathrm{ml}$ 
Sphäroplast-Puffer mit $60 \mu 110 \mathrm{mg} / \mathrm{ml}$ Zymolyase (Endkonz. $=300 \mu \mathrm{g} / \mathrm{ml}$ ) resuspendiert. Es folgte eine Sphäroplastierung für $1 \mathrm{~h}$ bei $30^{\circ} \mathrm{C}$ unter langsamen Schütteln. Die Zellen wurden daraufhin vorsichtig 3 x mit je $1 \mathrm{ml}$ Sphäroplast-Puffer, welchem Proteaseinhibitoren zugesetzt wurden, gewaschen und anschließend in $1 \mathrm{ml}$ Lyse-Puffer + Proteaseinhibitoren resuspendiert. Die Zellen wurden nun 5 x vorsichtig im Glaspotter (,loose“) homogenisiert. Der Ansatz wurde daraufhin für 5 min bei 2000 UpM (500 g) und $4^{\circ} \mathrm{C}$ zentrifugiert, um die Zelltrümmer abzutrennen. Der Überstand (Homogenat, $\mathbf{H}$ ) wurde vorsichtig abgenommen und $400 \mu \mathrm{l}$ bei $-20^{\circ} \mathrm{C}$ für das spätere Gel gesichert. $500 \mu \mathrm{l}$ des Homogenats wurden für $10 \mathrm{~min}$ bei $13,000 \mathrm{UpM}(13,000 \mathrm{~g})$ und $4^{\circ} \mathrm{C}$ zentrifugiert. Ca. $450 \mu \mathrm{l}$ des Überstandes (S13) wurden daraufhin vorsichtig, ohne das Pellet mitzunehmen, abgenommen und in ein neues, dickwandiges Eppendorf-Gefäß überführt. Der Rest des Überstandes wurde verworfen. Das Pellet (P13), welches vakuoläre, mitochondriale und ER-Membranen enthält, wurde in $500 \mu$ Lyse-Puffer + Proteaseinhibitoren resuspendiert und bei $-20^{\circ} \mathrm{C}$ gesichert. S13 wurde nun für 20 min bei $50,000 \mathrm{UpM}(200,000 \mathrm{~g})$ in einer Tabletop-Ultrazentrifuge bei $4^{\circ} \mathrm{C}$ zentrifugiert. Ca. 400 $\mu l$ des Überstandes (S200), welcher cytosolische Proteine enthält, wurden vorsichtig abgenommen, ohne das Pellet mitzunehmen. Der Rest des Überstandes wurde wieder verworfen. Das Pellet (P200), welches Membranen von kleinen Vesikeln und vom GolgiApparat enthält, wurde in ca. $450 \mu \mathrm{l}$ Lyse-Puffer + Proteaseinhibitoren resuspendiert und bei $-20^{\circ} \mathrm{C}$ gesichert.

\section{$\underline{\text { Gel: }}$}

Je $50 \mu 1$ der Fraktionen H, P13, P200 und S200 wurden mit $25 \mu 13 x$ Probenpuffer versetzt, für 5 min bei $95^{\circ} \mathrm{C}$ erhitzt und anschließend je $30 \mu \mathrm{im} \mathrm{SDS-PAGE} \mathrm{aufgetrennt.}$

Lyse-Puffer $(10 \mathrm{ml})$ :

$500 \mu \mathrm{l} \quad 1 \mathrm{M}$ Tris, $\mathrm{pH} 7.5$

$1 \mathrm{ml} 2 \mathrm{M}$ Sorbitol

$20 \mu \mathrm{l} \quad 0.5 \mathrm{M}$ EDTA

\author{
Endkonz.: \\ $50 \mathrm{mM}$ \\ $0.2 \mathrm{M}$ \\ $1 \mathrm{mM}$
}




\section{Ergebnisse}

\subsection{Identifizierung von Suppressoren der vtil-2-Mutante}

Um Gene zu identifizieren, die mit VTI1 im Transport vom Golgi-Apparat zur Prävakuole (spätes Endosom) bzw. im Transport zur Vakuole interagieren, wurde ein MulticopySuppressor-Screen mit der temperatursensitiven Mutante vtil-2 durchgeführt. Diese Mutante bietet sich an, da sie während der Inkubation bei der restriktiven Temperatur $\left(37^{\circ} \mathrm{C}\right)$ sowohl im CPY-, ALP- als auch API-Transport zur Vakuole blockiert ist, im Unterschied zu vtil-11 jedoch keinen Defekt im retrograden Transport zum cis-GolgiKompartiment aufweist. Außerdem besitzt vtil-2 im Unterschied zu vtil-1 einen Wachstumsdefekt bei $37^{\circ} \mathrm{C}$, welchen man benutzen kann, um in einem MulticopySuppressor-Screen Suppressoren zu identifizieren, die es vtil-2-Zellen erlauben, bei $37^{\circ} \mathrm{C}$ zu wachsen. Dieser Wachstumsdefekt von vtil-2 ist in Zellen mit einem 9Da-Hintergrund stärker ausgeprägt als in Zellen mit SEY6210-Hintergrund, weshalb der Stamm FvMY22 für diesen Suppressor-Screen verwendet wurde. Mittels Lithiumacetat-Transformation

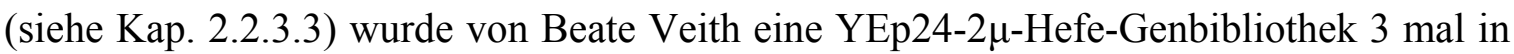
den Stamm FvMY22 transformiert und auf SD-Ura-Platten ausplattiert. Um die transformierten Gene zu exprimieren wurden die Platten anschließend über Nacht bei $30^{\circ} \mathrm{C}$ inkubiert. Daraufhin erfolgte eine Inkubation der Platten bei $37^{\circ} \mathrm{C}$. Insgesamt wurden ca. 38,700 Transformanten auf Suppression des Wachstumsdefektes der vtil-2Mutante untersucht. Aus Kolonien, die ein verbessertes Wachstum bei $37^{\circ} \mathrm{C}$ zeigten, wurden die Plasmide wie in Kap. 2.2.3.4 beschrieben isoliert und mittels Restriktionsverdau (siehe Kap. 2.2.2.3.1) mit SalI und EcoRV auf das Vorhandensein eines Inserts hin überprüft. Plasmide mit Insert wurden daraufhin wieder in den Stamm FvMY22 zurücktransformiert. Diese Retransformanten wurden einem erneuten Wachstumstest unterzogen (siehe Kap. 2.2.3.12) um ihre Suppressor-Aktivität zu verifizieren. 13 Retransformanten zeigten eine Suppression des Wachstumsdefektes der vtil-2-Mutante.

Sequenzierung (siehe Kap. 2.2.2.3.8) der Plasmide mit den Primern YEP24-3' bzw. YEP24-5' und Vergleich der Sequenzen mit der S. cerevisiae-Genom-Datenbank SGD (http://genome-www.stanford.edu/Saccharomyces) ergab - wie zu erwarten - die WTSequenz von VTI1 (2 Plasmide), welche die vtil-2-Mutation korrigierte. Außerdem enthielten 4 Plasmide die Sequenz des prävakuolären SNAREs PEP12, für welches eine 
genetische Interaktion mit der vtil-2-Mutante bereits beschrieben wurde (Fischer von Mollard and Stevens, 1999). Die Sequenz des vakuolären SNARE-Proteins VAM3 wurde allerdings nicht aufgefunden, obwohl VAM3-Überexpression den Wachstumsdefekt von vti1-2-Zellen supprimiert (Fischer von Mollard and Stevens, 1999). Das deutet darauf hin, dass der Suppressor-Screen nicht gesättigt war, d.h. innerhalb der 38,700 Transformanten nicht alle Hefe-Gene repräsentiert waren. Bei der Analyse der 7 restlichen Plasmide zeigte sich, dass das Plasmid pBK25 ein $11 \mathrm{~kb}$ großes Fragment von Chromosom XI (nt 69529 bis 80400) enthielt, welches unter anderem für das Gen des R-SNARE-Proteins Ykt6p codierte.

Bislang war bekannt, dass YKT6 genetisch und biochemisch mit VTI1 im retrograden Transport zum cis-Golgi interagiert (Lupashin et al., 1997). Außerdem konnte Ykt6p zusammen mit den SNAREs Vam3p, Vam7p, Vtilp und Nyv1p aus Detergenz-Extrakten von Hefe-Vakuolen immunpräzipitiert werden, wo es eine Funktion in der homotypischen Vakuolenfusion zu besitzen scheint (Ungermann et al., 1999). Um festzustellen, ob tatsächlich die YKT6-Sequenz alleine den Suppressionseffekt hervorruft, wurde ein $1.1 \mathrm{~kb}$ großes Fragment, welches ausschließlich YKT6 codiert, über eine PCR-Reaktion mit den Primern YKT6 5' und YKT6 3' aus genomischer Hefe-DNA amplifiziert und in den

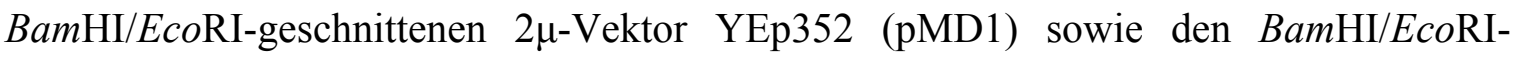
geschnittenen CEN-Vektor pRS316 (pMD21) kloniert. Beide Plasmide wurden daraufhin in den Stamm FvMY22 retransformiert.

Der Wachstumstest (siehe Kap. 2.2.3.12) in Abb. 1.1 zeigt, dass der Wachstumsdefekt der vtil-2-Mutante bei $37^{\circ} \mathrm{C}$ durch Überexpression von YKT6 sowohl von dem $2 \mu$-Plasmid (10 bis 20 Kopien pro Hefezelle) als auch von dem centromeren Plasmid (1 bis 3 Kopien pro Hefezelle) supprimiert wird. 


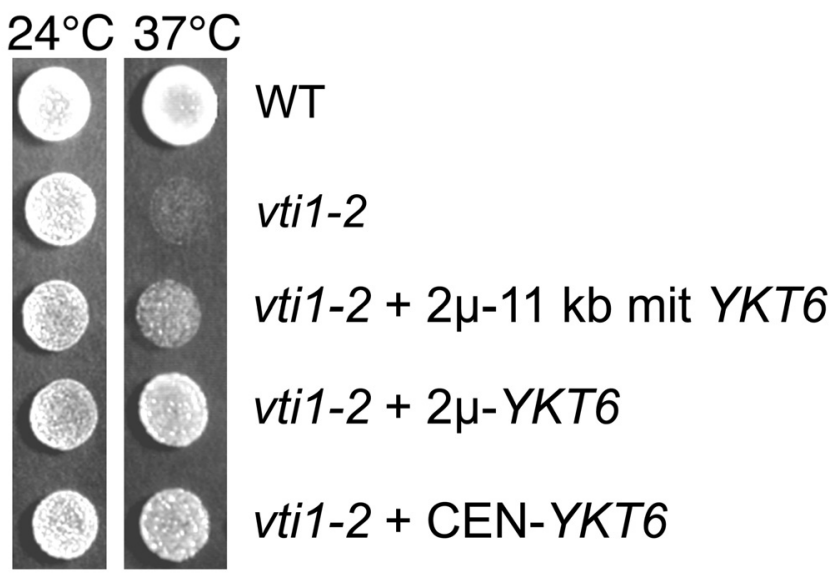

Abb. 3.1: Überexpression von YKT6 supprimiert den Wachstumsdefekt der vtil-2-Mutante. In einem Wachstumstest wurden Verdünnungen von WT (RPY10), vti1-2- (FvMY22), sowie vti12-Zellen, die YKT6 entweder vom ursprünglichen $2 \mu$-Genbibliotheks-Plasmid (pBK25) oder subkloniert in einem $2 \mu$-(pMD1) oder CEN-Plasmid (pMD21) exprimierten, bei $24^{\circ} \mathrm{C}$ oder $37^{\circ} \mathrm{C}$ auf YEPD-Platten inkubiert.

YKT6 als Suppressor der vtil-2-Mutante zu identifizieren war unerwartet, da es bislang keine Hinweise dafür gab, dass Ykt6p am Transport zur Prävakuole bzw. Vakuole beteiligt ist. Für die weitere Analyse des vti1-2-Suppressors Ykt6p siehe Kap. 3.1.2

Die Insertsequenzen der restlichen 6 Suppressorplasmide wurden ebenfalls mit der HefeGenom-Datenbank SGD verglichen:

Tab. 3.1: Ergebnis der Sequenzierung der Plasmide, welche eine Suppression des Wachstumsdefektes der vtil-2-Mutante bei $37^{\circ} \mathrm{C}$ zeigten.

\begin{tabular}{|l|l|l|l|l|l|}
\hline \multicolumn{5}{|c|}{ pBK18 (nt 788323 - 800579 [12.3 kb] auf Chromosom IV) } \\
\hline Bezeichnung & Anfang & Ende & Strang & Gen & Beschreibung \\
\hline YDR166C & 786299 & 789214 & Crick & SEC5 & $\begin{array}{l}\text { Komponente des Exozyst-Komplexes } \\
\text { (Exozytose) }\end{array}$ \\
\hline YDR167W & 789442 & 79062 & Watson & TAF25 & TFIID-Untereinheit (Transkriptionsfaktor) \\
\hline YDR168W & 790321 & 791841 & Watson & CDC37 & $\begin{array}{l}\text { mutmaßliches Chaperon, beteiligt an } \\
\text { Spindelpolkörper-Verdopplung }\end{array}$ \\
\hline YDR169C & 792341 & 793882 & Crick & STB3 & Sin3-Bindeprotein (Transkriptionsfaktor) \\
\hline YDR170C & 796186 & 802215 & Crick & SEC7 & $\begin{array}{l}\text { Guanin-Nukleotid-Austausch-Protein für } \\
\text { ARF }\end{array}$ \\
\hline
\end{tabular}




\begin{tabular}{|l|l|l|l|l|l|}
\hline \multicolumn{7}{|c|}{ pBK22 (nt 296042 - 299688 [3.6 kb] auf Chromosom XVI) } \\
\hline Bezeichnung & Anfang & Ende & Strang & Gen & Beschreibung \\
\hline YPL136W & 296285 & 296653 & Watson & n.d. & $\begin{array}{l}\text { hypothetischer offener Leserahmen, } \\
\text { Ähnlichkeit zu trg-Protein aus Rattus } \\
\text { norvegigus }\end{array}$ \\
\hline YPL135W & 297552 & 298049 & Watson & ISU1 & Eisen-Schwefel-Cluster, nifU-ähnliches Protein \\
\hline YPL134C & 298570 & 299502 & Crick & n.d. & $\begin{array}{l}\text { hypothetischer offener Leserahmen, starke } \\
\text { Ähnlichkeit mit YOR222W, Ähnlichkeit mit } \\
\text { ADP/ATP-Carrier-Proteinen }\end{array}$ \\
\hline
\end{tabular}

\begin{tabular}{|l|l|l|l|l|l|}
\hline \multicolumn{5}{|c|}{ pBK24 (nt 1009767 - 1014198 [4.4 kb] auf Chromosom XV) } \\
\hline Bezeichnung & Anfang & Ende & Strang & Gen & Beschreibung \\
\hline YOR358W & 1010153 & 1010881 & Watson & HAP5 & $\begin{array}{l}\text { Komponente des CCAAT-bindenden } \\
\text { Transkriptionsfaktors }\end{array}$ \\
\hline YOR359W & 1011181 & 1012752 & Watson & n.d. & hypothetischer offener Leserahmen \\
\hline YOR360C & 1013233 & 1014813 & Crick & PDE2 & $\begin{array}{l}\text { cAMP-Phosphodiesterase mit hoher } \\
\text { Affinität (niedriger Km) }\end{array}$ \\
\hline
\end{tabular}

\begin{tabular}{|l|l|l|l|l|l|}
\hline \multicolumn{7}{|c|}{ pBK26 (nt 174418 - 179405 [5.0 kb] auf Chromosom II) } \\
\hline Bezeichnung & Anfang & Ende & Strang & Gen & Beschreibung \\
\hline YBL023C & 174883 & 177489 & Crick & MCM2 & $\begin{array}{l}\text { Minichromosom-erhaltendes Protein, } \\
\text { Transkriptionsfaktor }\end{array}$ \\
\hline YBL022C & 177837 & 181238 & Crick & PIM1 & mitochondriale ATP-abhängige Protease \\
\hline
\end{tabular}

\begin{tabular}{|l|l|l|l|l|l|}
\hline \multicolumn{5}{|c|}{ pBK40 (nt 104357 - 112880 [8.5 kb] auf Chromosom XIII) } \\
\hline Bezeichnung & Anfang & Ende & Strang & Gen & Beschreibung \\
\hline YML081W & 104777 & 108531 & Watson & n.d. & $\begin{array}{l}\text { hypothetischer offener Leserahmen, } \\
\mathrm{C}_{2} \mathrm{H}_{2} \text {-Zinkfinger-DNA-Bindemotif }\end{array}$ \\
\hline YML080W & 108806 & 110077 & Watson & n.d. & $\begin{array}{l}\text { hypothetischer offener Leserahmen, } \\
\text { wenig coiled coil, kein paircoil, keine } \\
\text { Transmembrandomäne }\end{array}$ \\
\hline YML079W & 110247 & 110852 & Watson & n.d. & $\begin{array}{l}\text { hypothetischer offener Leserahmen, kein } \\
\text { coiled coil, kein paircoil, keine } \\
\text { Transmembrandomäne }\end{array}$ \\
\hline YML078W & 111002 & 111550 & Watson & CPR3 & $\begin{array}{l}\text { Cyclophilin-3 (Cyclosporin-sensitive } \\
\text { Prolin-Rotamase-3) }\end{array}$ \\
\hline YML077W & 111865 & 112344 & Watson & BET5 & Bet5p/18 kDa-Komponente von TRAPP \\
\hline YML076C & 112513 & 115347 & Crick & n.d. & hypothetischer offener Leserahmen \\
\hline
\end{tabular}




\begin{tabular}{|l|l|l|l|l|l|}
\hline \multicolumn{5}{|c|}{ pBK41 (nt 609360 - 617576 [8.2 kb] auf Chromosom IV) } \\
\hline Bezeichnung & Anfang & Ende & Strang & Gen & Beschreibung \\
\hline YDR081C & 607298 & 610075 & Crick & PDC2 & $\begin{array}{l}\text { Asparagin- und Serin-reiches Protein, } \\
\text { reguliert die Transkription der Pyruvat- } \\
\text { Decarboxylase) }\end{array}$ \\
\hline YDR082W & 610435 & 611919 & Watson & STN1 & Beteiligt in Regulation der Telomerlänge \\
\hline YDR083W & 612010 & 613218 & Watson & n.d. & $\begin{array}{l}\text { hypothetischer offener Leserahmen, } \\
\text { hoher coiled coil- und paircoil-Gehalt, } \\
\text { Transmembrandomäne }\end{array}$ \\
\hline YDR084C & 613398 & 613997 & Crick & n.d. & hypothetischer offener Leserahmen \\
\hline YDR085C & 614281 & 616143 & Crick & AFR1 & Cytoskelet-Protein, ähnelt Arrestinen \\
\hline
\end{tabular}

Gene, deren Produkte offensichtlich nicht am Transport zur Vakuole beteiligt sind, wie z.B. Gene für Transkriptionsfaktoren oder Gene, die für mitochondriale Proteine codieren, wurden nicht näher untersucht. Da in einer ALP-,,Pulse-Chase“-Immunpräzipitation (siehe Kap. 2.2.4.10) nur pBK24 eine deutliche Suppression des ALPTransportdefektes der vtil-2-Mutante zeigte (keine Abbildung), wurde nun zunächst dieses Suppressorplasmid genauer untersucht. pBK24 enthält zwei komplette Leserahmen: HAP5, eine Komponente eines Transkriptionsfaktors und der bislang uncharakterisierte hypothetische offene Leserahmen (,hypothetical open reading frame“ $=\mathrm{ORF})$ YOR359w. Um den ORF zu isolieren, wurde ein $2.3 \mathrm{~kb}$ großes ClaI/SpeIFragment aus pBK24 herausgeschnitten (nt 1010849 [332 bp stromaufwärts des StartATG] bis 1013168 [416 bp stromabwärts des Stop-Codons]) und sowohl in den $2 \mu$ Vektor YEp352 (pMD3) als auch in den CEN-Vektor pRS316 (pMD9) subkloniert. 


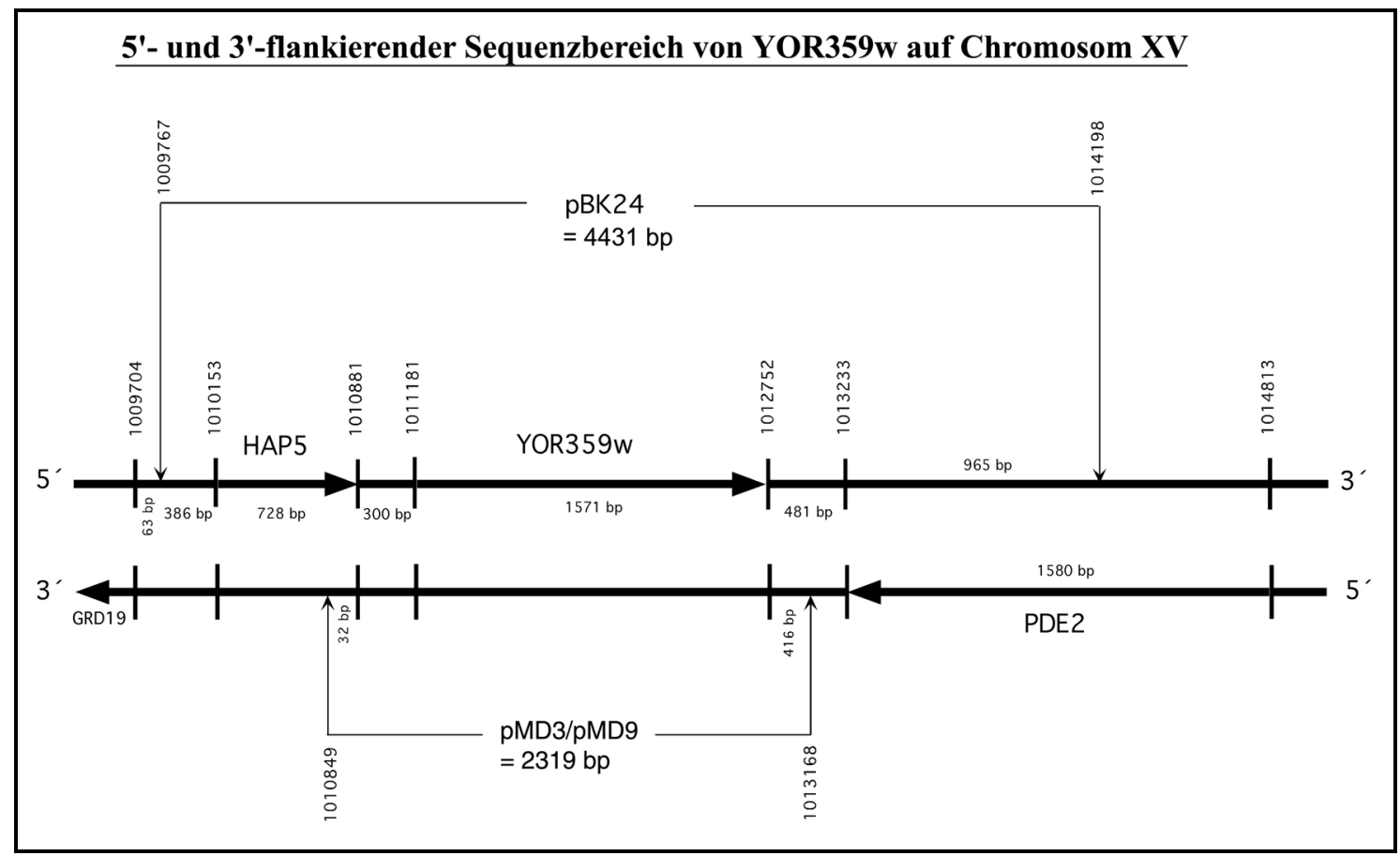

Abb. 3.2: Schematische Darstellung der Subklonierung des offenen Leserahmens YOR359w aus dem Suppressorplasmid pBK24. Die $2.3 \mathrm{~kb}$ große YOR359w-Sequenz wurde über ClaI/SpeIVerdau in das $2 \mu$-Plasmid YEp352 (pMD3) bzw. das CEN-Plasmid pRS316 (pMD9) subkloniert.

Überexpression von YOR359w, sowohl vom ursprünglichen $2 \mu$-Suppressorplasmid pBK24 mit einer $4.4 \mathrm{~kb}$ großen genomischen Sequenz, oder vom subklonierten

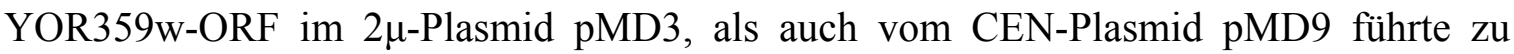
einer Verstärkung des Wachstums von vtil-2-Zellen bei $37^{\circ} \mathrm{C}$ (siehe Abb. 3.3). Dies beweist, dass die YOR359w-Sequenz alleine Suppressionsaktivität besitzt und genetisch mit VTII interagiert.

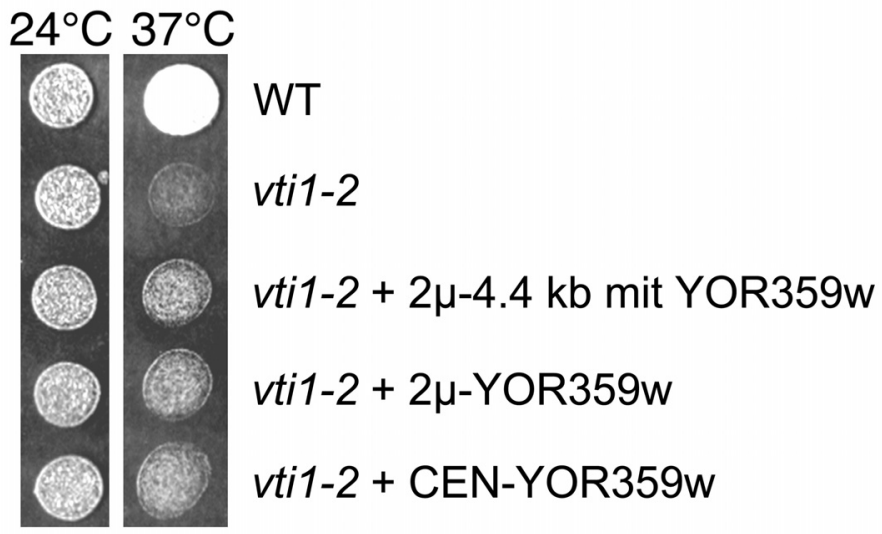

Abb. 3.3: Überexpression von YOR359w supprimierte den Wachstumsdefekt der vti1-2-Mutante. In einem Wachstumstest wurden Verdünnungen von WT (RPY10), vti1-2- (FvMY22), sowie vtil-2-Zellen, die YOR359w entweder vom ursprünglichen $2 \mu$-Genbibliotheks-Plasmid (pBK24) oder subkloniert in einem $2 \mu$ - (pMD3) oder CEN-Plasmid (pMD9) exprimierten, bei $24^{\circ} \mathrm{C}$ oder $37^{\circ} \mathrm{C}$ auf YEPD-Platten inkubiert. 
Um zu überprüfen, ob die Suppression durch YOR359w spezifisch für die vti1-2-Mutante und deren betroffene Transportschritte ist, und nicht etwa durch eine generelle Umgehung der VTI1-Funktion hervorgerufen wurde, sollte der Effekt der Überexpression von YOR359w in vtil-11-Zellen untersucht werden. Diese Mutante besitzt wie vtil-2 einen Wachstumsdefekt bei $37^{\circ} \mathrm{C}$ und ist bei dieser Temperatur ebenfalls im Transport zur Prävakuole und Vakuole blockiert. Im Gegensatz zu vtil-2 zeigt vti1-11 allerdings auch einen Defekt im Transport zum cis-Golgi-Kompartiment. Abb. 3.4 zeigt, dass der Wachstumdefekt von vtil-11-Zellen (FvMY23) bei $37^{\circ} \mathrm{C}$ durch Überexpression von YOR359w, entweder vom ursprünglichen $2 \mu$-Suppressorplasmid pBK24, oder von der subklonierten Sequenz im $2 \mu$-Plasmid pMD3 nicht supprimiert wird, was darauf hin deutet, dass die Suppression durch YOR359w Allel-spezifisch ist.

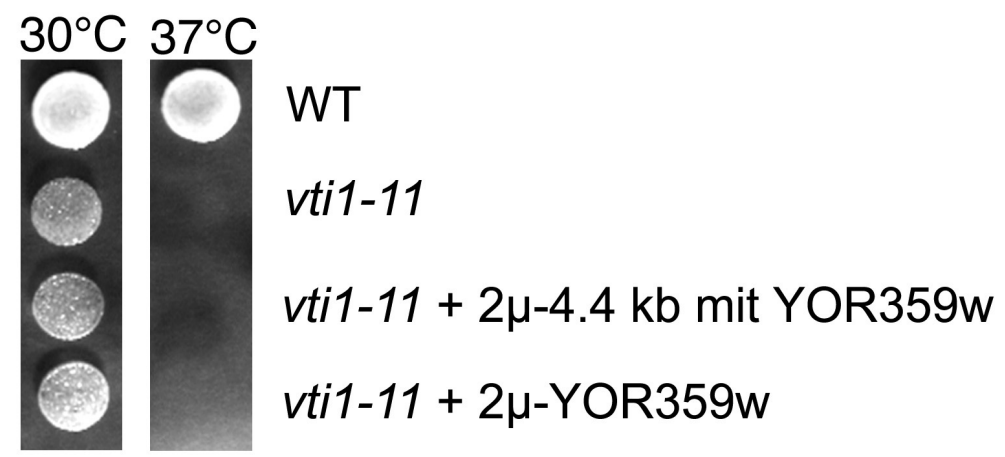

Abb. 3.4: Der Wachstumsdefekt in vti1-11-Zellen wird nicht durch Überexpression von YOR359w supprimiert. In einem Wachstumstest wurden Verdünnungen von WT (RPY10), vti1-11(FvMY21), sowie vti1-11-Zellen, die YOR359w entweder vom ursprünglichen $2 \mu$-Genbibliotheks-Plasmid (pBK24) oder subkloniert in einem $2 \mu$-Vektor (pMD3) exprimierten, bei $30^{\circ} \mathrm{C}$ oder $37^{\circ} \mathrm{C}$ auf YEPD-Platten inkubiert.

Aufgrund der Allel-spezifischen Suppression des Wachstumsdefektes der vti1-2-Mutante wurde YOR359w daher als VTS1 (vti1-2-Suppressor 1) bezeichnet. VTS1 codiert für ein 523 Aminosäure langes Protein. Sequenzanalysen zeigten keine hydrophoben Bereiche, die charakteristisch für eine Transmembrandomäne sein könnten, weshalb es sich bei VTS1 vermutlich um ein lösliches Protein handelt. Über Datenbankanalysen wurden nur zwei weitere Proteine mit Sequenzhomologien zu VTS1 in der Hefe Candida albicans (28 \% Aminosäure-Identität, GenBank ${ }^{\mathrm{TM}}$-Accessionnumber AL033497) und der Spalthefe Schizosaccharomyces pombe (24 \% Aminosäure-Identität, GenBank ${ }^{\mathrm{TM}}$-Accessionnumber CAB89878) gefunden. Beide Proteine besitzen eine vergleichbare Länge wie das VTS1Protein und enthalten ein SAM-Motiv (,sterile $\alpha$ motif‘) am C-Terminus. SAM-Domänen sind an der Ausbildung niedrig-affiner Protein-Protein-Interaktionen beteiligt und werden häufig in regulatorischen Proteinen gefunden (Ponting, 1995). 


\subsubsection{Charakterisierung von VTS1}

Um herauszufinden, welcher Transportschritt in der vtil-2-Mutante durch VTS1 supprimiert wird, sollte der Effekt der Überexpression von VTS1 auf den CPY-, ALP- und API-Transport zur Vakuole in vtil-2-Zellen untersucht werden. Hierzu wurden „PulseChase"-Immunpräzipitationsexperimente durchgeführt (siehe Kap. 2.2.4.10). CPY wird zuerst vom trans-Golgi zur Prävakuole transportiert und anschließend in einem zweiten Transportschritt von der Prävakuole zur Vakuole befördert. In vti1-2-Zellen sind beide Transportschritte schon während Inkubation bei $32^{\circ} \mathrm{C}$ blockiert (Abb. 3.5 Spur 1 und Spur 2). vti1-2-Zellen (FvMY24) sowie vti1-2-Zellen die VTS1 überexprimieren (FvMY24pBK24 und FvMY24-pMD3) wurden bei $24^{\circ} \mathrm{C}$ wachsen gelassen, danach für 15 min bei $32{ }^{\circ} \mathrm{C}$ inkubiert, anschließend mit $\left[{ }^{35} \mathrm{~S}\right]$-Cystein/Methionin gefüttert („Pulse“) und danach mit einem Überschuss nicht-radioaktivem Cystein/Methionin versetzt und für weitere 30 min bei $32^{\circ} \mathrm{C}$ inkubiert („Chase“). Die Zellen wurden daraufhin sphäroplastiert und CPY in den Zellextrakten sowie im Medium immunpräzipitiert. Aufgrund des Transportdefektes erreicht CPY die Vakuole in vtil-2-Zellen nicht, was am Fehlen der maturen CPY-Form ersichtlich ist (Abb. 3.5 Spur 1, Interne Fraktion). Fast das gesamte CPY wird als Golgi-modifiziertes p2CPY sekretiert (Abb. 3.5 Spur 2, Externe Fraktion). Dieser Defekt wird durch Überexpression von VTS1 nicht supprimiert (Abb. 3.5 Spuren 3 bis 6).

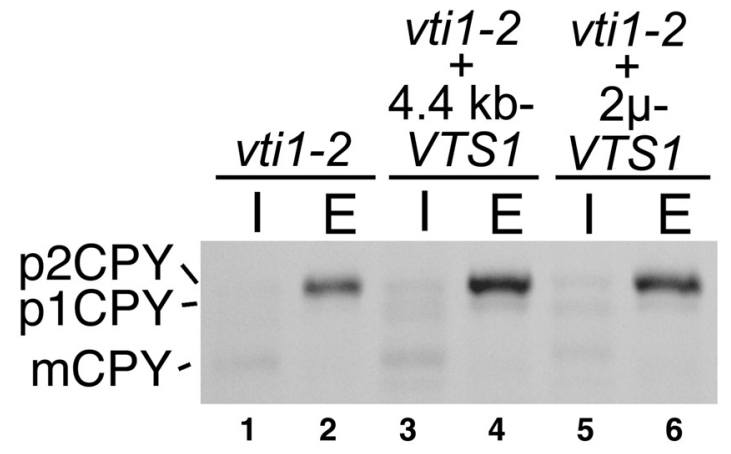

Abb. 3.5: Überexpression von VTS1 zeigte keine Suppression des CPY-Transportdefektes der vtil2-Zellen. In einer „Pulse-Chase“-Immunpräzipitation wurden vti1-2-Zellen (FvMY24), sowie vti1-2-Zellen die VTS1 entweder vom ursprünglichen $2 \mu$-Genbibliotheksplasmid (pBK24) oder subkloniert in einem $2 \mu$-Vektor (pMD3) exprimierten, analysiert. Die Zellen wurden bei $24^{\circ} \mathrm{C}$ vorinkubiert und anschließend bei $32^{\circ} \mathrm{C}$ radioaktiv markiert. Es folgte eine Immunpräzipitation für CPY in den Zellextrakten (intern, I) bzw. im Medium (extern, E). Die Immunpräzipitate wurden durch eine SDS-PAGE separiert und durch Autoradiographie analysiert. p1CPY: ERlokalisierte Proform von Carboxypeptidase Y (CPY); p2CPY: Golgi-lokalisierte Proform von CPY; mCPY: vakuoläres, matures CPY. 
Da der CPY-Transport vom trans-Golgi zur Vakuole in zwei Teilschritten verläuft, könnte es sein, dass Vts1p nur in einem dieser Transportschritte benötigt wird. Falls es nämlich nur im zweiten Teilschritt involviert ist, würde eine Überexpression von VTS1 keinen Einfluss auf den CPY-Transport haben, solange der erste Transportschritt vom trans-Golgi zur Prävakuole blockiert ist. Leider besitzen wird keine Vtilp-Mutante, die nur im zweiten Teilschritt des CPY-Transportes zur Vakuole blockiert ist. vtil-1-Zellen besitzen wie vtil-2-Zellen einen Defekt im CPY-Transport vom trans-Golgi zur Prävakuole. Im Unterschied zu vti1-2-Zellen sind vti1-1-Zellen jedoch nicht im Transport von der Prävakuole zur Vakuole blockiert, weshalb es mit Hilfe dieser Mutante möglich ist, zwischen diesen beiden Transportschritten zu unterscheiden. Überexpression von VTS1 vom $2 \mu$-Genbibliotheksplasmid pBK24 zeigte in vtil-1-Zellen keine Suppression des Defektes des CPY-Transportes vom trans-Golgi zur Prävakuole (Abb. 3.6), was darauf hin deutet, dass VTS1 in diesem Transportschritt nicht involviert ist.

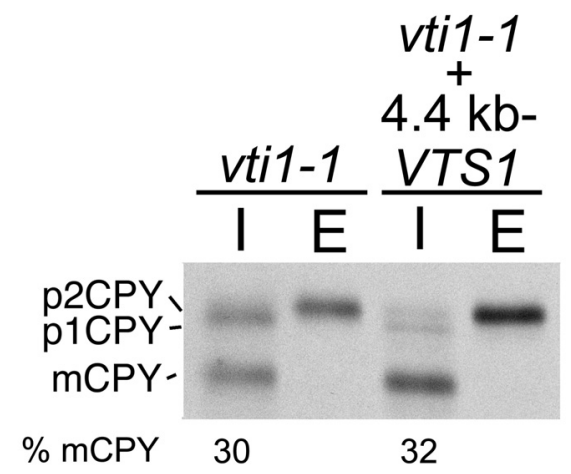

Abb. 3.6: Der CPY-Transportdefekt vom trans-Golgi zur Prävakuole wird in vti1-1-Zellen nicht durch Überexpression von VTS1 supprimiert. In einer „Pulse-Chase“-Immunpräzipitation wurden vti1-1-Zellen (FvMY7), sowie vti1-1-Zellen die VTS1 vom ursprünglichen $2 \mu-$ Genbibliotheksplasmid (pBK24) überexprimierten, analysiert. Die Zellen wurden bei $24^{\circ} \mathrm{C}$ vorinkubiert und anschließend bei $36^{\circ} \mathrm{C}$ radioaktiv markiert. Es folgte eine Immunpräzipitation für CPY in den Zellextrakten (intern, I) bzw. im Medium (extern, E). p1CPY: ER-lokalisierte Proform von Carboxypeptidase Y (CPY); p2CPY: Golgi-lokalisierte Proform von CPY; mCPY: vakuoläres, matures CPY.

Im Unterschied zu CPY wird das vakuoläre Membranprotein ALP in einem direkten Weg vom trans-Golgi zur Vakuole befördert, ohne den Umweg über die Prävakuole. Daher sollte nun mit „Pulse-Chase“-Experimenten untersucht werden, ob VTS1-Überexpression einen Effekt auf den Transport von ALP zur Vakuole zeigt. Nach einer 30-minütigen „Chase“-Periode betrug der Anteil an vakuolärem mALP in WT-Zellen generell ca. 95\%. vti1-2-Zellen zeigen einen Defekt im ALP-Transport bei $36^{\circ} \mathrm{C}$. Bei dieser Temperatur 
betrug der Anteil an mALP 41 \% (Abb. 3.7, Spur 3). Durch Überexpression von VTS1, entweder vom $2 \mu$-Genbibliothek-Plasmid pBK24 mit einem 4.4-kb VTS1-Insert (Spuren 4

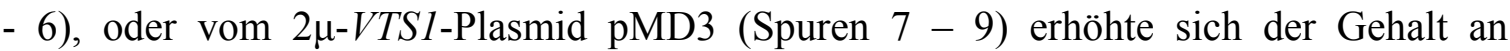
maturem ALP nach 30 Minuten auf 76 \% bzw. 70 \%. Lag VTS1 zusätzlich zur genomischen Kopie noch in 1 - 3 Kopien pro Zelle auf einem centromeren Plasmid (pMD9) vor, so erhöhte sich der Anteil an maturem ALP auf 54 \%. Diese Ergebnisse zeigen, dass Vts1p im ALP-Transport zur Vakuole involviert ist.

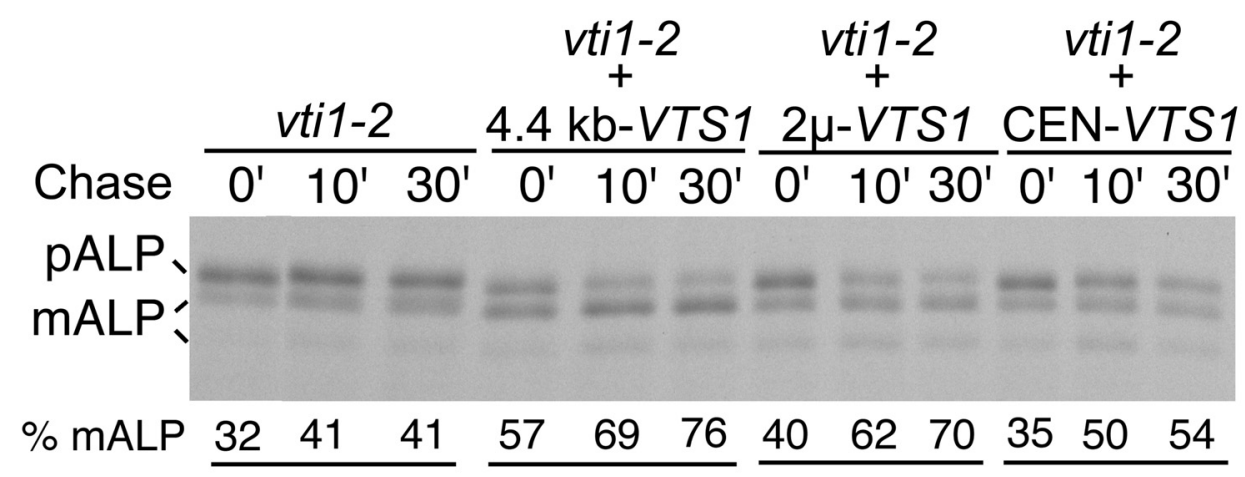

Abb. 3.7: Überexpression von VTS1 führte zu einer partiellen Suppression des ALP-Transportdefekt der vti1-2-Mutante. vtil-2-Zellen (FvMY24) mit den entsprechenden Suppressorplasmiden wurden bei $24^{\circ} \mathrm{C}$ wachsen gelassen und danach für 15 min bei $36^{\circ} \mathrm{C}$ inkubiert und radioaktiv markiert. Nach 0,10 und 30 min Inkubation bei $36^{\circ} \mathrm{C}$ (Chase) wurde ALP immunpräzipitiert und in einem SDS-PAGE mit anschließender Autoradiographie analysiert. pALP: Golgi-lokalisierte Proform von Alkalischer Phosphatase (ALP); mALP: vakuoläres, matures ALP.

API wird im Unterschied zu CPY und ALP im Cytosol synthetisiert, in Cvt-Vesikel, welche von einer Doppelmembran umgeben sind, eingeschlossen, und anschließend in einem Transportschritt, welcher der Autophagozytose ähnelt, zur Vakuole transportiert. API wurde nach einer 10-minütigen Markierung („Pulse“) und einer 120-minütigen „Chase“-Periode bei $37^{\circ} \mathrm{C}$ immunpräzipitiert. Abb. 3.8 zeigt, dass in der vtil-2-Mutante bei dieser Temperatur nur 27 \% API zur maturen Form prozessiert werden (Spur 1). Die

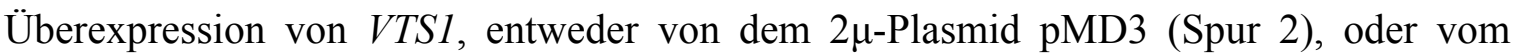
CEN-Plasmid pMD9 (Spur 3) führte zu einer partiellen Suppression des API-Transportdefektes der vtil-2-Mutante, was am Anstieg des Anteils der maturen API-Form auf $47 \%$ bzw. $43 \%$ zu ersehen ist. 


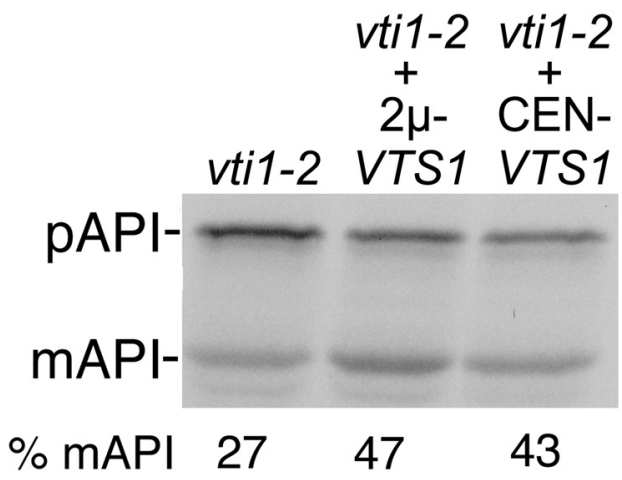

Abb. 3.8: Der API-Transportdefekt der vtil-2-Mutante wurde durch VTS1-Überexpression partiell supprimiert. vtil-2-Zellen (FvMY24) mit den entsprechenden Suppressorplasmiden wurden bei $24^{\circ} \mathrm{C}$ inkubiert, danach bei $37^{\circ} \mathrm{C}$ für 10 min radioaktiv markiert und API anschließend nach einer 2-stündigen Chase-Periode immunpräzipitiert. pAPI: cytosolische Proform von Aminopeptidase I (API); mAPI: vakuoläres, matures API.

Zusammen deuten diese Ergebnisse darauf hin, dass VTS1 genetisch mit VTI1 im biosynthetischen Transport zur Vakuole interagiert, während es am Transport vom transGolgi zur Prävakuole nicht beteiligt zu sein scheint.

\subsubsection{Deletionsmutanten von VTS1}

Als nächstes sollte herausgefunden werden, welchen Effekt der Verlust von Vts1p in Hefezellen hat. Hierzu wurde das VTS1-Gen sowohl in WT-Zellen, als auch in vti1-1- und vtil-2-Mutantenzellen deletiert, indem es gegen einen HIS3-Auxotrophiemarker ersetzt wurde (siehe Kap. 2.2.3.6). Das lineare, $1.2 \mathrm{~kb}$ große $v t s 1 \Delta:: H I S 3$-Deletionskonstrukt wurde über eine PCR-Reaktion mit den Hybridprimern SuKO-5' und SuKO-3' und dem HIS3-Plasmid pRS313 hergestellt. Das Deletionskonstrukt wurde daraufhin in haploide kompetente WT-Zellen (SEY6210), sowie kompetente vtil-1-(FvMY7)- und vtil-2(FvMY24)-Zellen transformiert (siehe Kap. 2.2.3.2.2), wo es das WT-VTSI-Gen über homologe Rekombination ersetzte. Die Zellen wurden daraufhin auf SD-His-Platten ausplattiert und bei RT inkubiert um gegen die Rekombinanten zu selektionieren. Aus den hochgewachsenen Kolonien wurde genomische DNA isoliert (siehe Kap. 2.2.3.5) und über eine PCR-Reaktion mit den Primern SU-3' und SU-5' das insertierte HIS3Auxotrophiegen amplifiziert und detektiert. Diese Primer erkennen Sequenzen, welche jeweils dem 5'- bzw. 3'-flankierenden Genbereich des zu deletierenden Genes entsprechen. Da diese Sequenzbereiche bei korrekter homologer Rekombination auch das 
Auxotrophiegen flankieren, kann dieses über die PCR-Reaktion identifiziert werden, sofern es eine andere Größe als das zu deletierende Gen besitzt.

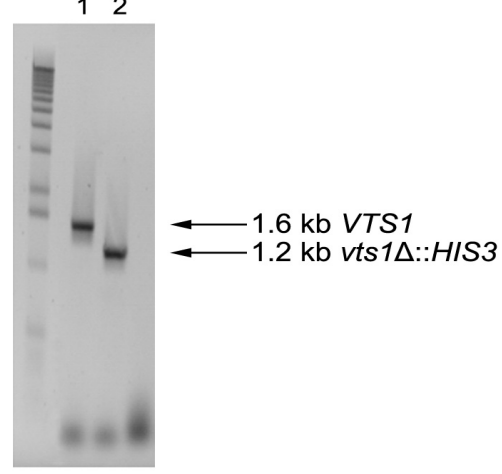

Abb. 3.9: Analyse der Deletion des VTS1-Genes über eine PCR-Reaktion und anschließende Agarose-Gelelektrophorese. Nach Austausch des VTS1-Genes gegen den Auxotrophiemarker HIS3 mittels homologer Rekombination wurde aus genomischer DNA der Rekombinanten über eine PCR-Reaktion mit den Primern SU-3' und SU-5' das 1.2 kb große HIS3-Gen amplifiziert (Spur 2) und so die Deletion nachgewiesen. Spur 1 zeigt das mit den gleichen Primern amplifizierte $1.6 \mathrm{~kb}$ große VTS1-Gen einer WT-DNA.

Auf diese Weise wurde die Deletionsmutante MDY1 (WT vts $1 \Delta:: H I S 3$ ), sowie die

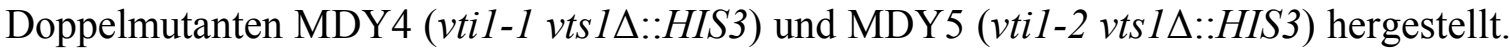
Da die Deletionsmutanten lebensfähig sind, handelt es sich bei VTS1 nicht um ein essentielles Gen. vts1 $\Delta$-Zellen (MDY1) zeigten keinen Defekt im Transport von CPY, ALP oder API zur Vakuole (Abb. 3.10).
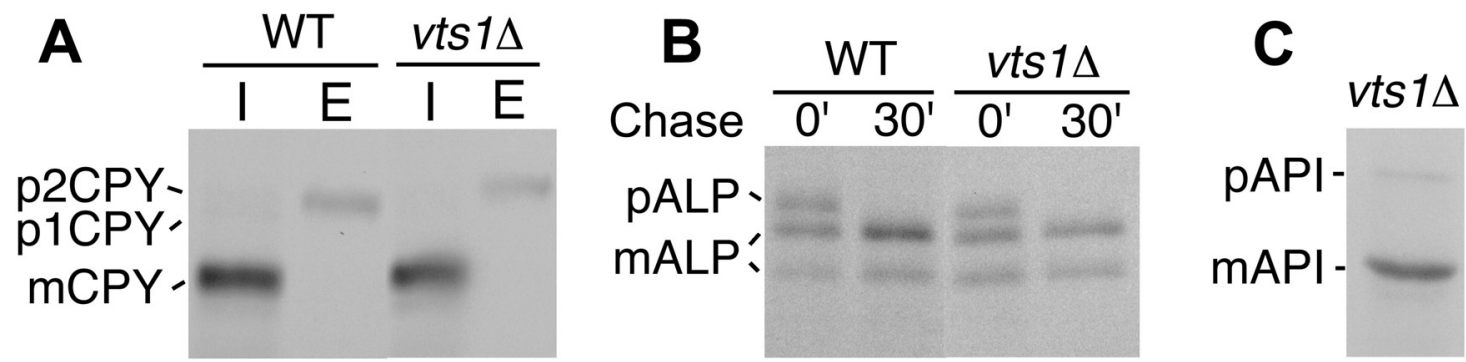

Abb. 3.10: VTS1-Deletionsmutanten besitzen keinen Defekt im CPY-, ALP- oder API-Transport zur Vakuole. WT- (SEY6210) und vts $1 \Delta$-Zellen (MDY1) wurden bei $30^{\circ} \mathrm{C}$ wachsen gelassen und ebenfalls bei $30^{\circ} \mathrm{C}$ radioaktiv markiert. (A) CPY wurde in den Zellextrakten (intern, I) und im Medium (extern, E) immunpräzipitiert. p1CPY: ER-lokalisierte Proform von Carboxypeptidase Y (CPY); p2CPY: Golgi-lokalisierte Proform von CPY; mCPY: vakuoläres, matures CPY. (B) Der ALP-Transport wurde in den gleichen Zellen untersucht. ALP wurde nach 0 und 30 min Inkubation (Chase) bei $30^{\circ} \mathrm{C}$ immunpräzipitiert. pALP: Golgi-lokalisierte Proform von Alkalischer Phosphatase (ALP); mALP: vakuoläres, matures ALP. (C) API wurde in vts1 $1 \Delta$ Zellen nach 2-stündiger Chase-Periode bei $37^{\circ} \mathrm{C}$ präzipitiert. Die Immunpräzipitate wurden in einem SDS-PAGE mit anschließender Autoradiographie analysiert. pAPI: cytosolische Proform von Aminopeptidase I (API); mAPI: vakuoläres, matures API. 
Die Defekte im CPY-, ALP- und API-Transport zur Vakuole waren in den

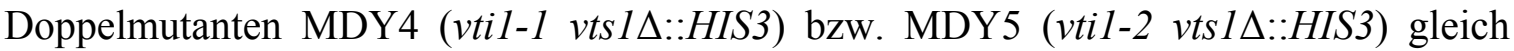
stark ausgeprägt wie in den Einzelmutanten vtil-1 (FvMY7) bzw. vti1-2 (FvMY24) (Abb. 3.11). Somit besitzen die Doppelmutanten keinen synthetischen Defekt im Proteintransport zur Vakuole.

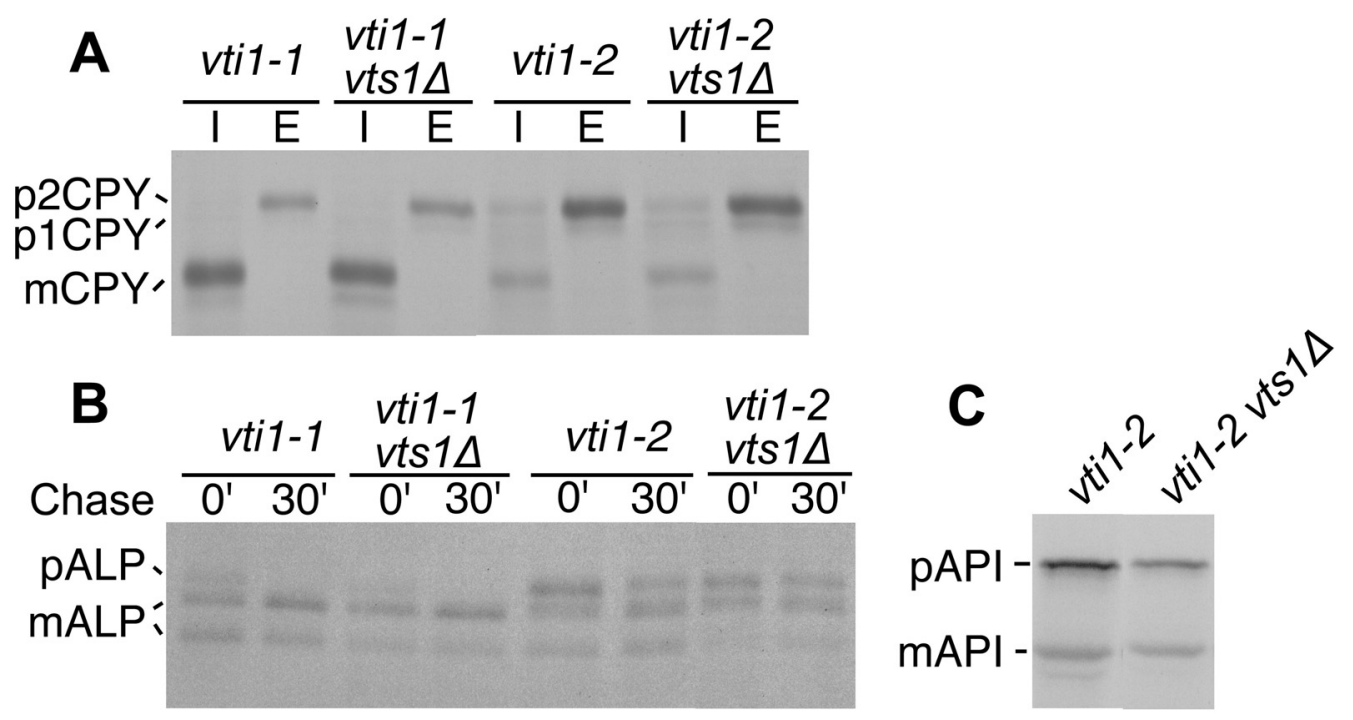

Abb. 3.11: VTS1-Doppelmutanten (vts1s in vti1-1- bzw. vti1-2-Hintergrund) besitzen keinen synthetischen Defekt im CPY-, ALP- oder API-Transport zur Vakuole. vti1-1- (FvMY7),

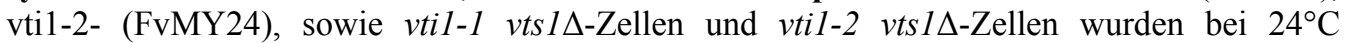
wachsen gelassen. (A) Die Zellen wurden für 15 min bei $31^{\circ} \mathrm{C}$ vorinkubiert und anschließend ebenfalls bei $31^{\circ} \mathrm{C}$ radioaktiv markiert. CPY wurde in den Zellextrakten (intern, I) und im Medium (extern, E) immunpräzipitiert. p1CPY: ER-lokalisierte Proform von Carboxypeptidase Y (CPY); p2CPY: Golgi-lokalisierte Proform von CPY; mCPY: vakuoläres, matures CPY. (B) Die Zellen wurden bei $36^{\circ} \mathrm{C}$ vorinkubiert und danach radioaktiv markiert. ALP wurde nach 0 und 30 min Inkubation (Chase) bei $36^{\circ} \mathrm{C}$ immunpräzipitiert. pALP: Golgi-lokalisierte Proform von Alkalischer Phosphatase (ALP); mALP: vakuoläres, matures ALP. (C) API wurde nach 2stündiger Chase-Periode bei $37^{\circ} \mathrm{C}$ präzipitiert. Die Immunpräzipitate wurden in einem SDSPAGE mit anschließender Autoradiographie analysiert. pAPI: cytosolische Proform von Aminopeptidase I (API); mAPI: vakuoläres, matures API.

Weder vts $1 \Delta$-Zellen (MDY1) noch vtil-1 vts1 $\Delta$-Zellen (MDY4) zeigten einen Wachstumsdefekt bei $24^{\circ} \mathrm{C}$ oder $37^{\circ} \mathrm{C}$ (Abb.3.12). vtil-2-(FvMY24)- und vtil-2 vts $1 \Delta$ Zellen (MDY5) wuchsen bei $24^{\circ} \mathrm{C}$ mit gleicher Geschwindigkeit. Bei $37^{\circ} \mathrm{C}$ wuchsen vtil2-Zellen langsam, während vti1-2 vts1 1 -Zellen überhaupt nicht mehr wuchsen. Somit besitzt die Doppelmutante vtil-2 vts $1 \Delta$ einen synthetischen Wachstumsdefekt bei $37^{\circ} \mathrm{C}$. Dies ist ein weiterer Beweis für die Allel-spezifische genetische Interaktion zwischen VTS1 und VTI1 im letzten Transportschritt zur Vakuole. 


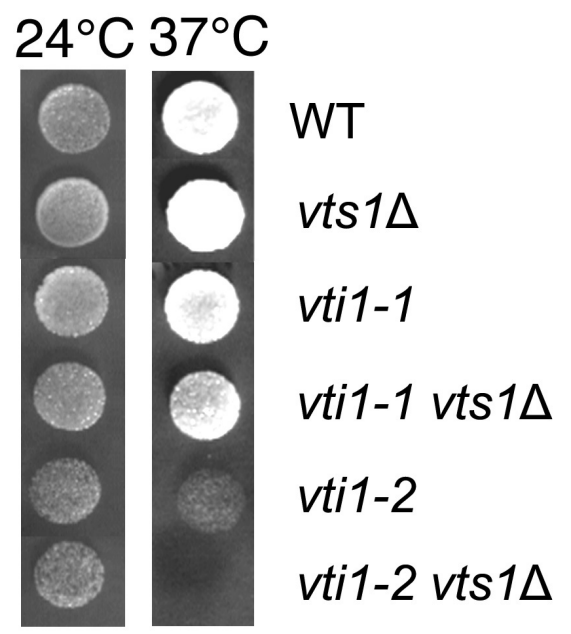

Abb. 3.12: vtil-2 vts1 $\Delta$-Zellen besitzen einen synthetischen Wachstumsdefekt bei $37^{\circ} \mathrm{C}$. In einem Wachstumstest wurden Verdünnungen von WT- (SEY6210), vts1 1 - (MDY1), vti1-1-

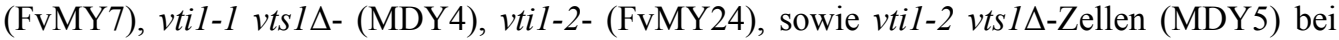
$24^{\circ} \mathrm{C}$ oder $37^{\circ} \mathrm{C}$ auf YEPD-Platten inkubiert.

Um zu untersuchen, ob Vts1p auch mit anderen SNARE-Proteinen im Transport zur Vakuole interagiert, wurde der Effekt der Überexpression von VTS1 bzw. der Deletion von VTS1 auf den CPY- und ALP-Transport in temperatursensitiven Mutanten der vakuolären SNAREs Vam3p und Vam7p mittels „Pulse-Chase“-Immunpräzipitationen analysiert. Es zeigte sich jedoch, dass weder die Vts1p-Überproduktion noch das Fehlen von Vts1p einen Effekt auf den Proteintransport in diesen Mutanten hatte (keine Abb.).

Da Vts1p im letzten Transportschritt zur Vakuole involviert ist, sollte untersucht werden, ob die VTS1-Deletionsmutante MDY1 eine veränderte Vakuolenmorphologie besitzt. Hierzu wurden die Vakuolen mit Quinacrin bzw. CDCFDA angefärbt und unter dem Fluoreszenzmikroskop untersucht. Es zeigte sich, dass die Vakuolen der vts 14-Mutante denen eines WT-Stammes ähnelten (nicht gezeigt).

Eine wesentliche Funktion der Vakuole besteht darin, nicht-benötigte Proteine zu degradieren um die Aminosäuren wiederzuverwerten. Diese Aufgabe ist besonders in Hungerperioden wichtig, in denen die Autophagozytose durch Nährstoffmangel induziert wird. Um zu untersuchen, ob die VTS1-Deletionsmutanten einen Defekt in der Autophagozytose besitzen, wurde ein Wachstumstest in Stickstoff-Mangelmedium durchgeführt. Die jeweiligen Stämme wurden bis zur stationären Phase inkubiert um die Autophagozytose zu induzieren. Anschließend wurden sie in Stickstoff-Mangelmedium (SD-Met $+0.17 \%$ Yeast-Nitrogen-Base) 1:2500 verdünnt, bei $30^{\circ} \mathrm{C}$ weiter inkubiert und 
in regelmäßigen Abständen die $\mathrm{OD}_{600}$ bestimmt. vts1 $\Delta$-Zellen (MDY1) erholten sich mit ähnlicher Geschwindigkeit wie WT-Zellen (SEY6210) aus der stationären Phase und traten in die logarithmische Wachstumsphase ein. Somit weisen sie keinen Defekt in der Autophagozytose auf. Im Gegensatz dazu zeigen vtil-2-Zellen (FvMY24), sowie Zellen der Doppelmutante vtil-2 vts1s (MDY5) eine Verzögerung der Erholungsphase, die stärker ausgeprägt war als in dem vtil-2-Stamm FvMY24. Somit besitzt die Doppelmutante vtil-2 vts1s (MDY5) einen schwachen synthetischen Defekt in der Autophagozytose.

\section{Wachstum in Stickstoff-Mangelmedium}

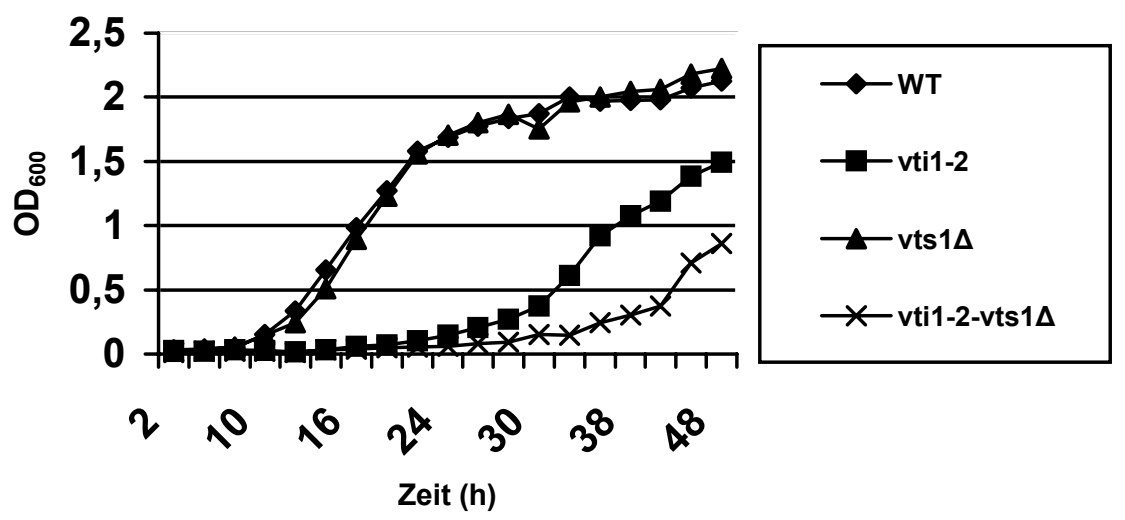

Abb. 3.13: Die Doppelmutante vtil-2 vts1s besitzt einen Defekt in der Autophagozytose. Die jeweiligen Stämme wurden für $48 \mathrm{~h}$ bei $30^{\circ} \mathrm{C}$ in YEPD-Medium bis zur stationären Phase inkubiert (WT-Zellen und vts $1 \Delta$-Zellen erreichten eine $\mathrm{OD}_{600}$ von $18.0 / \mathrm{ml}$, vtil-2-Zellen und Doppelmutanten-Zellen nur eine $\mathrm{OD}_{600}$ von $6.0 / \mathrm{ml}$ ). Anschließend wurden die Stämme 1:2500 in SD-Met $+0.17 \%$ Yeast-Nitrogen-Base verdünnt, weiter bei $30^{\circ} \mathrm{C}$ inkubiert und in regelmäßigen Abständen die $\mathrm{OD}_{600}$ bestimmt.

\subsubsection{Analyse der subzellulären Lokalisation von Vts1p}

Um die subzelluläre Lokalisation von Vts1p zu analysieren, wurden 3 Kopien eines Influenza-HA-Epitops am N-Terminus des offenen Leserahmens von VTS1 eingefügt. Hierzu wurde zuerst eine BamHI-Schnittstelle nach dem Start-Codon von VTS1 über eine PCR-Reaktion mit dem Plasmid pMD3 und den Primern SUBam3' und SUBam5' generiert (siehe Kap. 2.2.2.3.6).

In diese BamHI-Schnittstelle wurde daraufhin ein 126-Basenpaare langes BglII-Fragment aus dem Plasmid BJ7122, welches 3 Kopien des HA-Epitops codiert, ligiert (pMD8). 
HA-Vts1p war imstande das WT-Vts 1-Protein funktionell zu ersetzten, da die Expression des centromeren pMD8-Plasmides in vtil-2 vts1 1 -Zellen (MDY5) den Wachstumsdefekt der Doppelmutante bei $37^{\circ} \mathrm{C}$ wieder korrigierte (Abb. 3.14).

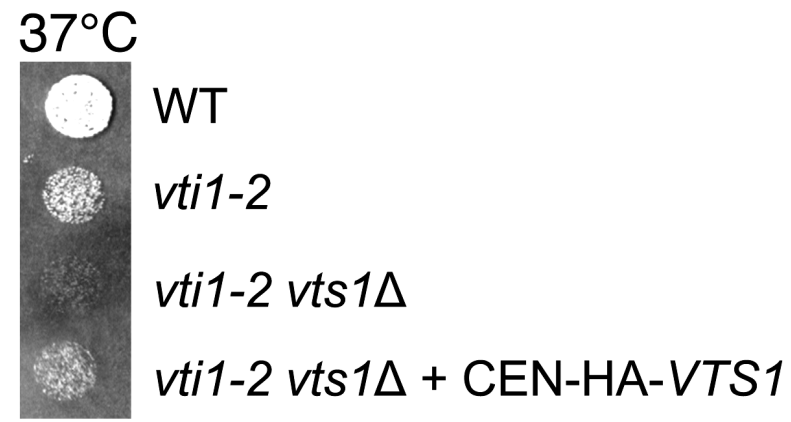

\begin{abstract}
Abb. 3.14: HA-Vts1p kann Vts1p funktionell ersetzen. In einem Wachstumstest wurden Verdünnungen

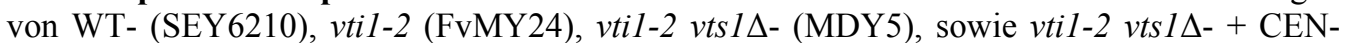
HA-VTS1- (pMD8) Zellen bei $37^{\circ} \mathrm{C}$ auf einer YEPD-Platte wachsen gelassen. HA-Vts1p konnte den synthetischen Wachstumsdefekt der vtil-2 vts $1 \Delta$-Doppelmutante bei $37^{\circ} \mathrm{C}$ komplementieren.
\end{abstract}

In einer subzellulären Fraktionierung (siehe Kap. 2.2.5.3) mit dem Stamm vts $1 \Delta+$ CENHA-Vts1p (MDY1-pMD8) trat HA-Vts1p ausschließlich in der S200-Fraktion der löslichen Proteine auf (Abb. 3.15). Zur Kontrolle der Fraktionierung wurde die Nitrozellulosemembran außerdem mit Antikörpern gegen Phosphoglycerat-Kinase (PGK) und Vtilp inkubiert. Das cytosolische Protein PGK zeigte die gleiche Verteilung wie HAVts1p, während Vtilp hauptsächlich mit vakuolären Membranen (P13), bzw. Vesikelund Golgi-Membranen (P200) assoziiert war. Dass Vtilp und HA-Vts1p nicht kofraktionieren, könnte möglicherweise darauf zurückzuführen sein, dass Vts1p nur sehr schwach mit Vtilp interagiert und dass diese niedrig-affine Interaktion den Bedingungen der subzellulären Fraktionierung daher nicht standhält. Auch eine Inaktivierung von Sec18p (der ATPase, die cis-SNARE-Komplexe deassembliert) durch Verwendung einer sec18-1-Mutante führte nicht zur Verschiebung der Lokalisation von HA-Vts1p (keine Abb.), was darauf hin deutet, dass Vts1p - zumindest nicht permanent - mit einem cisSNARE-Komplex assoziiert ist. 


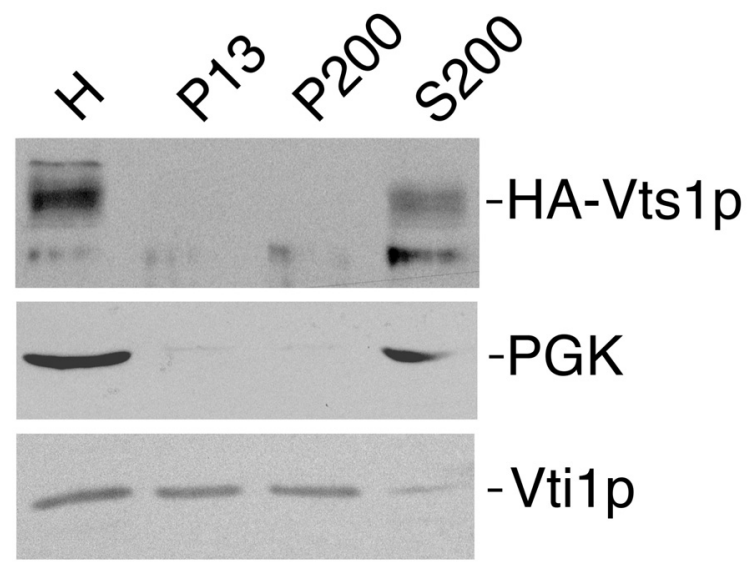

Abb. 3.15: HA-Vts1p tritt in einer subzellulären Fraktionierung in der Fraktion der löslichen Proteine auf. In einer subzellulären Fraktionierung mit dem Stamm MDY1-pMD8 taucht ein Signal für HA-Vts1p ausschließlich in der S200-Fraktion der löslichen Proteine auf (oben). Die gleiche Verteilung zeigt auch das cytosolische Protein Phosphoglycerat-Kinase (PGK, Mitte). Vtilp ist hauptsächlich mit vakuolären Membranen (P13) und Golgi- und Vesikelmembranen (P200, unten) assoziiert. H: Homogenat; P13: 13,000xg-Pellet; P200: 200,000xg-Pellet; S200: 200,000xg-Überstand.

In einer indirekten Immunfluoreszenz (siehe Kap. 2.2.5.1) mit dem Stamm MDY1-pMD8 $(v t s 1 \Delta+$ CEN-HA-Vts1p) zeigte das HA-erweiterte Vts1-Protein ein schwaches, diffuses über die gesamte Zelle verteiltes Signal (keine Abb.). Dieses Ergebnis steht in Übereinstimmung mit dem Ergebnis der subzellulären Fraktionierung, wonach es scheint, dass Vts $1 p$ unter normalen Bedingungen nicht mit Membranen assoziiert ist.

\subsubsection{Untersuchung der Interaktion zwischen Vti1p und Vts1p}

Um herauszufinden, ob Vtilp und Vts1p biochemisch interagieren, sollte untersucht werden, ob man beide Proteine koimmunpräzipitieren kann. Hierzu wurden zunächst antiHA-Antikörper an Protein-G-Sepharose-Beads gekoppelt (siehe Kap. 2.2.4.12.1) und anschließend mit einem Triton-X100-Extrakt eines MDY1-pMD10-(vts $1 \Delta+2 \mu$-HAVts1p)-Stammes (= Homogenat) inkubiert (siehe Kap. 2.2.4.12.2), wodurch HA-Vts1p an die anti-HA-Protein-G-Sepharose-Beads binden sollte. Falls Vti1p mit Vts1p biochemisch interagiert, sollte auch Vtilp an die Beads gebunden bleiben und so koimmunpräzipitiert werden. Abb. 3.16 A zeigt, dass HA-Vts1p mit den HA-Protein-G-Beads immunpräzipitiert werden konnte (obere Hälfte). Ein Signal für Vtilp taucht jedoch in der Spur der HA-Protein-G-Sepharose-Beads nicht auf (untere Hälfte). In der Spur der Protein-GSepharose-Beads zeigt Vtilp eine schwache unspezifische Bindung. 


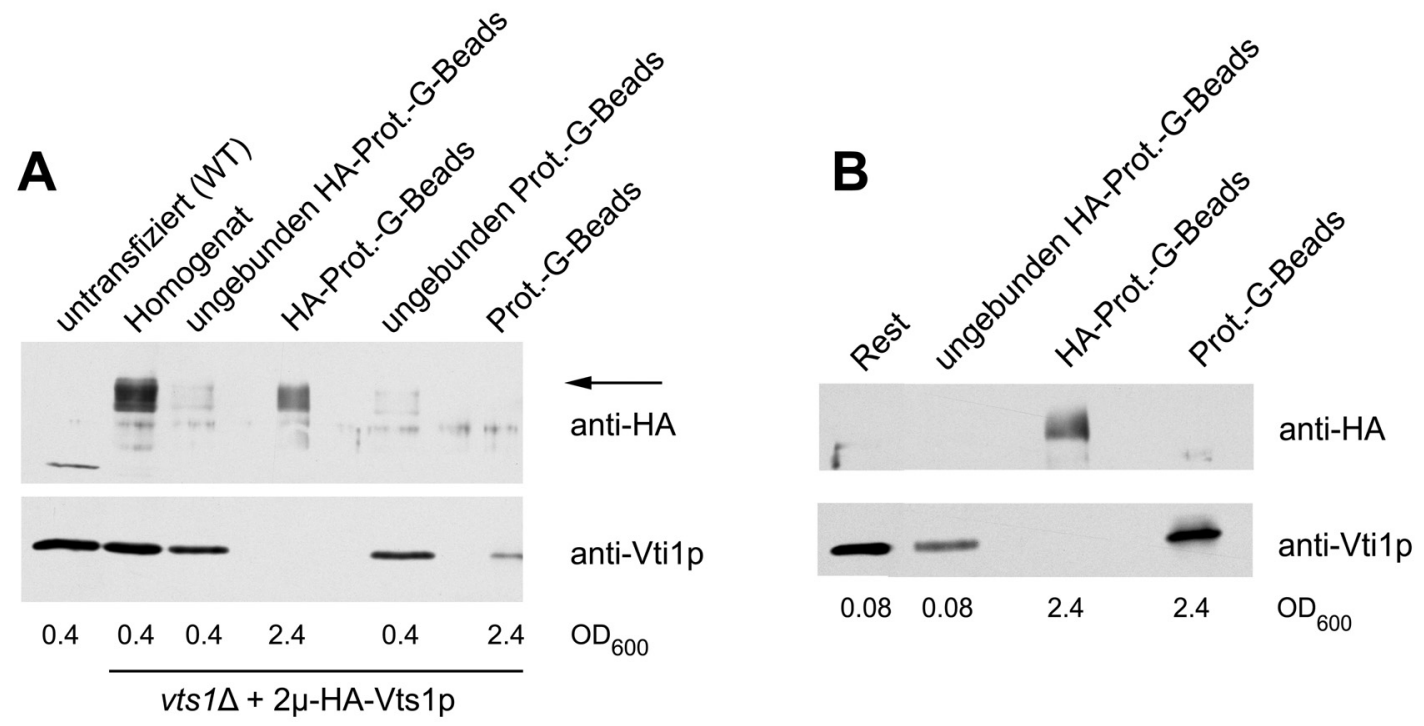

Abb. 3.16: HA-Vts1p und Vti1p konnten nicht kopräzipitiert werden. (A) Protein-G-Sepharose-Beads mit gekoppelten anti-HA-Antikörpern (HA-Prot.-G-Beads) wurden mit Zellhomogenat eines $v t s 1 \Delta+2 \mu$-HA-Vts1p-Stammes (MDY1-pMD10) inkubiert. HA-Vts1p wurde von den HAProt.-G-Beads präzipitiert (oben), während Vtilp nicht kopräzipitiert wurde (unten), sondern nur in der Fraktion der ungebundenen Proteine auftauchte. Protein-G-Beads ohne gekoppelten anti-HA-Antikörper (Prot.-G-Beads) wurden als Kontrolle auf eine spezifische Bindung benutzt. (B) Auch eine Kreuzvernetzung der Proteine mit DSP führte nicht zu einer Koimmunpräzipitation von HA-Vts1p und Vtilp.

Eine labile Interaktion zwischen Vtilp und Vts1p könnte jedoch evtl. durch die Solubilisierung der Proteine während der Triton-X100-Extraktion aufgehoben werden. Daher wurde nun versucht, nach der Herstellung von Sphäroplasten, diese mit dem membranpermeablen Kreuzvernetzer DSP zu inkubieren. Die Triton-X100-Extraktion erfolgte erst danach (siehe Kap. 2.2.4.12.3). Abb. 3.16 B zeigt, dass Vtilp und Vts1p nicht chemisch kreuzvernetzt werden konnten. HA-Vts1p wurde von den HA-Protein-GSepharose-Beads gebunden (obere Hälfte), es tauchte jedoch wieder kein Signal für Vtilp in der Spur der HA-Protein-G-Sepharose-Beads auf (untere Hälfte). Eine ungewöhnlich starke unspezifische Vtilp-Immunpräzipitation erfolgte jedoch in der Kontrolle mit den Protein-G-Sepharose-Beads. In den Fraktionen „Rest“ und „ungebunden HA-Prot.-GBeads" trat erst nach längerer Exposition eine Bande für HA-Vts1p auf (nicht gezeigt). Allerdings wurde hier auch nur 1/30 der Proteinmenge verglichen mit den BeadFraktionen aufgetragen. 
Darüber hinaus zeigten in vitro-Bindeversuche mit rekombinantem GST-Vtilp (lösliche Domäne) und 6xHis-Vts1p bzw. GST-Vts1p und 6xHis-Vtilp (lösliche Domäne) unter verschiedenen Pufferbedingungen ebenfalls keine spezifische biochemische Interaktion zwischen diesen beiden Proteinen (keine Abb.). Es ist jedoch möglich, dass beide Proteine nur transient interagieren, oder dass nur sehr wenig Vts1p an Vtilp bindet. Somit bleibt der Mechanismus der genetischen Interaktion zwischen Vts1p und vtil-2 unklar.

\subsubsection{Charakterisierung des vti1-2-Suppressors Ykt6p}

Nachdem in dem oben beschriebenen ts-Screen das R-SNARE Ykt6p als MulticopySuppressor des Wachstumsdefektes der vti1-2-Mutante identifiziert wurde, sollte nun untersucht werden, welchen Effekt eine Überexpression von YKT6 auf die verschiedenen Transportwege hat. Bei der restriktiven Temperatur besitzen vtil-2-Zellen sowohl einen Defekt im Transport von CPY und ALP vom trans-Golgi zur Vakuole, als auch im Transport von API vom Cytosol zur Vakuole. Mit einem „Pulse-Chase“-Experiment (siehe Kap. 2.2.4.10) wurde zunächst der API-Transport zur Vakuole in vtil-2-Zellen (FvMY24) und vtil-2-Zellen, welche YKT6 entweder von einem centromeren Plasmid (pMD21) oder einem 2 $\mu$-Plasmid (pMD1) überexprimierten, untersucht (Abb. 3.17). Eine schwache YKT6-Überexpression vom centromeren Plasmid pMD21 erhöhte den Gehalt an maturem API von $14 \%$ in der vtil-2-Mutante (Spur 1 ) auf $28 \%$ (Spur 2), während eine starke Überexpression vom 2 $\mu$-Plasmid pMD1 (Spur 3) den Gehalt an mAPI auf 55 $\%$ ansteigen ließ. Überexpression vom ursprünglichen Suppressorplasmid pBK25, welches ein $11 \mathrm{~kb}$ großes Insert mit der $1.1 \mathrm{~kb}$ großen YKT6-Sequenz enthält, führte zu einem Anstieg des mAPI-Gehaltes auf $64 \%$ (Spur 4). Somit scheint Ykt6p auch am Transport von API vom Cytosol zur Vakuole beteiligt ist. 


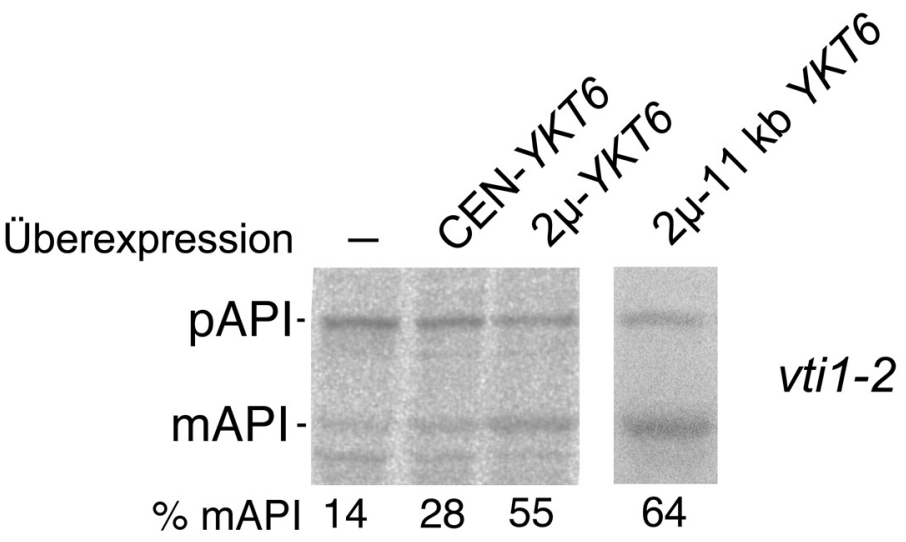

Abb. 3.17: Überexpression von YKT6 supprimierte den API-Transportdefekt der vtil-2-Mutante. In einer „Pulse-Chase“-Immunpräzipitation für API wurden vtil-2-Zellen (FvMY24) mit den entsprechenden Plasmiden bei $24^{\circ} \mathrm{C}$ wachsen gelassen, danach bei $37^{\circ} \mathrm{C}$ vorinkubiert und radioaktiv markiert. Nach einer 2-stündigen Chase-Periode wurde API immunpräzipitiert. pAPI: cytosolische Proform von Aminopeptidase I (API); mAPI: vakuoläres, matures API.

vti1-2-Zellen sind bei der restriktiven Temperatur ebenfalls im Transport von ALP vom trans-Golgi zur Vakuole blockiert. Daher wurde der ALP-Transport ebenfalls mittels „Pulse-Chase“-Immunpräzipitation in den gleichen Stämmen untersucht (Abb. 3.18). Schwache Überexpression von YKT6 vom centromeren Plasmid pMD21 verbesserte den ALP-Transport zur Vakuole leicht (Spur 2), während eine starke Überexpression vom $2 \mu$ Plasmid pMD1 nach einer 30-minütigen Chase-Periode zu einem mehr als doppelt so hohen mALP-Gehalt, verglichen mit der vti1-2-Mutante, führte (Spur 3). Der ALPTransportdefekt wurde auch durch das $11 \mathrm{~kb}$ große, genomische $2 \mu$-Suppressorplasmid pBK25 stark supprimiert (nicht gezeigt). Diese Ergebnisse lassen den Schluss zu, dass Ykt6p auch am Transport von ALP vom trans-Golgi zur Vakuole involviert ist. Um herauszufinden, ob dieser Effekt spezifisch für Ykt6p ist, oder ob auch die Überexpression anderer R-SNAREs einen Einfluss auf diesen Transportschritt hat, wurde das R-SNARE Snc2p, welches an Exo- und Endozytose beteiligt ist, sowie das R-SNARE Sec22p, welches im Transport zwischen ER und cis-Golgi involviert ist, durch $2 \mu$ Plasmide überexprimiert. Man sieht in den Spuren 4 und 5, dass die Überexpression beider R-SNAREs den ALP-Transportdefekt der vtil-2-Mutante bei der restriktiven Temperatur nicht signifikant supprimiert. 


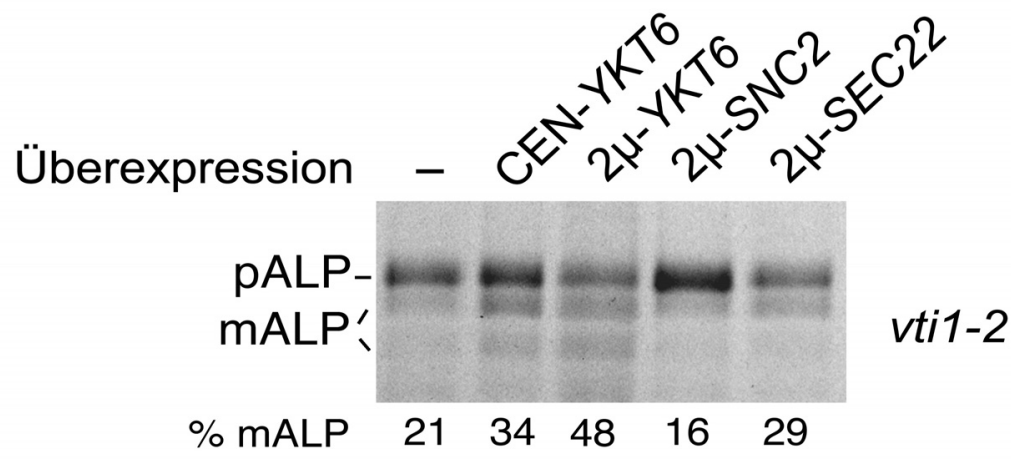

Abb. 3.18: Der ALP-Transportdefekt der vtil-2-Mutante wurde durch YKT6-Überexpression supprimiert, während Überexpression anderer R-SNAREs keinen Effekt zeigte. vtil-2Zellen (FvMY24) mit den entsprechenden Plasmiden wurden nach Temperatur-erhöhung auf $36^{\circ} \mathrm{C}$ radioaktiv markiert und ALP nach einer 30-minütigen Chase-Periode immunpräzipitiert. pALP: Golgi-lokalisierte Proform von Alkalischer Phosphatase (ALP); mALP: vakuoläres, matures ALP.

Da die Ykt6p-Überproduktion den API- und ALP-Transportdefekt der vtil-2-Mutante supprimiert, scheint Ykt6p eine zusätzliche Rolle im biosynthetischen Transport zur Vakuole zu besitzen.

In einem weiteren „Pulse-Chase“-Experiment wurde der CPY-Transport zur Vakuole in vti1-2-Zellen (FvMY24) sowie vti1-2-Zellen, welche YKT6 überexprimierten untersucht. Abb. 3.19 zeigt, dass die Überexpression von YKT6 vom ursprünglichen $2 \mu$-Suppressorplasmid pBK25, welches ein $11 \mathrm{~kb}$ großes Insert mit der $1.1 \mathrm{~kb}$ großen YKT6-Sequenz

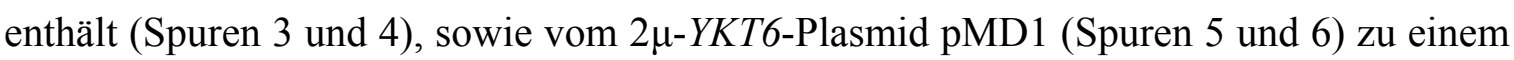
verbesserten Transport von CPY zur Vakuole führt, was an der Erhöhung des Anteils an maturem CPY zu ersehen ist. Somit scheint Ykt6p eine Rolle im CPY-Transport zu besitzen, entweder im Transport vom trans-Golgi zur Prävakuole, von der Prävakuole zur Vakuole, oder in beiden Transportschritten.

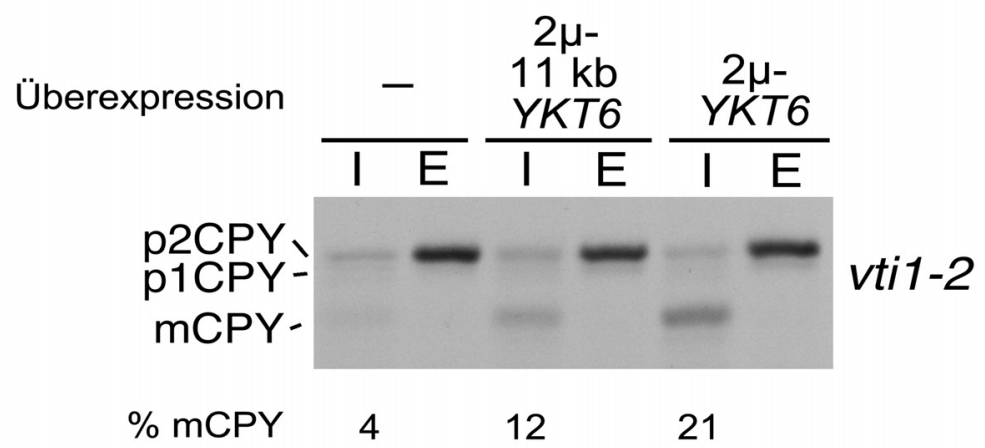

Abb. 3.19: Überexpression von YKT6 supprimierte den CPY-Transportdefekt der vtil-2-Zellen. vtil2-Zellen (FvMY24) mit den entsprechenden YKT6-Plasmiden wurden bei $32^{\circ} \mathrm{C}$ radioaktiv markiert und CPY nach einer 30-minütigen Chase-Periode in den Zellen (intern, I) und im Medium (extern, E) immunpräzipitiert. p1CPY: ER-lokalisierte Proform von Carboxypeptidase Y (CPY); p2CPY: Golgi-lokalisierte Proform von CPY; mCPY: vakuoläres, matures CPY. 
Um die Rolle von Ykt6p im CPY-Transport vom trans-Golgi zur Prävakuole genauer zu analysieren, wurde YKT6 in der Mutante vtil-1 überexprimiert, da diese Mutante nur in diesem Transportschritt blockiert ist, während der Transport von der Prävakuole zur Vakuole nicht betroffen ist. Überproduktion von Ykt6p, entweder vom centromeren

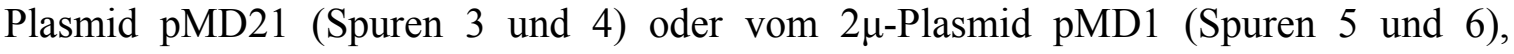
bewirkte eine Suppression des CPY-Transportdefektes der vtil-1-Mutante, was am Erscheinen der mCPY-Form zu ersehen ist (Abb. 3.20). Im Gegensatz dazu führte eine Überproduktion der R-SNAREs Snc2p oder Sec22p nicht zur Suppression des CPYTransportdefektes der vti1-1-Mutante. Diese genetischen Interaktionen deuten darauf hin, dass Ykt6p zusammen mit Vtilp auch am CPY-Transport vom trans-Golgi zur Prävakuole beteiligt ist.

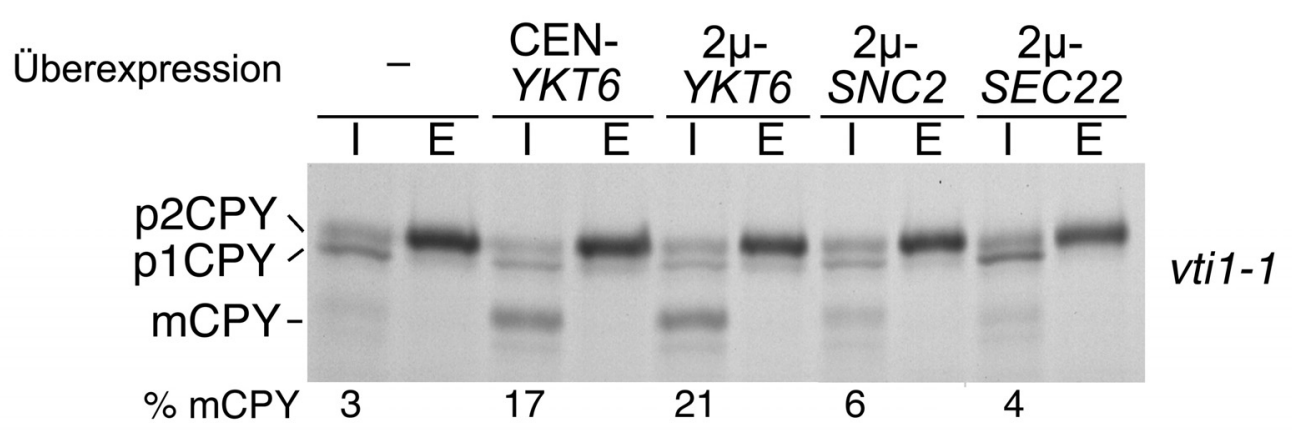

\begin{abstract}
Abb. 3.20: YKT6-Überexpression verbesserte auch den CPY-Transport vom trans-Golgi zur Prävakuole in vti1-1-Zellen, während Überexpression anderer R-SNAREs keinen Effekt zeigte. vtil-1-Zellen (FvMY7) mit den entsprechenden Plasmiden wurden bei $36^{\circ} \mathrm{C}$ radioaktiv markiert und CPY nach einer 30-minütigen Chase-Periode in den Zellen (intern, I) und im Medium (extern, E) immunpräzipitiert. p1CPY: ER-lokalisierte Proform von Carboxypeptidase Y (CPY); p2CPY: Golgi-lokalisierte Proform von CPY; mCPY: vakuoläres, matures CPY.
\end{abstract}

Die temperatursensitive Mutante vtil-11 zeigt während der Inkubation bei der restriktiven Temperatur von $36^{\circ} \mathrm{C}$ ebenfalls einen Defekt im Transport vom trans-Golgi zur Prävakuole und zur Vakuole. Zusätzlich besitzt diese Mutante auch einen Defekt im retrograden Transport zum cis-Golgi-Kompartiment, weshalb vtil-11-Zellen die ERmodifizierte Form p1CPY akkumulieren (Abb. 3.21, Spur 1). Durch Überexpression von YKT6, entweder vom ursprünglichen $2 \mu$-Suppressorplasmid pBK25 (Spur 3 und 4), oder vom $2 \mu$-Plasmid pMD1 (Spur 5 und 6), wird weniger p1CPY in der Zelle akkumuliert, während die Golgi-modifizierte Form p2CPY ins Medium sekretiert wird (externe 
Fraktionen, E). Dieses Ergebnis bestätigt, in Übereinstimmung mit der Arbeit von (Lupashin et al., 1997), dass YKT6 und VTII zusammen genetisch im Transport zum cisGolgi-Kompartiment interagieren.

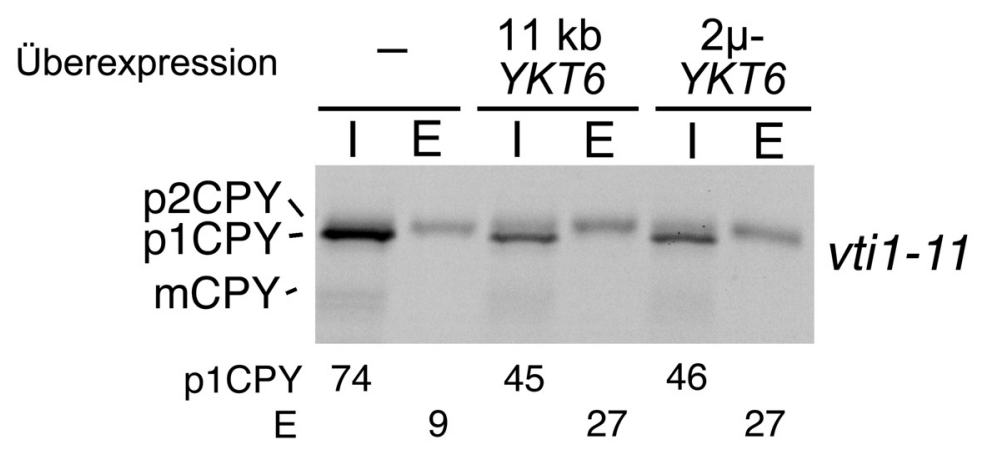

Abb. 3.21: YKT6-Überexpression supprimiert den CPY-Transportdefekt der vti1-11-Mutante. vti111-Zellen (FvMY21) mit den entsprechenden YKT6-Plasmiden wurden bei $36^{\circ} \mathrm{C}$ radioaktiv markiert und CPY nach einer 30-minütigen Chase-Periode in den Zellen (intern, I) und im Medium (extern, E) immunpräzipitiert. p1CPY: ER-lokalisierte Proform von Carboxypeptidase Y (CPY); p2CPY: Golgi-lokalisierte Proform von CPY; mCPY: vakuoläres, matures CPY.

\subsection{Identifizierung einer SNARE-verwandten Sequenz}

Bislang sind in der Hefe Saccharomyces cerevisiae 22 SNARE-Proteine identifiziert worden, darunter 5 R-SNAREs, 7 Qa-SNAREs (Syntaxine), 6 Qb-SNARE-Helices und 6 Qc-SNARE-Helices (Pelham, 2001). Würden alle SNARE-Komplexe in Saccharomyces cerevisiae aus vier unterschiedlichen und für den jeweiligen Komplex spezifischen SNARE-Proteinen bestehen, so würden die 22 identifizierten SNARE-Proteine nicht ausreichen, um alle SNARE-Komplexe in allen Transportschritten aufzubauen. Einige SNARE-Proteine, darunter Sed5p, Ykt6p und Vtilp, sind jedoch in mehreren unterschiedlichen SNARE-Komplexen involviert (Fischer von Mollard et al., 1997; Lupashin et al., 1997; Holthuis et al., 1998; Fischer von Mollard and Stevens, 1999). Da das gesamte Hefe-Genom sequenziert ist und dabei keine weitere SNARE-verwandte Sequenz gefunden wurde, nahm man an, dass für den Membrantransport in Hefe keine weiteren SNARE-Proteine benötigt werden. Die Sequenzen von Qa- und R-SNAREs sind stark konserviert. Qb- und Qc-SNAREs zeigen jedoch nur geringe Sequenzhomologien mit anderen Mitgliedern der SNARE-Familie. Daher ist es möglich, dass in S. cerevisiae zusätzliche Gene existieren, die für SNARE-Proteine codieren und die bislang übersehen wurden. Mit der Hilfe von Prof. Enno Hartmann wurde daher die Saccharomyces 
cerevisiae-Genom-Datenbank SGD (http://genome-www.stanford.edu/Saccharomyces) nach weiteren SNARE-Sequenzen untersucht. Hierbei wurde eine PSI-Blast-Suche mit den Sequenzen unterschiedlicher Hefe-SNAREs durchgeführt. Da die AminosäureSequenzen der SNARE-Motive untereinander starke Homologien aufweisen, wobei besonders die Positionen derjenigen Aminosäuren hochgradig konserviert sind, die während der SNARE-Komplex-Assemblierung ins Innere des 4-Helix-Bündels weisen (jede 3. und darauffolgend 4.) und über die Interaktion mit Aminosäuren anderer Helices planare Ebenen bilden (Layer), wurden dabei hauptsächlich solche Sequenzbereiche miteinander verglichen, die zu SNARE-Motiven homolog sind. Hierbei erschien die Sequenz eines bislang uncharakterisierten offenen Leserahmens mit der Bezeichnung YGL098w. Diese Sequenz codiert für ein hypothetisches Protein mit einer Länge von 245 Aminosäuren, was der charakteristischen Größe von SNARE-Proteinen entsprechen würde (Abb. 3.22).

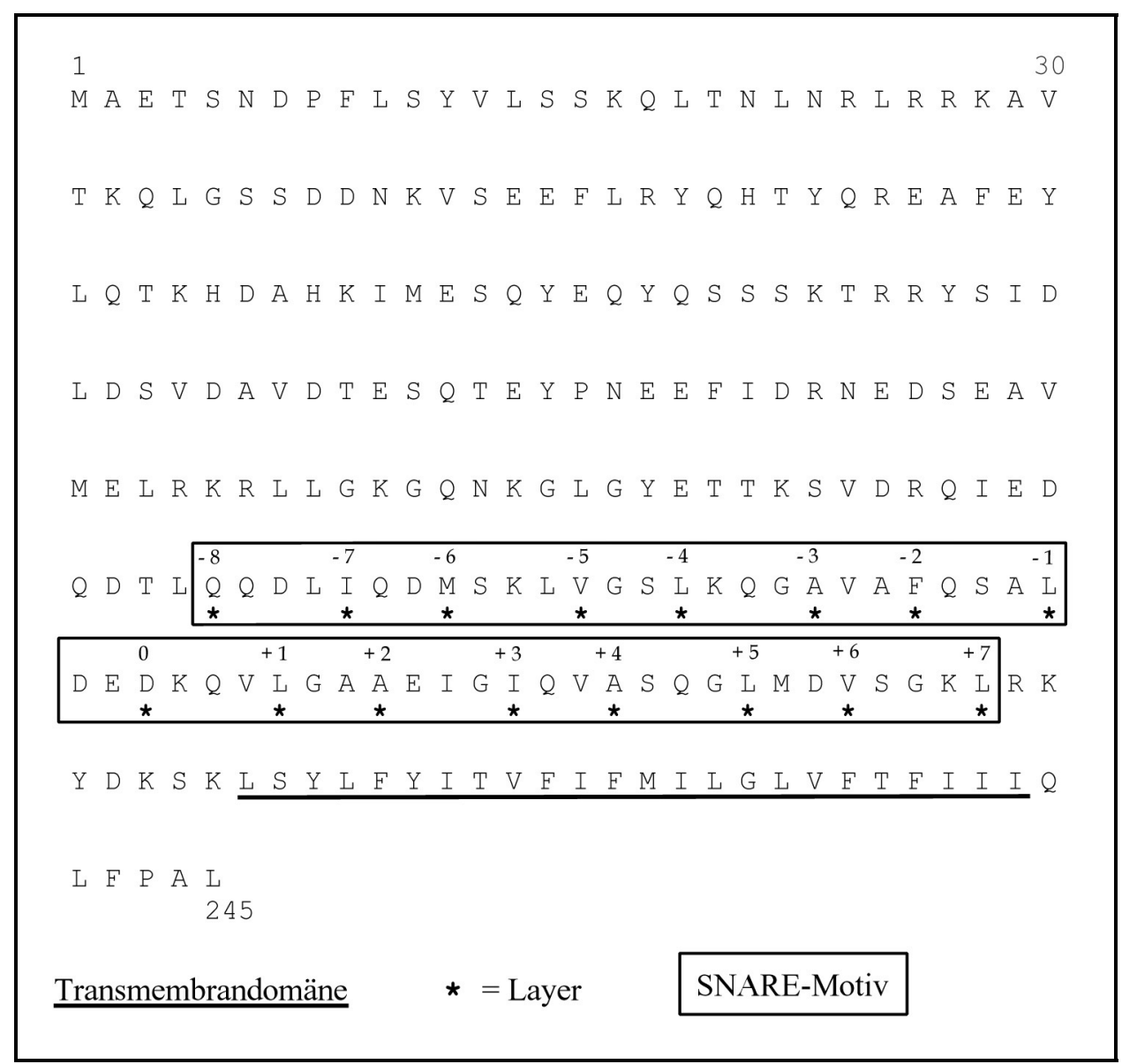

Abb. 3.22: Die Aminosäuresequenz des von dem offenen Leserahmens YGL098w codierten Proteins zeigt Charakteristika eines SNARE-Proteins. 
Die Gesamtsequenz zeigt zwar nur geringe Aminosäurehomologien mit anderen SNAREProteinen, neben einer C-terminalen Transmembrandomäne besitzt das Protein jedoch ein typisches SNARE-Motiv mit in „Heptad-Repeats“ angeordneten hydrophoben Aminosäuren. In der 0-Ebene (0-Layer) des SNARE-Motivs befindet sich ein Aspartat anstelle eines Glutamins wie in den meisten anderen Q-SNAREs. In der -1- und +1-Ebene besitzen alle SNARE-Proteine große hydrophobe Aminosäuren. Hierzu passt, das Ygl098w Leucine in beiden Positionen enthält. Qb- und Qc-SNARE-Helices besitzen außerdem in der -3-Position immer kleine Aminosäuren. Yg1098w enthält hier typischerweise ein Alanin.

Da SNARE-Proteine evolutionär konserviert sind, wurden auch Datenbanken anderer Organismen nach verwandten Sequenzen durchsucht. Hierbei wurden homologe Sequenzen in Candida albicans, Schizosaccharomyces pombe, Dictyostelium discoideum, Caenorhabditis elegans, Drosophila melanogaster, Arabidopsis thaliana, Maus sowie Plasmodium falciparum gefunden (Abb. 3.23). Die stärksten Sequenzhomologien zeigten sich dabei im Bereich des SNARE-Motivs, und hier besonders in den Positionen, die voraussichtlich an der Ausbildung der Interaktionsebenen (Layer) beteiligt sind (X). 


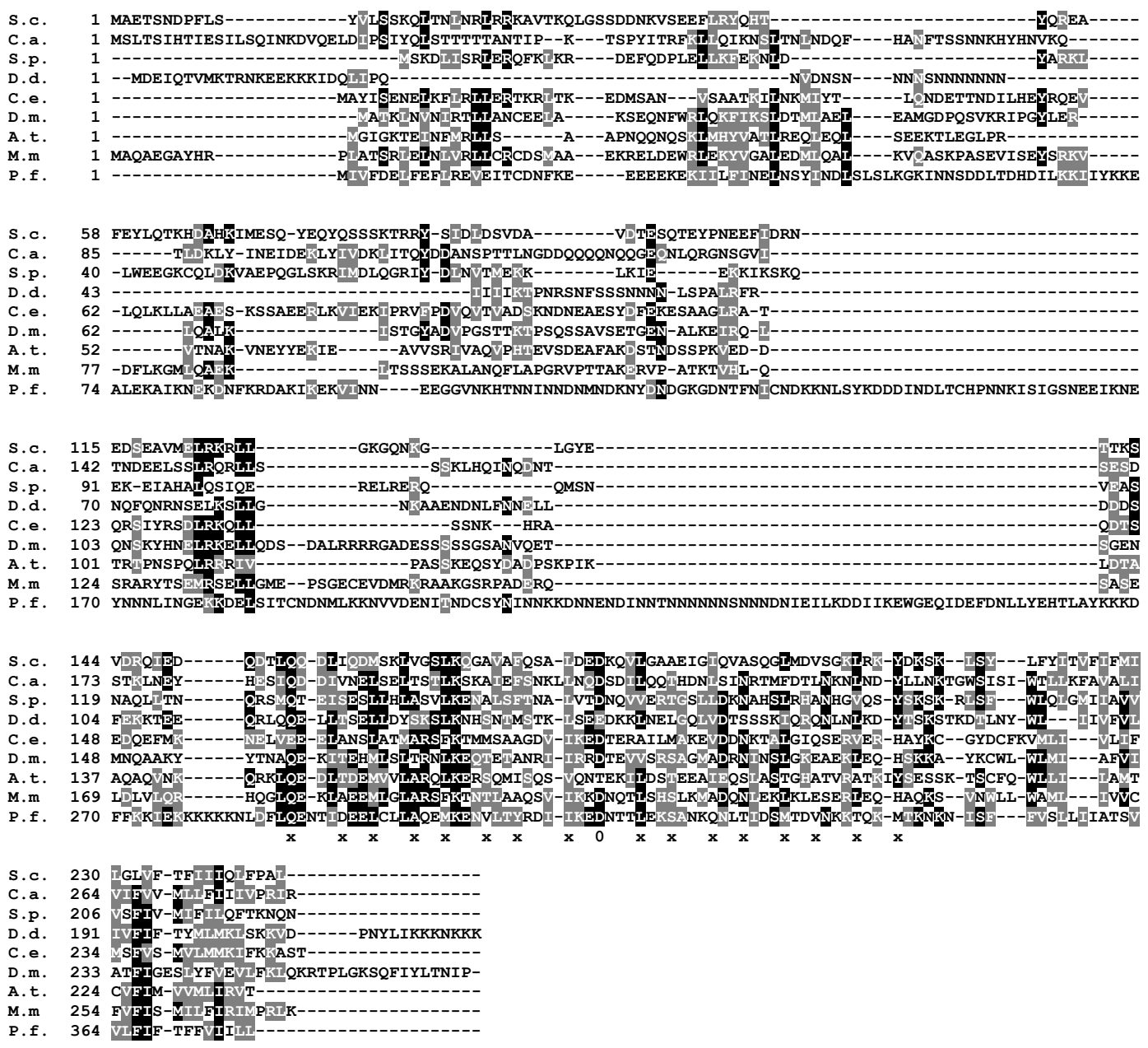

Abb. 3.23: Ygl098w-homologe Sequenzen in anderen Eukaryonten. Mit Yg1098w aus Saccharomyces cerevisiae (S.c.) verwandte Sequenzen wurden in Candida albicans (C.a., accession number gnl SDSTC 5476), Schizosaccharomyces pombe (S.p., Genbank accession number CAB16218), Dictyostelium discoideum (D.d., accession number IIAFP1D36343), Caenorhabditis elegans (C.e., Genbank accession number AAF60428), Drosophila melanogaster (D.m., Genbank accession number AC013969, nt 4505-4792, 4887-5339), Arabidopsis thaliana (A.t., Genbank accession number AAD25784), Maus (Mus musculus, M.m., Genbank accession number AA220426, AV002165) und Plasmodium falciparum (P.f., accession number gi 23612490) gefunden. Alle Ygl098w-Proteine besitzen eine C-terminale Transmembrandomäne, welche von einer konservierten Sequenz gefolgt wird, die Charakteristika eines SNARE-Motivs besitzt. Den höchsten Grad an Konservierung zeigen dabei die in „Heptad-Repeats“ angeordneten hydrophoben Aminosäuren, die in einem SNARE-Komplex 16 hydrophobe Interaktionsebenen (Layer) ausbilden können $(\mathbf{X})$, sowie der ionische 0-Layer, der in fast allen Proteinen ein Aspartat enthält (0). 


\subsection{Charakterisierung des von YGL098w codierten Proteins}

Da die Charakteristika der Aminosäuresequenzen von Ygl098w und seiner verwandten Proteine in anderen Organismen darauf hin deuten, dass es sich bei diesem Protein um ein bislang unidentifiziertes SNARE-Protein handeln könnte, sollte das von YGL098w codierte Protein nun genauer charakterisiert werden.

\subsubsection{Herstellung von YGL098w-Deletionsmutanten}

Analog zu der in Kap. 3.1.1.1 beschriebenen VTS1-Deletion wurde von Beate Veith mit Oligonukleotid-Primern, welche 40 Nukleotide der komplementären 5'- und 3'flankierenden Bereiche der YGL098w-Sequenz enthielten, über eine PCR-Reaktion mit dem TRP1-Plasmid pRS304 ein lineares Deletionskonstrukt erstellt (siehe Kap. 2.2.3.6). Dieses wurde in kompetente diploide WT-Zellen (SEY6210xSEY6211) transformiert und die heterozygote Deletion über eine zweite PCR-Reaktion verifiziert. Nach Sporulation dieses Stammes (siehe Kap. 2.2.3.8) entstanden nur jeweils 2 lebensfähige Sporen, welche die Deletion nicht enthielten. Somit muss es sich bei YGL098w um ein essentielles Gen handeln. Deshalb wurde der so erhaltene heterozygot-diploide Stamm daraufhin mit einem LEU2-Plasmid transformiert, welches die WT-Sequenz des YGL098w-Genes trägt (pBK85) und anschließend erneut sporuliert. Diesmal entstanden jeweils 4 lebensfähige Sporen. Jeweils 2 Sporen unterschiedlichen Paarungstyps, welche die Deletion trugen, wurden daraufhin wieder über eine PCR-Reaktion identifiziert (BKY3 und BKY4). Diese Stämme enthalten eine genomische Deletion des YGL098wGenes (Austausch gegen den Auxotrophie-Marker TRP1), sowie eine extrachromosomale WT-Kopie des Genes auf einem LEU2-Plasmid (pBK85). Da YGL098w essentiell ist, können die Stämme das pBK85-Plasmid nicht verlieren.

\subsubsection{Subzelluläre Lokalisation des von YGL098w codierten Proteins}

Um die Lokalisation des von YGL098w codierten Proteins innerhalb der Zelle zu analysieren wurden 3 Kopien eines Influenza-HA-Epitops am N-Terminus des Proteins analog der Prozedur zur Herstellung von HA-VTS1 (siehe Kap. 3.1.1.2) eingefügt. Dies resultierte in der Konstruktion des CEN-URA3-Plasmides pBK55 sowie des $2 \mu-U R A 3-$ Plasmides pBK64. Beide Plasmide wurden daraufhin in den Deletionsstamm BKY3pBK85 transformiert. Um das pBK85-Plasmid mit der WT-Sequenz aus dem Stamm zu entfernen, so dass nur das pBK55- bzw. pBK64-Plasmid übrig bleibt, wurde ein 
„Plasmid-Shuffling“ durchgeführt. Hierzu wurde der Stamm zunächst in einem Verdünnungsausstrich auf einer SD-Ura-Platte ausgestrichen um Einzelkolonien zu erhalten. Diese wurden anschließend mittels eines sterilen Samtkissens auf eine SD-Leuund SD-Ura-Platte überstempelt. Kolonien, die auf SD-Leu nicht mehr wuchsen wurden von der SD-Ura-Platte isoliert und erneut getestet. Da die resultierenden Stämme BKY3pBK55 und BKY3-pBK64 alleine mit der HA-erweiterten Version des Yg1098w-Proteins lebensfähig waren, kann man schlussfolgern, dass HA-Ygl098w das WT-Protein funktionell ersetzen kann. BKY3-pBK64-Zellen wurden daraufhin in einer indirekten Immunfluoreszenz (siehe Kap. 2.2.5.1) mit einem anti-HA-Antikörper mikroskopisch untersucht. Abb. 3.24 zeigt, dass das überexprimierte HA-erweiterte Yg1098w-Protein in ringförmigen Strukturen, welche den Zellkern umranden, gefunden wurde. Dies ist die typische Lokalisation des ER in Hefezellen.
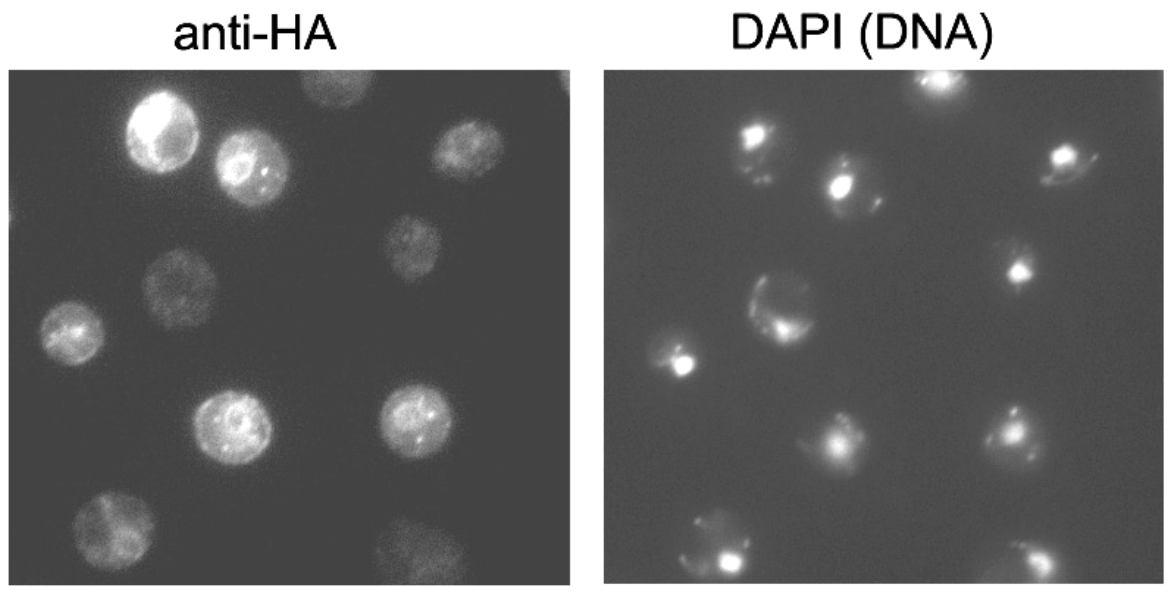

Abb. 3.24: Eine HA-erweiterte Version des Ygl098w-Proteins zeigt in der indirekten Immunfluoreszenz eine typische ER-Lokalisation.

Aufgrund der ER-Lokalisation des Yg1098w-Proteins und der geringen Sequenz-

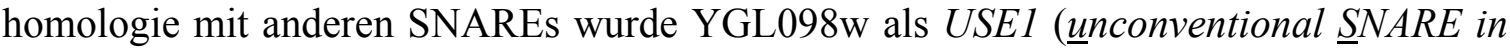
the $\underline{E R} \underline{1}$ ) bezeichnet.

Da eine ER-Lokalisation teilweise auch artifiziell durch eine starke Überexpression von Proteinen hervorgerufen werden kann, wurde ein Antiserum gegen Uselp in einem Kaninchen erzeugt (siehe Kap. 2.2.4.11) um hiermit die Lokalisation des endogenen Use1-Proteins zu bestimmen. Hierzu wurde zunächst über eine PCR-Reaktion mit den Primern 98-Nde und 98-Sol die cytoplasmatische Domäne von Uselp amplifiziert 
(Aminosäuren 1 - 215). Nach Zwischenklonierung in den Vektor pGEM-T und einer genauen Sequenzkontrolle wurde das Fragment anschließend über NdeI-EcoRI-Verdau in den Vektor pET28b kloniert, wodurch das Plasmid pMD19 entstand. Dies resultierte in der N-terminalen Erweiterung des Yg1098w-Proteins durch eine 6xHis-Sequenz. Nach Überexpression und Aufschluss der E. coli-Zellen wurde das Fusionsprotein an einer Epitop-spezifischen Affinitätsmatrix (Ni-NTA-Agarose, Qiagen) gebunden, gewaschen und anschließend in reiner Form eluiert. Mit dem so gewonnenen rekombinanten Protein wurde ein Kaninchen immunisiert und Antiserum gewonnen. Das Uselp-Antiserum erkannte nach SDS-PAGE mit Hefe-Proteinextrakten und anschließendem Immunoblot eine einzelne Bande auf der Höhe von $35 \mathrm{kDa}$. Das aus der Aminosäuresequenz vorausgesagte Molekulargewicht von Use1p beträgt $28 \mathrm{kDa}$. In einer subzellulären Fraktionierung (siehe Kap. 2.2.5.3) von WT-Hefezellen mit anschließendem SDS-PAGE und Immunoblot erschien das endogene Use1-Protein ausschließlich im 13,000xg-Pellet (Abb. 3.25, P13). Diese Fraktion enthält ER- und Vakuolenmembranen. Zur Kontrolle der Fraktionierung wurde die Nitrozellulosemembran außerdem mit Antikörpern gegen die vakuoläre ATPase Vph1p sowie das cytosolische Protein PGK inkubiert. Vph1p trat ausschließlich in der P13-Fraktion auf, während das PGK-Signal nur in der Fraktion der löslichen Proteine (S200) detektiert wurde.

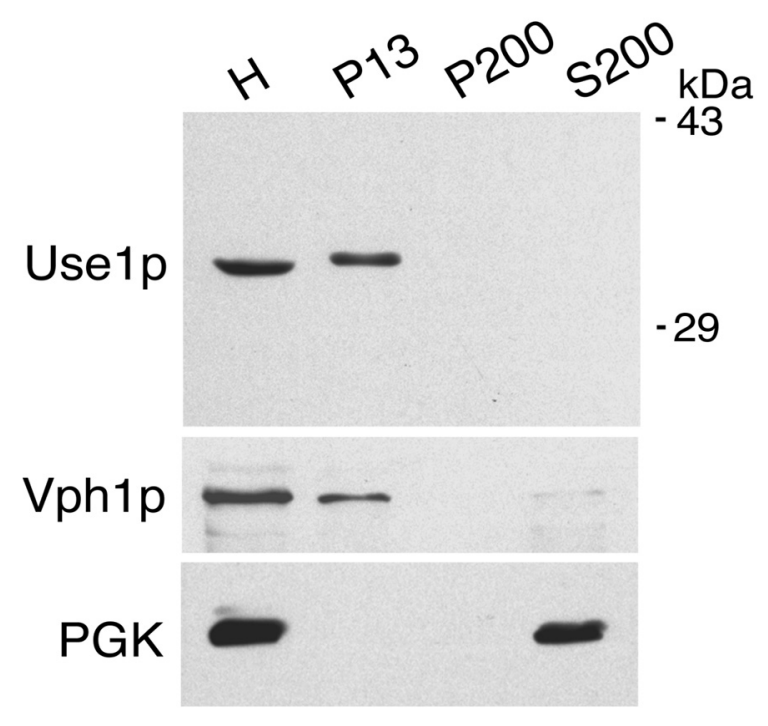

Abb. 3.25: In einer subzellulären Fraktionierung mit einem WT-Stamm tritt Use1p in der P13Fraktion auf, welche ER- und Vakuolenmembranen enthält. Das vakuoläre Membranprotein Vph1p tritt ebenfalls in der P13-Fraktion auf (Mitte), während das cytosolische Protein Phosphoglycerat-Kinase (PGK) ausschließlich in der S200-Fraktion zu finden ist (unten). H: Homogenat; P13: 13,000xg-Pellet; P200: 200,000xg-Pellet; S200: 200,000xg-Überstand. 
In einer von Beate Veith durchgeführten Saccharose-Dichtegradienten-Zentrifugation mit dem postnukleären Überstand eines WT-Hefestammes sowie eines Hefestammes, der HA-Use1p von einem centromeren Plasmid exprimiert (BKY3-pBK55), trat HA-Use1p in beiden Fällen ausschließlich in den späten Fraktionen zusammen mit dem ER-Protein Sec61p auf. Vakuoläre Proteine wurden dagegen hauptsächlich in den frühen Fraktionen gefunden. Zusammengefasst zeigen diese Ergebnisse, dass Use1p ER-lokalisiert ist. Es könnte somit entweder als SNARE im anterograden ER-Golgi-Transport agieren, oder eine Funktion im retrograden Transport vom Golgi zum ER besitzen.

\subsubsection{Temperatursensitive Mutanten von USE1}

Wie bereits erwähnt handelt es sich bei USE1 um ein essentielles Gen. Um die Funktion von Use1p $\mathrm{zu}$ analysieren wurde daher eine temperatursensitive usel-Mutante über ungerichtete in vitro-Mutagenese (siehe Kap. 2.2.2.3.7) hergestellt. Nach Plasmidshuffle wurde nach Zellen gesucht, die einen Wachstumsdefekt zeigen. Ein Plasmid (pBK83) erlaubte Wachstum bei $24^{\circ} \mathrm{C}$, jedoch nicht bei $30^{\circ} \mathrm{C}$ und $37^{\circ} \mathrm{C}$. Sequenzierung der Mutante ergab, dass das codierte Protein 10 Aminosäure-Austausche enthielt (Abb. 3.26), weshalb die Mutante als use1-10AA bezeichnet wurde. 5 der 10 Aminosäure-Austausche befanden sich im SNARE-Motiv, darunter die Mutation D183G in der mutmaßlichen 0Layer-Position.

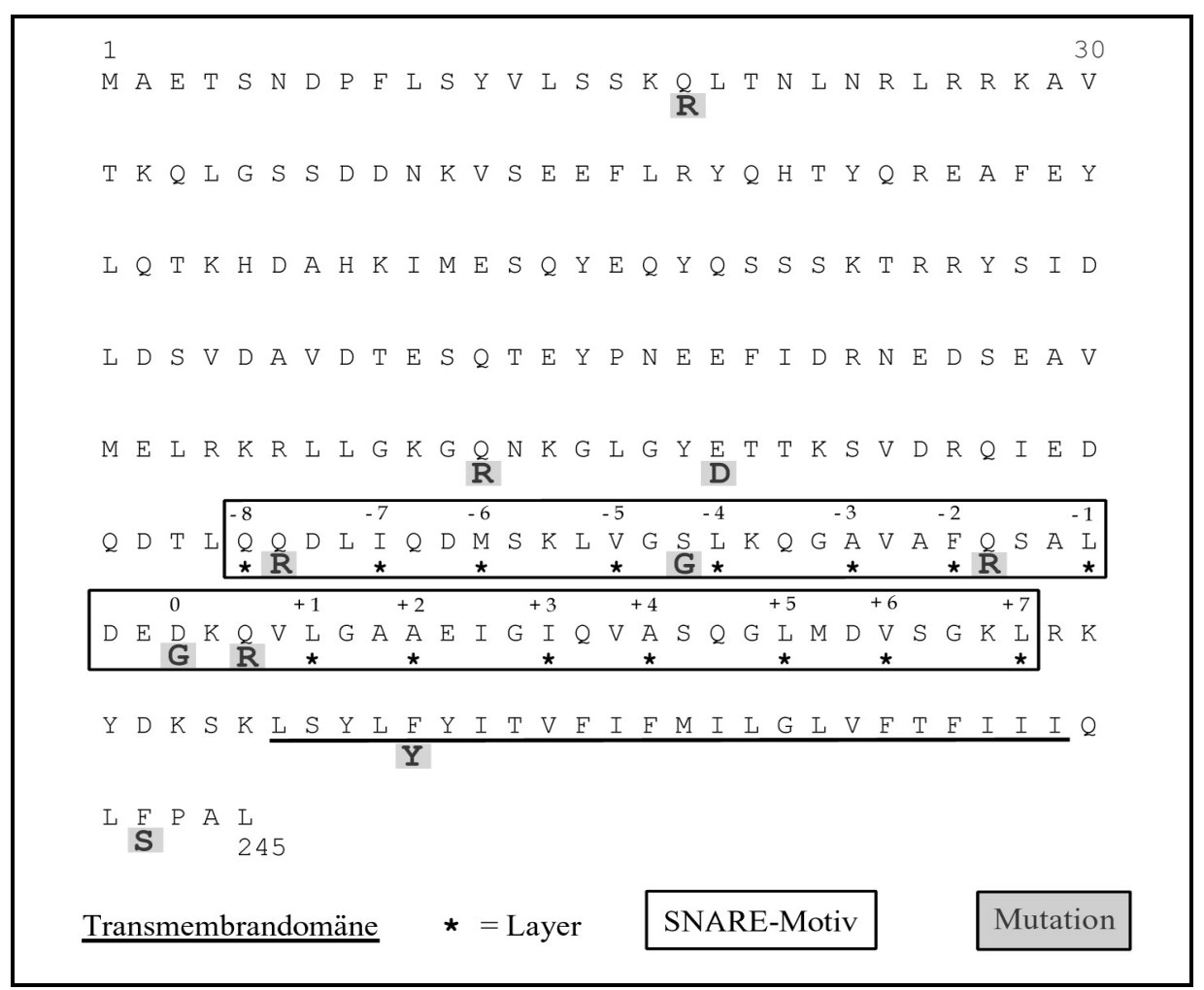

Abb. 3.26: Aminosäuresequenz der temperatursensitiven Mutante use1-10AA. 
Um den Effekt der 0-Layer-Mutation D183G in der temperatursensitiven Mutante genauer zu analysieren wurde zunächst über eine gerichtete PCR-Mutagenese (siehe Kap. 2.2.2.3.6) mit den Primern 098-DF und 098-DR das Allel use 1-2AA in einem pBlueskript KS-Vektor hergestellt und daraufhin in den Hefe-Vektor pRS315 umkloniert (pMD16). Das use1-2AA-Allel enthält neben der D183G-Mutation noch einen K184T-Austausch. Aufgrund dieser beiden Mutationen entsteht eine zusätzliche KpnI-Schnittstelle über die die Mutationen nachgewiesen werden können. Da die Position 184 direkt neben der 0Layer-Position liegt, und somit nicht am Aufbau der Interaktionsebenen beteiligt ist, sollte ihre Aminosäurekomposition auch nicht konserviert sein. Um trotzdem sicherzustellen, dass diese Mutation keinen Einfluss auf den Phänotyp hat, wurde über eine zweite gerichtete PCR-Mutagenese mit den Primern 098-DK und 098-DR die KpnISchnittstelle wieder entfernt, wodurch das Allel use1-Olayer entstand, welches nur die D183G-Mutation trägt (pMD25). In einem Wachstumstest zeigten use1-10AA-Zellen ein verlangsamtes Wachstum bei $24^{\circ} \mathrm{C}$ während sie bei $30^{\circ} \mathrm{C}$ oder $37^{\circ} \mathrm{C}$ überhaupt nicht mehr wuchsen (Abb. 3.27). Dagegen zeigten sowohl use1-Olayer-Zellen als auch use1-2AAZellen (nicht gezeigt) keinen Wachstumsdefekt.

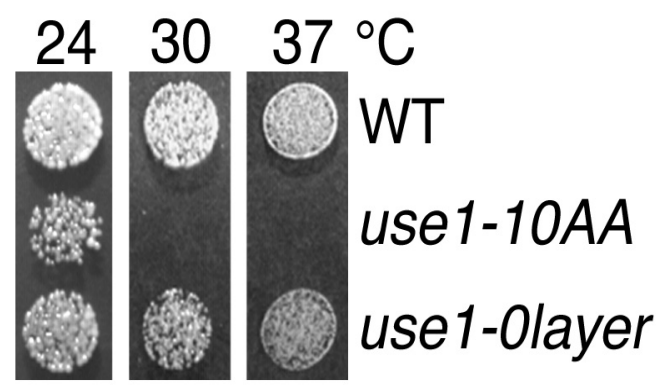

\begin{abstract}
Abb. 3.27: Im Gegensatz zur use1-0layer-Mutante besitzt die Mutante use1-10AA einen Wachstumsdefekt bei $24^{\circ} \mathrm{C}$ und kann bei $30^{\circ} \mathrm{C}$ und $37^{\circ} \mathrm{C}$ überhaupt nicht mehr wachsen. In einem Wachstumstest wurden Verdünnungen von WT-Zellen (BKY3-pBK85) sowie den Mutanten use1-10AA (BKY3-pBK83) und use1-Olayer (BKY3-pMD25) bei $24^{\circ} \mathrm{C}, 30^{\circ} \mathrm{C}$ und $37^{\circ} \mathrm{C}$ auf einer YEPD-Platte inkubiert.
\end{abstract}

\title{
3.3.4 Untersuchung der Funktion von Use1p im ER-Golgi-Transport
}

Um herauszufinden, ob Use1p tatsächlich eine Funktion im Membrantransport zwischen ER und Golgi besitzt, sollte die Reifung der löslichen vakuolären Hydrolase Carboxypeptidase Y (CPY) in den usel-Mutanten über „Pulse-Chase“-Experimente verfolgt werden. Abb. 3.28 zeigt, dass use 1-10AA-Zellen schon bei $25^{\circ} \mathrm{C}$ einen Defekt im Transport von CPY zur Vakuole besitzen, da der Gehalt an vakuolärem, maturem CPY 
drastisch verringert ist (23\% mCPY im Unterschied zu $82 \%$ mCPY in WT-Zellen). Dagegen akkumulieren use1-10AA-Zellen die ER-Form p1CPY (52\% p1CPY im Unterschied zu 7 \% in WT-Zellen). Diese Akkumulierung von p1CPY im ER verstärkte sich sogar noch nach Inkubation bei $31^{\circ} \mathrm{C}$ auf $84 \%$ p1CPY. use 1-Olayer-Zellen zeigten im Gegensatz zur use1-10AA-Mutante keinen CPY-Transportdefekt bei $25^{\circ} \mathrm{C}$. Nach Temperaturerhöhung auf $37^{\circ} \mathrm{C}$ erfolgte in der usel-Olayer-Mutante jedoch ebenfalls eine Akkumulierung von p1CPY im ER (53\% p1CPY im Unterschied zu $4 \%$ in WT-Zellen). Dieses Ergebnis beweist zum einen, dass es sich auch bei der use1-Olayer-Mutante um eine echte temperatursensitive Mutante handelt, und zum anderen, dass die Aminosäurekomposition der 0-Layer-Position in Use1p entscheidend für dessen Funktion als SNARE-Protein ist. Da bei der restriktiven Temperatur in keiner der beiden Mutanten p2CPY akkumuliert (I) oder ins Medium sekretiert wird (E) scheint der Transport vom Golgi zur Vakuole nicht betroffen zu sein. Daher dürfte Use1p nicht an späteren Transportschritten im Golgi oder am Transport zur Vakuole involviert sein. Insgesamt deuten die Ergebnisse der CPY-,,Pulse-Chase“-Experimente darauf hin, dass Use1p für den Transport zwischen ER und Golgi benötigt wird.

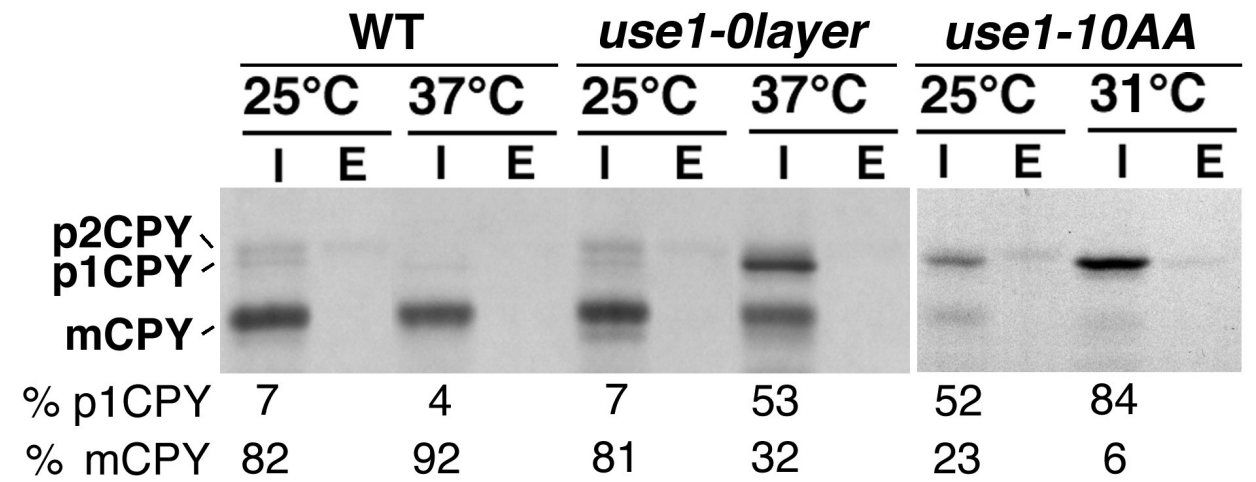

Abb. 3.28: Sowohl use1-10AA- als auch use1-0layer-Zellen akkumulieren nach Inkubation bei der restriktiven Temperatur die ER-Form p1CPY. In WT- (BKY3-pBK85), use1-10AA(BKY3-pBK83) sowie use1-Olayer-Zellen (BKY3-pMD25) wurde nach Vorinkubation und radioaktiver Markierung bei der angegebenen Temperatur CPY nach einer 30-minütigen Chase-Periode in den Zellen (intern, I) und im Medium (extern, E) immunpräzipitiert. p1CPY: ER-lokalisierte Proform von Carboxypeptidase Y (CPY); p2CPY: Golgi-lokalisierte Proform von $\mathrm{CPY}$; mCPY: vakuoläres, matures CPY. 
Ein weiterer Hinweis für eine Beteiligung von Use1p am Transport zwischen ER und Golgi lieferte die Untersuchung des Transportes und der Prozessierung des sekretorischen Enzyms Invertase mittels eines „Pulse-Chase“-Experimentes (siehe Kap. 2.2.4.10). Neusynthetisierte Invertase wird ins ER transloziert, wo sie glykosyliert wird („Core“Glykosylierung). Danach wird sie zum Golgi-Apparat transportiert, wo sie zusätzliche Oligosaccharid-Modifikationen erhält. Im trans-Golgi wird sie daraufhin in Vesikel verpackt und nach Fusion dieser Vesikel mit der Plasmamembran in den periplasmatischen Raum sekretiert, wo sie die Hydrolyse von Saccharose zu Glukose und Fruktose katalysiert (Franzusoff and Schekman, 1989). Abb. 3.29 zeigt, dass in WTZellen Invertase hauptsächlich in ihrer maturen Form sekretiert wird (E). Dagegen zeigen sowohl die use1-10AA-Mutante als auch die use1-Olayer-Mutante nach Inkubation bei der jeweiligen restriktiven Temperatur eine Akkumulierung der „core“-glykosylierten ERForm (I) und Sekretion der unterglykosylierten cis-Golgi-Form von Invertase (E). Dies ist ein weiteres Indiz dafür, dass Use1p eine wichtige Funktion im Proteintransport zwischen ER und Golgi besitzt.

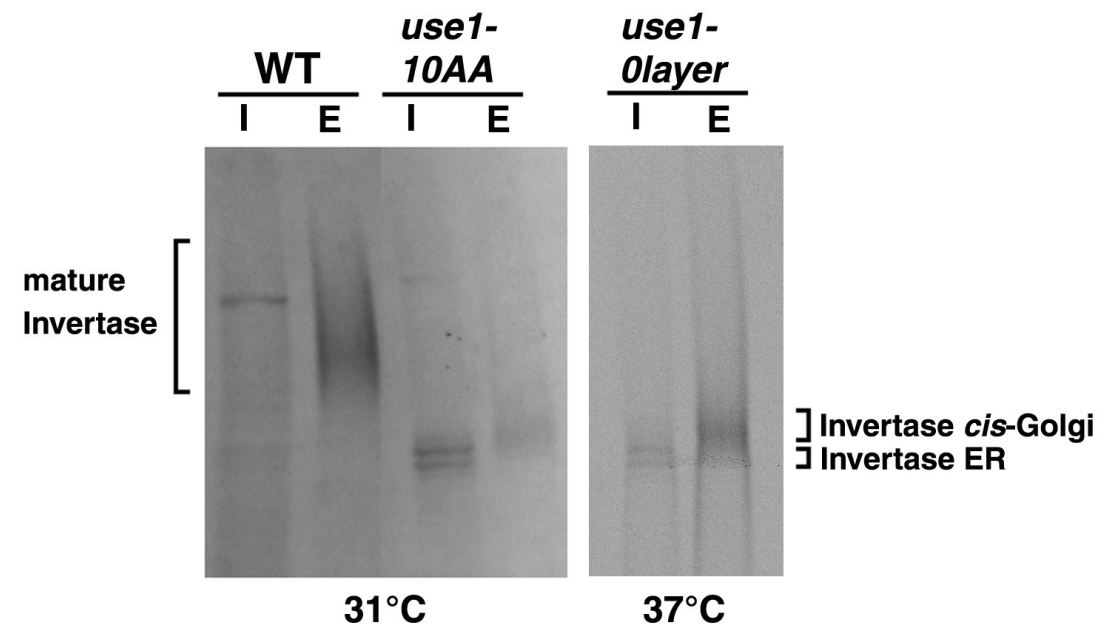

Abb. 3.29: Sowohl use1-10AA-Zellen als auch use1-0layer-Zellen akkumulieren nach Inkubation bei der restriktiven Temperatur die ,core“-glykosylierte ER-Form und sekretieren die unterglykosylierte cis-Golgi Form von Invertase. Nach radioaktiver Markierung und einer 30-minütigen Inkubation bei der jeweiligen restriktiven Temperatur (Chase) wurde Invertase in den Zellen (intern, I) und im Medium (extern, E) immunpräzipitiert. 


\subsubsection{Untersuchung der use1-Mutanten auf Defekte im anterograden bzw. retrograden ER-Golgi-Transport}

Die Akkumulierung von p1CPY bzw. der „core“-glykosylierten Form von Invertase im ER der use1-Mutanten könnte zwei Ursachen haben. Zum einen könnte sie durch einen Defekt im anterograden Transport vom ER zum cis-Golgi hervorgerufen werden, zum anderen aber auch aufgrund eines indirekten Effektes durch einen Block im retrograden Golgi-ER-Transport bedingt sein. Hierdurch könnten nämlich Komponenten, die für den Vorwärts-Transport benötigt werden nicht wieder zum ER zurücktransportiert werden. Daher sollte nun versucht werden, mit Hilfe verschiedener Recycling-Experimente zwischen diesen beiden Möglichkeiten zu unterscheiden. Das lösliche ER-Chaperonprotein Kar2p, bzw. sein Säugerhomolog BiP, werden sobald sie aus Versehen das ER verlassen beim Erreichen des cis-Golgi-Kompartiments aufgrund ihrer HDEL-Retentionssequenz von dem Recycling-Rezeptor Erd2p gebunden und über retrograde Transportvesikel wieder zum ER zurücktransportiert (Semenza et al., 1990). Ist der retrograde Transport zwischen Golgi und ER jedoch blockiert, so gelangt Kar2p zum trans-Golgi, wird dort in sekretorische Vesikel verpackt und nach Fusion dieser Vesikel mit der Plasmamembran in das Medium sekretiert (Abb. 3.30).

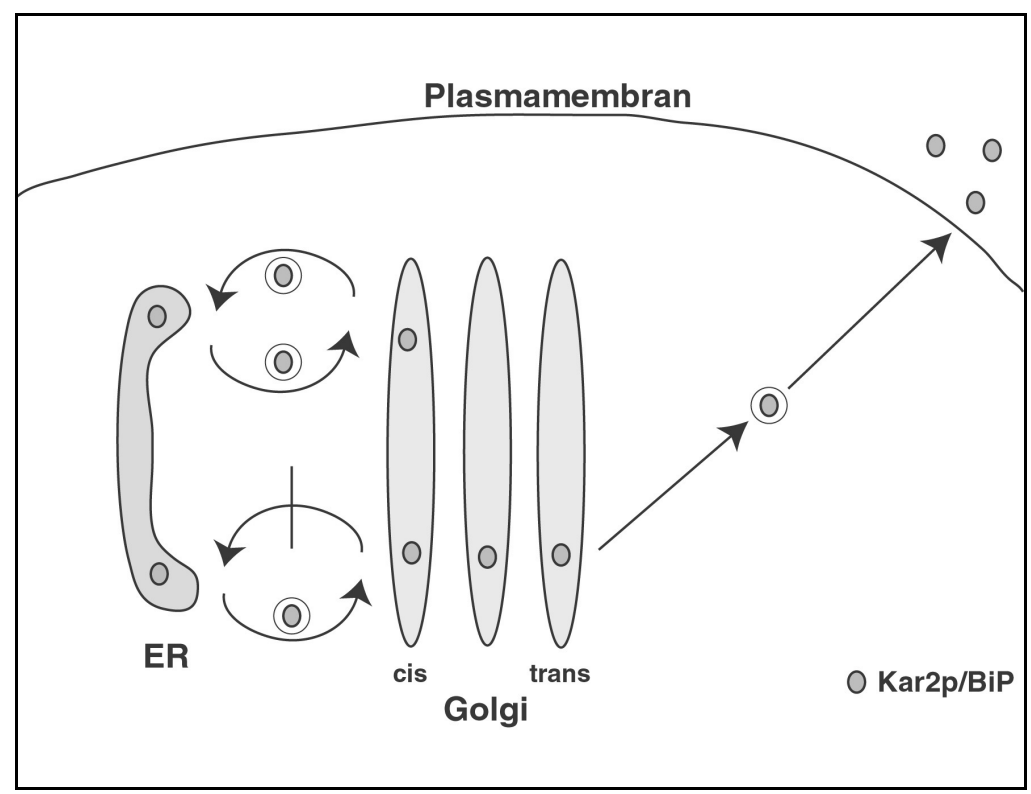

Abb. 3.30: Schema des Kar2p/BiP-Recycling-Experimentes. Das ER-Chaperonprotein Kar2p/BiP wird normalerweise sobald es das cis-Golgi-Kompartiment erreicht, in Transportvesikeln wieder zum ER zurücktransportiert. Ist der retrograde Transport zum ER jedoch blockiert, so wird es weiter zum trans-Golgi befördert und schließlich ins Medium sekretiert. 
Um zu Untersuchen, ob die temperatursensitiven usel-Mutanten einen Defekt im retrograden Golgi-ER-Transport besitzen, wurde daher der Gehalt an sekretiertem Kar2p nach 2-stündiger Inkubation bei entweder permissiver oder restriktiver Temperatur bestimmt (siehe Kap. 2.2.4.2). Abb. 3.31 zeigt, dass die use1-10AA-Mutante bereits bei $24^{\circ} \mathrm{C}$ Kar2p ins Medium sekretiert (Spur 6). Nach Temperaturerhöhung auf $30^{\circ} \mathrm{C}$ steigt der Gehalt an sekretiertem Kar2p noch weiter an (Spur 8). use1-Olayer-Zellen zeigen bei $24^{\circ} \mathrm{C}$ kaum Kar2p-Sekretion (Spur 10). Temperaturerhöhung auf $37^{\circ} \mathrm{C}$ führte jedoch auch hier zu einem erhöhten Gehalt an Kar2p im Medium (Spur 12). WT-Zellen zeigen weder bei $24^{\circ} \mathrm{C}$ noch bei $37^{\circ} \mathrm{C}$ Kar2p-Sekretion (Spuren 2 und 4), während eine temperatursensitive Mutante des ER-SNAREs Sec20p, sec20-1(RH236-3A), welche hauptsächlich im retrograden Transport blockiert ist, nach Temperaturerhöhung auf $30^{\circ} \mathrm{C}$ viel Kar2p ins Medium sekretiert (Spur16). Somit deuten diese Ergebnisse darauf hin, dass use1-10AAZellen sowie use1-Olayer-Zellen einen Defekt im retrograden Transport zum ER besitzen.

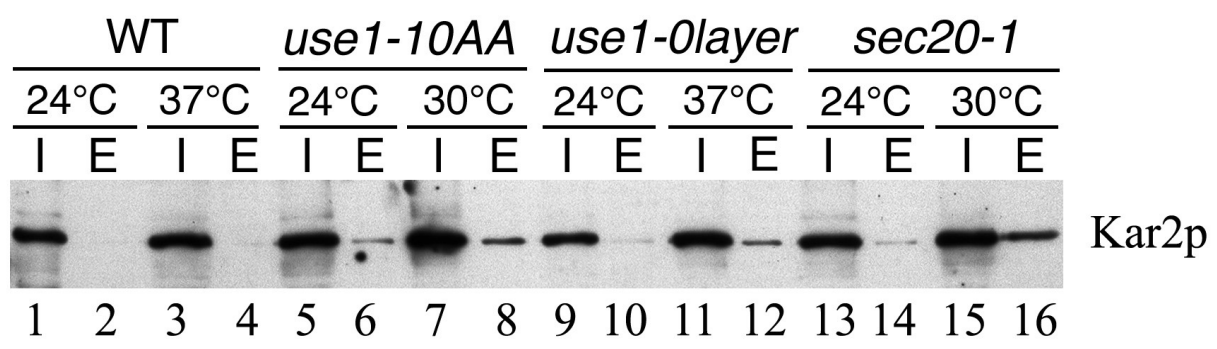

\begin{abstract}
Abb. 3.31: Die Sekretion von Kar2p nach Inkubation bei der restriktiven Temperatur deutet auf einen Defekt im retrograden Transport zum ER in den temperatursensitiven Use1pMutanten. WT- (BKY3-pBK85), use1-10AA- (BKY3-pBK83), use1-Olayer- (BKY3-pMD25), sowie sec20-1-Zellen (RH236-3A) wurden bei $24^{\circ} \mathrm{C}$ wachsen gelassen und danach für $2 \mathrm{~h}$ bei der jeweiligen restriktiven Temperatur in frischem YEPD-Medium inkubiert. Sekretierte Proteine wurden aus dem Medium durch TCA-Fällung präzipitiert (extern, E). Aus den Zellpellets wurden Proteinextrakte gewonnen (intern, I). Für die Pellet-Fraktionen wurden jeweils $0.19 \mathrm{OD}_{600}$ und für die externen Fraktionen 3.6 $\mathrm{OD}_{600}$ in einem SDS-PAGE aufgetrennt. Es folgte ein Western-Blot und eine Inkubation mit anti-Kar2p-Antikörper.
\end{abstract}

Ein weiteres Experiment zur Unterscheidung zwischen Defekten im anterograden und retrograden ER-Golgi-Transport basiert auf der Analyse des Transportes eines Sec22pHybridproteins (Boehm et al., 1997; Ballensiefen et al., 1998). Das R-SNARE Sec22p ist sowohl im anterograden als auch retrograden ER-Golgi-Transport involviert, weshalb es sich ständig zwischen ER und cis-Golgi hin und her bewegt. Im vorgestellten RecyclingExperiment wurde das Hybridprotein Sec22- $\alpha$ benutzt, in welchem der C-Terminus von Sec22p durch ein 10 Aminosäure langes humanes c-Myc-Epitop gefolgt von einer Kex2p- 
Schnittstelle sowie einer 13 Aminosäure langen $\alpha$-Faktor-Sequenz erweitert wurde. Sec22- $\alpha$ verhält sich wie das WT-Sec22p. Ist der retrograde Transport zum ER blockiert, so gelangt Sec22- $\alpha$ ins trans-Golgi-Kompartiment, wo sich die Protease Kex $2 p$ befindet. Diese spaltet nun die $\alpha$-Faktor-Sequenz ab, was zur Verkürzung des Proteins führt (Abb. 3.32). Daher kann dieses Ereignis durch SDS-PAGE und Immunoblot mit einem Antikörper gegen das c-Myc-Epitop verfolgt werden, welcher sowohl Sec22- $\alpha$ als auch das Kex2p-Proteolyseprodukt erkennt. Darüber hinaus könnte auch das sekretierte $\alpha$ Faktor-Pheromon detektiert werden. Eine wichtige Voraussetzung für dieses Experiment ist, dass man nur Stämme mit Paarungstyp $\alpha$ verwendet, da diesen Zellen die im ER lokalisierte Protease Barlp fehlt. MATa-Zellen, welche Barlp besitzen, zeigen nämlich eine sehr schnelle Prozessierung von Sec22- $\alpha$ im ER (Ballensiefen and Schmitt, 1997).

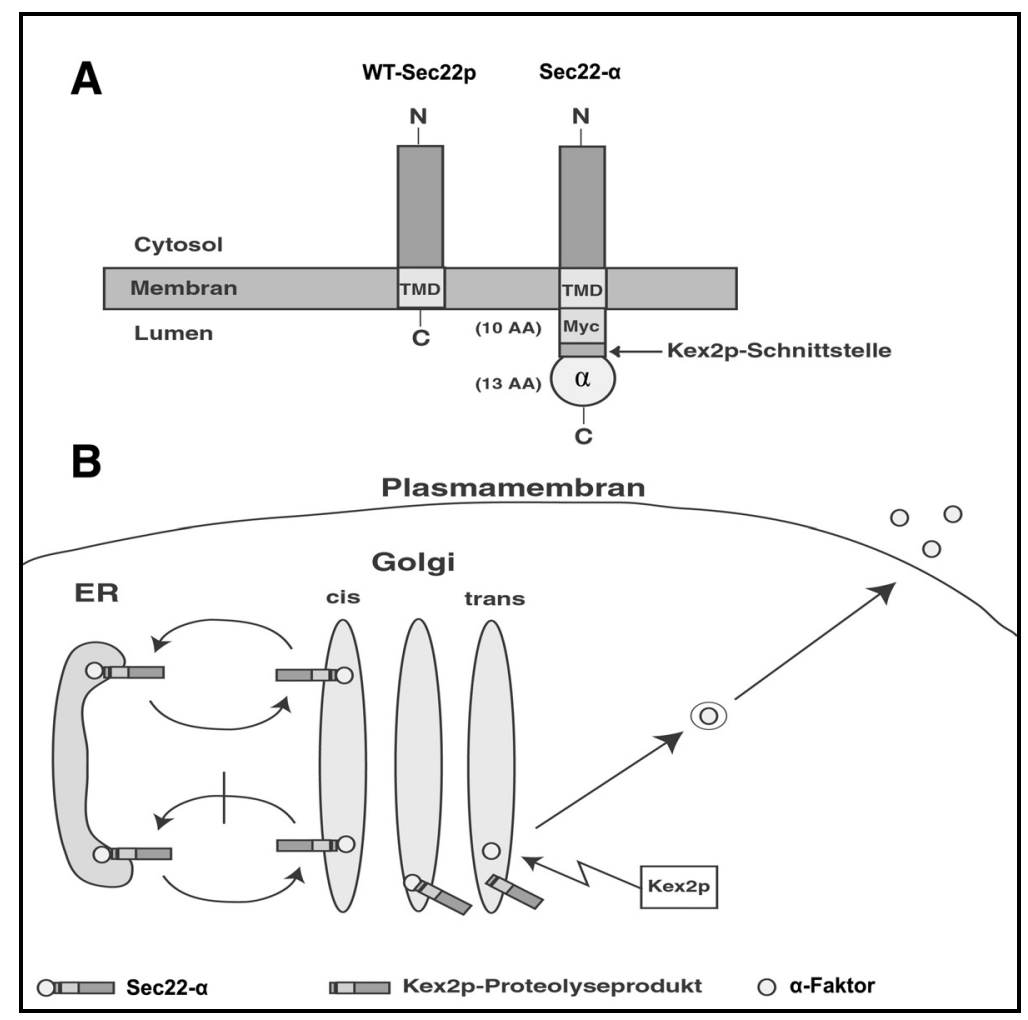

Abb. 3.32: Schema des Sec22- $\alpha$-Recycling-Experimentes. (A) Das Sec22- $\alpha$-Hybridprotein enthält am CTerminus eine zusätzliche 10 Aminosäure lange Sequenz eines c-Myc-Epitops, gefolgt von einer Kex2p-Schnittstelle und einer 13 Aminosäure langen $\alpha$-Faktor-Sequenz. (B) Sec22- $\alpha$ wird wie das WT-Sec22p zwischen ER und cis-Golgi hin und her transportiert. Ist der retrograde Transport zum ER blockiert, so gelangt Sec22- $\alpha$ ins trans-Golgi-Kompartiment, wo der $\alpha-$ Faktor durch die dort lokalisierte Protease Kex2p abgespalten und ins Medium sekretiert wird (nach Boehm et al., 1997; Ballensiefen et al., 1998). 
Abb. 3.33 zeigt, dass in use1-10AA- sowie use1-Olayer-Zellen nur die Bande des ungeschnittenen Sec22- $\alpha$ detektiert wird (Spuren 3-5 und 9-11). Allerdings reduzierte sich dieser Gehalt nach Temperaturerhöhung. Dies legte die Vermutung nahe, dass Sec22- $\alpha$ bzw. sein Kex2p-Proteolyseprodukt in den use1-Mutanten nicht im trans-Golgi verbleiben, sondern weiter zur Vakuole transportiert und degradiert werden. Um die Degradierung in der Vakuole zu verhindert wurden daher PEP4-defiziente Stämme der usel-Mutanten hergestellt. Das PEP4-Gen codiert für die vakuoläre Proteinase A (PrA), welche für die Aktivierung aller vakuolären Proteasen benötigt wird. Die use1-10AAMutante (BKY3-pBK83), use1-Olayer-Mutante (BKY3-pMD25) sowie der isogene WT (BKY3-pBK85) wurden mit einem PEP4-defizienten WT-Stamm (MDY9) gekreuzt (siehe Kap. 2.2.3.7), die dipoiden Zellen anschließend sporuliert (siehe Kap. 2.2.3.8), die Meiosporen der Tetraden unter dem Mikroskop separiert und auf ihren Genotyp hin analysiert (siehe Kap. 2.2.3.9). Auf diese Weise entstanden die PEP4-defizienten use1Mutanten BKY10-pBK83 und BKY10-pMD25. Abb. 3.33 zeigt, dass in den use1Mutanten ohne aktive vakuoläre Proteasen (pep4A) Sec22- $\alpha$ stabilisiert wird (Spuren 6-8 und 12-14). Zusätzlich tritt in diesen Stämmen die Bande des Kex2p-Proteolyseproduktes auf, während sie im PEP4-defizienten WT-Stamm BKY12 nicht zu detektieren ist (Spur 2). Somit deuten diese Ergebnisse darauf hin, dass aufgrund eines Defektes im retrograden Transport zum ER Sec22- $\alpha$ bzw. sein Kex2p-Proteolyseprodukt in use110AA-Zellen sowie use1-Olayer-Zellen zur Vakuole transportiert und dort degradiert wird.

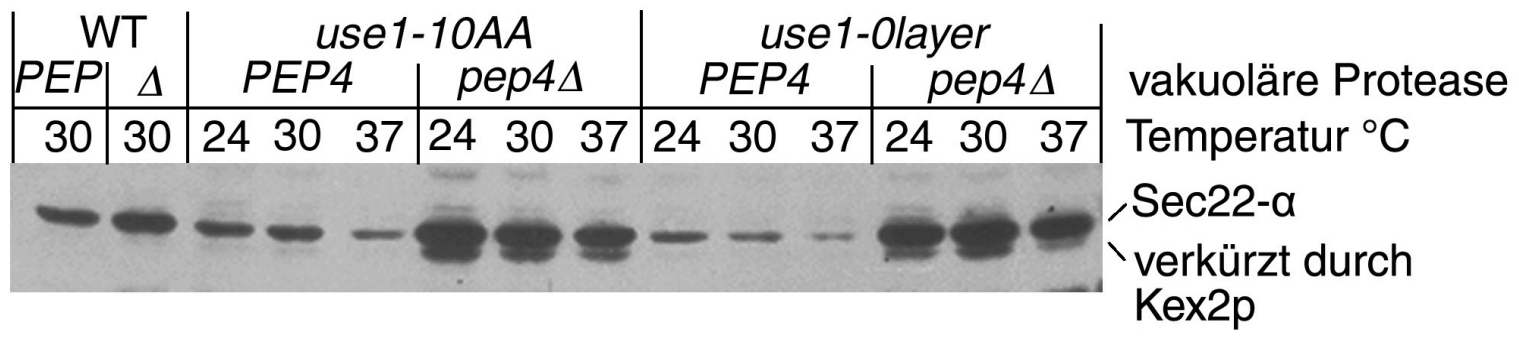

Abb. 3.33: Spaltung von Sec22- $\alpha$ und Abbau des Kex2p-Proteolyseproduktes in der Vakuole deuten darauf hin, dass in use1-Mutanten der retrograde Transport zum ER blockiert ist. WT-, use1-10AA- und use1-Olayer-Zellen die Sec22- $\alpha$ exprimierten wurden bei $24^{\circ} \mathrm{C}$ wachsen gelassen und danach für $30 \mathrm{~min}$ bei der jeweiligen restriktiven Temperatur inkubiert. PEP bzw. PEP4 bedeutet, dass diese Stämme aktive vakuoläre Proteasen besitzen, während $\Delta$ - und pep $4 \Delta$-Stämme aufgrund einer Deletion des PEP4-Genes keine aktiven vakuolären Proteasen enthalten. Proteinextrakte der jeweiligen Stämme wurden durch SDS-PAGE und Immunoblot mit einem Antikörper gegen das c-Myc-Epitop analysiert. 
Ein weiteres Recycling-Experiment zur Unterscheidung zwischen anterogradem und retrogradem ER-Golgi-Transport bedient sich des Typ-I-Transmembranproteins Emp47p, welches ebenfalls vom ER zum cis-Golgi und zurück transportiert wird (Schröder et al., 1995). Im Gegensatz zu Sec22p, welches hauptsächlich im ER lokalisiert ist, befindet sich Emp47p unter normalen Bedingungen überwiegend im Golgi (Abb. 3.34). Daher zeigen WT-Zellen in einer indirekten Immunfluoreszenz mit anti-Emp47p-Antikörpern (siehe Kap. 2.2.5.2) punktförmige Strukturen, was das typische Erscheinungsbild des GolgiApparates in Hefezellen darstellt. In Mutanten, in denen der anterograde ER-GolgiTransport blockiert ist, da sich keine COPII-Transportvesikel bilden können („ERKnospungsmutanten“), akkumuliert Emp47p im ER. Daher zeigen diese Zellen in der indirekten Immunfluoreszenz mit anti-Emp47p-Antikörpern ringförmige ER-Strukturen, die den Zellkern umranden. In Recycling-Mutanten erreicht Emp47p dagegen langsam die Vakuolenmembranen, welche in der indirekten Immunfluoreszenz als Ringe um die im differentiellen Interferenz-Kontrast (DIC) sichtbaren Vakuolen erscheinen. Damit Emp47p - falls es die Vakuole erreicht - nicht durch vakuolären Proteasen degradiert wird, muss auch in diesem Experiment mit PEP4-defizienten Stämmen gearbeitet werden.

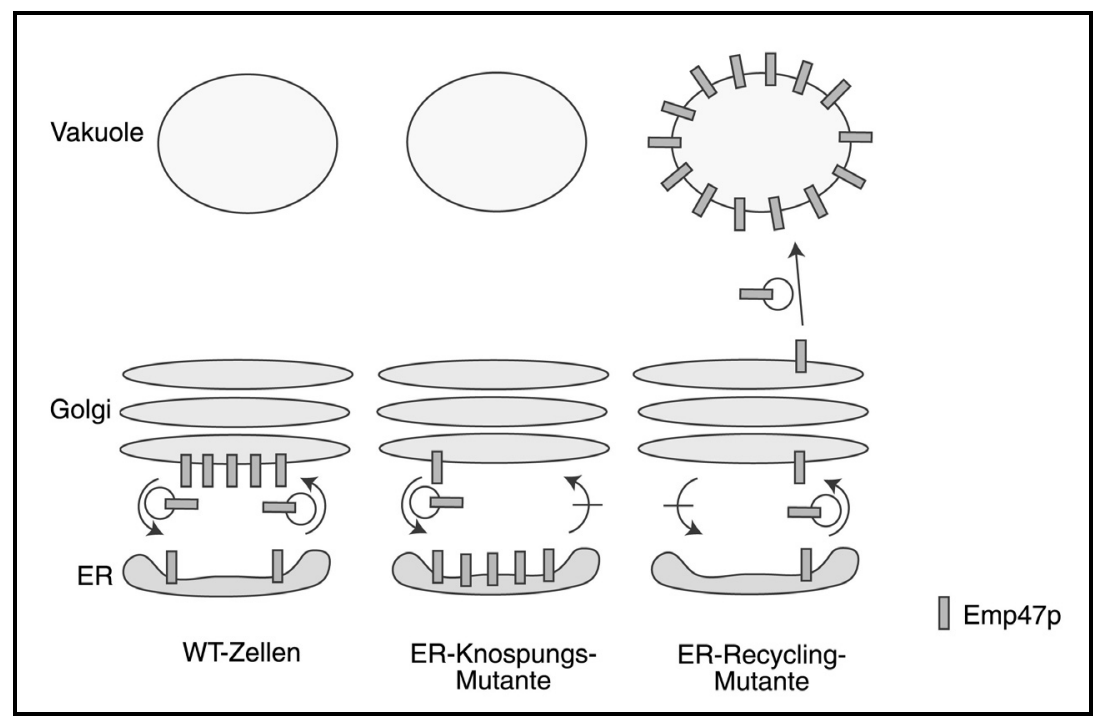

Abb. 3.34: Schema des Emp47p-Recycling-Experimentes. In WT-Zellen befindet sich Emp47p unter normalen Bedingungen überwiegend im Golgi-Apparat. In „ER-Knospungsmutanten“ akkumuliert Emp47p aufgrund eines Defektes im anterograden ER-Golgi-Transport im ER. In ER-Recycling-Mutanten erreicht Emp47p die Vakuolenmembran (nach Schröder et al., 1995). 


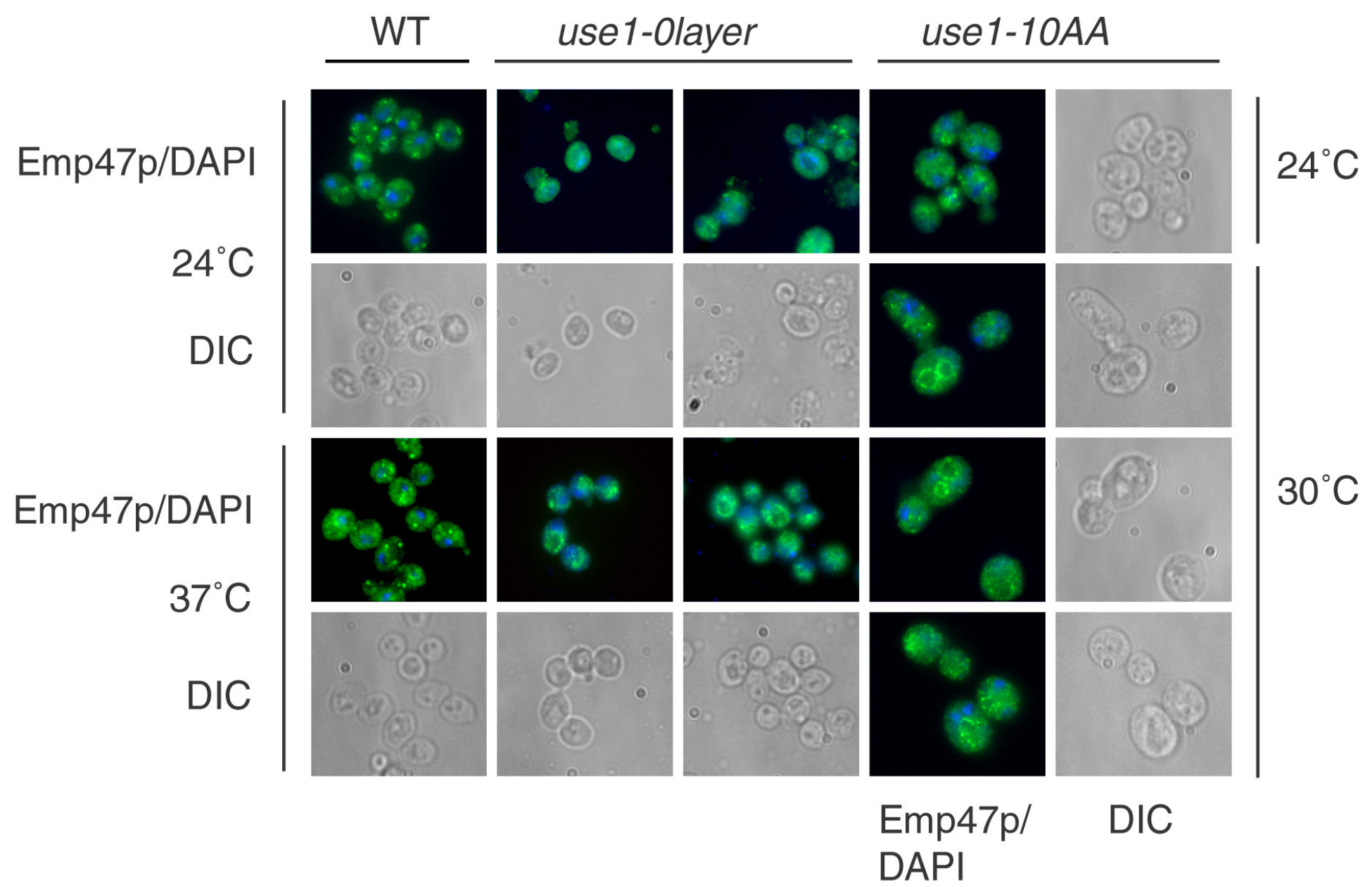

Abb. 3.35: Emp47p wird in den use1-Mutanten bei restriktiver Temperatur teilweise zur Vakuole befördert. $P E P 4$-defiziente WT-, use 1-10AA- und use1Olayer-Zellen wurden bei $24^{\circ} \mathrm{C}$ wachsen gelassen, danach für $1 \mathrm{~h} 30 \mathrm{~min}$ bei der jeweiligen restriktiven Temperatur inkubiert und anschließend Emp $47 \mathrm{p}$ über indirekte Immunfluoreszenz detektiert. In WT-Zellen zeigt Emp47p überwiegend eine Golgi-Lokalisation (punktförmige Strukturen). use1-0layerund besonders use1-10AA-Zellen zeigen teilweise eindeutige vakuoläre Lokalisation für Emp47p (ringförmige Strukturen im Bereich der in der Transmission (DIC) sichtbaren Vakuolen). Diese ringförmigen Strukturen umranden nicht den durch die DAPI-Färbung sichtbaren Zellkern, was darauf hindeutet, dass Emp47p nicht im ER akkumuliert. grün: Emp47p; blau: DAPI; DIC = differentieller Interferenz-Kontrast. 
Abb. 3.35 zeigt, dass Emp47p sowohl in PEP4-defizienten WT-Zellen (BKY12) als auch in use1-10AA-Zellen (BKY10-pBK83) und use1-Olayer-Zellen (BKY10-pMD25) bei $24^{\circ} \mathrm{C}$ in punktförmigen Golgi-Strukturen akkumuliert. Nach Inkubation für $1 \mathrm{~h} 30$ min bei $30^{\circ} \mathrm{C}$ bzw. $37^{\circ} \mathrm{C}$ befindet sich Emp47p in der Mehrzahl der use1-10AA- bzw. use1Olayer-Zellen weiterhin im Golgi-Apparat, wobei einige Zellen aber auch eine eindeutige vakuoläre Lokalisation für Emp47p zeigen. Eine Akkumulierung von Emp47p im ER wurde in keiner der Zellen beobachtet. Dieses Ergebnis deutet in Übereinstimmung mit den Ergebnissen der vorangegangenen Recycling-Experimente auf eine Beteiligung von Use1p am retrograden Golgi-ER-Transport hin.

\subsubsection{Genetische Interaktionen zwischen USE1 und ER-Golgi-SNAREs}

Um zu untersuchen, mit welchen SNARE-Proteinen Use1p im gleichen Transportschritt funktionell interagiert, wurden gezielt unterschiedliche SNAREs, die im anterograden und retrograden ER-Golgi-Transport beteiligt sind, in der use1-10AA-Mutante überproduziert. Anhand ihrer Suppressions-Effekte sollte analysiert werden, ob sie mit dem tsmutierten Protein genetisch interagieren. Der SNARE-Komplex des anterograden Transportes vom ER zum cis-Golgi besteht aus dem R-SNARE Sec22p, dem Qa-SNARE (Syntaxin) Sed5p, dem Qb-SNARE Bos1p sowie dem Qc-SNARE Bet1p (Hardwick and Pelham, 1992; Newman et al., 1990; Søgaard et al., 1994). Sec22p ist auch im retrograden Transport zum ER involviert, wo es einen Komplex mit dem Qa-SNARE (Syntaxin) Ufe1p und dem Qb-SNARE Sec20p bildet (Lewis et al., 1997; Spang and Schekman, 1998). Das cytosolische Protein Tip20p interagiert ebenfalls biochemisch mit Sec20p (Sweet and Pelham, 1993) und scheint eine Funktion im retrograden Golgi-ERTransport zu besitzen (Lewis and Pelham, 1996), enthält jedoch kein SNARE-Motiv (Lewis et al., 1997).

Um zu analysieren, ob die Überexpression unterschiedlicher ER- und Golgi-SNAREs den Wachstumsdefekt der use1-10AA-Mutante supprimieren kann, wurden entweder centromere Plasmide $(1-3$ Kopien pro Zelle) oder $2 \mu$-Plasmide $(10-20$ Kopien pro Zelle), welche die entsprechenden Gene trugen, in die use1-10AA-Mutante transformiert und das Wachstum bei $24^{\circ} \mathrm{C}, 30^{\circ} \mathrm{C}$ und $37^{\circ} \mathrm{C}$ untersucht. Abb. 3.36 zeigt, dass eine starke Überexpression von SEC20 vom $2 \mu$-Plasmid use1-10AA-Zellen ermöglichte bei $37^{\circ} \mathrm{C} z \mathrm{z}$ wachsen. Überproduktion von Sec20p vom centromeren Plasmid erlaubte der use 1-10AAMutante noch bei $30^{\circ} \mathrm{C} \mathrm{zu}$ wachsen. Überexpression von SEC22 (anterograd und 
retrograd) oder BOS1 (anterograd), entweder vom CEN- oder vom $2 \mu$-Plasmid führte ebenfalls zur Suppression des Wachstumsdefektes bei $30^{\circ} \mathrm{C}$. Überproduktion von Ufe1p (retrograd) bzw. Bet1p und Sed5p (beide anterograd) resultierte nach längerer Inkubation im langsamen Wachstum der use 1-10AA-Zellen bei $30^{\circ} \mathrm{C}$ (nicht gezeigt). Zusammenfassend zeigen diese Ergebnisse, dass USE1 die stärksten genetischen Interaktionen mit SEC20 zeigte, einem SNARE des retrograden Transportes zum ER.

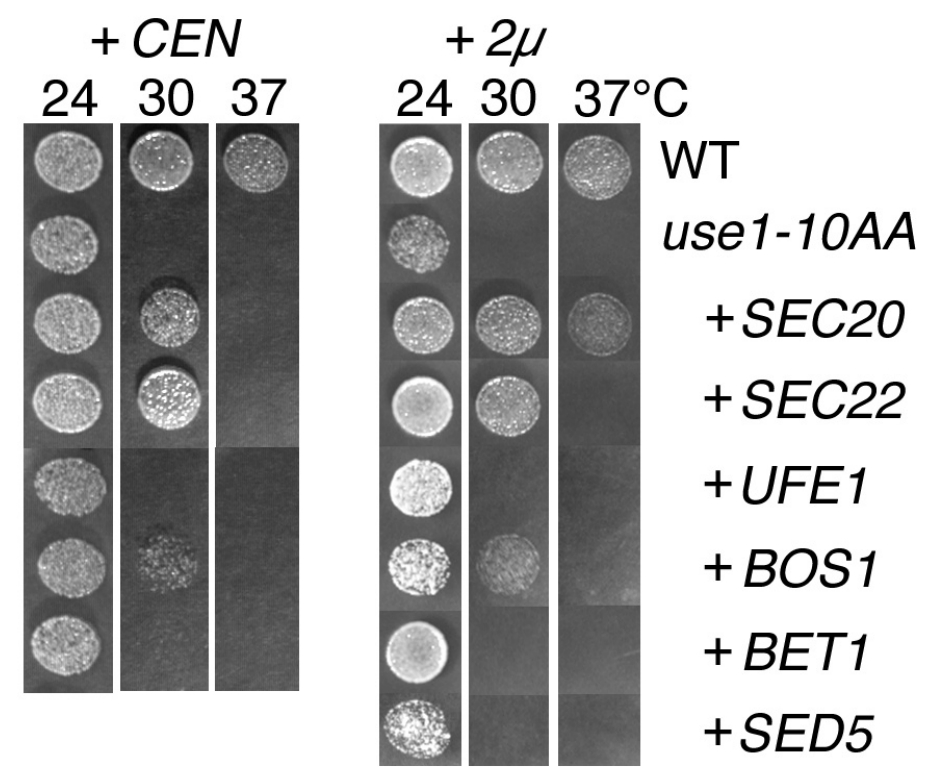

Abb. 3.36: Die stärkste Suppression des Wachstumsdefektes der use1-10AA-Mutante zeigte eine Überexpression von SNAREs des retrograden Golgi-ER-Transportes. In einem Wachstumstest wurden Verdünnungen von WT-Zellen (BKY3-pBK85), use1-10AA-Zellen (BKY3-pBK83), sowie use1-10AA-Zellen, die unterschiedliche SNARE-Proteine entweder von CEN-Plasmiden (linke Seite) oder $2 \mu$-Plasmiden (rechte Seite) überexprimierten, bei $24^{\circ} \mathrm{C}$, $30^{\circ} \mathrm{C}$ oder $37^{\circ} \mathrm{C}$ auf YEPD-Platten inkubiert.

In den gleichen Stämmen wurde außerdem der CPY-Transport mit Hilfe eines „PulseChase“-Experimentes untersucht (Abb. 3.37). Überexpression von SEC20 (Spur 3), SEC22 (Spur 5) und BOS1 (Spur 9) von $2 \mu$-Plasmiden führte bei $30^{\circ} \mathrm{C} \mathrm{zu}$ einer verringerten Akkumulation von p1CPY im ER der use1-10AA-Zellen und erhöhten Mengen mCPY in den Vakuolen. Überexpression von UFE1, BET1 und SED5 supprimierte den CPY-Transportdefekt der use1-10AA-Mutante etwas schwächer. Bei der schwächeren Überexpression von centromeren Plasmiden zeigte SEC22 den stärksten Effekt, während SEC20 nur eine schwache Suppression hervorrief. BOS1- und UFE1Überexpression hatten diesmal keinen Effekt auf den CPY-Transportdefekt. 
A

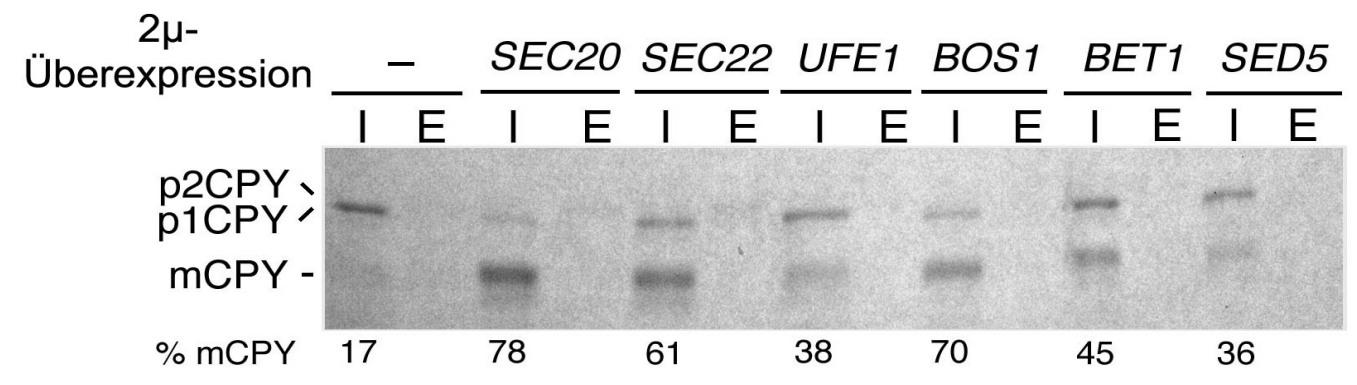

B

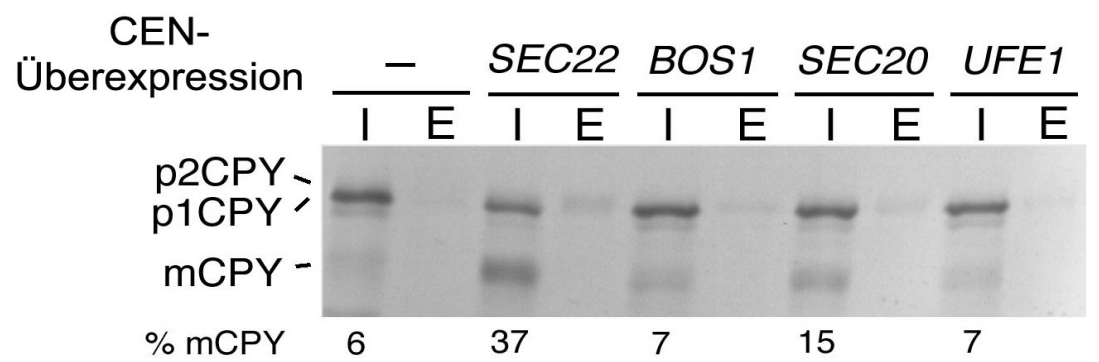

Abb. 3.37: Überproduktion von Sec20p, Sec22p oder Bos1p führte zu einer Suppression des CPYTransportdefektes der use1-10AA-Mutante. use1-10AA-Zellen (BKY3-pBK83) und use1$10 A A$-Zellen, die unterschiedliche ER-Golgi-SNARE Proteine überexprimierten, wurden bei $24^{\circ} \mathrm{C}$ wachsen gelassen. CPY wurde nach Pulse-Chase-Markierung bei $30^{\circ} \mathrm{C}$ in den Zellextrakten (intern, I) und im Medium (extern, E) immunpräzipitiert. (A) Überexpression von SEC20 (retrograd), SEC22 (retrograd und anterograd) und BOS1 (anterograd) von einem $2 \mu-$ Plasmid verbesserte den CPY-Transport zur Vakuole in use1-10AA-Zellen. (B) Überproduktion von Sec22p (anterograd und retrograd) von einem CEN-Plasmid zeigte eine starke Suppression des CPY-Transportdefektes der use1-10AA-Mutante. Überexpression von SEC20 (retrograd) vom CEN-Plasmid hatte einen etwas schwächeren Suppressionseffekt.

\subsubsection{Biochemische Charakterisierung des Use1p-SNARE-Komplexes}

Da die bislang beschriebenen Ergebnisse zeigen, dass use1-Mutanten einen Defekt im retrograden Transport zum ER besitzen und dass USE1 funktionell am stärksten mit SNARE-Proteinen interagiert, die in diesem Transportschritt beteiligt sind, sollte nun analysiert werden, ob Use1p tatsächlich eine Komponente des retograden Golgi-ERSNARE-Komplexes darstellt und biochemisch mit den anderen SNARE-Proteinen dieses Komplexes interagiert. Hierzu wurde zunächst Untersucht, ob man in vitro einen SNARE-Komplex aus den rekombinanten 6xHis-erweiterten SNARE-Motiven der SNARE-Proteine Sec20p (pUF5, Aminosäuren 201 - 274), Sec22p (pUF6, Aminosäuren 121 - 188), Use1p (pUF7, Aminosäuren 147 - 215) und Ufe1p (pUF8, Aminosäuren 253 326) assemblieren kann. Die aufgereinigten rekombinanten SNARE-Proteine wurden zusammen in einer Endkonzentration von jeweils $12 \mu \mathrm{g}$ pro $100 \mu \mathrm{l}$ in Assemblierungspuffer über Nacht bei $4^{\circ} \mathrm{C}$ auf der Wippe inkubiert (nach Antonin et al., 2000a). Der 
Ansatz wurde danach in Probenpuffer resuspendiert, jedoch nicht bei $95^{\circ} \mathrm{C}$ inkubiert, um eine Deassemblierung des SNARE-Komplexes zu verhindern. Nach elektrophoretischer Auftrennung des Ansatzes in einem SDS-PAGE und anschließender Färbung der Proteine mit Coomassie-Blau traten nur die Banden der einzelnen SNARE-Proteine auf, aber keine höhermolekulare Bande, die auf einen SDS-resistenten SNARE-Komplex schließen könnte (nicht gezeigt). Da jedoch nicht alle SNARE-Komplexe SDS-resistent sind, könnte es sein, dass der Komplex während der Elektrophorese zerfiel. In einem nativen Gel (ohne SDS) in welchem parallel auch die einzelnen SNARE-Proteine aufgetrennt wurden, tauchte jedoch keine zusätzliche Bande in der Spur des Assemblierungsansatzes auf, was darauf hindeutet, dass die einzelnen SNARE-Proteine unter diesen Bedingungen nicht stabil miteinander interagierten (keine Abb.).

Als nächstes wurde versucht, die SNARE-Komplex-Assemblierung durch eine Auftrennung der Proteine mittels Gelfiltration in einer HPLC-Anlage (SMART ${ }^{\circledR}$-System, Pharmacia, Uppsala, Schweden) zu untersuchen (siehe Kap. 2.2.4.13). Hierzu wurde eine Superdex ${ }^{\circledR} 75$ PC 3.2/30-Säule mit einem Gelvolumen von $2.4 \mathrm{ml}$ verwendet. Die Flussrate betrug $40 \mu \mathrm{l} / \mathrm{min}$. Die Eluate wurden über UV-Detektion bei den Wellenlängen $280 \mathrm{~nm}$ (aromatische Aminosäuren), $214 \mathrm{~nm}$ (Peptidbindung) und $340 \mathrm{~nm}$ (Verunreinigungen) analysiert. Hierbei zeigte sich, dass $6 x$ His-Sec20p und 6xHis-Use1p anscheinend Dimere bilden, während 6xHis-Ufe1p als Tetramer erschien. Da dieses Tetramer ein ähnliches Molekulargewicht wie der zu erwartende SNARE-Komplex besaß, konnte über diese Methode nicht zwischen Oligomer-Bildung und KomplexBildung unterschieden werden. Aus diesem Grund wurde nun versucht, die SNAREKomplex-Assemblierung durch eine Ionenaustausch-Chromatographie über eine Mono $\mathrm{S}^{\circledR}$ PC 1.6/5-Kationenaustauschersäule mit einem Gelvolumen von $100 \mu \mathrm{l}$ in der oben beschriebenen HPLC-Anlage zu analysieren (siehe Kap. 2.2.4.13), da hier die Proteine nicht über ihre Masse, sondern über ihre Nettoladung getrennt werden. Die SNAREKomplex-Assemblierung erfolgte diesmal für $40 \mathrm{~h}$ bei $4^{\circ} \mathrm{C}$ auf der Wippe.

Nur 6xHis-Use1p ist bei physiologischem pH-Wert negativ geladen, die anderen drei SNARE-Proteine besitzen sehr basische isoelektrische Punkte und sind erst oberhalb von pH 9.5 negativ geladen. 
Tab. 3.2: Biophysikalische Eigenschaften der rekombinanten SNARE-Proteine.

\begin{tabular}{c|c|c|c} 
SNARE & isoelektrischer Punkt & Ladung bei pH 7.0 & Anzahl der Tyrosine \\
\hline 6xHis-Sec22p & 9.46 & +5.07 & 3 \\
\hline 6xHis-Sec20p & 9.47 & +4.24 & 1 \\
\hline 6xHis-Ufe1p & 9.82 & +6.25 & 0 \\
\hline 6xHis-Use1p & 6.69 & -0.92 & 1
\end{tabular}

6xHis-Use1p würde aufgrund seiner negativen Ladung nicht an den Kationenaustauscher binden. Wenn es jedoch in einen Komplex bindet, welcher durch die von den anderen drei SNARE-Proteinen erzeugte positive Ladung an der Säule haften bleibt, müsste 6xHisUse1p zusammen mit den anderen SNARE-Proteinen erst wieder bei der Elution mit ansteigender Salzkonzentration und ansteigendem pH-Wert (2 ml Gradient: $30 \mathrm{mM} \mathrm{NaCl}$ bis $0.5 \mathrm{M} \mathrm{NaCl}$, pH 7.4 bis 10.5 , Flussrate $100 \mu \mathrm{l} / \mathrm{min}$, Fraktionsvolumen $100 \mu \mathrm{l}$ ) von der Säule gewaschen werden. Die Peak-Fraktionen wurden daraufhin einem SDS-PAGE mit anschließendem Immunoblot mit anti-Use1p-Antikörper sowie anti-Sec22p-Antikörper unterzogen. Falls beide Proteine in einem Komplex miteinander interagierten, sollten sie zusammen in den späten Fraktionen erscheinen. Abb. 3.38 zeigt, dass 6xHis-Use1p hauptsächlich in den Fraktionen 3 und 6 eluiert wurde, während $6 x H i s-S e c 22 p$ überwiegend in den Fraktionen 19 und 20 auftrat. Daher kann nicht davon ausgegangen werden, dass 6xHis-Use1p und 6xHis-Sec22p unter den gewählten Bedingungen zusammen in einem SNARE-Komplex assoziiert waren.

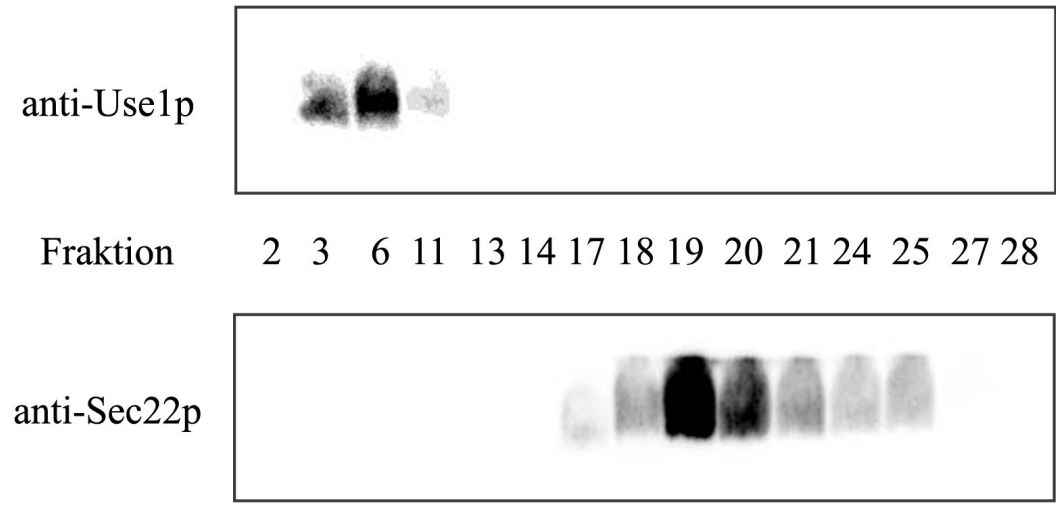

Abb. 3.38: Die rekombinanten, 6xHis-erweiterten SNARE-Proteine Ufe1p, Sec20p, Sec22p und Use1p formen in vitro gemeinsam keinen SNARE-Komplex. 6xHis-Ufe1p, 6xHis-Sec20p, $6 x$ His-Sec22p und $6 x$ His-Use1p wurden gemeinsam für $40 \mathrm{~h}$ bei $4^{\circ} \mathrm{C}$ in Assemblierungs-Puffer inkubiert, anschließend über eine Mono $\mathrm{S}^{\circledR}$ PC 1.6/5-Kationentauschersäule in einer SMART ${ }^{\circledR}$ HPLC-Anlage chromatographisch getrennt und die Peak-Fraktionen einem SDS-PAGE und Western-Blot mit anti-Use1p- und anti-Sec22p-Antikörperinkubation unterzogen. 
$\mathrm{Da}$ die in vitro-SNARE-Komplex-Assemblierung jedoch möglicherweise durch das Vorhandensein der 6xHis-Erweiterungen an den rekombinanten SNARE-Proteinen behindert wurde, sollte nun versucht werden, den retrograden Golgi-ER-SNAREKomplex in vivo zu isolieren. Hierzu wurde eine Koimmunpräzipitation mit Membranextrakten eines sec18-1-Stammes (SEY5186 $\alpha$ ) durchgeführt (siehe Kap. 2.2.4.12.4). Sec 18p ist das Hefehomolog der ATPase NSF welche zusammen mit $\alpha$-SNAP (Sec17p in Hefe) an der Deassemblierung von cis-SNARE-Komplexen beteiligt ist. Das mutierte Sec18-Protein in der sec18-1-Mutante ist hierzu nach Temperaturerhöhung nur eingeschränkt fähig, weshalb cis-SNARE-Komplexe akkumulieren. Hierdurch sollte die Isolierung von SNARE-Partnern eines SNARE-Komplexes erleichtert werden.

Die sec18-1-Membranextrakte wurden mit an Protein-A-Sepharose-Beads gekoppeltem anti-Use1p-Antiserum (Use1-Beads) bzw. Präimmunserum (Präimmun-Beads) inkubiert, die ungebundenen Proteine gesichert und zusammen mit den Beads (Immunpräzipitate) einer SDS-PAGE mit anschließendem Western-Blot unterzogen. Die NitrozelluloseMembran wurde daraufhin mit Antikörpern gegen die verschiedenen SNARE-Proteine inkubiert und diese über eine ECL-Reaktion detektiert. Abb. 3.39 zeigt, dass die Use1Beads sowohl das SNARE Ufe1p, welches im retrograden Transport zum ER involviert ist, als auch Sec22p, welches für beide Transportschritte (retrograd und anterograd) benötigt wird, immunpräzipitierten. Im Gegensatz dazu wurden die SNAREs Bos1p und Bet1p, welche nur im anterograden Transport involviert sind, nicht immunpräzipitiert. Auch das für den Vorwärtstransport zum cis-Golgi benötigte Sed5p bzw. das in späteren Transportschritten zwischen Golgi und Vakuole involvierte Vtilp wurden in einer Wiederholung des Experimentes nicht immunpräzipitiert (keine Abb.). Eine Bindung von Sec20p an die Use1-Beads konnte nicht getestet werden, da wir keinen anti-Sec20pAntikörper besitzen. Das Präimmunserum präzipitierte keines der SNAREs, was für die Spezifität der Koimmunpräzipitation spricht. Überraschenderweise zeigte sich kein Unterschied in der Menge der präzipitierten SNARE-Proteine zwischen der Inkubation der sec $18-1$-Mutante bei $24^{\circ} \mathrm{C}$ bzw. $37^{\circ} \mathrm{C}$. Zusammenfassend zeigen diese Ergebnisse, dass Use $1 p$ einen Komplex mit den SNAREs Ufe1p und Sec22p bildet, welche im retrograden Transport zum ER involviert sind. 


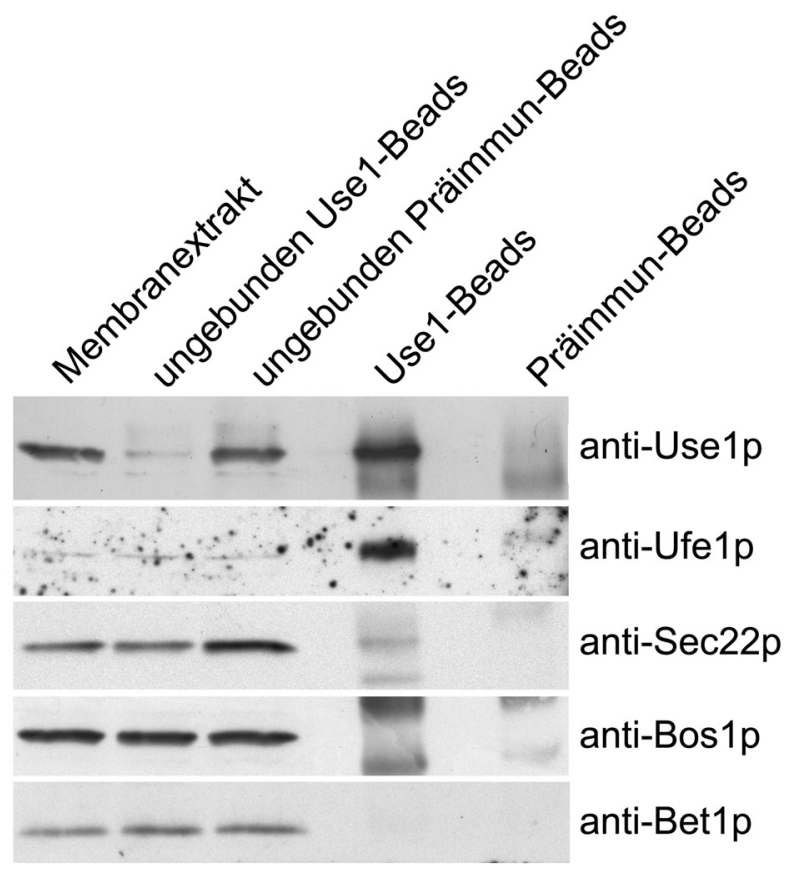

Abb. 3.39: Use1p-Antikörper kopräzipitieren SNAREs des retrograden Transportes vom cis-Golgi zum ER. Membranextrakte von sec18-1-Zellen (SEY5186 $\alpha, 24^{\circ} \mathrm{C}$ ) wurden mit an Protein-ASepahrose-Beads gekoppeltem anti-Use1p-Antiserum (Use1-Beads) bzw. zur Kontrolle mit an Protein-A-Sepharose-Beads gekoppeltem Präimmun-Serum (Präimmun-Beads) inkubiert und ungebundene Proteine separiert. Die Fraktionen wurden über SDS-PAGE und Immunoblot mit Antikörpern gegen Use1p, Ufe1p, Sec22p, Bos1p und Bet1p analysiert. Das Immunpräzipitat (Use1-Beads) des anti-Use1-Blots war 4.5x konzentrierter als der Membranextrakt, währen die Immunpräzipitate der restlichen Blots 22.5x konzentrierter waren als das Startmaterial. 


\section{Diskussion}

\subsection{Analyse von Suppressoren der vti1-2-Mutante}

\subsubsection{Identifizierung des vtil-2-Suppressors VTS1 (YOR359w)}

Das Hefe Qb-SNARE Vtilp ist an der Ausbildung unterschiedlicher SNARE-Komplexe in verschiedenen Transportrouten beteiligt, darunter in 3 Transportwegen zur HefeVakuole, in denen es genetisch bzw. biochemisch mit den vakuolären SNARE-Proteinen Vam3p (Qa) und Vam7p (Qc) (Fischer von Mollard and Stevens, 1999; Ungermann et al., 1999), sowie funktionell und biochemisch mit dem prävakuolären SNARE Pep12p (Qa) interagiert (Fischer von Mollard et al., 1997; Fischer von Mollard and Stevens, 1999). Unter der Voraussetzung, dass alle SNARE-Komplexe aus 4 unterschiedlichen SNAREHelices aufgebaut sind, kann man die Schlussfolgerung ziehen, dass in den vakuolären SNARE-Komplexen noch jeweils ein R-SNARE unidentifiziert ist, während im prävakuolären SNARE-Komplex noch zwei SNARE-Partner fehlen (R- und Qc-SNARE). Um diese fehlenden SNARE-Proteine zu identifizieren und evtl. noch zusätzliche Interaktionspartner von Vtilp aufzufinden, welche möglicherweise für die Spezifität dieser 3 verschiedenen Transportschritte verantwortlich sind, wurde ein MulticopySuppressor-Screen mit der temperatursensitiven Mutante vtil-2 durchgeführt. Diese Mutante zeigt einen Defekt im Transport vom trans-Golgi zur Prävakuole sowie in allen biosynthetischen Transportwegen zur Vakuole nach Inkubation bei der restriktiven Temperatur. Außerdem besitzt sie einen Wachstumsdefekt bei $37^{\circ} \mathrm{C}$ (Fischer von Mollard

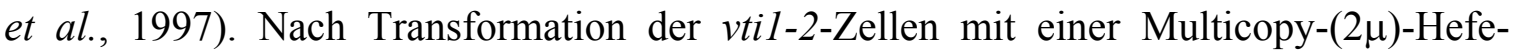
Genbank konnten daher potentielle Interaktionspartner aufgrund der Suppression des Wachstumsdefektes identifiziert werden. Wie zu erwarten zeigten Plasmide, die für Vtilp selbst codierten eine Suppression des Wachstumsdefektes der vtil-2-Zellen. Plasmide mit der Sequenz des prävakuolären SNAREs Pep12p riefen, wie auch schon früher beschrieben (Fischer von Mollard and Stevens, 1999), den gleichen Suppressionseffekt hervor. Die Sequenz des vakuolären SNAREs Vam3p wurde allerdings nicht gefunden, obwohl Vam3p-Überproduktion den Wachstumsdefekt der vti1-2-Mutante supprimiert (Fischer von Mollard and Stevens, 1999). Dies spricht dafür, dass der Suppressor-Screen nicht gesättigt war und somit nicht alle Hefe-Gene in den Transformanten repräsentiert 
waren. Zwei zusätzliche Plasmide verbesserten sowohl das schwache Wachstum der vtil2-Zellen bei $37^{\circ} \mathrm{C}$, als auch den Proteintransport zur Vakuole. Das eine Suppressorplasmid enthielt unter anderem den bislang uncharakterisierten offenen Leserahmen YOR359w, das andere die Sequenz des R-SNAREs Ykt6p (siehe Kap. 4.1.2).

\subsubsection{Charakterisierung des vti1-2-Suppressors VTS1 (YOR359w)}

Es zeigte sich, dass sowohl ein $2 \mu$-YOR359w-, als auch ein CEN-YOR359w-Plasmid den Wachstumsdefekt der vtil-2-Mutante bei $37^{\circ} \mathrm{C}$ supprimierten. Eine Überexpression von YOR359w in der Mutante vtil-11, welche ebenfalls einen Wachstumsdefekt bei $37^{\circ} \mathrm{C}$ zusätzlich zu Defekten im Transport zum cis-Golgi, zur Prävakuole und zur Vakuole besitzt, zeigte keinen Suppressionseffekt. Daher muss die Suppression der Defekte der vtil-2-Mutante durch YOR395w-Überexpression Allel-spezifisch sein. Aus diesem

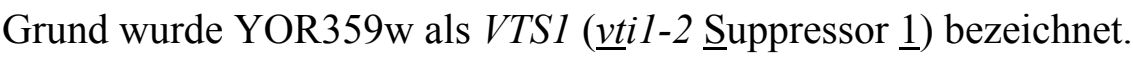

VTS1 codiert für ein Protein von 523 Aminosäuren Länge, das keine hydrophoben Bereiche enthält, die eine Transmembrandomäne ausbilden könnten. Über eine Datenbanksuche wurden nur zwei weitere homologe Proteine ähnlicher Länge in der Hefe Candida albicans (28 \% Aminosäure-Identität, GenBank accession no. AL033497) und der Spalthefe Schizosaccharomyces pombe (24 \% Aminosäure-Identität, GenBank accession no. CAB89878) gefunden. Alle drei Proteine besitzen eine SAM-Domäne (,sterile $\alpha$ motif $\left.{ }^{\circ}\right)$ in ihrem C-Terminus, welche mit Hilfe des SMART-Programms auf der EMBL-Homepage (http://smart.embl-heidelberg.de) identifiziert wurde. SAMDomänen sind ca. 70 Aminosäuren lang und scheinen über die Ausbildung von homound heterotypischen Oligomeren an der Entstehung niedrig-affiner Protein-ProteinInteraktionen beteiligt zu sein (Ponting, 1995; Peterson et al., 1997). SAM-Domänen werden häufig in regulatorischen Proteinen, darunter Tyrosin- und Serin-/ThreoninProteinkinasen, sowie in Adapter-Proteinen, GTPasen, Proteinen des Lipid-Metabolismus und Transkriptionsfaktoren der ETS-Familie bzw. in den mit dem Tumor-Suppressorgen p53 verwandten Transkriptionsfaktoren p63 und p73 gefunden (Schultz et al., 1997; Thanos and Bowie, 1999). Andere Hefe-Proteine mit einer SAM-Domäne sind die MAPKinase-Kinase-Kinase Ste11p, welche im Pheromon-Signaltransduktionsweg involviert ist, sowie die Proteine Boilp und Boi2p, welche Bem1p im Zuge der Knospung binden. 
Eine Deletion des VTS1-Genes hatte keinen Einfluss auf die Vitalität der Hefezellen. Somit handelt es sich bei VTS1 nicht um ein essentielles Gen. Die VTS1-Deletionsmutante zeigte außerdem keinen Defekt im Transport von CPY, ALP oder API zur Vakuole. Somit scheint die Funktion von Vts1p durch ein verwandtes Protein übernommen zu werden. Allerdings existiert in S. cerevisiae kein weiteres Protein mit einer homologen Sequenz. In einer von Wickner und Kollegen durchgeführten Untersuchung von Deletionsmutanten nicht-essentieller Gene auf Defekte in der homotypischen Vakuolenfusion zeigte ein $v t s 1 \Delta$-Stamm in $25 \%$ der Zellen einen vps-B-Phänotyp (viele kleine Vakuolen) und in $25 \%$ einen vps-C-Phänotyp (hochgradig fragmentierte Vakuolen). Zusätzlich zu diesem Defekt zeigten die Zellen eine schwache CPY-Sekretion (Seeley et $a l ., 2002)$. In einem spezifischen genetischen Screen von Deletionsmutanten auf Defekte im CPY-Transport zeigten vts1 $\Delta$-Zellen jedoch keine Fehllokalisation von CPY (Bonangelino et al., 2002). In beiden Experimenten wurden allerdings Euroscarf-Stämme untersucht, die einen anderen genetischen Hintergrund als die in dieser Arbeit verwendeten Stämme besitzen.

Zusätzlich zur VTS1-Deletion in WT-Zellen wurde das VTS1-Gen auch in den VTI1Mutanten vtil-1 und vtil-2 deletiert um Doppelmutaten zu erzeugen. Die Defekte der Doppelmutanten im CPY-, ALP- oder API-Transport waren nicht stärker ausgeprägt als die der VTI1-Mutanten vtil-1 und vtil-2, was dafür spricht, dass die Doppelmutanten keinen synthetischen Defekt im Proteintransport besitzen. In einem Wachstumstest zeigte sich, dass die Doppelmutante vtil-1 vts $1 \Delta$ sowohl bei $24^{\circ} \mathrm{C}$ als auch bei $37^{\circ} \mathrm{C}$ normal wuchs. Dagegen wuchs die Doppelmutante vtil-2 vts $1 \Delta$ bei $37^{\circ} \mathrm{C}$ überhaupt nicht mehr. Somit führt die VTS1-Deletion in Kombination mit der vtil-2-Mutation zu einem synthetischen Wachstumsdefekt bei hoher Temperatur, was ein weiteres Beispiel für die Allel-spezifische genetische Interaktion zwischen VTS1 und VTI1 darstellt. Außerdem besitzt die Doppelmutante vtil-2 vts1 $\Delta$ einen Defekt in der Autophagozytose, was darauf hin deutet, dass intaktes Vtilp und Vts1p für diesen Transportschritt benötigt werden. Um Vts1p weiter zu charakterisieren wurde zunächst versucht, seine subzelluläre Lokalisation zu bestimmen. Zwar besitzt Vts1p keine Transmembrandomäne, es könnte jedoch entweder durch posttranslationale Modifikationen oder über die Bindung an Vtilp oder andere Membranproteine mit Membranen assoziiert sein. In einer subzellulären Fraktionierung mit einem Stamm, der eine HA-erweiterte Version des Proteins 
exprimierte, trat ein Signal für HA-Vts1p allerdings nur in der Fraktion der cytosolischen Proteine auf. In einer indirekten Immunfluoreszenz mit dem gleichen Stamm schien HAVts1p ebenfalls nicht mit Membranen assoziiert zu sein. Möglicherweise ist die Bindung zwischen Vtilp und Vts1p jedoch nur transient, oder wird nur von einer geringen Anzahl von Vts1p-Proteinen ausgebildet, weshalb sie in der subzellulären Fraktionierung und indirekten Immunfluoreszenz nicht detektierbar ist. Vtilp und Vts1p konnten allerdings auch nicht koimmunpräzipitiert werden. Zudem gelang der Versuch, beide Proteine über chemische Kreuzvernetzung in einem Komplex zu isolieren, nicht. Darüberhinaus zeigten GST-Vtilp und 6xHis-Vts1p-Fusionsproteine in einem in vitro-Bindeexperiment unter unterschiedlichen Pufferbedingungen ebenfalls keine spezifischen Interaktionen.

\subsubsection{VTS1 ist im letzten Transportschritt zur Vakuole involviert}

Als nächstes sollte herausgefunden werden, welche Transportschritte in der vtil-2Mutante durch Überexpression von VTS1 supprimiert werden. Hierzu wurde zunächst der Transport der vakuolären Hydrolase Carboxypeptidase Y (CPY) zur Vakuole mit Hilfe einer „Pulse-Chase“-Immunpräzipitation untersucht (Übersicht in: Bryant and Stevens, 1998; Conibear and Stevens, 1998). In vti1-1-Zellen ist bei der restriktiven Temperatur nur der erste Transportschritt vom trans-Golgi zur Prävakuole blockiert, während der Transport von der Prävakuole zur Vakuole nicht betroffen ist (Fischer von Mollard et al., 1997). Daher sollte es mit Hilfe dieser Mutante möglich sein, zwischen den beiden Transportschritten zu unterscheiden. VTS1-Überexpression in vtil-1-Zellen zeigte keine Suppression des CPY-Transportdefektes, was darauf hin deutet, dass Vts1p nicht am Tranport zur Prävakuole involviert ist. Das vakuoläre Membranprotein ALP wird in einer direkten Route vom Golgi zur Vakuole transportiert, ohne den Umweg über die Prävakuole (Piper et al., 1997). Daher wurde der ALP-Transport ebenfalls mittels eines „Pulse-Chase“-Experimentes in der vtil-2-Mutante untersucht, welche bei $36^{\circ} \mathrm{C}$ aufgrund eines Transportdefektes die Proform pALP akkumuliert (Fischer von Mollard et al., 1997). Überexpression von VTS1 verbesserte den ALP-Transport zur Vakuole signifikant. Der Transport von Aminopeptidase I (API) zur Vakuole ist in vtil-2-Zellen bei der restriktiven Temperatur ebenfalls stark behindert (Fischer von Mollard et al., 1997). API wird im Gegensatz zu CPY und ALP im Cytosol synthetisiert und nach Oligomerisierung in sogenannte Cvt-Vesikel verpackt, die von einer Doppelmembran umgeben sind. Diese werden daraufhin zur Vakuole transportiert wo die äußere Membran mit der Vakuolen- 
membran fusioniert. pAPI wird nach Abbau der zweiten Membran durch vakuoläre Proteasen zur maturen mAPI-Form prozessiert (Klionsky et al., 1992). Überexpression von VTS1 sowohl vom $2 \mu$ - als auch vom centromeren Plasmid supprimierte den APITransportdefekt der vti1-2-Mutante partiell.

Zusammenfassend kann man sagen, dass VTS1 und VTI1 genetisch im letzten Transportschritt zur Vakuole interagieren, jedoch nicht im Transport vom trans-Golgi zur Prävakuole. Diese Interaktion ist spezifisch für das vtil-2-Allel, was dafür spricht, dass sie nicht durch einen generellen Effekt der VTS1-Überexpression hervorgerufen wird. Daher könnte es sein, dass Vts1p die Spezifität dieses letzten Transportschrittes determiniert. Eine direkte biochemische Interaktion zwischen Vts1p und Vtilp konnte nicht nachgewiesen werden. Somit bleibt der Mechanismus der genetischen Interaktion zwischen VTS1 und VTI1 unklar.

\subsubsection{Identifizierung und Charakterisierung des vti1-2-Suppressors YKT6}

Das zweite vti1-2-Suppressorplasmid enthielt ein Fragment, das unter anderem für das RSNARE Ykt6p codierte. Ykt6p ist ein ungewöhnliches SNARE, da es keine Transmembrandomäne besitzt, sondern über eine Isoprenylierung in der Membran verankert ist (McNew et al., 1997). McNew et al. zeigten auch, dass Ykt6p im retrograden Transport zum cis-Golgi-Kompartiment involviert ist. Außerdem soll Ykt6p an der homotypischen Vakuolenfusion beteiligt sein (Ungermann et al., 1999). Die YKT6-Sequenz wurde sowohl in einen $2 \mu$ - als auch einen CEN-Vektor subkloniert. Beide Plasmide supprimierten den Wachstumsdefekt der vtil-2-Mutante bei $37^{\circ} \mathrm{C}$. Somit handelte es sich bei YKT6 tatsächlich um den Suppressor. Daher wurde nun untersucht, ob YKT6-Überexpression einen Effekt auf die unterschiedlichen Transportschritte hat.

\subsubsection{Ykt6p ist eine Komponente der SNARE-Komplexe des biosynthetischen Transportes zur Vakuole}

In einer „Pulse-Chase“-Immunpräzipitation für API zeigte sich, dass sowohl die Überexpression durch $2 \mu-Y K T 6$ als auch CEN-YKT6 in vtil-2-Zellen zu einem Anstieg der Menge an vakuolärem mAPI bei $36^{\circ} \mathrm{C}$ führte. Der ALP-Transport zur Vakuole wurde in den gleichen Stämmen untersucht. Auch hier zeigte die Überexpression von YKT6 sowohl vom $2 \mu$ - als auch vom centromeren Plasmid eine Suppression des ALP-Transportdefektes der vti1-2-Mutante. Diese Suppression war spezifisch, da eine Überexpression der R- 
SNAREs Sec22p (involviert im ER-Golgi-Transport) und Snc2p (involviert in Endozytose und Exozytose), welche in einem SNARE-Komplex die gleiche Position wie Ykt6p einnehmen könnten, nicht zur Suppression des Transportdefektes der vti1-2-Zellen führte. Die Ergebnisse dieser „Pulse-Chase“-Experimente deuten darauf hin, dass Ykt6p neben den bereits beschriebenen Funktionen im retrograden Transport zum cis-Golgi (McNew et al., 1997) und der homotypischen Vakuolenfusion (Ungermann et al., 1999) noch eine weitere Funktion im biosynthetischen Transport zur Vakuole besitzt. Diese Vermutung wird durch Untersuchungen an der temperatursensitiven Mutante ykt6-1 unterstützt, welche die Golgi-modifizierte p2CPY-Form sekretiert, was auf eine Blockade in einem post-Golgi-Transportschritt hindeutet (Tsui and Banfield, 2000). Da in den biosynthetischen Transportschritten zur Vakuole bislang nur die drei Q-SNAREs Vtilp, Vam3p und Vam7p als Komponenten der vakuolären SNARE-Komplexe identifiziert wurden (Sato et al., 1998; Darsow et al., 1997; Wada et al., 1997; Piper et al., 1997; Fischer von Mollard and Stevens, 1999), es aber so aussieht, als seien alle SNAREKomplexe aus 4-SNARE-Helices mit einer 1R:3Q-Stöchiometrie aufgebaut, spricht anhand der vorgelegten Daten viel dafür, dass das R-SNARE Ykt6p die 4. SNAREPosition in den SNARE-Komplexen des biosynthetischen Transportes zur Vakuole einnimmt. Der gleiche SNARE-Komplex ist höchstwahrscheinlich auch am CPYTransport von der Prävakuole zur Vakuole beteiligt. Da Ykt6p und Vtilp jedoch auch im vorangeschalteten Transportschritt vom trans-Golgi zur Prävakuole involviert sind (s. u.), konnte dies nicht im Detail geklärt werden. Ein weiteres R-SNARE der Vakuolenmembran ist Nyv1p. Anhand von „Pulse-Chase“-Experimenten konnte jedoch gezeigt werden, dass Nyv1p nicht für den biosynthetischen Transport zur Vakuole benötigt wird, da Nyv1p-Überexpression keine Suppression der Transportdefekte der vtil-2-Mutante bewirkte und eine Deletion von NYV1 keine Defekte im biosynthetischen Transport zur Vakuole hervorrief (Fischer von Mollard and Stevens, 1999). Somit scheint Nyv1p ausschließlich an der homotypischen Vakuolenfusion beteiligt zu sein. Außerdem kann man ausschließen, dass Ykt6p ein endogenes SNARE-Protein in den biosynthetischen SNARE-Komplexen verdrängte, da selbst die geringe YKT6-Überexpression vom centromeren Plasmid einen Suppressionseffekt hervorrief. Daher scheinen alle drei SNARE-Komplexe des CPY-, ALP- und API-Transportes zur Vakuole aus den QSNAREs Vtilp, Vam3p, Vam7p und dem R-SNARE Ykt6p aufgebaut zu sein. Dieser 
SNARE-Komplex hätte damit eine ähnliche Struktur wie der neuronale SNARE-Komplex bestehend aus den Q-SNARE-Helices von Syntaxin 1, SNAP-25-N-Terminus und SNAP25-C-Terminus sowie dem R-SNARE Synaptobrevin 2 (Sutton et al., 1998) bzw. wie der SNARE-Komplex des späten Endosoms in Säugern bestehend aus den Q-SNAREs Syntaxin 7, Syntaxin 8 und Vtilb sowie dem R-SNARE Endobrevin/VAMP-8 (Antonin et al., 2000a). Das Hefe-Vtilp ist homolog zur N-terminalen Helix von SNAP-25 (Qb), beide tragen die kleine Aminosäure Glycin in der hochkonservierten -3-Ebene. Vam7p ist homolog zur C-terminalen Helix von SNAP-25 (Qc), beide enthalten ein Alanin in der 3-Position. Vam3p trägt wie Syntaxin 1 (Qa) ein Phenylalanin im -3-Layer, während das R-SNARE Ykt6p mit Synaptobrevin 2 verwandt ist. Ykt6p besitzt ein Leucin im -3Layer während Synaptobrevin ein Methionin enthält. Leucin und Methionin besitzen in etwa die gleiche Größe. Die drei beschriebenen SNARE-Komplexe enthalten jedoch alle unterschiedliche Membrananker. Syntaxin 1 und Synaptobrevin 2 sind im neuronalen SNARE-Komplex über Transmembrandomänen mit der Membran verbunden, während SNAP-25 palmitoyliert ist. Im endosomalen SNARE-Komplex in Säugern besitzen alle SNARE-Proteine eine Transmembrandomäne, während im hier beschriebenen vakuolären SNARE-Komplex nur Vti1p und Vam3p über Transmembrandomänen mit der Membran assoziiert sind. Ykt6p enthält eine C-terminale Farnesylierungssequenz, während Vam7p möglicherweise palmitoyliert ist. Für die Fusion eines Transportvesikels mit der Zielmembran reicht es jedoch aus, wenn mindestens ein SNARE auf jeder Membran eine Transmembrandomäne besitzt. Vti1p müsste mit der Membran des Vesikels und Vam3p mit der Vakuolenmembran assoziiert sein.

Ungermann et al. schlugen vor, dass Ykt6p auch an der homotypischen Vakuolenfusion beteiligt ist, da Antikörper gegen Ykt6p diesen Prozess in einem in vitro-Experiment inhibierten (Ungermann et al., 1999). Da auch Antikörper gegen die SNAREs Vam3p, Vam7p, Vtilp und Nyv1p den gleichen Effekt hatten, und sie Ykt6p und Nyv1p kopräzipitieren konnten, postulierten sie, dass ein pentamerer SNARE-Komplex bestehend aus Vam3p, Vam7p, Vti1p, Nyv1p und Ykt6p für die homotypische Vakuolenfusion benötigt wird. Fukuda et al. konnten jedoch zeigen, dass ein quartärer SNAREKomplex aus rekombinantem GST- bzw. 6xHis-erweitertem Vam3p, Vam7p, Vtilp und Nyv1p hinreichend war um in vitro Liposomen zu fusionieren (Fukuda et al., 2000). In dem gleichen Experiment wurde außerdem gezeigt, dass die Bindung von Ykt6p an einen 
trimeren Komplex aus Vam3p, Vam7p und Vtilp durch äquimolare Mengen an Nyv1p inhibiert werden konnte. Somit scheinen Nyvlp und Ykt6p miteinander zu konkurrieren und nicht gleichzeitig an der Ausbildung des gleichen SNARE-Komplexes beteiligt zu sein. Dies spricht für die Existenz von zwei unterschiedlichen quartären vakuolären SNARE-Komplexen, was durch die in dieser Arbeit vorgelegten Ergebnisse unterstützt wird. Die Inhibierung der homotypischen Vakuolenfusion durch anti-Ykt6p-Antikörper in dem von Ungermann et al. beschriebenen in vitro-Experiment könnte dadurch zustande gekommen sein, dass hier komplette Antikörper verwendet wurden und nicht nur die Antigen-bindenden Fab-Fragmente. Hierdurch könnten die Fc-Fragmente der anti-Ykt6pAntikörper die SNARE-Komplex-Assemblierung benachbarter SNARE-Proteine während der homotypischen Fusion sterisch behindert haben. Die beobachtete Koimmunpräzipitation von Nyv1p und Ykt6p könnte durch die Assoziation der beiden benachbarten quartären SNARE-Komplexe hervorgerufen worden sein.

\subsubsection{Ykt6p ist auch am Aufbau des prävakuolären SNARE-Komplexes beteiligt} Da YKT6-Überexpression auch den CPY-Transportdefekt der vtil-2-Mutante supprimierte, diese Mutante jedoch sowohl im Transport vom trans-Golgi zur Prävakuole als auch im anschließenden Transportschritt zur Vakuole blockiert ist (Fischer von Mollard et al., 1997), stellte sich nun die Frage, ob Ykt6p nur für einen dieser Transportschritte benötigt wird, oder für beide. Um dies zu ergründen, wurde YKT6 in vti1-1-Zellen überexpremiert, da diese Mutante bei der restriktiven Temperatur nur im ersten Transportschritt vom trans-Golgi zur Prävakuole behindert ist. YKT6-Überexpression zeigte eine Suppression des CPY-Transportdefektes dieser Mutante, während die Überexpression anderer R-SNAREs keine Suppression hervorrief. Dieses Ergebnis deutet darauf hin, dass Ykt6p zusätzlich zum Transport zur Vakuole auch im Transport vom trans-Golgi zur Prävakuole involviert ist. Bislang waren nur Vtilp $(\mathrm{Qb})$ und das Syntaxin Pep12p (Qa) als Komponenten des prävakuolären SNARE-Komplexes identifiziert worden. Die hier gezeigten Ergebnisse sind der erste Hinweis, dass es sich bei Ykt6p um das fehlende R-SNARE des prävakuolären SNARE-Komplexes handelt. Da davon auszugehen ist, dass alle SNARE-Komplexe aus 4 SNARE-Helices aufgebaut sind, würde noch eine Qc-Helix fehlen. Kürzlich wurde von Gupta und Brent Heath über eine Datenbanksuche ein weiteres SNARE-Protein in C. albicans und $S$. pombe identifiziert, welches Homologien zu Syntaxin 6, 8 und 10 aus Säugern zeigt und daher als Syn10p- 
ähnlich bezeichnet wurde (Gupta and Brent Heath, 2002). Bei dem Vergleich der Saccharomyces cerevisiae-Genom-Datenbank mit den Syn10p-ähnlichen Sequenzen aus C. albicans und $S$. pombe entdeckte man einen offenen Leserahmen (YAL014c) mit schwacher Homologie, dessen Proteinprodukt jedoch keine Transmembrandomäne und auch kein SNARE-Motiv enthielt. Lewis und Pelham konnten zeigen, dass aufgrund eines Fehlers bei der Sequenzierung des $S$. cerevisiae-Genoms eine Verschiebung des Leserahmens erfolgte, wodurch das von YAL014c codierte Protein bislang nicht als SNARE-Protein erkannt wurde (Lewis and Pelham, 2002). Die Translation der korrigierten Sequenz ergibt nämlich ein typisches SNARE-Protein mit Transmembrandomäne und SNARE-Motiv, das die stärkste Homologie mit Syntaxin 8 aufweist, und daher als Syn8p bezeichnet wurde. In Hefe zeigt Syn8p die stärkste Verwandtschaft mit Vam7p und Tlg1p, beides Mitglieder der Qc-SNARE-Familie. Bei Syntaxin 8 aus Säugern handelt es sich trotz seines Namens nicht um ein Syntaxin, sondern ebenfalls um ein Mitglied der Qc-SNAREs, das mit Syntaxin 7 (Qa), Vtilb (Qb) und Endobrevin/VAMP-8 (R) einen SNARE-Komplex des späten Endosoms ausbildet (Antonin et al., 2000a). Syntaxin 7 ist homolog zum prävakuolären Syntaxin Pep12p (Becherer et al., 1996), während Vtilb aus Säugern das Hefe-Vtilp im Transport vom trans-Golgi zur Prävakuole ersetzen kann (Fischer von Mollard and Stevens, 1998). Lewis und Pelham konnten zeigen, dass Pep12p (Qa), Vtilp (Qb) und Ykt6p (R) mit Syn8p kopräzipitierten (Lewis and Pelham, 2002). Somit scheint Syn8p tatsächlich das fehlende Qc-SNARE des prävakuolären SNARE-Komplexes zu sein. Zusätzlich wurde auch das R-SNARE Snc1p mit Syn8p kopräzipitiert, was darauf hin deutet, dass es noch einen zweiten SNARE-Komplex geben könnte, in dem Syn8p mit Snc1p, Pep12p und Vti1p interagiert. Dieser Komplex könnte am Transport von der Plasmamembran über frühe Endosomen zur Prävakuole involviert sein. Da syn8 8 -Zellen keinen Phänotyp zeigen, scheint ein anderes SNARE-Protein Syn8p in einem SNARE-Komplex ersetzen zu können. Möglicherweise handelt es sich hierbei um Tlg1p, welches mit Pep12p kopräzipitiert (Lewis and Pelham, 2002). 
Aufgrund der hier beschriebenen Ergebnisse kann man ein neues Modell der HefeSNARE-Komplexe und der sie aufbauenden SNARE-Proteine zeichnen:

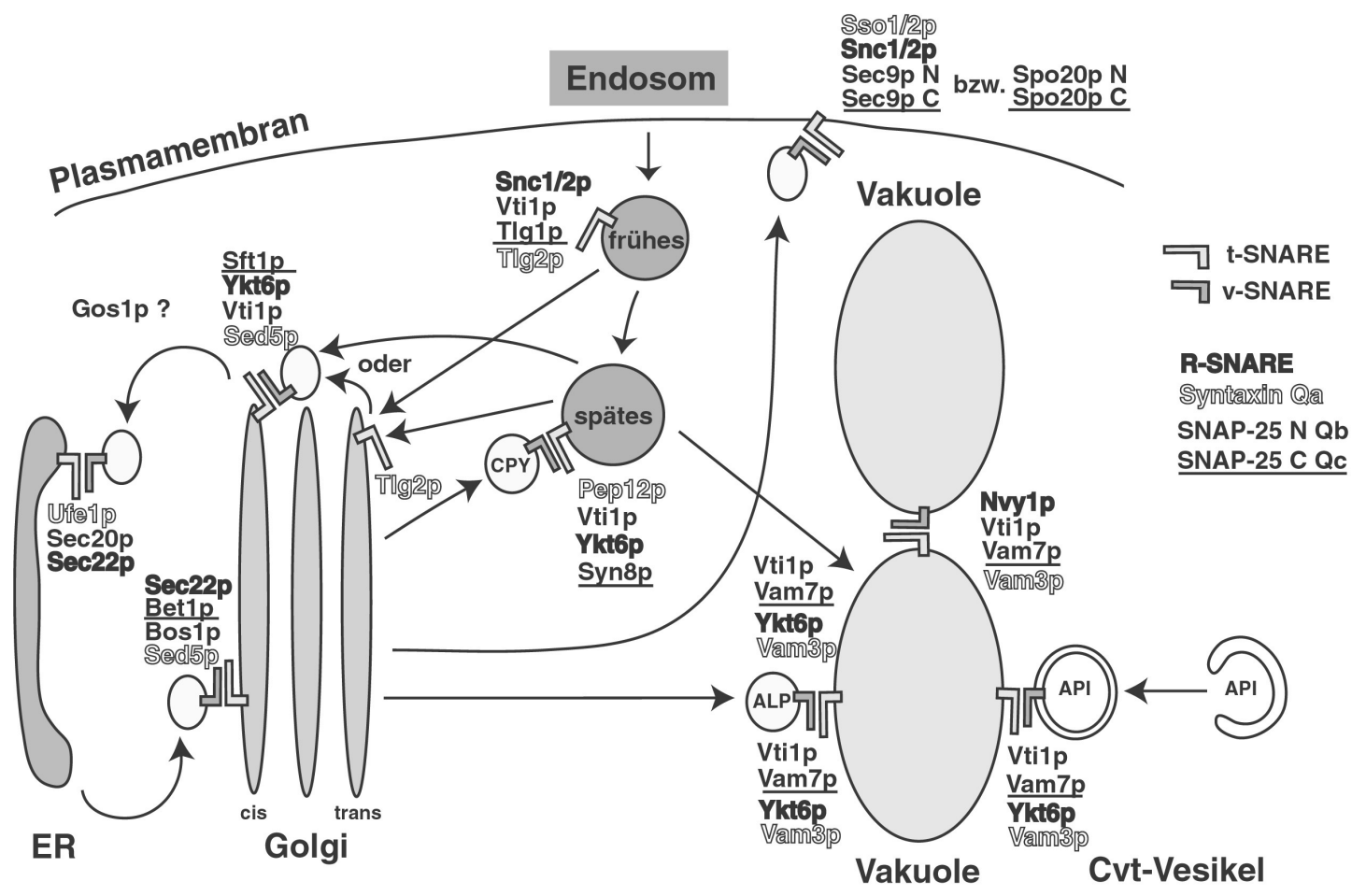

Abb. 4.1: Das SNARE Ykt6p ist Bestandteil von 3 unterschiedlichen SNARE-Komplexen. Die Ergebnisse dieser Arbeit zeigen, dass Ykt6p nicht nur am Transport zum cis-GolgiKompartiment beteiligt ist, sondern auch am CPY-Transport vom trans-Golgi zur Prävakuole über eine Interaktion mit Pep12p, Vtilp und evtl. Syn8p, sowie an allen biosynthetischen Transportschritten zur Vakuole, wo es SNARE-Komplexe mit Vtilp, Vam7p und Vam3p bildet.

\subsection{Identifizierung eines neuen SNARE-Proteins in Hefe}

Da im Zuge der Sequenzierung des Hefe-Genoms keine weiteren SNARE-verwandten Sequenzen gefunden wurden, nahm man an, dass in S. cerevisiae alle SNARE-Proteine identifiziert seien. Obwohl die Sequenzen von Qa- und R-SNAREs stark konserviert sind, zeigen Qb- und Qc-SNAREs jedoch nur geringe Sequenzhomologien mit anderen Mitgliedern der SNARE-Familie. Daher ist es möglich, dass in S. cerevisiae zusätzliche SNARE-Proteine existieren die bislang übersehen wurden, was auch durch die im vorhergehenden Kapitel beschriebene Identifizierung des SNAREs Syn8p durch Gupta und Heath bzw. Lewis und Pelham bestätigt wurde. Mit der Hilfe von Prof. Enno Hartmann wurde die Saccharomyces cerevisiae-Genom-Datenbank (SGD) nach weiteren SNARE-Sequenzen untersucht, wobei eine PSI-Blast-Suche mit den Sequenzen unterschiedlicher Hefe-SNAREs durchgeführt wurde. Hierbei wurde die Sequenz des 
bislang uncharakterisierten offenen Leserahmens YGL098w identifiziert. Das von dieser

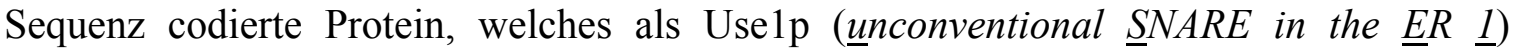
bezeichnet wurde, enthält eine Domäne, welche die Kriterien eines SNARE-Motivs erfüllt. Im Unterschied zu den meisten anderen Q-SNARE-Proteinen enthält Use1p ein Aspartat anstelle eines Glutamins in der 0-Layer-Position. Allerdings besitzt auch das Hefe-Qc-SNARE Sft1p sowie das Qb-SNARE Vtila aus Säugern ein Aspartat in dieser Position (Bock et al., 2001). Aspartat kann Glutamin jedoch funktionell ersetzen (Antonin et al., 2000c). Über Datenbankvergleiche wurden Use1p-homologe Sequenzen in höheren Eukaryonten aufgefunden. Hierbei zeigte sich, dass Use1-Proteine in Pflanzen ein Threonin in der 0-Layer-Position tragen. Eine ähnliche Divergenz in der 0-Layer-Position zwischen verschiedenen Spezies zeigt auch das Qc-SNARE Bet1p. Hefen enthalten ein Serin oder Threonin in der 0-Layer-Position von Bet1p (Gupta and Brent Heath, 2002), während sich in den Bet1-Homologen von Drosophila und Säugern ein Glutamin in dieser Position befindet (Bock et al., 2001). Eine weitere für die Klassifizierung von SNARE-Proteinen wichtige Position ist der -3-Layer. Use1p enthält hier ein Alanin, was typisch für Qb- oder Qc-SNAREs ist. Allerdings besitzt die Gesamtsequenz von Use1p nur sehr geringe Aminosäurehomologien zu anderen SNARE-Proteinen, weshalb es nicht möglich ist, Use1p anhand seiner Aminosäuresequenz in eine dieser beiden Familien einzuordnen.

\subsection{Use1p ist ER-lokalisiert und im Transport zwischen ER und Golgi involviert}

In einer subzellulären Fraktionierung trat das endogene Use1p ausschließlich in der Fraktion auf, die ER- und Vakuolenmembranen enthielt. Des weiteren zeigte ein HAerweitertes Use1p in einer indirekten Immunfluoreszenz eine typische ER-Lokalisation. Diese Ergebnisse stehen in Übereinstimmung mit dem Ergebnis einer von Beate Veith durchgeführten Saccharose-Dichtegradienten-Zentrifugation, in welcher Use1p mit dem ER-Marker Sec61p kolokalisierte. Da Use1p also offensichtlich mit ER-Membranen assoziiert ist, könnte es entweder als SNARE des anterograden ER-Golgi-Transportes agieren, oder aber eine Komponente des retrograden Transports vom cis-Golgi zum ER darstellen. Im anterograden Transport interagiert Sed5p (Qa) mit Bos1p (Qb), Bet1p (Qc) und Sec22p (R) (Søgaard et al., 1994). Somit sind hier Proteine aus jeder SNAREFamilie repräsentiert um einen SNARE-Komplex auszubilden. Überraschenderweise 
zeigte sich in einem in vitro-Transportexperiment jedoch auch, dass Betlp sowohl am anterograden als auch retrograden Transport beteiligt ist, während Sec22p nur für den retrograden Transport benötigt wurde (Spang and Schekman, 1998). Betlp wurde jedoch nicht in einem Komplex zusammen mit dem ER-Syntaxin Ufelp gefunden (Lewis et al., 1997). Lewis et al. fanden auch heraus, dass Ufelp (Qa) einen Komplex mit den SNAREs Sec20p $(\mathrm{Qb})$ und Sec22p (R) bildet, der im retrograden Transport zum ER involviert ist. Das periphäre Membranprotein Tip20p wurde ebenfalls als Komponente dieses Komplexes identifiziert. Es bindet an Sec20p (Sweet and Pelham, 1993), möglicherweise über eine Interaktion mit dessen N-terminaler Domäne.

Use1p ist ein essentielles Protein, da eine Deletion des Genes für die Zellen lethal ist. Um die Funktion von Uselp genauer $\mathrm{zu}$ untersuchen wurden daher temperatursensitive Mutanten hergestellt. Sowohl die Mutante use1-10AA, welche 10 Aminosäuremutationen enthält, als auch die Mutante use1-Olayer, welche nur eine dieser Mutationen, nämlich ein Austausch von Aspartat gegen Glycin im 0-Layer des SNARE-Motivs enthält, zeigten bei der restriktiven Temperatur eine Akkumulierung der ER-Form p1CPY sowie der Nglykosylierten ER-Form von Invertase.

\subsection{Use1p wird für den retrograden Transport zum ER benötigt}

Da die Akkumulierung der ER-Formen von CPY und Invertase in den use1-Mutanten auch aufgrund eines indirekten Effektes, basierend auf einer Blockierung des retrograden Golgi-ER-Transportes, ausgelöst werden könnte, wurde mittels verschiedener RecyclingExperimente untersucht, in welchem Transportschritt Use1p involviert ist. Analog zu der ER-Recycling-Mutante sec20-1 sekretieren die temperatursensitiven usel-Mutanten ebenfalls das ER-Chaperonprotein Kar2p/BiP. Außerdem entkommt ein Sec22- $\alpha-$ Hybridprotein, welches sich in mit diesem Konstrukt transformierten WT-Zellen zwischen dem ER und cis-Golgi hin und her bewegt, in den use1-Mutanten zur Vakuole. Darüber hinaus zeigen die temperatursensitiven usel-Mutanten die gleiche vakuoläre Lokalisation des ER-Golgi-Transmembranproteins Emp47p wie ER-Recycling-Mutanten. Somit scheint Use1p für den retrograden Transport zum ER benötigt zu werden. 


\subsection{USE1 zeigt eine starke genetische Interaktion mit SNAREs des retrograden Golgi-ER-Transportes}

Durch gezielte Überproduktion von Kandidaten für Partner-Proteine kann man in tsMutanten anhand der Suppressionseffekte herausfinden, ob diese Proteine mit den tsmutierten Proteinen genetisch interagieren. Der Wachstumsdefekt der use1-10AAMutante wurde am stärksten durch Überproduktion von Sec20p supprimiert, welches ausschließlich am retrograden Transport zum ER beteiligt ist. Sec22p, welches sowohl für den anterograden als auch retrograden Transport benötigt wird, zeigte nach Überproduktion einen etwas schwächeren Suppressionseffekt. Auch die Überexpression von BOS1, einem SNARE-Protein des anterograden Transportes, rief eine schwache Suppression des Wachstumsdefektes der use1-Mutante hervor. Dagegen führte die Überproduktion von Ufe1p (retrograd) sowie von Bet1p und Sed5p (beide anterograd) nicht zu einer Verbesserung des Wachstums der use1-10AA-Zellen bei der restriktiven Temperatur. Analoge Suppressionseffekte wurden auch in einer CPY-,Pulse-Chase“Immunpräzipitation mit den gleichen Stämmen beobachtet. Dass die UFE1-Überexpression keinen Suppressionseffekt zeigte, muss nicht zwangsläufig gegen eine Beteiligung von Use1p im retrograden Transport sprechen. In einigen Beispielen zeigen nämlich auch SNARE-Proteine des gleichen SNARE-Komplexes keine genetische Interaktion. So führt SED5-Überexpression z.B. nicht zu einer Suppression der Defekte einer bos1-1-Mutante (Wuestehube et al., 1996). Dass Bos1p-Überproduktion einen schwachen Suppressionseffekt auf die use1-10AA-Mutante hat, könnte damit erklärt werden, dass SNARE-Proteine der gleichen Unterfamilie, die jedoch aus anderen SNARE-Komplexen stammen, teilweise deletierte oder funktionsunfähige SNAREProteine substituieren können. So kann das prävakuoläre Qa-SNARE Pep12p durch das vakuoläre Qa-SNARE Vam3p funktionell ersetzt werden (Darsow et al., 1997; Götte and Gallwitz, 1997). Darüber hinaus kann das R-SNARE Ykt6p eine Deletion des R-SNAREs Sec22p komplementieren (Liu and Barlowe, 2002), bzw. das vakuoläre R-SNARE Nyv1p in einem in vitro-Liposomenfusionsexperiment ersetzen (Fukuda et al., 2000). Dies ist vermutlich der Grund, weshalb Sec22p das einzige nicht-essentielle R-SNARE in Hefe ist und eine NYV1-Deletion nicht zu Defekten in der Vakuolenmorphologie führt. Es ist daher möglich, dass die Überproduktion von Bos1p ein defektes Use1-Protein im retrograden SNARE-Komplex ersetzen kann. Da es sich bei Bos1p um ein Qb-SNARE 
handelt, würde dies jedoch bedeuten, dass Use1p ebenfalls ein Qb-SNARE sein müsste. In diesem Fall könnte Sec20p nur die Position eines Qc-SNAREs im retrograden GolgiER-SNARE-Komplex einnehmen, vorausgesetzt, alle SNARE-Komplexe bestehen aus je einer Helix einer unterschiedlichen SNARE-Familie (Qa, Qb, Qc, R).

Die hier beschriebenen genetischen Interaktionen zwischen USE1 und SNAREs des retrograden Golgi-ER-Transportes wurden auch in einem von Beate Veith durchgeführten Kreuzungsversuch bestätig. Hierbei wurde die use1-10AA-Mutante mit Stämmen gekreuzt, die Mutationen in ER- oder Golgi-SNAREs besaßen (sec20-1, sec22-3, ufe1-1, bos 1-1, bet1-1, sed5-1). Die diploiden Zellen wurden sporuliert um Doppelmutanten zu erzeugen. Es zeigte sich, dass die use 1-10AA-Mutation in Kombination mit Mutationen in SNAREs, die für den retrograden Transport vom Golgi zum ER benötigt werden (sec201, sec22-3, ufe1-1) einen synthetisch-lethalen Phänotyp hervorrief. Kombinationen mit anterograden SNAREs führten dagegen teilweise nur $\mathrm{zu}$ einer Erniedrigung der restriktiven Temperatur.

\subsection{Use1p ist Bestandteil des retrograden Golgi-ER-SNARE- Komplexes}

Da Use1p die stärksten genetischen Interaktionen mit SNARE-Proteinen des retrograden Transports zum ER zeigte, sollte untersucht werden, ob Uselp auch biochemisch mit diesen Proteinen interagiert und gemeinsam mit ihnen $\mathrm{zu}$ einem SNARE-Komplex assembliert. Hierzu wurde zunächst versucht, diesen SNARE-Komplex in vitro unter den bei (Antonin et al., 2000a) beschriebenen Bedingungen mit 6xHis-erweiterten SNAREMotiven der SNARE-Proteine aufzubauen. Weder in einer anschließenden SDS-PAGE noch in einer Analyse über eine Gelfiltration oder Ionenaustausch-Chromatographie an einer HPLC-Anlage konnte jedoch ein Hinweis auf eine in vitro-SNARE-KomplexAssemblierung mit den verwendeten SNARE-Proteinen erhalten werden. Möglicherweise wurde die SNARE-Komplex-Bildung von den 6xHis-Erweiterungen, welche für die Aufreinigung der Proteine benötigt wurden, gestört. Es könnte auch sein, dass zusätzlich die akzessorischen Proteine Tip20p und Dsl1p, welche beide eine essentielle Funktion in Hefe besitzen, für die korrekte Assemblierung des SNARE-Komplexes benötigt werden. Daher sollte nun versucht werden, den SNARE-Komplex des retrograden Transportes zum ER in vivo zu isolieren. Hierzu wurde eine Koimmunpräzipitation mit Triton-X100Membranextrakten eines sec18-1-Stammes durchgeführt, welcher aufgrund einer 
Mutation cis-SNARE-Komplexe akkumuliert. Es zeigte sich, dass Ufelp (retrograd) und Sec22p (anterograd und retrograd) mit Use1p kopräzipitierten, während Bos1p, Bet1p und Sed5p (alle anterograd) keine Interaktion mit Use1p aufwiesen. Eine biochemische Interaktion zwischen Use1p und dem SNARE Sec20p, welches ebenfalls Bestandteil dieses Komplex ist, konnte nicht untersucht werden, da uns kein anti-Sec20p-Antikörper zur Verfügung stand. Dieses Ergebnis beweist, dass es sich bei Use1p um ein SNAREProtein des retrograden Golgi-ER-SNARE-Komplexes handelt.

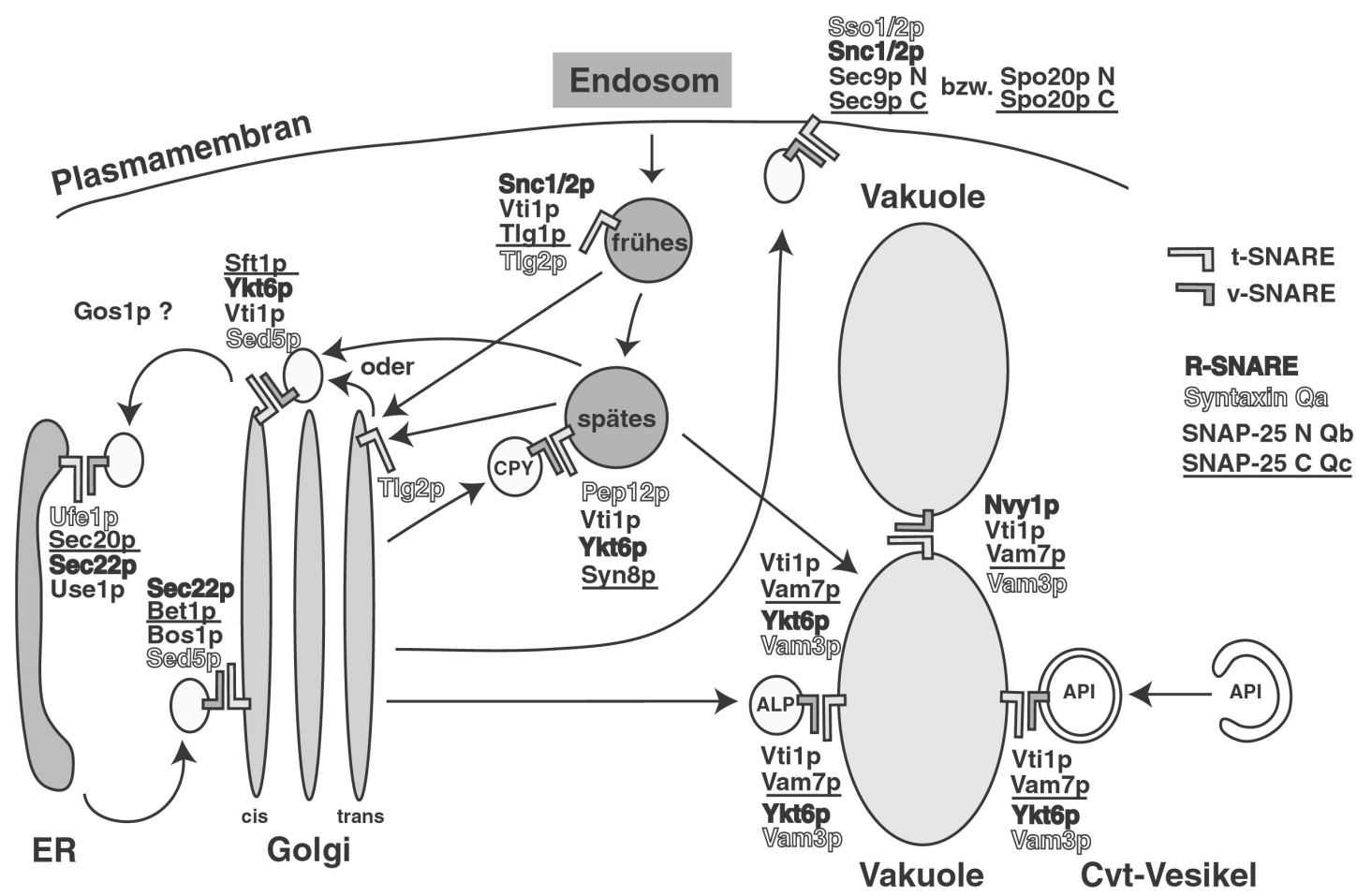

Abb. 4.2: Das SNARE Use1p ist Bestandteil des retrograden SNARE Komplexes im Transport vom Golgi zum ER. Das in dieser Arbeit identifizierte neue SNARE-Protein Uselp bildet zusammen mit Ufe1p, Sec20p und Sec22p einen SNARE-Komplex des retrograden Golgi-ERTransportes. 


\section{$5 \quad$ Zusammenfassung}

Projekt 1:

Um weitere SNARE-Proteine oder regulatorische Faktoren zu identifizieren, die mit dem SNARE-Protein Vtilp im Transport vom trans-Golgi zur Prävakuole oder im Transport zur Vakuole interagieren, wurde ein Multicopy-Suppressor-Screen mit der temperatursensitiven Mutante vtil-2 durchgeführt. Diese Mutante zeigt neben einem Wachstumsdefekt bei $37^{\circ} \mathrm{C}$ Defekte in diesen Transportschritten. Zwei Suppressoren des Wachstumsund Transportdefektes der vtil-2-Mutante wurden dabei identifiziert:

1) Der bislang uncharakterisierte, nicht-essentielle, offene Leserahmen YOR359w,

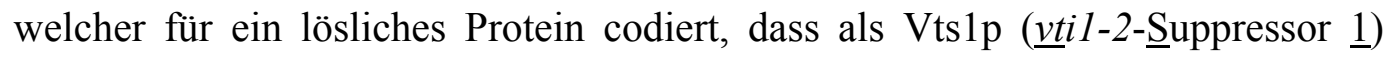
bezeichnet wurde. Es besitzt nur zwei weitere Homologe in Candida albicans und Schizosaccharomyces pombe. Alle drei Proteine enthalten eine SAM-Domäne in ihrem C-Terminus, welche an niedrig-affinen Protein-Protein-Interaktionen beteiligt ist. Über Koimmunpräzipitationsexperimente und in vitro-Bindeversuche konnte jedoch keine biochemische Interaktion zwischen Vts1p und Vtilp aufgezeigt werden. In der Mutante vtil-1, welche nur im ersten Transportschritt zur Prävakuole blockiert ist, zeigte VTS1-Überexpression keine Suppression des Transportdefekts. Da der ALP- und API-Transportdefekt der vtil-2-Mutante jedoch durch Vts1p-Überproduktion supprimiert wird, scheint Vts1p nur im letzten Schritt des biosynthetischen Transportes zur Vakuole involviert zu sein. VTS1-Deletionsmutanten besitzen weder Defekte im CPY-, ALP- oder APITransport zur Vakuole noch einen Wachstumsdefekt, was darauf hin deutet, dass seine Funktion von einem anderen Protein übernommen werden kann. Darüber hinaus zeigen Doppelmutanten mit vtil-1- und vtil-2-Hintergrund keine synthetischen Transportdefekte. Eine Doppelmutante mit vtil-2-Hintergrund zeigte jedoch einen synthetischen Wachstumsdefekt bei $37^{\circ} \mathrm{C}$. Aufgrund der Allel-spezifischen genetischen Interaktionen zwischen VTS1 und VTI1 muss es sich bei Vts1p um ein regulatorisches Protein handeln, dass möglicherweise die Spezifität im letzten Schritt des biosynthetischen Transportes zur Vakuole determiniert. 
2) Bei dem zweiten vtil-2-Suppressor handelte es sich um das R-SNARE Ykt6p, von dem bisher bekannt war, dass es im retrograden Transport zum cis-Golgi (McNew et al., 1997) und der homotypischen Vakuolenfusion (Ungermann et al., 1999) beteiligt ist. Überexpression von YKT6 supprimierte den ALP- und APITransportdefekt der vtil-2-Mutante, weshalb Ykt6p auch im biosynthetischen Transport zur Vakuole involviert sein muss, wo es einen SNARE-Komplex mit Vti1p, Vam3p und Vam7p bildet. Somit müssen zwei unterschiedliche vakuoläre SNARE-Komplexe existieren. Der eine, bestehend aus Vtilp, Vam3p, Vam7p und Nyv1p, ist an der homotypischen Vakuolenfusion beteiligt, während ein zweiter aus Vti1p, Vam3p, Vam7p und Ykt6p für den biosynthetischen Transport von CPY, ALP als auch API zur Vakuole benötigt wird. Da die Ykt6pÜberproduktion auch den CPY-Transportdefekt der vtil-1-Mutante supprimierte, welche nur im ersten Transportschritt vom trans-Golgi zur Prävakuole blockiert ist, muss Ykt6p auch eine Komponente des prävakuolären SNARE-Komplexes, zusammen mit Vti1p, Pep12p und Syn8p sein. Somit ist das R-SNARE Ykt6p Bestandteil von 3 unterschiedlichen SNARE-Komplexen.

\section{Projekt 2:}

Da bislang noch nicht alle SNARE-Partner in allen Hefe-SNARE-Komplexen identifiziert sind und es möglich ist, dass zusätzliche Qb- oder Qc-SNAREs in Hefe existieren, die aufgrund ihrer geringen Sequenzhomologien bislang übersehen wurden, sollte über eine verbesserte Datenbanksuche mit den Sequenzen unterschiedlicher Hefe-SNARE-Proteine versucht werden, diese fehlenden SNAREs aufzufinden. Hierbei wurde die Sequenz des bislang uncharakterisierten offenen Leserahmens YGL098w identifiziert. Das hiervon codierte essentielle Protein besitzt neben einer C-terminalen Transmembrandomäne ein typisches SNARE-Motiv. Homologe dieses Proteins wurden in allen höheren Eukaryonten gefunden. In einer subzellulären Fraktionierung und einer indirekten Immunfluoreszenz zeigte das Protein eine typische ER-Lokalisation, weshalb es als Use1p (unconventional $\underline{S} N A R E$ in the $\underline{E} R \underline{1}$ ) bezeichnet wurde. Die ts-Mutanten use1-10AA und usel-Olayer akkumulierten nach Inkubation bei der restriktiven Temperatur die ER-Form p1CPY und die N-glykosylierte ER-Form von Invertase. In drei unterschiedlichen Recycling- 
Experimenten besaßen die ts-Mutanten eindeutige Defekte im retrograden Transport vom Golgi zum ER. Außerdem zeigte die ts-Mutante use1-10AA in einem Wachstumstest und einer CPY-,,Pulse-Chase“-Immunpräzipitation die stärkste genetische Interaktion mit SNAREs des retrograden Transportes zum ER. In einer Koimmunpräzipitation konnte Use1p mit den SNAREs Ufe1p (retrograd) und Sec22p (retrograd und anterograd) kopräzipitiert werden, während die anterograden SNAREs Bos1p, Bet1p und Sed5p keine Interaktion mit Use1p zeigten. Daher muss Use1p der 4. SNARE-Partner des retrograden Golgi-ER-SNARE-Komplexes, bestehend aus Ufe1p (Qa), Sec22p (R) und Sec20p (möglicherweise Qc) sein, und vermutlich zur Familie der Qb-SNAREs gehören. 


\section{$6 \quad$ Literaturverzeichnis}

Amara, J. F., S. H. Cheng and A. E. Smith (1992). "Intracellular protein trafficking defects in human disease." Trends In Cell Biology 2: 145-149.

Andag, U., T. Neumann and H. D. Schmitt (2001). "The coatomer-interacting protein Dsl1p is required for Golgi-to- endoplasmic reticulum retrieval in yeast." J Biol Chem 276(42): 39150-60.

Antonin, W., C. Holroyd, D. Fasshauer, S. Pabst, G. F. Von Mollard and R. Jahn (2000a). "A SNARE complex mediating fusion of late endosomes defines conserved properties of SNARE structure and function.” Embo J 19(23): 6453-64.

Antonin, W., C. Holroyd, R. Tikkanen, S. Honing and R. Jahn (2000b). "The RSNARE endobrevin/VAMP-8 mediates homotypic fusion of early endosomes and late endosomes." Mol Biol Cell 11(10): 3289-98.

Antonin, W., D. Riedel and G. F. von Mollard (2000c). "The SNARE Vtila-beta is localized to small synaptic vesicles and participates in a novel SNARE complex." J Neurosci 20(15): 5724-32.

Antonin, W., D. Fasshauer, S. Becker, R. Jahn and T. R. Schneider (2002). "Crystal structure of the endosomal SNARE complex reveals common structural principles of all SNAREs." Nat Struct Biol 9(2): 107-11.

Ballensiefen, W. and H. D. Schmitt (1997). "Periplasmic Bar1 protease of Saccharomyces cerevisiae is active before reaching its extracellular destination." Eur J Biochem 247(1): 142-7.

Ballensiefen, W., D. Ossipov and H. D. Schmitt (1998). "Recycling of the yeast vSNARE Sec22p involves COPI-proteins and the ER transmembrane proteins Ufe1p and Sec20p.” J Cell Sci 111(Pt 11): 1507-20.

Banfield, D. K., M. J. Lewis and H. R. Pelham (1995). "A SNARE-like protein required for traffic through the Golgi complex." Nature 375(6534): 806-9.

Bankaitis, V. A., L. M. Johnson and S. D. Emr (1986). "Isolation of yeast mutants defective in protein targeting to the vacuole." Proc Natl Acad Sci U S A 83(23): 9075-9.

Barlowe, C., L. Orci, T. Yeung, M. Hosobuchi, S. Hamamoto, N. Salama, M. F. Rexach, M. Ravazzola, M. Amherdt and R. Schekman (1994). "COPII: a membrane coat formed by Sec proteins that drive vesicle budding from the endoplasmic reticulum." Cell 77(6): 895-907. 
Baudin, A., O. Ozier-Kalogeropoulos, A. Denouel, F. Lacroute and C. Cullin (1993). "A simple and efficient method for direct gene deletion in Saccharomyces cerevisiae." Nucleic Acids Res 21(14): 3329-30.

Baumert, M., P. R. Maycox, F. Navone, P. De Camilli and R. Jahn (1989). "Synaptobrevin: an integral membrane protein of 18,000 daltons present in small synaptic vesicles of rat brain.” Embo J 8(2): 379-84.

Becherer, K. A., S. E. Rieder, S. D. Emr and E. W. Jones (1996). "Novel syntaxin homologue, Pep12p, required for the sorting of lumenal hydrolases to the lysosome-like vacuole in yeast." Mol Biol Cell 7(4): 579-94.

Bennett, M. K., N. Calakos and R. H. Scheller (1992). "Syntaxin: a synaptic protein implicated in docking of synaptic vesicles at presynaptic active zones." Science 257(5067): 255-9.

Bennett, M. K. and R. H. Scheller (1993). "The molecular machinery for secretion is conserved from yeast to neurons." Proc Natl Acad Sci U S A 90(7): 2559-63.

Birnboim, H. C. and J. Doly (1979). "A rapid alkaline extraction procedure for screening recombinant plasmid DNA." Nucl. Acids Res. 7: 1513-1523.

Black, M. W. and H. R. Pelham (2000). "A selective transport route from Golgi to late endosomes that requires the yeast GGA proteins." J Cell Biol 151(3): 587-600.

Blobel, G. (1980). "Intracellular protein topogenesis." Proc Natl Acad Sci U S A 77(3): 1496-500.

Block, M. R., B. S. Glick, C. A. Wilcox, F. T. Wieland and J. E. Rothman (1988). "Purification of an N-ethylmaleimide-sensitive protein catalyzing vesicular transport." Proc Natl Acad Sci U S A 85(21): 7852-6.

Bock, J. B., H. T. Matern, A. A. Peden and R. H. Scheller (2001). "A genomic perspective on membrane compartment organization." Nature 409(6822): 839-41.

Boehm, J., H. D. Ulrich, R. Ossig and H. D. Schmitt (1994). "Kex2-dependent invertase secretion as a tool to study the targeting of transmembrane proteins which are involved in ER-->Golgi transport in yeast." Embo J 13(16): 3696-710.

Boehm, J., F. Letourneur, W. Ballensiefen, D. Ossipov, C. Demolliere and H. D. Schmitt (1997). "Sec12p requires Rer1p for sorting to coatomer (COPI)-coated vesicles and retrieval to the ER." J Cell Sci 110(Pt 8): 991-1003.

Boman, A. L., C. Zhang, X. Zhu and R. A. Kahn (2000). "A family of ADPribosylation factor effectors that can alter membrane transport through the transGolgi." Mol Biol Cell 11(4): 1241-55. 
Bonangelino, C. J., E. M. Chavez and J. S. Bonifacino (2002). "Genomic screen for vacuolar protein sorting genes in Saccharomyces cerevisiae." Mol Biol Cell 13(7): 2486-501.

Bonfanti, L., A. A. Mironov, Jr., J. A. Martinez-Menarguez, O. Martella, A. Fusella, M. Baldassarre, R. Buccione, H. J. Geuze, A. A. Mironov and A. Luini (1998). "Procollagen traverses the Golgi stack without leaving the lumen of cisternae: evidence for cisternal maturation.” Cell 95(7): 993-1003.

Bradford, M. M. (1976). "A rapid and sensitive method for the quantification of microgram quantities of protein utilizing the principle of protein dye binding." Anal. Biochem. 72: 248-254.

Brennwald, P., B. Kearns, K. Champion, S. Keranen, V. Bankaitis and P. Novick (1994). "Sec9 is a SNAP-25-like component of a yeast SNARE complex that may be the effector of Sec4 function in exocytosis." Cell 79(2): 245-58.

Brose, N., C. Rosenmund and J. Rettig (2000). "Regulation of transmitter release by Unc-13 and its homologues." Curr Opin Neurobiol 10(3): 303-11.

Bryant, N. J. and T. H. Stevens (1998). "Vacuole biogenesis in Saccharomyces cerevisiae: protein transport pathways to the yeast vacuole." Microbiol Mol Biol Rev 62(1): 230-47.

Cao, X., N. Ballew and C. Barlowe (1998). "Initial docking of ER-derived vesicles requires Usolp and Yptlp but is independent of SNARE proteins.” Embo J 17(8): 2156-65.

Cao, X. and C. Barlowe (2000). "Asymmetric requirements for a Rab GTPase and SNARE proteins in fusion of COPII vesicles with acceptor membranes." J Cell Biol 149(1): 55-66.

Cereghino, J. L., E. G. Marcusson and S. D. Emr (1995). "The cytoplasmic tail domain of the vacuolar protein sorting receptor Vps10p and a subset of VPS gene products regulate receptor stability, function, and localization." Mol Biol Cell 6(9): 1089102.

Chapman, E. R., P. I. Hanson, S. An and R. Jahn (1995). "Ca2+ regulates the interaction between synaptotagmin and syntaxin 1." J Biol Chem 270(40): 2366771.

Clague, M. J. (1999). "Membrane transport: Take your fusion partners." Curr Biol 9(7): R258-60.

Clary, D. O., I. C. Griff and J. E. Rothman (1990). "SNAPs, a family of NSF attachment proteins involved in intracellular membrane fusion in animals and yeast." Cell 61(4): 709-21. 
Clary, D. O. and J. E. Rothman (1990). "Purification of three related peripheral membrane proteins needed for vesicular transport." J Biol Chem 265(17): 1010917.

Cohen, S. N., A. C. Chang and L. Hsu (1972). "Nonchromosomal antibiotic resistance in bacteria: genetic transformation of Escherichia coli by R-factor DNA." Proc Natl Acad Sci U S A 69(8): 2110-4.

Conibear, E. and T. H. Stevens (1998). "Multiple sorting pathways between the late Golgi and the vacuole in yeast." Biochim Biophys Acta 1404(1-2): 211-30.

Cooper, A. A. and T. H. Stevens (1996). "Vps10p cycles between the late-Golgi and prevacuolar compartments in its function as the sorting receptor for multiple yeast vacuolar hydrolases.” J Cell Biol 133(3): 529-41.

Cosson, P., S. Schroder-Kohne, D. S. Sweet, C. Demolliere, S. Hennecke, G. Frigerio and F. Letourneur (1997). "The Sec20/Tip20p complex is involved in ER retrieval of dilysine-tagged proteins." Eur J Cell Biol 73(2): 93-7.

Cowles, C. R., G. Odorizzi, G. S. Payne and S. D. Emr (1997a). "The AP-3 adaptor complex is essential for cargo-selective transport to the yeast vacuole." Cell 91(1): 109-18.

Cowles, C. R., W. B. Snyder, C. G. Burd and S. D. Emr (1997b). "Novel Golgi to vacuole delivery pathway in yeast: identification of a sorting determinant and required transport component." Embo J 16(10): 2769-82.

Crick, F. H. C. (1953). "The packing of alpha-helices: simple coiled coils." Acta Crystallographica 6: 689-697.

Darsow, T., S. E. Rieder and S. D. Emr (1997). "A multispecificity syntaxin homologue, Vam3p, essential for autophagic and biosynthetic protein transport to the vacuole." J Cell Biol 138(3): 517-29.

Darsow, T., C. G. Burd and S. D. Emr (1998). "Acidic di-leucine motif essential for AP-3-dependent sorting and restriction of the functional specificity of the Vam3p vacuolar t-SNARE." J Cell Biol 142(4): 913-22.

Dascher, C., R. Ossig, D. Gallwitz and H. D. Schmitt (1991). "Identification and structure of four yeast genes (SLY) that are able to suppress the functional loss of YPT1, a member of the RAS superfamily." Mol Cell Biol 11(2): 872-85.

de Duve, C. (1975). “Exploring cells with a centrifuge." Science 189(4198): 186-94.

Dell'Angelica, E. C., J. Klumperman, W. Stoorvogel and J. S. Bonifacino (1998). "Association of the AP-3 adaptor complex with clathrin." Science 280(5362): 4314. 
Dell'Angelica, E. C., V. Shotelersuk, R. C. Aguilar, W. A. Gahl and J. S. Bonifacino (1999). "Altered trafficking of lysosomal proteins in Hermansky-Pudlak syndrome due to mutations in the beta 3A subunit of the AP-3 adaptor." Mol Cell 3(1): 1121

Evan, G. I., G. K. Lewis, G. Ramsay and J. M. Bishop (1985). "Isolation of monoclonal antibodies specific for human c-myc proto- oncogene product." Mol Cell Biol 5(12): 3610-6.

Fasshauer, D., D. Bruns, B. Shen, R. Jahn and A. T. Brunger (1997a). "A structural change occurs upon binding of syntaxin to SNAP-25." J Biol Chem 272(7): 458290 .

Fasshauer, D., H. Otto, W. K. Eliason, R. Jahn and A. T. Brunger (1997b). "Structural changes are associated with soluble N-ethylmaleimide- sensitive fusion protein attachment protein receptor complex formation." J Biol Chem 272(44): 28036-41.

Fasshauer, D., W. K. Eliason, A. T. Brunger and R. Jahn (1998a). "Identification of a minimal core of the synaptic SNARE complex sufficient for reversible assembly and disassembly." Biochemistry 37(29): 10354-62.

Fasshauer, D., R. B. Sutton, A. T. Brunger and R. Jahn (1998b). "Conserved structural features of the synaptic fusion complex: SNARE proteins reclassified as Q- and R-SNAREs.” Proc Natl Acad Sci U S A 95(26): 15781-6.

Fasshauer, D., W. Antonin, M. Margittai, S. Pabst and R. Jahn (1999). "Mixed and non-cognate SNARE complexes. Characterization of assembly and biophysical properties." J Biol Chem 274(22): 15440-6.

Fernandez, I., J. Ubach, I. Dulubova, X. Zhang, T. C. Sudhof and J. Rizo (1998). "Three-dimensional structure of an evolutionarily conserved $\mathrm{N}$-terminal domain of syntaxin 1A." Cell 94(6): 841-9.

Ferro-Novick, S. and R. Jahn (1994). "Vesicle fusion from yeast to man." Nature 370(6486): 191-3.

Fiebig, K. M., L. M. Rice, E. Pollock and A. T. Brunger (1999). "Folding intermediates of SNARE complex assembly.” Nat Struct Biol 6(2): 117-23.

Fischer von Mollard, G., S. F. Nothwehr and T. H. Stevens (1997). "The yeast vSNARE Vtilp mediates two vesicle transport pathways through interactions with the t-SNAREs Sed5p and Pep12p." Journal of Cell Biology 137(7): 1511-1524.

Fischer von Mollard, G. and T. H. Stevens (1998). "A human homolog can functionally replace the yeast vesicle-associated SNARE Vtilp in two vesicle transport pathways." J Biol Chem 273(5): 2624-30. 
Fischer von Mollard, G. and T. H. Stevens (1999). "The Saccharomyces cerevisiae vSNARE Vtilp is required for multiple membrane transport pathways to the vacuole." Mol Biol Cell 10(6): 1719-32.

Franzusoff, A. and R. Schekman (1989). "Functional compartments of the yeast Golgi apparatus are defined by the sec7 mutation." Embo J 8(9): 2695-702.

Fukuda, R., J. A. McNew, T. Weber, F. Parlati, T. Engel, W. Nickel, J. E. Rothman and T. H. Sollner (2000). "Functional architecture of an intracellular membrane tSNARE." Nature 407(6801): 198-202.

Gerona, R. R., E. C. Larsen, J. A. Kowalchyk and T. F. Martin (2000). "The C terminus of SNAP25 is essential for $\mathrm{Ca}(2+)$-dependent binding of synaptotagmin to SNARE complexes.” J Biol Chem 275(9): 6328-36.

Gerst, J. E. (1997). "Conserved alpha-helical segments on yeast homologs of the synaptobrevin/VAMP family of v-SNAREs mediate exocytic function." J Biol Chem 272(26): 16591-8.

Glick, B. S. and J. E. Rothman (1987). "Possible role for fatty acyl-coenzyme A in intracellular protein transport." Nature 326(6110): 309-12.

Görlich, D. and R. A. Laskey (1995). "Roles of importin in nuclear protein import." Cold Spring Harb Symp Quant Biol 60: 695-9.

Götte, M. and D. Gallwitz (1997). "High expression of the yeast syntaxin-related Vam3 protein suppresses the protein transport defects of a pep12 null mutant." FEBS Lett 411(1): 48-52.

Govindan, B., R. Bowser and P. Novick (1995). "The role of Myo2, a yeast class V myosin, in vesicular transport.” J Cell Biol 128(6): 1055-68.

Griffiths, G. and K. Simons (1986). "The trans Golgi network: sorting at the exit site of the Golgi complex." Science 234(4775): 438-43.

Grote, E., C. M. Carr and P. J. Novick (2000). "Ordering the final events in yeast exocytosis." J Cell Biol 151(2): 439-52.

Guo, W., M. Sacher, J. Barrowman, S. Ferro-Novick and P. Novick (2000). "Protein complexes in transport vesicle targeting." Trends Cell Biol 10(6): 251-5.

Gupta, G. D. and I. Brent Heath (2002). "Predicting the distribution, conservation, and functions of SNAREs and related proteins in fungi." Fungal Genet Biol 36(1): 121. 
Hanson, P. I., R. Roth, H. Morisaki, R. Jahn and J. E. Heuser (1997). "Structure and conformational changes in NSF and its membrane receptor complexes visualized by quick-freeze/deep-etch electron microscopy." Cell 90(3): 523-35.

Harding, T. M., K. A. Morano, S. V. Scott and D. J. Klionsky (1995). "Isolation and characterization of yeast mutants in the cytoplasm to vacuole protein targeting pathway." J Cell Biol 131(3): 591-602.

Hardwick, K. G. and H. R. Pelham (1992). "SED5 encodes a 39-kD integral membrane protein required for vesicular transport between the ER and the Golgi complex." $\underline{\mathrm{J}}$ Cell Biol 119(3): 513-21.

Harlow, E. and D. Lane (1988). Antibodies: A Laboratory Manual. N.Y., Cold Spring Harbor Press.

Hay, J. C. (2001). “SNARE complex structure and function.” Exp Cell Res 271(1): 1021.

Hayashi, T., H. McMahon, S. Yamasaki, T. Binz, Y. Hata, T. C. Sudhof and H. Niemann (1994). "Synaptic vesicle membrane fusion complex: action of clostridial neurotoxins on assembly." Embo J 13(21): 5051-61.

Helling, R. B., H. M. Goodman and H. W. Boyer (1974). "Analysis of endonuclease EcoRI fragments of DNA from bacteriophages and other viruses by agarose gel electrophoresis.” J. Virol. 14: 1235-1244.

Hess, D. T., T. M. Slater, M. C. Wilson and J. H. Skene (1992). "The $25 \mathrm{kDa}$ synaptosomal-associated protein SNAP-25 is the major methionine-rich polypeptide in rapid axonal transport and a major substrate for palmitoylation in adult CNS.” J Neurosci 12(12): 4634-41.

Hirst, J., W. W. Lui, N. A. Bright, N. Totty, M. N. Seaman and M. S. Robinson (2000). "A family of proteins with gamma-adaptin and VHS domains that facilitate trafficking between the trans-Golgi network and the vacuole/lysosome." J Cell Biol 149(1): 67-80.

Holthuis, J. C., B. J. Nichols, S. Dhruvakumar and H. R. Pelham (1998). "Two syntaxin homologues in the TGN/endosomal system of yeast." Embo J 17(1): 11326.

Jahn, R. and H. Niemann (1994). "Molecular mechanisms of clostridial neurotoxins." Ann N Y Acad Sci 733: 245-55.

Jahn, R. and T. C. Südhof (1999). "Membrane fusion and exocytosis." $\underline{\text { Annu Rev }}$ Biochem 68: 863-911. 
Jones, E. W. (1977). "Proteinase mutants of Saccharomyces cerevisiae." Genetics 85(1): 23-33.

Katz, L. and P. Brennwald (2000). "Testing the 3Q:1R "rule": mutational analysis of the ionic "zero" layer in the yeast exocytic SNARE complex reveals no requirement for arginine." Mol Biol Cell 11(11): 3849-58.

Katz, L., P. I. Hanson, J. E. Heuser and P. Brennwald (1998). "Genetic and morphological analyses reveal a critical interaction between the C-termini of two SNARE proteins and a parallel four helical arrangement for the exocytic SNARE complex.” Embo J 17(21): 6200-9.

Klionsky, D. J., R. Cueva and D. S. Yaver (1992). "Aminopeptidase I of Saccharomyces cerevisiae is localized to the vacuole independent of the secretory pathway." J Cell Biol 119(2): 287-99.

Klionsky, D. J. (1998). "Nonclassical protein sorting to the yeast vacuole.” J Biol Chem 273(18): 10807-10.

Kornfeld, S. and I. Mellman (1989). "The biogenesis of lysosomes." Annu Rev Cell Biol 5: 483-525.

Kreykenbohm, V., D. Wenzel, W. Antonin, V. Atlachkine and G. F. von Mollard (2002). "The SNAREs vtila and vtilb have distinct localization and SNARE complex partners." Eur J Cell Biol 81(5): 273-80.

Laemmli, U. K. (1970). "Cleavage of structural proteins during the assembly of the head of the bacteriophage T4." Nature 227: 680-685.

Lazar, T., M. Gotte and D. Gallwitz (1997). "Vesicular transport: how many Ypt/RabGTPases make a eukaryotic cell?” Trends Biochem Sci 22(12): 468-72.

Le Borgne, R. and B. Hoflack (1998). "Protein transport from the secretory to the endocytic pathway in mammalian cells." Biochimica et Biophysica Acta 1404: 195-209.

Letourneur, F., E. C. Gaynor, S. Hennecke, C. Demolliere, R. Duden, S. D. Emr, H. Riezman and P. Cosson (1994). "Coatomer is essential for retrieval of dilysinetagged proteins to the endoplasmic reticulum." Cell 79(7): 1199-207.

Lewis, M. J. and H. R. Pelham (1996). "SNARE-mediated retrograde traffic from the Golgi complex to the endoplasmic reticulum." Cell 85(2): 205-15.

Lewis, M. J., J. C. Rayner and H. R. Pelham (1997). "A novel SNARE complex implicated in vesicle fusion with the endoplasmic reticulum." Embo J 16(11): 3017-24. 
Lewis, M. J. and H. R. Pelham (2002). "A New Yeast Endosomal SNARE Related to Mammalian Syntaxin 8.” Traffic 3(12): 922-9.

Li, C., B. Ullrich, J. Z. Zhang, R. G. Anderson, N. Brose and T. C. Sudhof (1995). " $\mathrm{Ca}(2+)$-dependent and -independent activities of neural and non-neural synaptotagmins.” Nature 375(6532): 594-9.

Liu, Y. and C. Barlowe (2002). "Analysis of Sec22p in Endoplasmic Reticulum/Golgi Transport Reveals Cellular Redundancy in SNARE Protein Function." Mol Biol Cell 13(9): 3314-24.

Low, S. H., P. A. Roche, H. A. Anderson, S. C. van Ijzendoorn, M. Zhang, K. E. Mostov and T. Weimbs (1998). "Targeting of SNAP-23 and SNAP-25 in polarized epithelial cells.” J Biol Chem 273(6): 3422-30.

Lupashin, V. V., I. D. Pokrovskaya, J. A. McNew and M. G. Waters (1997). "Characterization of a novel yeast SNARE protein implicated in Golgi retrograde traffic.” Mol Biol Cell 8(12): 2659-76.

Malhotra, V., L. Orci, B. S. Glick, M. R. Block and J. E. Rothman (1988). "Role of an $\mathrm{N}$-ethylmaleimide-sensitive transport component in promoting fusion of transport vesicles with cisternae of the Golgi stack." Cell 54(2): 221-7.

Mallard, F., B. L. Tang, T. Galli, D. Tenza, A. Saint-Pol, X. Yue, C. Antony, W. Hong, B. Goud and L. Johannes (2002). "Early/recycling endosomes-to-TGN transport involves two SNARE complexes and a Rab6 isoform." J Cell Biol 156(4): 653-64.

Marcusson, E. G., B. F. Horazdovsky, J. L. Cereghino, E. Gharakhanian and S. D. Emr (1994). "The sorting receptor for yeast vacuolar carboxypeptidase $Y$ is encoded by the VPS10 gene." Cell 77(4): 579-86.

Martinez, O. and B. Goud (1998). "Rab proteins." Biochim Biophys Acta 1404(1-2): $101-12$.

May, T. and J. Soll (1999). "Chloroplast precursor protein translocon." FEBS Lett 452(1-2): 52-6.

Mayer, A., W. Wickner and A. Haas (1996). "Sec18p (NSF)-driven release of Sec17p (alpha-SNAP) can precede docking and fusion of yeast vacuoles." Cell 85(1): 8394.

Mayer, A. and W. Wickner (1997). "Docking of yeast vacuoles is catalyzed by the Raslike GTPase Ypt7p after symmetric priming by Sec18p (NSF)." J Cell Biol 136(2): 307-17. 
McNew, J. A., M. Søgaard, N. M. Lampen, S. Machida, R. R. Ye, L. Lacomis, P. Tempst, J. E. Rothman and T. H. Sollner (1997). "Ykt6p, a prenylated SNARE essential for endoplasmic reticulum-Golgi transport." J Biol Chem 272(28): 17776-83.

McNew, J. A., F. Parlati, R. Fukuda, R. J. Johnston, K. Paz, F. Paumet, T. H. Sollner and J. E. Rothman (2000). "Compartmental specificity of cellular membrane fusion encoded in SNARE proteins.” Nature 407(6801): 153-9.

Mellman, I. and G. Warren (2000). "The road taken: past and future foundations of membrane traffic." Cell 100(1): 99-112.

Meyer, C., D. Zizioli, S. Lausmann, E. L. Eskelinen, J. Hamann, P. Saftig, K. von Figura and P. Schu (2000). "mu1A-adaptin-deficient mice: lethality, loss of AP1 binding and rerouting of mannose 6-phosphate receptors." Embo J 19(10): 2193203.

Misura, K. M., R. H. Scheller and W. I. Weis (2000). "Three-dimensional structure of the neuronal-Sec1-syntaxin 1a complex." Nature 404(6776): 355-62.

Montecucco, C. and G. Schiavo (1995). "Structure and function of tetanus and botulinum neurotoxins." Q Rev Biophys 28(4): 423-72.

Mu, F. T., J. M. Callaghan, O. Steele-Mortimer, H. Stenmark, R. G. Parton, P. L. Campbell, J. McCluskey, J. P. Yeo, E. P. Tock and B. H. Toh (1995). "EEA1, an early endosome-associated protein. EEA1 is a conserved alpha- helical peripheral membrane protein flanked by cysteine "fingers" and contains a calmodulin-binding IQ motif.” J Biol Chem 270(22): 13503-11.

Muhlrad, D., R. Hunter and R. Parker (1992). "A rapid method for localized mutagenesis of yeast genes.” Yeast 8(2): 79-82.

Mullins, C. and J. S. Bonifacino (2001). "Structural requirements for function of yeast GGAs in vacuolar protein sorting, alpha-factor maturation, and interactions with clathrin." Mol Cell Biol 21(23): 7981-94.

Mullis, K. B. and F. A. Faloona (1987). "Specific synthesis of DNA in vitro via a polymerase-catalyzed chain reaction." Methods in Enzymology 155: 335-350.

Munson, M., X. Chen, A. E. Cocina, S. M. Schultz and F. M. Hughson (2000). "Interactions within the yeast t-SNARE Ssolp that control SNARE complex assembly." Nat Struct Biol 7(10): 894-902.

Neiman, A. M. (1998). "Prospore membrane formation defines a developmentally regulated branch of the secretory pathway in yeast." J Cell Biol 140(1): 29-37. 
Neupert, W. (1997). "Protein import into mitochondria." Annu Rev Biochem 66: 863917.

Newman, A. P., J. Shim and S. Ferro-Novick (1990). "BET1, BOS1, and SEC22 are members of a group of interacting yeast genes required for transport from the endoplasmic reticulum to the Golgi complex." Mol Cell Biol 10(7): 3405-14.

Nichols, B. J. and H. R. Pelham (1998). "SNAREs and membrane fusion in the Golgi apparatus.” Biochim Biophys Acta 1404(1-2): 9-31.

Nicholson, K. L., M. Munson, R. B. Miller, T. J. Filip, R. Fairman and F. M. Hughson (1998). "Regulation of SNARE complex assembly by an N-terminal domain of the t- SNARE Sso1p." Nat Struct Biol 5(9): 793-802.

Nielsen, M. S., P. Madsen, E. I. Christensen, A. Nykjaer, J. Gliemann, D. Kasper, R. Pohlmann and C. M. Petersen (2001). "The sortilin cytoplasmic tail conveys Golgi-endosome transport and binds the VHS domain of the GGA2 sorting protein.” Embo J 20(9): 2180-90.

Novick, P., S. Ferro and R. Schekman (1981). "Order of events in the yeast secretory pathway." Cell 25(2): 461-9.

Odorizzi, G., C. R. Cowles and S. D. Emr (1998). "The AP-3 complex: a coat of many colours." Trends Cell Biol 8(7): 282-8.

Ossig, R., C. Dascher, H. H. Trepte, H. D. Schmitt and D. Gallwitz (1991). "The yeast SLY gene products, suppressors of defects in the essential GTP-binding Ypt1 protein, may act in endoplasmic reticulum-to-Golgi transport." Mol Cell Biol 11(6): 2980-93.

Ossig, R., H. D. Schmitt, B. de Groot, D. Riedel, S. Keranen, H. Ronne, H. Grubmuller and R. Jahn (2000). "Exocytosis requires asymmetry in the central layer of the SNARE complex." Embo J 19(22): 6000-10.

Oyler, G. A., G. A. Higgins, R. A. Hart, E. Battenberg, M. Billingsley, F. E. Bloom and M. C. Wilson (1989). "The identification of a novel synaptosomal-associated protein, SNAP-25, differentially expressed by neuronal subpopulations." J Cell Biol 109(6 Pt 1): 3039-52.

Palade, G. (1975). "Intracellular aspects of the process of protein synthesis." Science 189(4200): 347-58.

Panek, H. R., J. D. Stepp, H. M. Engle, K. M. Marks, P. K. Tan, S. K. Lemmon and L. C. Robinson (1997). "Suppressors of YCK-encoded yeast casein kinase 1 deficiency define the four subunits of a novel clathrin AP-like complex." Embo J 16(14): 4194-204. 
Paravicini, G., B. F. Horazdovsky and S. D. Emr (1992). "Alternative pathways for the sorting of soluble vacuolar proteins in yeast: a vps35 null mutant missorts and secretes only a subset of vacuolar hydrolases." Mol Biol Cell 3(4): 415-27.

Pelham, H. R. (1999). "SNAREs and the secretory pathway-lessons from yeast." Exp Cell Res 247(1): 1-8.

Pelham, H. R. (2001). "SNAREs and the specificity of membrane fusion." Trends Cell Biol 11(3): 99-101.

Peters, C. and A. Mayer (1998). "Ca2+/calmodulin signals the completion of docking and triggers a late step of vacuole fusion." Nature 396(6711): 575-80.

Peters, C., M. J. Bayer, S. Buhler, J. S. Andersen, M. Mann and A. Mayer (2001). "Trans-complex formation by proteolipid channels in the terminal phase of membrane fusion.” Nature 409(6820): 581-8.

Peterson, A. J., M. Kyba, D. Bornemann, K. Morgan, H. W. Brock and J. Simon (1997). "A domain shared by the Polycomb group proteins Scm and ph mediates heterotypic and homotypic interactions." Mol Cell Biol 17(11): 6683-92.

Pfeffer, S. R. (1999). "Transport-vesicle targeting: tethers before SNAREs." Nat Cell Biol 1(1): E17-22.

Piper, R. C., E. A. Whitters and T. H. Stevens (1994). "Yeast Vps45p is a Sec1p-like protein required for the consumption of vacuole-targeted, post-Golgi transport vesicles." Eur J Cell Biol 65(2): 305-18.

Piper, R. C., A. A. Cooper, H. Yang and T. H. Stevens (1995). "VPS27 controls vacuolar and endocytic traffic through a prevacuolar compartment in Saccharomyces cerevisiae." J Cell Biol 131(3): 603-17.

Piper, R. C., N. J. Bryant and T. H. Stevens (1997). "The membrane protein alkaline phosphatase is delivered to the vacuole by a route that is distinct from the VPSdependent pathway." J Cell Biol 138(3): 531-45.

Ponting, C. P. (1995). "SAM: a novel motif in yeast sterile and Drosophila polyhomeotic proteins." Protein Sci 4(9): 1928-30.

Porat, A. and Z. Elazar (2000). "Regulation of intra-Golgi membrane transport by calcium." J Biol Chem 275(38): 29233-7.

Pringle, J. R., R. A. Preston, A. E. Adams, T. Stearns, D. G. Drubin, B. K. Haarer and E. W. Jones (1989). "Fluorescence microscopy methods for yeast." Methods Cell Biol 31: 357-435. 
Pryor, P. R., B. M. Mullock, N. A. Bright, S. R. Gray and J. P. Luzio (2000). "The role of intraorganellar $\mathrm{Ca}(2+)$ in late endosome-lysosome heterotypic fusion and in the reformation of lysosomes from hybrid organelles." J Cell Biol 149(5): 105362.

Puertollano, R., R. C. Aguilar, I. Gorshkova, R. J. Crouch and J. S. Bonifacino (2001). "Sorting of mannose 6-phosphate receptors mediated by the GGAs." Science 292(5522): 1712-6.

Rapoport, T. A. (1992). "Transport of proteins across the endoplasmic reticulum membrane." Science 258(5084): 931-6.

Reggiori, F., M. W. Black and H. R. Pelham (2000). "Polar transmembrane domains target proteins to the interior of the yeast vacuole." Mol Biol Cell 11(11): 3737-49.

Rehling, P., T. Darsow, D. J. Katzmann and S. D. Emr (1999). "Formation of AP-3 transport intermediates requires Vps41 function." Nat Cell Biol 1(6): 346-53.

Reilly, B. A., B. A. Kraynack, S. M. VanRheenen and M. G. Waters (2001). "Golgito-endoplasmic reticulum (ER) retrograde traffic in yeast requires Dsllp, a component of the ER target site that interacts with a COPI coat subunit." Mol Biol Cell 12(12): 3783-96.

Rice, L. M., P. Brennwald and A. T. Brunger (1997). "Formation of a yeast SNARE complex is accompanied by significant structural changes." FEBS Lett 415(1): 4955.

Roberts, C. J., C. K. Raymond, C. T. Yamashiro and T. H. Stevens (1991). "Methods for studying the yeast vacuole." Methods Enzymol 194: 644-61.

Robinson, J. S., D. J. Klionsky, L. M. Banta and S. D. Emr (1988). "Protein sorting in Saccharomyces cerevisiae: isolation of mutants defective in the delivery and processing of multiple vacuolar hydrolases." Mol Cell Biol 8(11): 4936-48.

Rothman, J. E. (1994). "Mechanisms of intracellular protein transport." Nature 372(6501): 55-63.

Rothman, J. H. and T. H. Stevens (1986). "Protein sorting in yeast: mutants defective in vacuole biogenesis mislocalize vacuolar proteins into the late secretory pathway." Cell 47(6): 1041-51.

Rothstein, R. J. (1983). “One-step gene disruption in yeast.” Methods Enzymol 101: 202-11. 
Sacher, M., Y. Jiang, J. Barrowman, A. Scarpa, J. Burston, L. Zhang, D. Schieltz, J. R. Yates, 3rd, H. Abeliovich and S. Ferro-Novick (1998). "TRAPP, a highly conserved novel complex on the cis-Golgi that mediates vesicle docking and fusion.” Embo J 17(9): 2494-503.

Sambrook, J., E. F. Fritsch and T. Maniatis (1989). Molecular Cloning: A Laboratory Manual. Cold Spring Harbor, New York, Cold Spring Harbor Laboratory.

Sanderfoot, A. A., F. F. Assaad and N. V. Raikhel (2000). "The Arabidopsis genome. An abundance of soluble N-ethylmaleimide- sensitive factor adaptor protein receptors." Plant Physiol 124(4): 1558-69.

Sanger, F., S. Nicklen and A. Coulson (1977). "DNA-sequencing with chaintermination inhibitors." Proc Natl Acad Sci U S A 74: 5463-5467.

Sato, T. K., T. Darsow and S. D. Emr (1998). "Vam7p, a SNAP-25-like molecule, and Vam3p, a syntaxin homolog, function together in yeast vacuolar protein trafficking." Mol Cell Biol 18(9): 5308-19.

Scales, S. J., B. Y. Yoo and R. H. Scheller (2001). "The ionic layer is required for efficient dissociation of the SNARE complex by alpha-SNAP and NSF." Proc Natl Acad Sci U S A 98(25): 14262-7.

Schmid, S. L. (1997). "Clathrin-coated vesicle formation and protein sorting: an integrated process." Annu Rev Biochem 66: 511-48.

Schröder, S., F. Schimmoller, B. Singer-Kruger and H. Riezman (1995). "The Golgilocalization of yeast Emp47p depends on its di-lysine motif but is not affected by the ret1-1 mutation in alpha-COP.” J Cell Biol 131(4): 895-912.

Schultz, J., C. P. Ponting, K. Hofmann and P. Bork (1997). "SAM as a protein interaction domain involved in developmental regulation." Protein Sci 6(1): 24953.

Seeley, E. S., M. Kato, N. Margolis, W. Wickner and G. Eitzen (2002). "Genomic analysis of homotypic vacuole fusion." Mol Biol Cell 13(3): 782-94.

Semenza, J. C., K. G. Hardwick, N. Dean and H. R. Pelham (1990). "ERD2, a yeast gene required for the receptor-mediated retrieval of luminal ER proteins from the secretory pathway." Cell 61(7): 1349-57.

Simpson, F., N. A. Bright, M. A. West, L. S. Newman, R. B. Darnell and M. S. Robinson (1996). "A novel adaptor-related protein complex." J Cell Biol 133(4): 749-60. 
Søgaard, M., K. Tani, R. R. Ye, S. Geromanos, P. Tempst, T. Kirchhausen, J. E. Rothman and T. Sollner (1994). "A rab protein is required for the assembly of SNARE complexes in the docking of transport vesicles." Cell 78(6): 937-48.

Söllner, T., M. K. Bennett, S. W. Whiteheart, R. H. Scheller and J. E. Rothman (1993a). "A protein assembly-disassembly pathway in vitro that may correspond to sequential steps of synaptic vesicle docking, activation, and fusion." Cell 75(3): 409-18.

Söllner, T., S. W. Whiteheart, M. Brunner, H. Erdjument-Bromage, S. Geromanos, P. Tempst and J. E. Rothman (1993b). "SNAP receptors implicated in vesicle targeting and fusion." Nature 362(6418): 318-24.

Spang, A. and R. Schekman (1998). "Reconstitution of retrograde transport from the Golgi to the ER in vitro." J Cell Biol 143(3): 589-99.

Stahl, B., J. H. Chou, C. Li, T. C. Sudhof and R. Jahn (1996). "Rab3 reversibly recruits rabphilin to synaptic vesicles by a mechanism analogous to raf recruitment by ras." Embo J 15(8): 1799-809.

Steegmaier, M., B. Yang, J. S. Yoo, B. Huang, M. Shen, S. Yu, Y. Luo and R. H. Scheller (1998). "Three novel proteins of the syntaxin/SNAP-25 family." J Biol Chem 273(51): 34171-9.

Stepp, J. D., A. Pellicena-Palle, S. Hamilton, T. Kirchhausen and S. K. Lemmon (1995). "A late Golgi sorting function for Saccharomyces cerevisiae Apm1p, but not for Apm2p, a second yeast clathrin AP medium chain-related protein." Mol Biol Cell 6(1): 41-58.

Sutton, R. B., D. Fasshauer, R. Jahn and A. T. Brunger (1998). "Crystal structure of a SNARE complex involved in synaptic exocytosis at 2.4 A resolution." Nature 395(6700): 347-53.

Sweet, D. J. and H. R. Pelham (1992). "The Saccharomyces cerevisiae SEC20 gene encodes a membrane glycoprotein which is sorted by the HDEL retrieval system." Embo J 11(2): 423-32.

Sweet, D. J. and H. R. Pelham (1993). "The TIP1 gene of Saccharomyces cerevisiae encodes an $80 \mathrm{kDa}$ cytoplasmic protein that interacts with the cytoplasmic domain of Sec20p.” Embo J 12(7): 2831-40.

TerBush, D. R., T. Maurice, D. Roth and P. Novick (1996). "The Exocyst is a multiprotein complex required for exocytosis in Saccharomyces cerevisiae." Embo J 15(23): 6483-94.

Thanos, C. D. and J. U. Bowie (1999). "p53 Family members p63 and p73 are SAM domain-containing proteins.” Protein Sci 8(8): 1708-10. 
Tochio, H., M. M. Tsui, D. K. Banfield and M. Zhang (2001). "An autoinhibitory mechanism for nonsyntaxin SNARE proteins revealed by the structure of Ykt6p." Science 293(5530): 698-702.

Towbin, H., T. Staehlin and J. Gordon (1979). "Electrophoretic transfer of proteins from polyacrylamide gels to nitrocellulose sheets: procedure and some applications." Proc Natl Acad Sci U S A 76: 4350-4354.

Traub, L. M. and S. Kornfeld (1997). "The trans-Golgi network: a late secretory sorting station." Curr Opin Cell Biol 9(4): 527-33.

Trimble, W. S., D. M. Cowan and R. H. Scheller (1988). "VAMP-1: a synaptic vesicleassociated integral membrane protein." Proc Natl Acad Sci U S A 85(12): 453842.

Tsui, M. M. and D. K. Banfield (2000). "Yeast Golgi SNARE interactions are promiscuous." J Cell Sci 113(Pt 1): 145-52.

Ullrich, A., J. Shine, J. Chirgwin, R. Pictet, E. Tischer, W. J. Rutter and H. M. Goodman (1977). "Rat insulin genes: construction of plasmids containing the coding sequences." Science 196: 1313-1409.

Ungermann, C., K. Sato and W. Wickner (1998). "Defining the functions of transSNARE pairs." Nature 396(6711): 543-8.

Ungermann, C., G. F. von Mollard, O. N. Jensen, N. Margolis, T. H. Stevens and W. Wickner (1999). "Three v-SNAREs and two t-SNAREs, present in a pentameric cis-SNARE complex on isolated vacuoles, are essential for homotypic fusion." $\underline{J}$ Cell Biol 145(7): 1435-42.

Vowels, J. J. and G. S. Payne (1998). "A dileucine-like sorting signal directs transport into an AP-3- dependent, clathrin-independent pathway to the yeast vacuole." Embo J 17(9): 2482-93.

Wada, Y., N. Nakamura, Y. Ohsumi and A. Hirata (1997). "Vam3p, a new member of syntaxin related protein, is required for vacuolar assembly in the yeast Saccharomyces cerevisiae." J Cell Sci 110(Pt 11): 1299-306.

Wang, Y., I. Dulubova, J. Rizo and T. C. Sudhof (2001). "Functional analysis of conserved structural elements in yeast syntaxin Vam3p." J Biol Chem 276(30): 28598-605.

Weber, T., B. V. Zemelman, J. A. McNew, B. Westermann, M. Gmachl, F. Parlati, T. H. Sollner and J. E. Rothman (1998). "SNAREpins: minimal machinery for membrane fusion." Cell 92(6): 759-72. 
Weimbs, T., S. H. Low, S. J. Chapin, K. E. Mostov, P. Bucher and K. Hofmann (1997). "A conserved domain is present in different families of vesicular fusion proteins: a new superfamily." Proc Natl Acad Sci U S A 94(7): 3046-51.

Weimbs, T., K. Mostov, S. H. Low and K. Hofmann (1998). "A model for structural similarity between different SNARE complexes based on sequence relationships." Trends Cell Biol 8(7): 260-2.

Whiteheart, S. W., I. C. Griff, M. Brunner, D. O. Clary, T. Mayer, S. A. Buhrow and J. E. Rothman (1993). "SNAP family of NSF attachment proteins includes a brain-specific isoform." Nature 362(6418): 353-5.

Wilson, D. W., C. A. Wilcox, G. C. Flynn, E. Chen, W. J. Kuang, W. J. Henzel, M. R. Block, A. Ullrich and J. E. Rothman (1989). "A fusion protein required for vesicle-mediated transport in both mammalian cells and yeast." Nature 339(6223): 355-9.

Wolf, D. H. and G. R. Fink (1975). "Proteinase C (carboxypeptidase Y) mutant of yeast." J. Bacteriol. 123: 1150-1156.

Wuestehube, L. J., R. Duden, A. Eun, S. Hamamoto, P. Korn, R. Ram and R. Schekman (1996). "New mutants of Saccharomyces cerevisiae affected in the transport of proteins from the endoplasmic reticulum to the Golgi complex." Genetics 142(2): 393-406.

Xiao, W., M. A. Poirier, M. K. Bennett and Y. K. Shin (2001). "The neuronal tSNARE complex is a parallel four-helix bundle." Nat Struct Biol 8(4): 308-11.

Yang, B., L. Gonzalez, Jr., R. Prekeris, M. Steegmaier, R. J. Advani and R. H. Scheller (1999). "SNARE interactions are not selective. Implications for membrane fusion specificity." J Biol Chem 274(9): 5649-53.

Zheng, H., G. F. von Mollard, V. Kovaleva, T. H. Stevens and N. V. Raikhel (1999). "The plant vesicle-associated SNARE AtVTI1a likely mediates vesicle transport from the trans-Golgi network to the prevacuolar compartment." Mol Biol Cell 10(7): 2251-64. 



\section{Publikation:}

Dilcher, M., B. Köhler and G. Fischer von Mollard (2001): „Genetic interactions with the yeast Q-SNARE VTII reveal novel functions for the R-SNARE YKT6.“ Journal of Biological Chemistry 276(37): 34537-34544. 


\section{Danksagung:}

Ich danke Herrn Prof. Dr. Kurt von Figura, dass ich diese Arbeit in seiner Abteilung anfertigen konnte und Herrn Prof. Dr. Gerhard Gottschalk, dass er das Korreferat übernahm.

Mein ganz besonderer Dank gilt Frau Dr. Gabriele Fischer von Mollard für die interessante Themenstellung, die ausgezeichnete wissenschaftliche Betreuung und die Korrektur des Manuskriptes. Durch die hervorragende Planung und Vorarbeit der Projekte war ein Gelingen schon vorprogrammiert. Vielen Dank Gabi, für alles was ich von Dir lernen durfte!

Spezieller Dank gilt auch Beate Veith für die sehr gute und fruchtende Zusammenarbeit. Sie hat durch ihre technische Unterstützung des Projektes und ihr feinmotorisches Geschick bei der Tetradenanalyse maßgeblich zur erfolgreichen Publikation der Ergebnisse beigetragen und mir dadurch einige unliebsame Arbeiten abgenommen.

Dr. Vadim Atlachkine, Vera Kreykenbohm, Nina Müllers und Subbulakshmi Chidambaram danke ich für ihre Hilfe, die angenehme und humorvolle Arbeitsatmosphäre und die tolle Zeit, die ich mit ihnen hatte. Ich werde euch sehr vermissen !

Anna Boulankina danke ich für ihre geduldige Hilfe bei der Bedienung des Mikroskops, sowie Dr. Thomas Dierks, Klaus Neifer, Petra Schlotterhose und Ljudmila Borissenko für die Unterstützung an der SMART-Anlage.

Dr. Hans Dieter Schmitt und Dr. Uwe Andag danke ich für den regen wissenschaftlichen Austausch, für Tipps zu den Recycling-Experimenten und für die vielen Plasmide und Antikörper die ich von ihnen geschnorrt habe. Herrn Prof. Dr. Enno Hartmann danke ich für die Hilfe bei der Sequenzanalyse.

Dr. Peter Schu danke ich für die Unterstützung bei der Analyse der AutophagozytoseDefekte. Rekha Naga Pasupuleti und Guruprasad Medigeshi Ramarao möchte ich für ihre Diskussionsbereitschaft und ihr Interesse am Verlauf meiner Projekte, sowie für den Einblick in ihre Kultur und Küche danken. Constanze Riel danke ich für ihre genialen Ideen.

Uta Ferch danke ich für die Herstellung der Plasmide der 6xHis-erweiterten SNAREs auch wenn das Experiment nicht funktioniert hat.

Darüber hinaus möchte ich mich bei allen Mitarbeiterinnen und Mitarbeitern dieses Institutes für die nette Zusammenarbeit und Hilfsbereitschaft bedanken.

Ein besonderer Dank gilt dem BAföG-Amt für die Finanzierung meines Studiums und meinen Eltern und Geschwistern für ihre emotionale Unterstützung in all den Jahren. 


\section{Lebenslauf:}

Name:

Geburtsdatum:

Geburtsort:

Staatsangehörigkeit:

$1979-1983$

$1983-1985$

$1985-1989$

$1989-1992$

Oktober 1992

März 1993 - April 1994

April 1994

Oktober 1995

WS 1997

März 1998 - Dez. 1998

Februar 1999

März 1999 - Dez. 2002
Meik Dilcher

27.02.1973

Bad Hersfeld

deutsch

Grundschule in Neuenstein-Obergeis

Förderstufe der Gesamtschule Geistal, Bad Hersfeld

Realschulzweig der Gesamtschule Geistal, Bad Hersfeld

Modellschule Obersberg in Bad Hersfeld, Abschluss: Abitur

Beginn des Studiums der Biologie (Diplom) an der GeorgAugust Universität in Göttingen

Zivildienst in der Bahnhofsmission in Bebra

Fortführung des unterbrochenen Biologie-Studiums an der Georg-August-Universität in Göttingen

Diplomvorprüfung in den Fächern Botanik, Mikrobiologie, Anorganische Chemie, Physikalische Chemie

mündliche Diplomprüfung in den Fächern Biochemie, Botanik und Organische Chemie

Diplomarbeit in der Abteilung für Allgemeine und Entwicklungsphysiologie der Pflanze unter der Anleitung von Frau Prof. Dr. C. Gatz mit dem Thema: „Analyse der Komplexität der in Blatt exprimierten Transkriptionsfaktoren vom Typ TGA in Tabak“"

Biologie-Diplom

Anfertigung der vorliegenden Dissertation mit dem Thema:

„Charakterisierung von SNARE-Proteinen in der Hefe Saccharomyces cerevisiae" in der Abteilung von Prof. Dr. K. von Figura im Zentrum für Biochemie und Molekulare Zellbiologie der Georg-August-Universität unter der Anleitung von Frau Dr. Gabriele Fischer von Mollard 